\section{Pacific Northwest}

National Laboratory

Operated by Battelle for the

U.S. Department of Energy

\title{
Bulk Vitrification Castable Refractory Block Protection Study
}

\author{
P. Hrma \\ J. Matyas \\ L.M. Bagaasen \\ K.B.C. Minister \\ A.E. Beck \\ M.J. Schweiger \\ T.M. Brouns \\ D.M. Strachan \\ D.D. Caldwell \\ B.P. Tinsley \\ M.L. Elliott \\ G.W. Hollenberg
}

April 2005

Prepared for the U.S. Department of Energy

under Contract DE-AC05-76RL01830 


\title{
DISCLAIMER
}

This report was prepared as an account of work sponsored by an agency of the United States Government. Neither the United States Government nor any agency thereof, nor Battelle Memorial Institute, nor any of their employees, makes any warranty, express or implied, or assumes any legal liability or responsibility for the accuracy, completeness, or usefulness of any information, apparatus, product, or process disclosed, or represents that its use would not infringe privately owned rights. Reference herein to any specific commercial product, process, or service by trade name, trademark, manufacturer, or otherwise does not necessarily constitute or imply its endorsement, recommendation, or favoring by the United States Government or any agency thereof, or Battelle Memorial Institute. The views and opinions of authors expressed herein do not necessarily state or reflect those of the United States Government or any agency thereof.

\author{
PACIFIC NORTHWEST NATIONAL LABORATORY \\ operated by \\ BATTELLE \\ for the \\ UNITED STATES DEPARTMENT OF ENERGY
}

under Contract DE-AC06-76RL01830

Printed in the United States of America

Available to DOE and DOE contractors from the

Office of Scientific and Technical Information,

P.O. Box 62, Oak Ridge, TN 37831-0062;

ph: (865) 576-8401

fax: (865) 576-5728

email: reports@adonis.osti.gov

\begin{abstract}
Available to the public from the National Technical Information Service, U.S. Department of Commerce, 5285 Port Royal Rd., Springfield, VA 22161 ph: (800) 553-6847 fax: (703) 605-6900

email: orders@ntis.fedworld.gov

online ordering: http://www.ntis.gov/ordering.htm
\end{abstract}

This document was printed on recycled paper.

$(8 / 00)$ 


\title{
Bulk Vitrification Castable Refractory Block Protection Study
}

\author{
Pavel Hrma \\ Kevin B.C. Mimister \\ Larry M. Bagaasen \\ Michael J. Schweiger \\ Andrew E. Beck \\ Denis M. Strachan \\ Dustin D. Caldwell \\ Bronnie P. Tinsley \\ Michael L. Elliott \\ Josef Matyas \\ Glenn W. Hollenberg
}

February 2005

Prepared for the U.S. Department of Energy

under Contract DE-AC05-76RL01830

Pacific Northwest National Laboratory

Richland, Washington 99352 


\section{Executive Summary}

The U.S. Department of Energy is constructing a waste treatment plant at the Hanford Site in southeastern Washington State to vitrify the large amount of radioactive waste stored in underground tanks. Supplemental treatment technologies were studied to accelerate the cleanup of low-activity waste, and a decision was made to proceed with a pilot-scale test and demonstration facility to further evaluate bulk vitrification (BV).

Experimental research, engineering-scale (ES) tests, and the science of glass melting provide ample evidence that a small fraction of Tc and Re were transferred out of the low-activity waste (LAW) glass feed and molten LAW glass and deposited on the surface and within the internal pore surfaces of the castable refractory block (CRB), both by low-temperature molten salt penetration and by hightemperature evaporation-condensation. In this task, laboratory experiments were undertaken to evaluate the capability of these two mechanisms to transport Tc/Re into the CRB during vitrification and to evaluate various means of CRB protection against the deposition of leachable radioactive Tc (and Re, its nonradioactive surrogate). All tests conducted in this task and described in this report used Re as a chemical surrogate for Tc.

Both standard and newly designed experimental methods were applied to assess the extent of Tc/Re transport to the CRB, both unprotected (the baseline) and protected with a glaze or a tile. These methods include:

- the measurement of Re concentration distribution in an unprotected CRB sample taken from an ES test

- suspended refractory rod test for vapor deposition

- simulant condensate penetration tests to determine the penetration of vapor condensates

- gas permeability test and porosity measurement for vapor penetration

- partially immersed rod test for molten salt penetration

- manufacturing demonstration testing to determine the compatibility of tiles and CRB and the adherence of tile to CRB

- refractory corrosion test for tiles.

In many cases, experimental conditions were selected to enhance the transport mechanism so as to make the very small levels of Tc/Re normally transported easier to detect.

The tests with unprotected (baseline) CRB showed that the molten LAW penetrates into CRB pores before it converts to glass, leaving deposits of sulfates and chlorides when the nitrate components decompose. $\mathrm{Na}_{2} \mathrm{O}$ from the LAW reacts with the CRB to create a durable glass phase that may contain limited quantities of insoluble Tc/Re. Limited data from a single CRB sample taken from an ES experiment indicates that, while a fraction of Tc/Re is present in the CRB in a readily leachable form, most of the Tc/Re deposited in the refractory is retained in the form of a durable glass phase.

In addition to the direct penetration into the porous CRB, the molten salts from the LAW, mainly sulfates, chlorides, and nitrates, begin to evaporate from BV feeds at temperatures below $800^{\circ} \mathrm{C}$ and condense on 
solid surfaces at temperatures below $530^{\circ} \mathrm{C}$. The condensed salt readily wets and penetrates into the unprotected CRB material. Potassium perrhenates precipitate from the condensed salt deposits on cooling. The gas permeability tests on the baseline CRB showed that the permeability of the unprotected refractory increases by two to three orders of magnitude after heat treating to $1050^{\circ} \mathrm{C}$. This indicates that the microstructure changes that occur in the CRB when it is heated during the BV process will tend to coarsen the fine porosity and increase the penetration of liquid salts and vapors.

Three possible approaches aimed at reducing or preventing the deposition of soluble Tc/Re within the CRB were proposed and evaluated:

1. Lining the CRB with metal

2. Sealing the CRB surface with a glaze

3. Lining the CRB with ceramic tiles.

Metal liners were deemed unsuitable and were not tested because evaluations showed that they can cause unacceptable distortions of the electric field in the BV system. Testing focused on refractory glazes and ceramic tile linings.

Several glaze candidates were screened to determine which glazes adhered to the CRB and produced continuous layers when heated to $1100^{\circ} \mathrm{C}$. Of the glazes investigated, sodium silicate and a low-alkali borosilicate glaze were selected for further testing. Suspended refractory rod tests and tests with simulated condensate indicated that the selected glazes provide partial protection to the CRB from vapor penetration but not from vapor deposition. The glazes slowed down molten salt condensate penetration, and the borosilicate melt tended to keep the deposited Re salt on the CRB surface in a soluble form. The immersed refractory rod tests showed that the glazes did little to reduce the penetration of molten salt. Gas permeation tests indicated that the glazes resulted in a minor reduction in the gas permeability relative to the baseline $\mathrm{CRB}$ heat-treated to $1050^{\circ} \mathrm{C}$.

Several refractory tile candidates were screened to determine if they could be applied to the interior of the CRB to potentially reduce the transport of Tc/Re into the refractory. Only greystone and fused-cast alumina-zirconia-silica (AZS) refractory remained intact and well bonded after firing to $1000^{\circ} \mathrm{C}$. A net thermal expansion of $2.2 \%$ during firing of the greystone tile caused deformation of the refractory/tile composite. This deformation was avoided by prefiring the greystone tile to $800^{\circ} \mathrm{C}$. Half sections of ES CRBs were successfully fabricated with the greystone tiles. Tiles of AZS could not be cut from the bricks available at the time of testing, but AZS tiles that are $25 \mathrm{~mm}$ thick were subsequently identified and should be considered for future CRB lining tests.

Limited suspended rod tests with dense tiles showed that condensed vapors did not penetrate, and Re salts tended to condense on the surface of the tiles. Simulant condensate penetration tests with the greystone tile showed that there was no penetration of the condensate material through the tile. The gas permeability of the greystone tiles appeared to increase after heat treating to $600^{\circ} \mathrm{C}$ but was still several orders of magnitude less permeable than the baseline Vibrocast 60PC. The AZS was not tested but, based on its density and microstructure, is expected to have low permeability. Refractory corrosion tests that exposed greystone tiles to melt temperatures of $1350^{\circ} \mathrm{C}$ for 22 hours indicate that a 0.25 -inch-thick greystone tile would not corrode during a BV melt. 
Tiles appear to be the most promising protection method for the CRB and can reduce both vapor penetration and molten salt penetration. However, vapor deposition on the CRB surface above the melt line will occur even with tiles. Greystone tiles were effective, but the AZS tiles that were identified after the testing phase of this study was completed should be examined further.

Extrapolating the results available from this and other laboratory and ES tests leads to a plausible conceptual model for Tc/Re transport into the CRB during the bulk vitrification process. In the BV process, especially during startup, the feed/glass refractory interface is exposed to a moving temperature gradient that starts at ambient and proceeds to $1200^{\circ} \mathrm{C}$ or greater. Considering the evolution of the temperature field within the $\mathrm{CRB}$, the Tc/Re transport scenario can be outlined as proceeding in the following stages:

- The first step in the melting process is the formation of a molten ionic salt (MIS) in the feed that includes all the Tc/Re within the porosity of the soil and other insoluble grains. By capillarity, this MIS penetrates the CRB open porosity as the interface temperature increases to approximately $700^{\circ} \mathrm{C}$.

- At approximately $750^{\circ} \mathrm{C}$, the MIS decomposes through the loss of $\mathrm{NO}_{\mathrm{x}}$, leaving mainly sulfate and chloride salts. The $\mathrm{Na}_{2} \mathrm{O}$ formed in the decomposition of the nitrates also starts to react with insoluble grains in the feed (soil and $\mathrm{ZrO}_{2}$ ), and to some extent the aluminosilicates in the CRB, to form more viscous liquids that reduce further liquid penetration into the CRB.

- At 800 to $1000^{\circ} \mathrm{C}$, a continuous glass phase starts to form that traps the remains of the MIS in the form of inclusions in the bulk glass melt.

- At 1000 to $1200^{\circ} \mathrm{C}$, the salt inclusions in the glass slowly dissolve but also rise to the surface. The salt inclusions in the CRB continue to react and form glassy phases that may incorporate some of the Tc/Re but also evaporate and condense in colder portions of the porous CRB, distributing Tc/Re as they condense. The Tc/Re salts also evaporate from the free surface of the glass melt that is rapidly renewed by convective currents.

- Available data support the conclusion that a substantial fraction of Tc/Re deposits is incorporated into a durable glass phase as the maximum temperatures are reached in the lower CRB regions. At 1200 to $1400^{\circ} \mathrm{C}$, the low-density inclusions of sulfate/chloride MIS continue to reach the surface of the glass melt where they volatilize and condense on cooler surfaces in the upper portion of the CRB, the box lid, and the off-gas system. The condensate from the sulfate/chloride MIS will readily penetrate the CRB and deposit Tc/Re in the upper portions. Without the $\mathrm{Na}_{2} \mathrm{O}$ from the nitrate decomposition and the higher temperatures seen in the lower sections of the box, the Tc/Re deposits in the upper region of the CRB are not incorporated in a refractory glass phase and remain in a leachable form.

- An additional yet similar mechanism of the Tc removal from molten glass is the partitioning of metallic Tc into droplets of metallic iron. Metallic Fe can be reduced from $\mathrm{Fe}_{2} \mathrm{O}_{3}$ (4-8 mass\% of Hanford soil), manly by the unoxidized residue of carbon used as the starter path for electric melting. A fraction of the Fe droplets sinks to the melt bottom and forms flat Tc-containing ingots.

The conceptual model of the mechanism of leachable Tc salt deposition in the bulk vitrification process is based on the direct and indirect evidence from the past studies. Additional testing is needed to fill the gaps in the model, to decrease uncertainty in data and measurements that were predominantly proof-ofprinciple testing, and to obtain missing data. Therefore, the following path forward is recommended.

- A study is needed to obtain the rate and extent of MIS penetration from the feed into the CRB, both under isothermal conditions and into the CRB with a temperature gradient. The MIS penetration rate and extent, measured with respect to the depth of penetration and the degree of pore filling, can be 
measured with the submerged rod testing at $\mathrm{T}<750^{\circ} \mathrm{C}$. Only very limited data are available for the distribution of MIS components in the CRB from ES testing. The scoping tests that have been performed so far need an improved methodology of dry CRB thin sectioning to be applied to a number of samples selected to represent various positions within the CRB of ES tests. For better understanding of the mechanism of Re penetration into the CBR (convection, diffusion, vapor deposition), the atomic ratios of Re to S and Re to Na, both with the CRB and segregated MIS, should be measured by EDS and chemical analyses on samples taken at various temperatures.

- Direct measurements are needed regarding the kinetics of the $\mathrm{NO}_{\mathrm{x}}$ evolution as nitrate reacts with feed refractory components and with the CRB. These data can be obtained from combining several techniques, such as evolved gas analysis, X-ray diffraction, and scanning electron microscopyelectron dispersive spectroscopy. Attention needs to be paid to chloride and sulfate behavior during these reactions. Direct evidence is also needed to document the formation of intergranular crystalline and amorphous phases within the CRB as functions of temperature, the volume fraction of MIS in the $\mathrm{CRB}$, the volume reduction to MIS as $\mathrm{NO}_{3}$ decomposes, and the viscosity of the amorphous phase in the CRB.

- Particular attention needs to be paid to Tc/Re volatilization and incorporation into the glassy phase in bulk melt and the CRB. Additional data need to be obtained from the cold-finger test with ground glass quenched at $800^{\circ} \mathrm{C}$ and from pre-melted glass held at $1000^{\circ} \mathrm{C}$ and $1100^{\circ} \mathrm{C}$ to evaluate $\mathrm{Tc} / \mathrm{Re}$ volatilization and condensation 


\section{Acronyms}

AMEC

AZS

BV

CFT

CH2M HILL

CRB

CS

DI

DOE

DTA

DTG

EDS

EGA

ES

ICP

ICV

ISV

LAW

LRB

MP

MS

MIS

PCT

PNNL

QA

RA

RCRA

SBMS

SEM

SR

TGA

WTP

XRD
AMEC Earth \& Environmental, Inc.

alumina-zirconia-silica

bulk vitrification

cold-finger test

CH2M HILL Hanford Group, Inc.

castable refractory block

cast stone

deionized water

U.S. Department of Energy

differential thermal analysis

differential thermal gravimetric analysis

energy dispersive spectroscopy

evolved gas analysis

engineering scale

inductively coupled plasma

in-container vitrification

in situ vitrification

low-activity waste

laboratory record book

melting point

mass spectrometry

molten ionic salt

product consistency test

Pacific Northwest National Laboratory

quality assurance

risk assessment

Resource Conservation and Recovery Act

Standards Based Management System

scanning electron microscopy

steam reformation

thermal gravimetric analysis

Waste Treatment Plant

$\mathrm{X}$-ray diffraction 



\section{Contents}

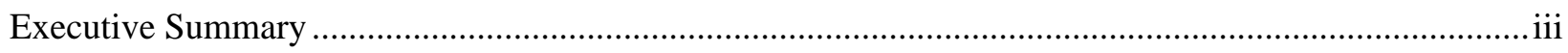

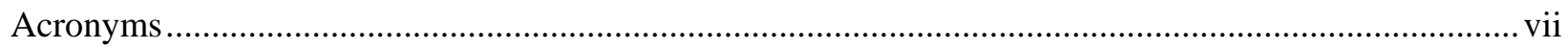

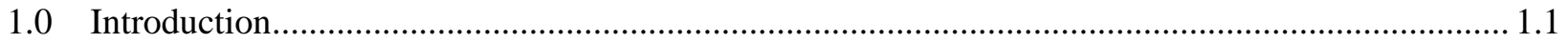

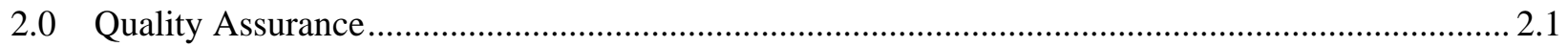

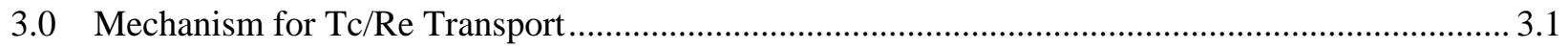

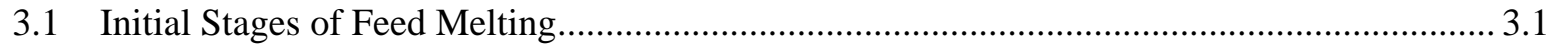

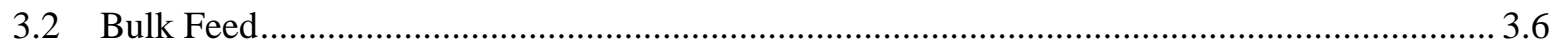

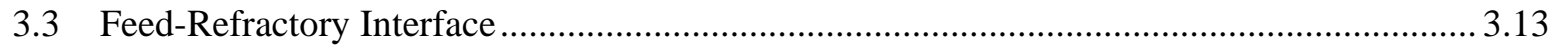

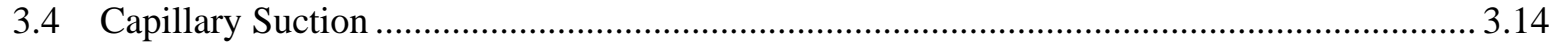

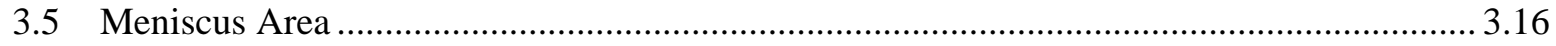

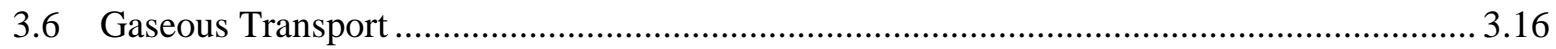

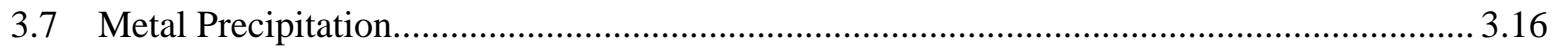

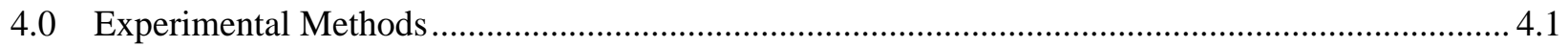

4.1 Suspended Refractory Rod Test ….............................................................................. 4.1

4.2 Partially Immersed Refractory Rod Test ............................................................................ 4.1

4.3 Simulated Condensate Penetration Test …........................................................................ 4.2

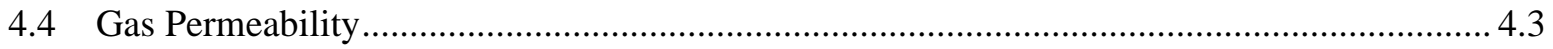

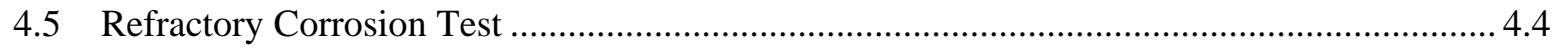

4.6 Near Surface Concentration Gradient in the CRB ............................................................... 4.4

4.7 Manufacturing Demonstration Testing ................................................................................ 4.5

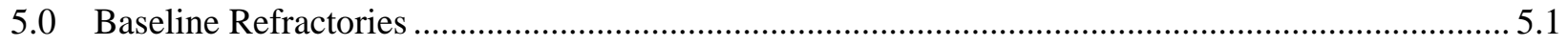

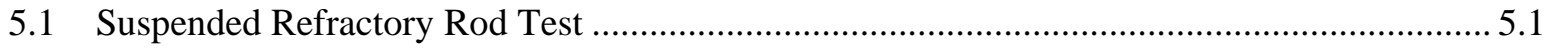

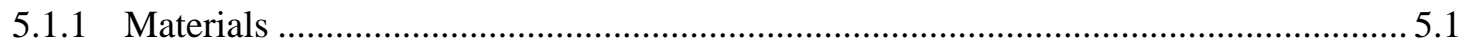

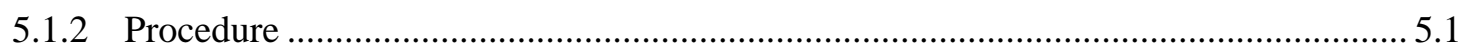

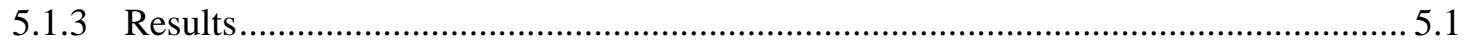




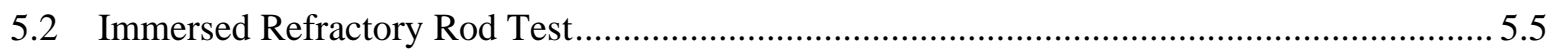

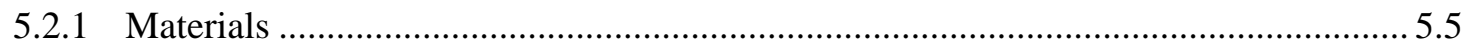

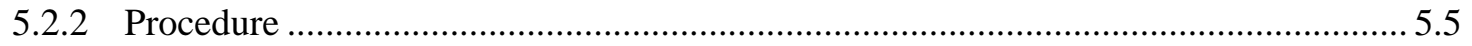

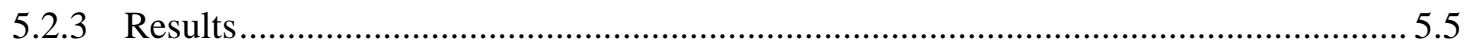

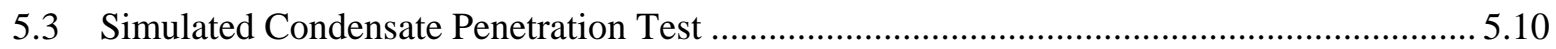

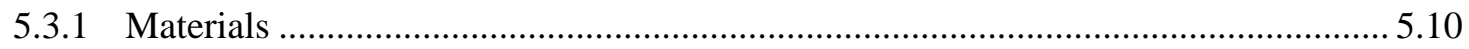

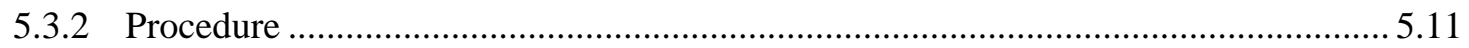

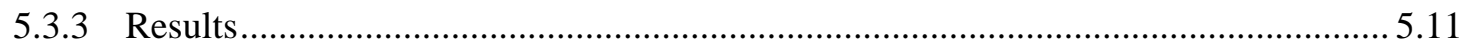

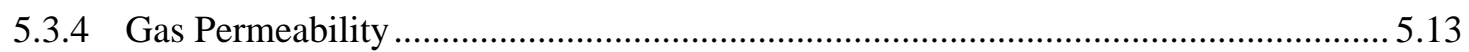

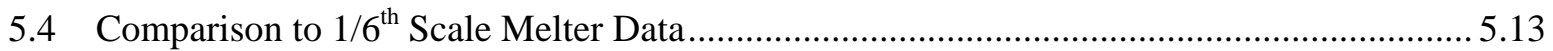

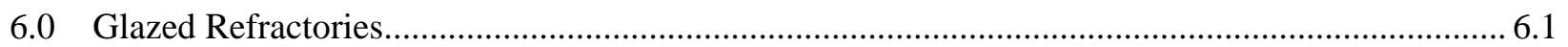

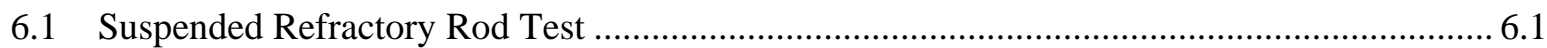

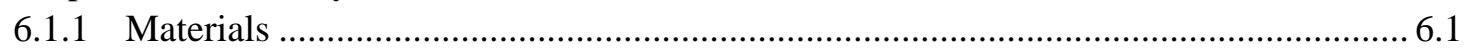

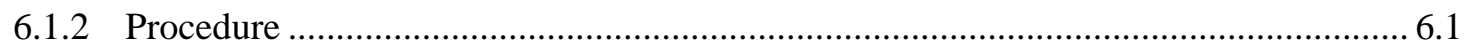

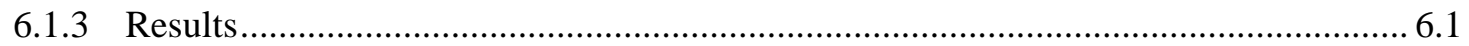

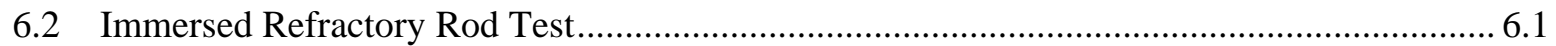

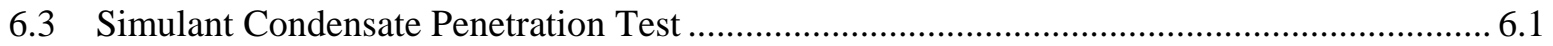

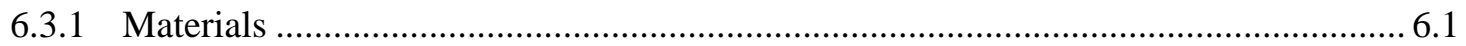

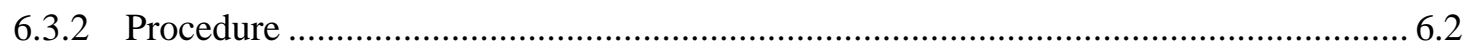

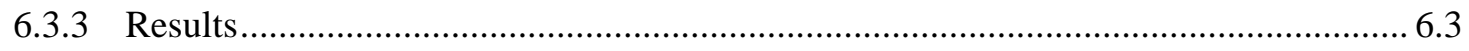

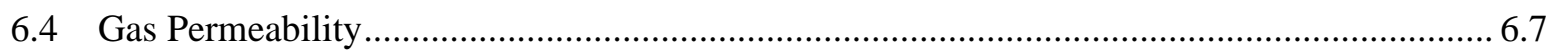

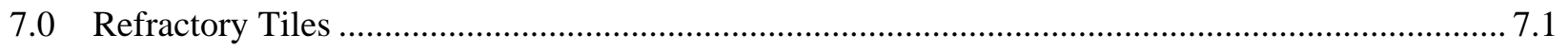

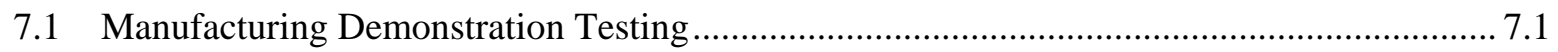

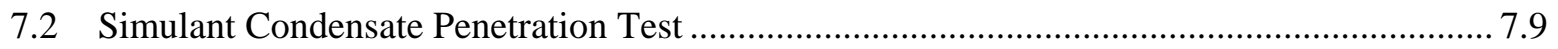

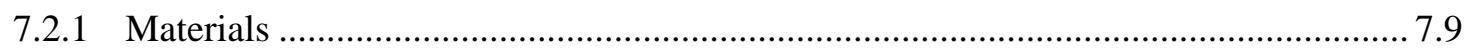

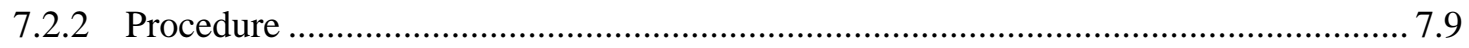

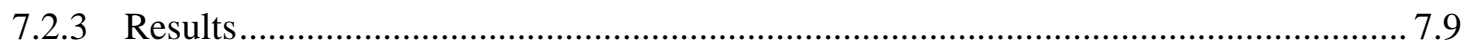

7.3 Gas Permeability, Density, and Porosity ...................................................................... 7.11

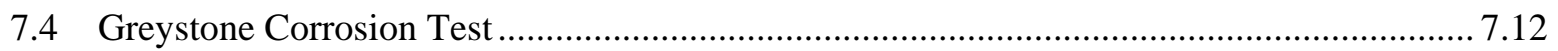

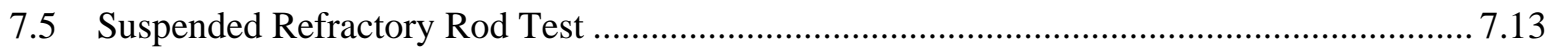

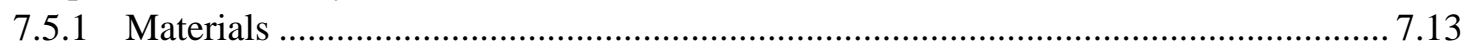

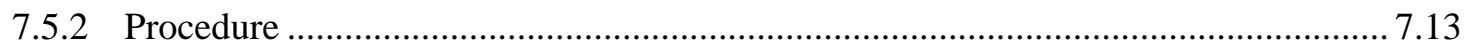

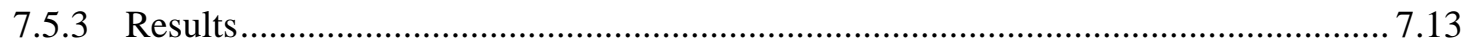

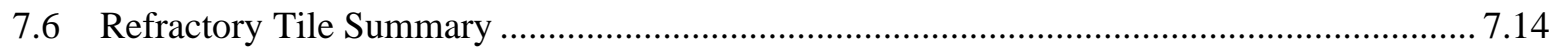




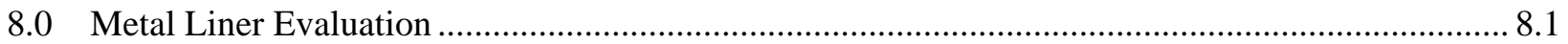

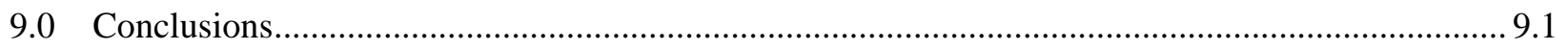

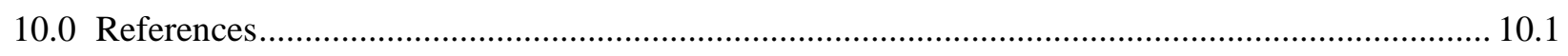

Appendix A: Suspended Refractory Rod Test Results .................................................................. A.1

Appendix B: Simulant Condensate Penetration Test Results .............................................................

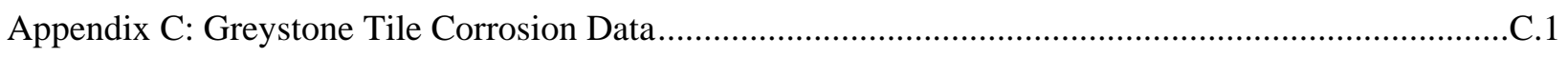

Appendix D Castable Refractory Block Material Selection for the Bulk Vitrification Process .............. D.1 


\section{Figures}

3.1. A Pictorial Representation of the Initial Stage of Feed Melting ..................................................... 3.2

3.2. A Pictorial Representation of the Early Stage of Feed Melting..................................................... 3.4

3.3. A Pictorial Representation of an Advanced Stage of Feed Melting: Glass Forming Melt is Connected .....

3.4. A Pictorial Representation of the Final Stage of Feed Melting: the Remaining Solid, Gas, and

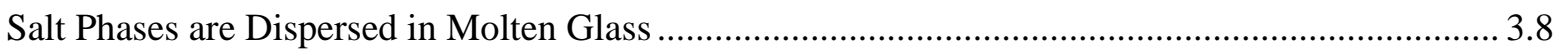

3.5. A Pictorial Representation of Tc/Re Transport out of the BV Feed/Melt .................................... 3.10

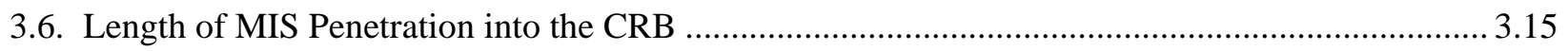

3.7. Vapor Pressure Versus Temperature for Tc and Re Compounds ............................................. 3.14

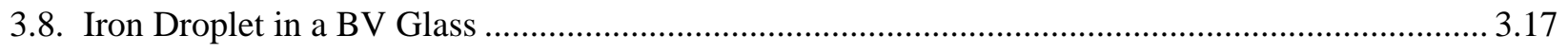

3.9. An Ingot of Iron Accumulated at the BV Melt Bottom ......................................................... 3.17

3.10. A Typical EDS Spectrum of a Metallic Precipitate in a BV Melt .............................................. 3.18

3.11. An FeS Phase Between Glass (left) and a Carbon Flake (right) …........................................... 3.18

4.1. Test Assembly for Rhenium Evaporation-Condensation Study .................................................. 4.2

4.2. Partially Immersed Refractory Rod Setup .............................................................................. 4.2

4.3. Refractory Coupon with a Groove at Bottom Surface (before and after fracturing) ....................... 4.3

5.1. Grey $\mathrm{NaCl}$ Crystal (2) and White $\mathrm{KReO}_{4}$ Deposits (1) on Fused Silica Glass Tube at $235^{\circ} \mathrm{C}$ (SEM micrograph, feed heated to $1000^{\circ} \mathrm{C}$ with 2-h hold) ............................................................ 5.2

5.2. White $\mathrm{KReO}_{4}$ Deposits (4) on Spherical $\mathrm{Na}_{2} \mathrm{SO}_{4}$ on Fused Silica Glass Tube at $423^{\circ} \mathrm{C}$ that Appears Corroded by Fluoride Vapors (SEM micrograph, feed heated to $1350^{\circ} \mathrm{C}$ with 2-h dwell) 5.2

5.3. White $\mathrm{KReO}_{4}$ Deposits (4) Around Patches of $\mathrm{NaNO}_{3}$ on Fused Silica Glass Tube at $432^{\circ} \mathrm{C}$ (SEM micrograph, feed heated to $800^{\circ} \mathrm{C}$ with 2-h hold)

5.4. Clusters of $\mathrm{KReO}_{4}$ Crystals on Fused Silica Glass Tube at $467^{\circ} \mathrm{C}$ (SEM micrograph, feed heated to $1000^{\circ} \mathrm{C}$ with 2 -h hold).

5.5. Concentration Distribution of Condensate in Fused Silica Glass Tube (feed heated to $1350^{\circ} \mathrm{C}$

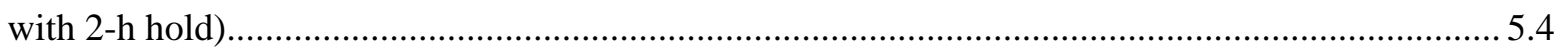

5.6. Partially Immersed Refractory Rods after Removal from Sulfate-Enriched Glass Melt.................. 5.6 
5.8. The Immersed Part of the Vibrocast Rods with Sulfate Enriched Feed (left, a detail of 5.7), and with normal feed (right).

5.9. Vertical Concentration Profiles of S, Cl, and Na from Bottom to Top at the Axis/Center of Immersed Refractory Rod from Vibrocast 60PC after Heat-Treatment at the Temperatures Indicated.

5.10. Horizontal Concentration Profile of S, Cl, and $\mathrm{Na}$ at the Indicated Vertical Distance above Bottom; Horizontal Distance is Measured from Center to side of Immersed Refractory Rod Heat-Treated at Temperatures Indicated.

5.11. Excess of Na over Sulfate and Chloride in Immersed Refractory Rod Heat-Treated at Various Temperatures (2.4 cm from bottom)

5.12. Surface Morphology of Vibrocast 60PC Treated with Condensate Simulant at Various Temperatures

5.13. Results of Gas Permeability Measurement for Vibrocast 60PC [by Equation (3.1), $\left.k=K A /\left(2 \mu L P_{2}\right)\right]$

5.14. Concentration Distribution of Water Soluble Re (at $90^{\circ} \mathrm{C}$ ) in the ES-31B Refractory Wall......

5.15. Concentration Distribution of Re (leachable and non-leachable) in the ES-31B Refractory Wall.

5.16. Atomic Fractions of Na, S, and Cl in CRB (in ES-31B Test) as Functions of Distance from the Interface with Molten Glass.

6.1. $\mathrm{NaReO}_{4}$ Formations on Borosilicate Glaze at $523^{\circ} \mathrm{C}$ (SEM micrograph, feed heated to $1000^{\circ} \mathrm{C}$ with 2-h hold).

6.2. Condensate Simulant on Baseline Refractory Coupon $(25 \times 25 \mathrm{~mm})$ Treated with Borosilicate Frit (left) and Sodium Silicate (right) and Heat-Treated at $1100^{\circ} \mathrm{C}$.

6.3. Vibrocast 60PC Coated with Borosilicate Glaze and Heat-Treated with Simulated Condensate at $1000^{\circ} \mathrm{C}$ for 5 hours.

6.4. Surface Morphology of Vibrocast 60PC Coated with Sodium Silicate Glaze and Treated with Condensate Simulant at Various Temperatures

6.5. Surface Morphology of Vibrocast 60PC Coated with Borosilicate Glaze and Treated with Condensate Simulant at $800^{\circ} \mathrm{C}$

6.6. Vibrocast 60PC Coated with Sodium Silicate Glaze and Treated with Simulated Condensate at $800^{\circ} \mathrm{C}$ 
6.7. Vibrocast 60PC Coated with Sodium Silicate Glaze and Treated with Simulated Condensate at $1100^{\circ} \mathrm{C}$ (there is no distinct interface between glaze, salts, and the refractory)

6.8. Vibrocast 60PC Coated with Borosilicate Glaze and Treated with Simulated Condensate at $800^{\circ} \mathrm{C}$.....

6.9. Deposits of Re Salt in Vibrocast 60PC Coated with Borosilicate Glaze and Treated with Simulated Condensate at $1100^{\circ} \mathrm{C}$

7.1. Tiles on Vibrocast $60 \mathrm{PC}$ as Cast (left) and after Firing to $1000^{\circ} \mathrm{C}$ (right)

7.2. Thermal Expansion of Greystone Tile, AZS, and Vibrocast 60PC Specimen (specimens heated and cooled down at $2^{\circ} \mathrm{C} / \mathrm{min}$ )

7.3. XRD Pattern of Greystone, Unfired and Fired at $800^{\circ}$ and $1300^{\circ} \mathrm{C}$

7.4. Greystone Tile Bonded to CRB after Ramp Heating to $1200^{\circ} \mathrm{C}$, Holding for 8 hours, and Attempting to Remove the Tile with Hammer and Chisel

7.5. Greystone Tile Preparation

7.6. Prefired (top) and Unfired (bottom) Greystone Tiles Heat-Treated with Simulated Condensate at $1000^{\circ} \mathrm{C}$

7.7. Simulated Condensate on Unfired Greystone Tile Heated at $1000^{\circ} \mathrm{C}$

7.8. Results of Gas Permeability Measurement for Greystone Tile.

7.9. Linear Loss of Greystone Tile During 22-h Exposure to Melt at $1350^{\circ} \mathrm{C}$ as a Function of Distance Measured from the Top of the Tile Downward

7.10. $\mathrm{KReO}_{4}$ Formations on Alumina Tile Surface at $354^{\circ} \mathrm{C}$ (SEM micrograph, feed heated to $1000^{\circ} \mathrm{C}$ with 2-h hold)

8.1. Plan View of ICV ${ }^{\mathrm{TM}}$ with Resistor Schematic.

8.2. Elevation View of ICVTM with Resistor Schematic.

8.3. Immersion of Metal Liner Versus Power Dissipation in Back of Electrodes at Constant 15-kW Total Power. 


\section{Tables}

3.1. A Typical Feed Recipe for an Engineering-Scale Test ............................................................... 3.1

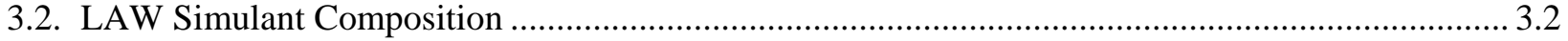

3.3. Conceptual Model of the Mechanism of Leachable Technetium Salt Deposition in the Bulk Vitrification Process

3.4. Conceptual Model of the Mechanism of Leachable Technetium Salt Deposition in the Bulk Vitrification Process

3.5. Conceptual Model of the Mechanism of Leachable Technetium Salt Deposition in the Bulk Vitrification Process

3.6. Conceptual Model of the Mechanism of Leachable Technetium Salt Deposition in the Bulk Vitrification Process

3.7. Conceptual Model of the Mechanism of Leachable Technetium Salt Deposition in the Bulk Vitrification Process

5.1. Results of Re Extraction Analysis

5.2. Condensate Simulant Composition

5.3. Simulated Condensate Penetration Test: Summary of Results for Untreated Vibrocast 60PC 5.12

5.4. Gas Permeability of Glazed and Unglazed Vibrocast 60PC

6.1. Frit Selections for CRB: Initial Screening Test Results 6.2

6.2. CRB Glazes: Summary of Test Results

7.1. Tile Selection Criteria 7.1

7.2. Bonding Between Tiles and Vibrocast 60PC After Ramp Heating to $1000^{\circ} \mathrm{C}$ : Summary of Testing

7.3. Gas Permeability of Greystone Tile in Comparison to Vibrocast 60PC.

7.4. Bulk Density, Solid Density, and Void Fraction (Porosity) of Greystone as Functions of Temperature

7.5. Tiles Deemed Accepfor Melter Lining: Summary of Testing 


\subsection{Introduction}

The Hanford Site has the largest volume of high-level radioactive tank waste in the United States, with the highest life-cycle cost for cleanup of any other program area and site within the U.S. Department of Energy's (DOE) Environmental Management program. With 177 underground storage tanks containing 53 million gallons of waste and 200 million Curies $\left(7 \times 10^{18} \mathrm{~Bq}\right)$ of radioactivity, the life-cycle cost for cleanup has been estimated at nearly $\$ 50$ billion over 50 years. The Waste Treatment Plant (WTP) is under construction and will immobilize both high-level waste for disposal at a national repository and low-activity waste (LAW) for onsite disposal at Hanford.

Vitrifying the high volume of LAW is the rate-limiting step in the WTP and results in the 50-year project duration. The DOE accelerated cleanup mission for the Hanford Site is a strategic initiative to accelerate tank waste treatment by increasing the capacity of the WTP and using supplemental technologies for waste treatment and immobilization for as much as $70 \%$ of the LAW. Three supplemental treatment technology options (bulk vitrification [BV], steam reformation [SR], and cementation or cast stone [CS]) were evaluated in 2003 for immobilizing LAW. Detailed discussions of the preliminary FY 2003 risk assessment (RA) results are included in Mann et al. 2003. These results helped support the decision to proceed with a pilot-scale test and demonstration facility to further evaluate BV as a potential supplemental treatment technology for treating LAW at Hanford (Raymond et al. 2004). The use of this supplemental waste form would help DOE meet the long-term groundwater protection criteria for disposing of waste in a shallow land burial facility.

Bulk vitrification by AMEC Earth \& Environmental, Inc., is a modification of the in situ vitrification (ISV) process developed for remediation of buried wastes and contaminant plumes in soil (Luey and Seiler 1995; Tixier 1991). An in-container vitrification process has been designed in which LAW, soil, and glass-forming chemicals are mixed, dried, and then melted at approximately $1500^{\circ} \mathrm{C}$ by electrical resistance (Kim et al. 2003). A more detailed description of the overall BV process is given in Sederburg and Thompson (2004).

Work in FY 2003 on engineering-scale (ES) ${ }^{(a)}$ and large-scale tests of early configurations of the BV process suggested that a very small portion of the waste stream ${ }^{99} \mathrm{Tc}$ inventory would end up in a soluble form deposited in a vesicular glass layer located at the top of the BV melt and in the sand used as an insulator after vitrification. Low concentrations of soluble Tc were also seen on the metal box lid that covers the BV box during melting. An early risk assessment (Mann et al. 2003) showed that the soluble Tc salt in the BV waste packages created a ${ }^{99}$ Tc concentration peak at early times in the groundwater extracted from a 100-m down-gradient well. Although this peak concentration was below drinking water standards, CH2M HILL Hanford Group, Inc. (CH2M HILL) and AMEC initiated changes to the BV process in FY 2004 to reduce the deposition of soluble ${ }^{99}$ Tc salts. These changes included replacing a portion of the refractory sand layer with a castable refractory block (CRB) and using a bottom-up melting technique to eliminate the vesicular glass layer at the top of the melt. Early attempts to include a CRB in place of the refractory sand layer and using a bottoms-up melting technique have eliminated the two main areas where soluble Tc was depositing in the prior process design. However, the refractory block is still

(a) Engineering scale is approximately $1 / 6^{\text {th }}$ linear scale of the full-size waste package. This scale is useful for generating processing information related to melt behavior at full scale. 
quite porous, and early analyses have shown that larger than desired quantities of Re (a chemical surrogate for Tc) are depositing in the pores of the CRB. Based on these early results, a BV performance enhancement task team was put together to explore possible ways to reduce the amount of soluble Tc in the BV waste package. This team developed three main approaches to reducing the problem:

(1) modifying the chemistry of the Tc in the BV feed to reduce volatilization, (2) improving the refractory materials to reduce the locations for soluble material to collect, and (3) changing the BV operating parameters to better control Tc volatilization. This report covers the initial laboratory-scale work for the refractory materials modification approach and supplies information that can be used to help understand Tc deposition mechanisms and direct future laboratory, ES, and full-scale testing. The other approaches are addressed in Kim et al. (2005).

The experimental investigation focused on the two major modes of Tc transport from the LAW glass feed and molten LAW glass to the external and internal surfaces of the CRB, namely, low-temperature molten salt penetration and high-temperature evaporation-condensation. Experiments were undertaken to evaluate the capability of these two mechanisms to transport Tc and Re, its nonradioactive surrogate, into the CRB during vitrification and to evaluate various means of CRB protection against Tc/Re deposition. Three basic approaches to protecting the CRB from the deposition by leachable Tc were tested and evaluated: sealing the CRB surface with a glaze, lining the CRB with ceramic tiles, and lining the CRB with metal. Both standard and newly designed experimental methods were used to study the Tc/Re transport to the unprotected (the baseline) CRB and to assess the practicability of the protective measures. For example, (1) Re concentration distribution was measured in an unprotected CRB sample taken from an ES test, (2) manufacturing demonstration tests were performed to determine the compatibility of tiles and CRB and the adherence of tile to CRB, and (3) a suspended refractory rod test was developed for a vapor deposition study, and a partially immersed rod test was designed for a molten salt penetration study. Metal lining was evaluated with a numerical, rather than experimental, analysis. 


\subsection{Quality Assurance}

All the tests in this report were proof-of-principle testing in nature and performed with the Pacific Northwest National Laboratory's (PNNL's) Standards Based Management System (SBMS) and the Supplemental Technologies Support Program's Tank Waste Support Quality Assurance Plan, Rev. 6. The SBMS Quality Assurance Program meets DOE Order 414.1A and 10 CFR 830, Subpart A. Staff training is documented and test plans, procedures, and instructions are approved and in project records. Records for this report are the data sheets from the test instructions, applicable procedures, and any laboratory record book (LRB) pages used to record data and test information. These include instrument calibrations, test set up and standards, data logging, hand calculations, and review comments and signatures. Copies of all test records are provided to the project records custodian for storage in accordance with the quality assurance (QA) plan. 


\subsection{Mechanism for Tc/Re Transport}

A few tenths of a percent of Tc, or Re, its nonradioactive surrogate, was found to be transported from the BV melter feed into the refractory walls of the melter - the CRB - while the feed was being converted to molten glass (Pierce et. al. 2004). At first glance, it is difficult to understand how a substantial portion of a well dispersed but very minute component ( $\sim 90 \mathrm{mg} / \mathrm{kg}$ of $\mathrm{Re}_{2} \mathrm{O}_{7}$ in dry feed—see Table 3.1) can segregate from a large volume of feed (typically $130 \mathrm{~kg}$ for an ES test) during a well controlled process. In this section, a conceptual model for the mechanism of Tc/Re segregation from melter feed to CRB is proposed. It is shown that, when considering some intricacies of the conversion process from melter feed to molten glass, a plausible mechanism governing this segregation. The segregation Tc/Re begins with Tc/Re partitioning to phase-segregated inclusions of molten ionic salt (MIS) in which Tc/Re salts concentrate and are transported into the CRB and on the melt surface. Once outside the bulk of the glass melt, Tc/Re salts evaporate and condense, either on the CRB or other colder surfaces. Droplets of metallic iron reduced from $\mathrm{Fe}_{2} \mathrm{O}_{3}$ (4-8 mass\% of Hanford soil) can also strip Tc from the melt and incorporate it in the form of an alloy. A fraction of the Fe droplets sinks to the melt bottom, where the droplets may fuse into flat ingots.

Table 3.1. A Typical Feed Recipe for an Engineering-Scale Test

\begin{tabular}{||l|c||}
\hline & Mass\% \\
\hline HRTS Soil & 54.6 \\
\hline $\mathrm{ZrO}_{2}$ & 6.2 \\
\hline $\mathrm{B}_{2} \mathrm{O}_{3}$ & 4.3 \\
\hline Dry LAW Simulant & 30.0 \\
\hline $\mathrm{Al}\left(\mathrm{NO}_{3}\right)_{3} \cdot 9 \mathrm{H}_{2} \mathrm{O}^{(\mathrm{a})}$ & 2.2 \\
\hline $\mathrm{NaOH}^{\mathrm{Re}_{2} \mathrm{O}_{7}}$ & 2.7 \\
\hline $\begin{array}{l}\text { (a) Aluminum nitrate is a simulant component } \\
\text { that is added separately. }\end{array}$ \\
\hline
\end{tabular}

\subsection{Initial Stages of Feed Melting}

As shown in Table 3.1, BV melter feed is a mixture of LAW, aluminosilicate soil, and additives (currently $\mathrm{ZrO}_{2}$ and $\mathrm{B}_{2} \mathrm{O}_{3}$ ). The LAW is a mixture of salts (see Table 3.2) that melts, forming a single MIS phase that incorporates some or all $\mathrm{B}_{2} \mathrm{O}_{3}$. The MIS can first appear at a temperature as low as $200^{\circ} \mathrm{C}$. It wets the refractory components of the feed, i.e., wets and bridges the grains of soil minerals and $\mathrm{ZrO}_{2}$, filling some of the space between the grains. This stage is schematically portrayed in Figure 3.1 and described as Step 1 in Table 3.3. 
Table 3.2. LAW Simulant Composition

\begin{tabular}{||l|c|l|c||}
\hline \multicolumn{1}{|c|}{ Chemical } & $\begin{array}{c}\text { Mass fraction } \\
\text { g/kg }\end{array}$ & \multicolumn{1}{|c||}{ Chemical } & $\begin{array}{c}\text { Mass fraction } \\
\text { g/kg }\end{array}$ \\
\hline $\mathrm{CH}_{3} \mathrm{COONa}$ & 28.4 & $\mathrm{NaCl}$ & 6.7 \\
\hline $\mathrm{KNO}_{3}$ & 3.3 & $\mathrm{NaF}$ & 3.5 \\
\hline $\mathrm{Na}_{2} \mathrm{C}_{2} \mathrm{O}_{4}$ & 4.2 & $\mathrm{NaNO}_{2}$ & 77.0 \\
\hline $\mathrm{Na}_{2} \mathrm{CO}_{3}$ & 132.5 & $\mathrm{NaNO}_{3}$ & 516.3 \\
\hline $\mathrm{Na}_{2} \mathrm{CrO}_{4}$ & 4.4 & $\mathrm{NaOH}$ & 77.9 \\
\hline $\mathrm{Na}_{2} \mathrm{SO}_{4}$ & 33.6 & $\mathrm{Al}\left(\mathrm{NO}_{3}\right)_{3} \cdot 9 \mathrm{H}_{2} \mathrm{O}^{(\mathrm{a})}$ & 62.9 \\
\hline $\mathrm{Na}_{3} \mathrm{PO}_{4} \cdot 12 \mathrm{H}_{2} \mathrm{O}$ & 49.2 & \multicolumn{2}{||}{} \\
\hline $\begin{array}{l}\text { (a) Aluminum nitrate is kept separately to prevent formation and settling } \\
\text { of gel in the LAW simulant solution }\end{array}$ \\
\hline
\end{tabular}
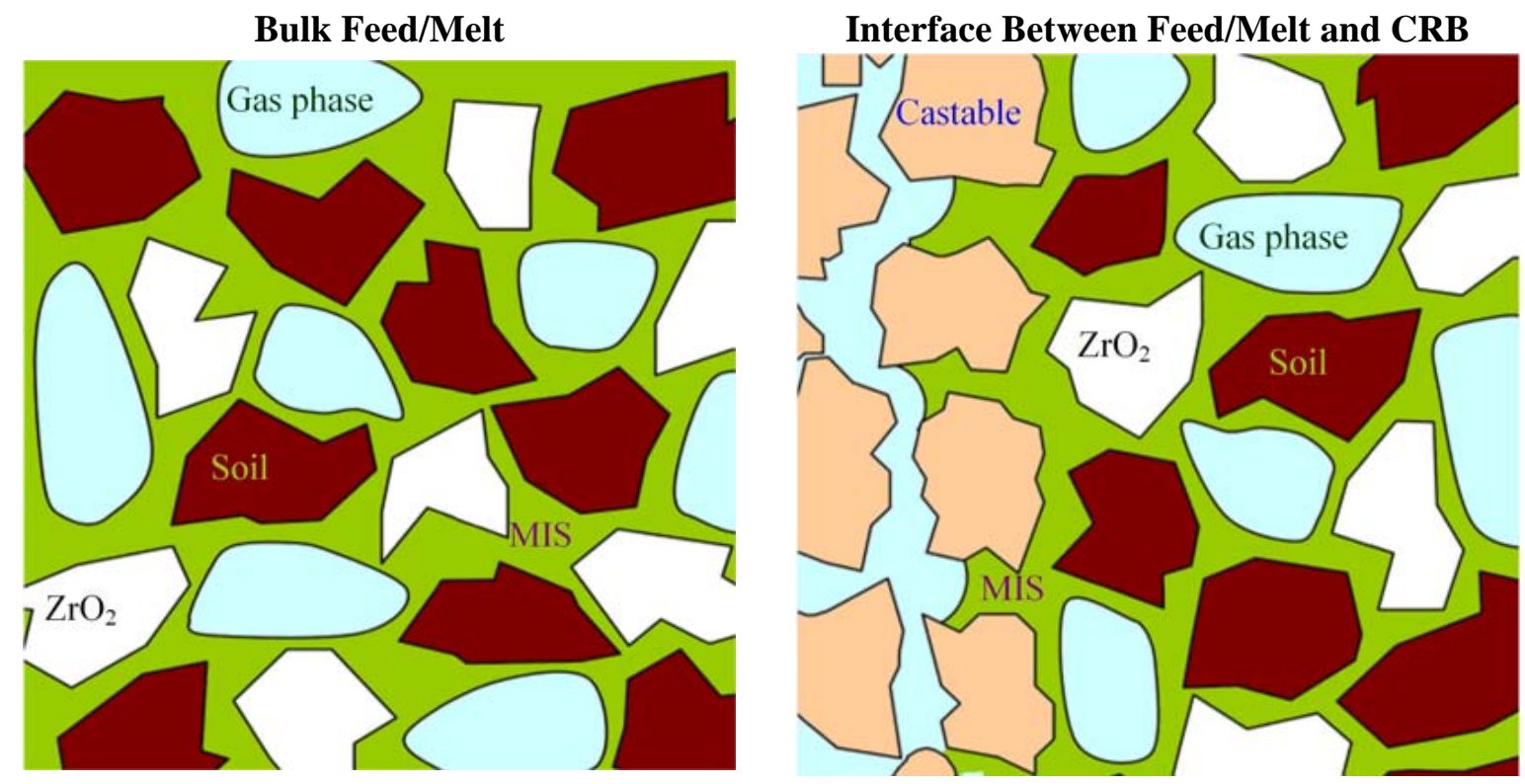

$300^{\circ} \mathrm{C}$ to $700^{\circ} \mathrm{C}$

Grains of soil (brown) and zirconia (white) become coated and bridged by MIS and borates (green). Gas bubbles (light blue) fill the remaining space. The MIS is drawn into the pores between the refractory grains (salmon) of the CRB by capillary forces. The pores in the castable (CRB) are partially filled with fine-grained material (not shown in the pictures) ${ }^{(\mathrm{a})}$

Figure 3.1. A Pictorial Representation of the Initial Stage of Feed Melting

(a) The MIS penetration is a complex process. (1) The penetration time is limited by the temperature increase rate; it stops when nitrates are decomposed. (2) The supply of MIS is limited by the excess of MIS in the feed beyond that necessary for wetting and bridging the grains. (3) Pore size distribution is affected by the fraction of small grains in the CRB. 4) The rate of penetration depends on pore geometry. 5) The temperature gradient in the CRB also affects the movement of MIS in the pore structure. 
Table 3.3. Conceptual Model of the Mechanism of Leachable Technetium Salt Deposition in the Bulk Vitrification Process

Step 1. MIS Melts and Penetrates the CRB $^{(\text {a) }}$

\begin{tabular}{|c|c|c|c|c|}
\hline \multirow{2}{*}{ Description } & \multirow{2}{*}{$\begin{array}{l}\text { Key Elements/ } \\
\text { Assumptions }\end{array}$} & \multicolumn{2}{|r|}{ Evidence/Basis } & \multirow[t]{2}{*}{ Recommended Testing } \\
\hline & & Test & Result & \\
\hline \multirow{7}{*}{$\begin{array}{l}\text { The first step in the melting process } \\
\text { is the formation of a molten ionic } \\
\text { salt (MIS) in the feed that includes } \\
\text { all the Tc/Re within the porosity of } \\
\text { the soil and other insoluble grains. } \\
\text { This MIS penetrates the CRB open } \\
\text { porosity as the interface } \\
\text { temperature increases to } \\
\text { approximately } 700^{\circ} \mathrm{C} \text { along with its } \\
\text { highly concentrated Tc/Re. }\end{array}$} & $\begin{array}{l}\text { All Tc/Re is } \\
\text { contained within } \\
\text { the MIS. }\end{array}$ & & $\begin{array}{l}\text { Oxy-ionic salts are mutually soluble }\left(\mathrm{KTc} 0_{4}\right. \\
\left.\text { melts at } 532^{\circ} \mathrm{C}, \mathrm{NaTc}_{4} \text { at } 378^{\circ} \mathrm{C}\right) \text {. Salts } \\
\text { tend to form eutectics. }\end{array}$ & $\begin{array}{l}\text { Verify kinetics of dissolution of the higher } \\
\text { melting temp pertechnetates in lower } \\
\text { melting point salts. }\end{array}$ \\
\hline & $\begin{array}{l}\text { Tc is not yet } \\
\text { volatilizing from } \\
\text { the melt. }\end{array}$ & $\begin{array}{l}\text { Cold finger } \\
\text { test (CFT) }\end{array}$ & $\begin{array}{l}\text { Tc was non-detectable below } 600^{\circ} \mathrm{C} \text { and } \\
\text { very small at } 800^{\circ} \mathrm{C} \text { (Kim et al. 2005). }\end{array}$ & \\
\hline & \multirow[t]{5}{*}{$\begin{array}{l}\text { MIS penetrates the } \\
\text { CRB open porosity. }\end{array}$} & $\begin{array}{l}\text { Thin section } \\
\text { ES-31B }\end{array}$ & $\begin{array}{l}\text { Na penetrates to } 12 \mathrm{~mm} \text { (at long times) and } \\
\text { is present at higher concentrations than } \mathrm{S} \text { and } \\
\mathrm{Cl} \text {, indicating that Na penetrated as } \mathrm{NaNO}_{3} \\
\text { or } \mathrm{NaOH} \text {. }\end{array}$ & $\begin{array}{l}\text { Perform } \\
\text { 1) Additional and improved thin sectioning } \\
\text { 2) Test submerged as-cast CRB coupons at } \\
\mathrm{T}<750^{\circ} \mathrm{C} \text {. }\end{array}$ \\
\hline & & CFT & $\begin{array}{l}\text { Nitrate begins decomposing at } 600^{\circ} \mathrm{C} \text { and is } \\
\text { completely decomposed by } 800^{\circ} \mathrm{C} \text {. }\end{array}$ & $\begin{array}{l}\text { Obtain volume of molten material and gas } \\
\text { in CRB. }\end{array}$ \\
\hline & & ES-31D & $\begin{array}{l}\text { The ES test with } \mathrm{NaOH} \text { rather than } \\
\text { nitrate/nitrite resulted in significantly lower } \\
\text { Re deposition-possibly the result of less } \\
\text { penetration of a highly viscous } \mathrm{NaOH} \text { MIS. }\end{array}$ & $\begin{array}{l}\text { 1) Confirm penetration of nitrate vs. } \\
\text { hydroxide MIS. } \\
\text { 2) Evaluate nature of penetration of 38A } \\
\text { CRB (high and low) for low } \\
\text { nitrate/hydroxide, soil only melt. } \\
\end{array}$ \\
\hline & & $\begin{array}{l}\text { ES-31C and } \\
\text { Gas } \\
\text { Permeability } \\
\text { Tests }\end{array}$ & $\begin{array}{l}\text { Test with fired refractory (for application of } \\
\text { glazes) resulted in highest Re deposition- } \\
\text { possibly caused by greater porosity resulting } \\
\text { from higher temperature firing. }\end{array}$ & \\
\hline & & ES-31E & $\begin{array}{l}\text { CRB samples from behind tiles show } \mathrm{Na}, \mathrm{S} \text {, } \\
\text { and Re deposition. }\end{array}$ & \\
\hline
\end{tabular}

(a) CFT results were reported by Kim et al. (2005); ES-31C-E test results were reported by Pierce et al. (2005) 
As the temperature increases to $750^{\circ} \mathrm{C}$, the nitrate and nitrite salts ( 66 mass $\%$ of LAW simulant) are decomposed (see Thomason and Wilburn 1960; Abe et al. 1983; Smith et al. 1995; Hrma et al. 2002; Matyas et al. 2004; and Kim et al. 2005; see also Appendix D, Section 2), leaving behind less reactive salts, such as sulfate, chloride, borate, and chromate. Tc and Re are present in this phase as pertechnetate and perrhenate. Some experiments described in this report indicate that the remaining salt phase probably separates at some point into at least two liquid phases, one of them rich in sulfate and chromate and the other rich in chloride. If this is happening, the pertechnetate and perrhenate salt partitions between these two liquid phases. The further fate of Tc/Re depends on whether the feed is far from or close to the interface with the CRB. This stage is schematically portrayed in Figure 3.2 (see also Table 3.4).
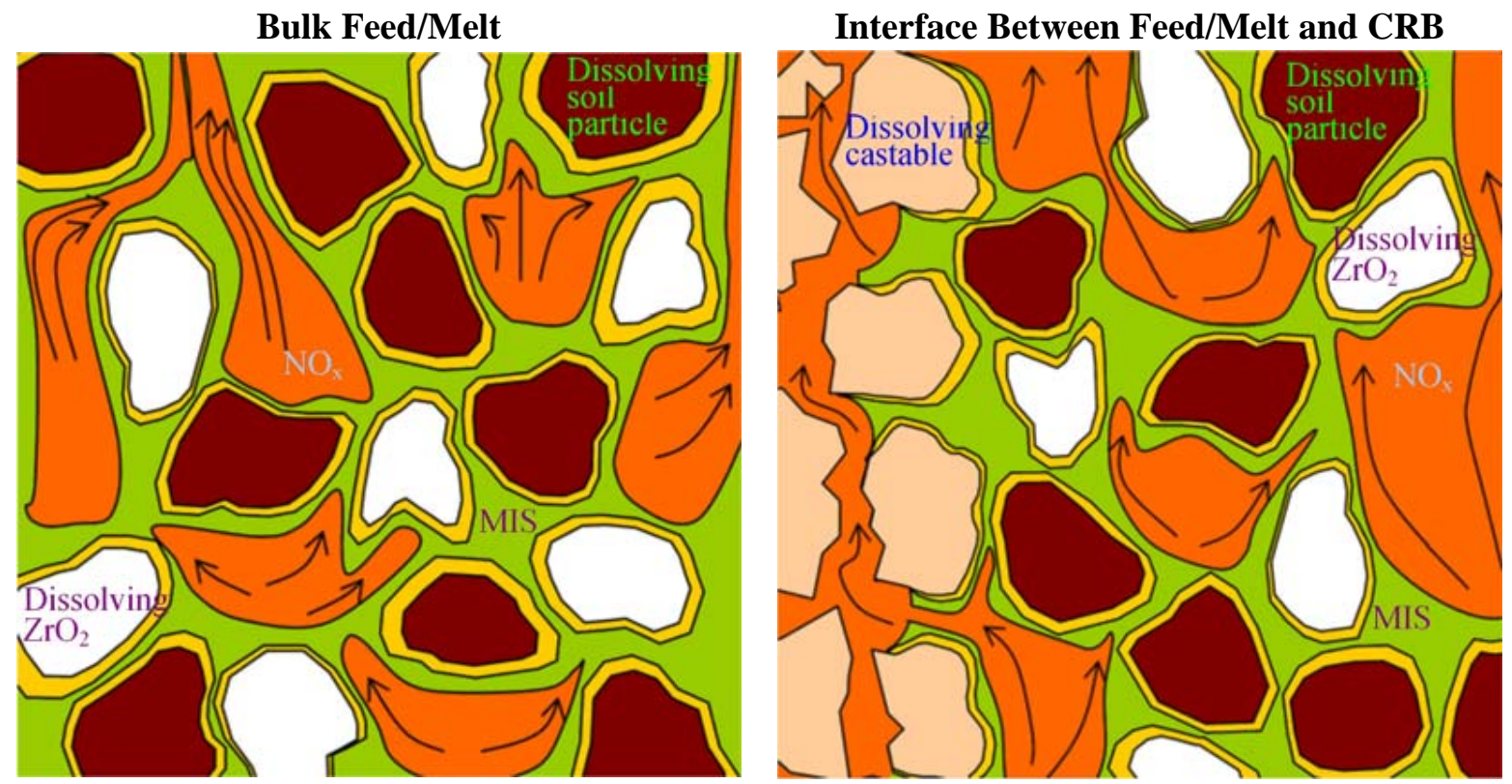

$700^{\circ} \mathrm{C}$ to $750^{\circ} \mathrm{C}$

Most (80 to 90\%) of the molten salts decompose, releasing $\mathrm{NO}_{\mathrm{x}}$ (bright orange); $\mathrm{NO}_{\mathrm{x}}$ gas rises toward the surface in large bubbles and open channels. Grains of soil (brown) and zirconia (white) react with $\mathrm{Na}_{2} \mathrm{O}$ from nitrates and other salts, creating intermediate crystalline phases and the initial glass-forming melt (mustard). Molten salt that has penetrated into the CRB also decomposes, releasing $\mathrm{NO}_{\mathrm{x}}$ and creating an intergranular glass phase.

Figure 3.2. A Pictorial Representation of the Early Stage of Feed Melting 
Table 3.4. Conceptual Model of the Mechanism of Leachable Technetium Salt Deposition in the Bulk Vitrification Process

Step 2. MIS Decomposes and Reacts with Refractory Components ${ }^{(a)}$

\begin{tabular}{|c|c|c|c|c|}
\hline \multirow{2}{*}{ Description } & \multirow{2}{*}{$\begin{array}{l}\text { Key Elements/ } \\
\text { Assumptions }\end{array}$} & \multicolumn{2}{|r|}{ Evidence/Basis } & \multirow{2}{*}{$\begin{array}{l}\text { Recommended } \\
\text { Testing }\end{array}$} \\
\hline & & Test & Result & \\
\hline \multirow{4}{*}{$\begin{array}{l}\text { At approximately } 750^{\circ} \mathrm{C} \text {, } \\
\text { the MIS loses } \mathrm{NO}_{\mathrm{x}} \text {, } \\
\text { leaving mainly sulfate } \\
\text { and chloride salts. The } \\
\mathrm{Na}_{2} \mathrm{O} \text { from nitrates reacts } \\
\text { with refractory grains in } \\
\text { the feed (soil, } \mathrm{ZrO}_{2} \text { ) and } \\
\text { to some extent the } \\
\text { aluminosilicates in the } \\
\text { CRB to form viscous } \\
\text { glass-forming liquid. }\end{array}$} & \multirow{2}{*}{$\begin{array}{l}\text { Nitrates } \\
\text { decompose at } \\
\sim 750^{\circ} \mathrm{C} \text {. }\end{array}$} & CFT & $\begin{array}{l}\text { Nitrate decomposition begins at } 600^{\circ} \mathrm{C} \text {, and is } \\
\text { complete by } 800^{\circ} \mathrm{C} \text {. }\end{array}$ & \multirow{2}{*}{$\begin{array}{l}\text { Perform evolved gas } \\
\text { analysis, XRD, }{ }^{(\mathrm{c})} \text { and SEM- } \\
\text { EDS }^{(\mathrm{d})} \text { for feed reactions to } \\
\text { document nitrate, chloride, } \\
\text { and sulfate behavior. }\end{array}$} \\
\hline & & DTA-TGA $^{(\mathrm{b})}$ & $\begin{array}{l}\text { Mass loss from waste begins at }>600^{\circ} \mathrm{C} \text { and ends } \\
\text { by } 700^{\circ} \mathrm{C} \text {. }\end{array}$ & \\
\hline & \multirow{3}{*}{$\begin{array}{l}\mathrm{Na}_{2} \mathrm{O} \text { from MIS } \\
\text { starts to react } \\
\text { with soil, } \mathrm{ZrO}_{2} \text {, } \\
\text { and CRB. }\end{array}$} & CFT & $\begin{array}{l}\text { Crucible washes at } 800^{\circ} \mathrm{C} \text { show no significant } \\
\text { molten salt. Soluble fraction contains } \sim 5 \% \text { of the } \\
\mathrm{NO}_{3} \text {, and } 20-30 \% \text { of the } \mathrm{Cl} \text { and S. }\end{array}$ & \multirow{5}{*}{$\begin{array}{l}\text { Confirm formation of an } \\
\text { intergranular "glass" phase } \\
\text { by obtaining } \\
\text { - T profile through CRB to } \\
\text { help understand } \\
\text { how/where quenching of } \\
\text { MIS occurs } \\
\text { - Volume of MIS in CRB } \\
\text { - Volume reduction to } \\
\text { MIS as } \mathrm{NO}_{3} \text { decomposes } \\
\text { - Viscosity of amorphous } \\
\text { phase in CRB. }\end{array}$} \\
\hline & & $\begin{array}{l}\text { Thin Section } \\
\text { ES-31B }\end{array}$ & Na present within CRB to $\sim 12 \mathrm{~mm}$ depth. & \\
\hline \multirow{4}{*}{$\begin{array}{l}\text { Most (80 to 90\%) of MIS } \\
\text { decomposes, releasing } \\
\mathrm{NO}_{x} ; \mathrm{NO}_{x} \text { gas rises } \\
\text { toward the surface in } \\
\text { large bubbles and open } \\
\text { channels. Grains of soil, } \\
\text { zirconia, and CRB react } \\
\text { with } \mathrm{Na}_{2} \mathrm{O} \text { from MIS, } \\
\text { creating intermediate } \\
\text { crystalline phases and the } \\
\text { initial glass-forming melt. }\end{array}$} & & $\begin{array}{l}\text { Immersion } \\
\text { Test at } \\
\geq 900^{\circ} \mathrm{C}\end{array}$ & $\begin{array}{l}\text { Penetration of CRB is at least } 6-10 \mathrm{~mm} \text {. CRB } \\
\text { swells at }>1100^{\circ} \mathrm{C} \text {. Not certain when glass phase } \\
\text { begins to occur. }\end{array}$ & \\
\hline & \multirow{2}{*}{$\begin{array}{l}\text { MIS shrinks as } \\
\text { nitrates } \\
\text { decompose. }\end{array}$} & ES tests & $\begin{array}{l}\text { Analysis of salt deposits shows that Tc/Re } \\
\text { concentrates in the MIS. }\end{array}$ & \\
\hline & & CFT & $\begin{array}{l}\text { Tc volatility is low at }<800^{\circ} \mathrm{C} \text {. Tc/Re to S ratio } \\
\text { increases at }>800^{\circ} \mathrm{C} \text {. }\end{array}$ & \\
\hline & $\begin{array}{l}\text { Tc/Re stays in } \\
\text { MIS as MIS } \\
\text { begins reaction } \\
\text { with CRB. }\end{array}$ & $\begin{array}{l}\text { ES Tests, } \\
\text { Steam } \\
\text { Reforming } \\
\text { Testing, and } \\
\text { CFT }\end{array}$ & $\begin{array}{l}\text { Nosean and nepheline form in CRB. Steam } \\
\text { reforming tests indicate that Re can incorporate } \\
\text { into nosean (McGrail et al. 2003). Tc can } \\
\text { dissolve in glassy phase. ES-32B indicated lower } \\
\text { base Re concentrations, possibly resulting from } \\
\text { higher base temperatures. }\end{array}$ & $\begin{array}{l}\text { Measure rates of Tc/Re } \\
\text { volatilization and } \\
\text { incorporation into the } \\
\text { glassy phase in bulk melt } \\
\text { and CRB. }\end{array}$ \\
\hline $\begin{array}{l}\text { (a) CFT results were reported b } \\
\text { (b) DTA-TGA = differential th } \\
\text { (c) XRD = X-ray diffraction } \\
\text { (d) SEM-EDS = scanning elect }\end{array}$ & & alysis & & \\
\hline
\end{tabular}




\subsection{Bulk Feed}

Alkali nitrites, nitrates, carbonates, and hydroxides react with silicate and aluminosilicate components of the soil grains, creating glass-forming melt. As the melt fuses, the open space between solid grains shrinks into closed pores that become bubbles (Figure 3.3 and Table 3.5). The residual salt phase (sulfates and chlorides) is trapped into spherical inclusions that may or may not contain gas (Figure 3.4 and Table 3.6). Because the density of inclusions is lower than the density of molten glass, the inclusions tend to ascend to the top surface of the melt. Some inclusions can stay in the melt for a long time because of either their small size (by the Stokes law, their velocity is proportional to the square of their radius) or because they circulate in the melter with the circulation currents.

\section{Bulk Feed/Melt}

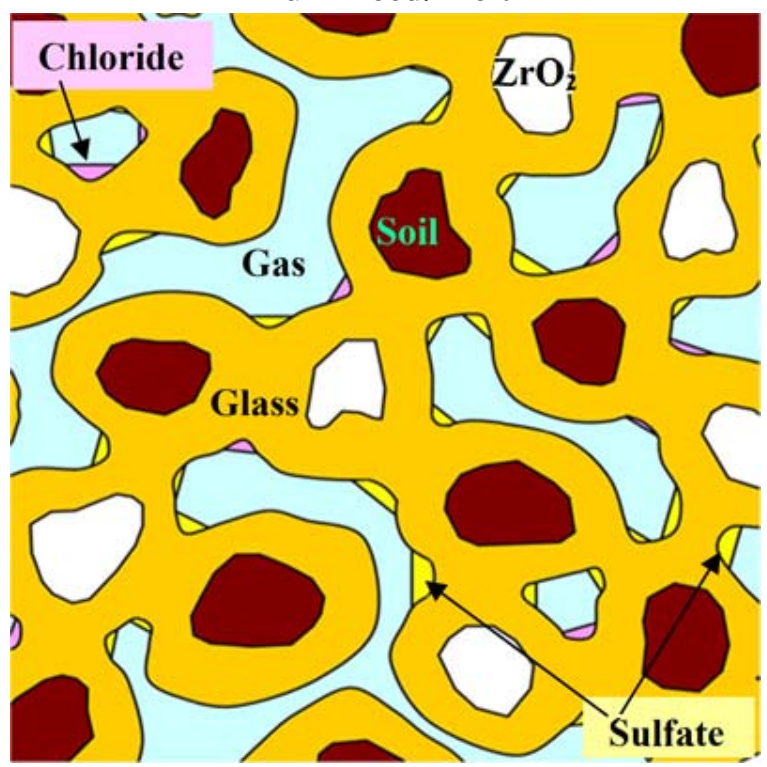

Interface Between Feed/Melt and CRB

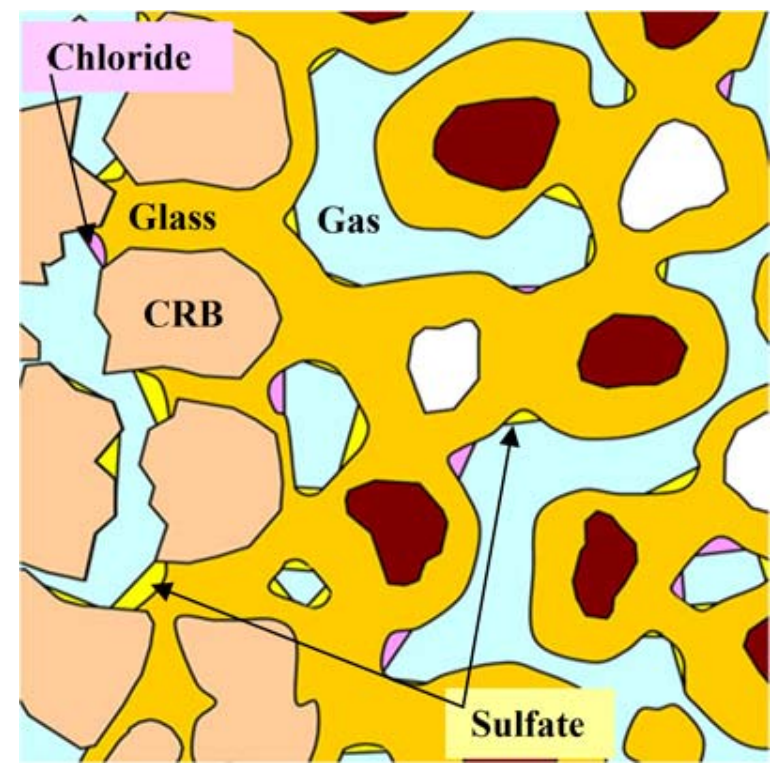

$\sim 750^{\circ} \mathrm{C}-950^{\circ} \mathrm{C}$

Grains of soil and zirconia (brown and white) continue to dissolve in the glass-forming melt (mustard) that becomes connected. The gas phase is partly connected and partly confined in bubbles. Extremely fluid sulfate (yellow) and chloride (pink) salts, the remains of the MIS, are trapped in gas bubbles and channels (light blue). Chromates, perrhenates, pertechnetates, and other thermally stable MISs are components of the sulfate and chloride phases. Sulfate and chloride salts, containing chromates, perrhenates, pertechnetates, etc., are left behind also in the CRB pores.

\section{Figure 3.3. A Pictorial Representation of an Advanced Stage of Feed Melting: Glass Forming Melt is Connected}


Table 3.5. Conceptual Model of the Mechanism of Leachable Technetium Salt Deposition in the Bulk Vitrification Process

Step 3. Glass Melt Becomes Continuous ${ }^{(a)}$

\begin{tabular}{|c|c|c|c|c|}
\hline \multirow{2}{*}{ Description } & \multirow{2}{*}{$\begin{array}{l}\text { Key Elements/ } \\
\text { Assumptions }\end{array}$} & \multicolumn{2}{|r|}{ Evidence/Basis } & \multirow{2}{*}{$\begin{array}{l}\text { Recommended } \\
\text { Testing }\end{array}$} \\
\hline & & Test & Result & \\
\hline $\begin{array}{l}\text { At } 750 \text { to } 950^{\circ} \mathrm{C} \text {, a continuous glass phase } \\
\text { starts to form that traps the remains of the } \\
\text { MIS in inclusions in the glass. }\end{array}$ & $\begin{array}{l}\text { Gas bubbles continue } \\
\text { to evolve from the } \\
\text { melt. }^{\text {(b) }}\end{array}$ & $\begin{array}{l}\text { DTA- } \\
\text { DTG }^{(c)}\end{array}$ & $\begin{array}{l}\text { Some } \mathrm{NO}_{\mathrm{x}} \text { continues to } \\
\text { evolve at } 800^{\circ} \mathrm{C} \text {, possibly } \\
\text { from sodalite. }\end{array}$ & \\
\hline $\begin{array}{l}\text { Grains of soil and zirconia continue to } \\
\text { dissolve in the glass-forming melt that } \\
\text { becomes connected. Extremely fluid sulfate } \\
\text { and chloride salts, the remains of the MIS, } \\
\text { are trapped in gas bubbles or separate } \\
\text { phases in the bulk melt and also left behind } \\
\text { in the CRB pores. Chromates, perrhenates, } \\
\text { pertechnetates, and other thermally stable } \\
\text { salts are components of the sulfate and } \\
\text { chloride phases. }\end{array}$ & $\begin{array}{l}\text { K and Na perrhenates } \\
\text { and pertechnetates } \\
\text { concentrate in the } \\
\text { MIS phases, rather } \\
\text { than dissolving in the } \\
\text { glass melt. }\end{array}$ & CFT & $\begin{array}{l}\text { Sulfate significantly } \\
\text { influences Tc/Re } \\
\text { volatilization. No-sulfur test } \\
\text { indicates significant increase } \\
\text { in glass retention (30-40\%) } \\
\text { and decrease in condensation } \\
(15-25 \%) \text {. }\end{array}$ & $\begin{array}{l}\text { Repeat CFT with ground glass } \\
\text { quenched at } 800^{\circ} \mathrm{C} \text {. Evaluate } \\
\text { Re:S and Re:Na ratios to } \\
\text { confirm whether Re } \\
\text { preferentially concentrates with } \\
\text { the sulfate phase at lower } \\
\text { temperatures. }\end{array}$ \\
\hline $\begin{array}{l}\text { (a) CFT results were reported by Kim et al. (2005); ES-31c } \\
\text { (b) Gases contain } \mathrm{CO}_{2} \text { from carbon and carbonates and rem } \\
\text { (c) DTA-DTG = differential thermal analysis-differential tt }\end{array}$ & sis & & & \\
\hline
\end{tabular}




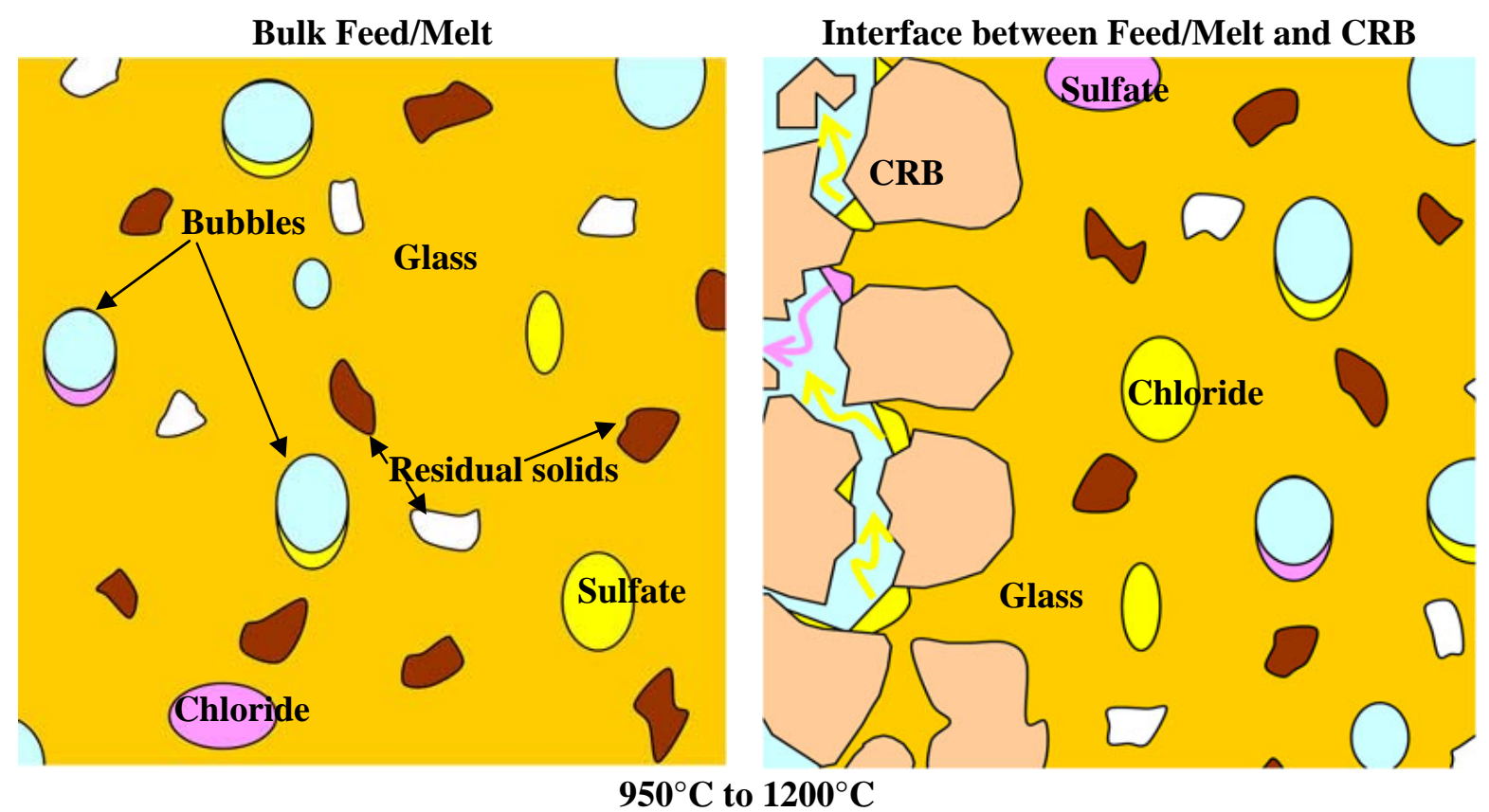

Solid grains are nearly entirely dissolved. Sulfate and chlorate salts form inclusions in the glass phase and are also present in bubbles. Whereas sulfate and chlorate inclusions rise to the surface in molten glass, they stay in the CRB; they may evaporate only to condense at colder portions of the porous CRB, distributing Tc and Re throughout the block (as indicated by yellow and pink arrows).

Figure 3.4. A Pictorial Representation of the Final Stage of Feed Melting: the Remaining Solid, Gas, and Salt Phases are Dispersed in Molten Glass 
Table 3.6. Conceptual Model of the Mechanism of Leachable Technetium Salt Deposition in the Bulk Vitrification Process

Step 4. Remaining Solids Dissolve and Remaining SIM Segregates ${ }^{(a)}$

\begin{tabular}{|c|c|c|c|c|}
\hline \multirow[b]{2}{*}{ Description } & \multirow{2}{*}{$\begin{array}{c}\text { Key } \\
\text { Elements/ } \\
\text { Assumptions }\end{array}$} & \multicolumn{2}{|c|}{ Evidence/Basis } & \multirow{2}{*}{$\begin{array}{c}\text { Recommended } \\
\text { Testing }\end{array}$} \\
\hline & & Test & Result & \\
\hline $\begin{array}{l}\text { At } 1000 \text { to } 1200^{\circ} \mathrm{C} \text {, the salt inclusions in the glass slowly dissolve but also rise to } \\
\text { the surface. The salt inclusions in the CRB continue to react and form a glassy } \\
\text { phase that incorporates some of the Tc/Re but also evaporates and condenses in } \\
\text { colder portions of the CRB, distributing Tc/Re as they condense. } \\
\text { Solid grains are nearly entirely dissolved. Sulfate and chloride salts form } \\
\text { inclusions in the glass phase and are also present in bubbles. While sulfate and } \\
\text { chloride inclusions rise to the surface in molten glass, they stay in the CRB; they } \\
\text { may evaporate only to condense at colder portions of the porous CRB, distributing } \\
\text { Tc and Re throughout the block. }\end{array}$ & $\begin{array}{l}\text { Tc/Re within } \\
\text { the melt also } \\
\text { volatilize } \\
\text { directly and } \\
\text { condense on } \\
\text { cooler } \\
\text { surfaces. }\end{array}$ & CFT & $\begin{array}{l}\text { Tc/Re } \\
\text { volatilized } \\
\text { from } \\
\text { Tc/Re- } \\
\text { spiked } \\
\text { premelted } \\
\text { glass at } \\
1200^{\circ} \mathrm{C} \text {. }\end{array}$ & $\begin{array}{l}\text { Perform CFT to } \\
\text { evaluate Tc/Re } \\
\text { evolution and } \\
\text { condensation from } \\
\text { pre-melted glass } \\
\text { held at } 1000^{\circ} \mathrm{C} \text { anc } \\
1100^{\circ} \mathrm{C} \text {. }\end{array}$ \\
\hline
\end{tabular}

(a) CFT results were reported by Kim et al. (2005) 

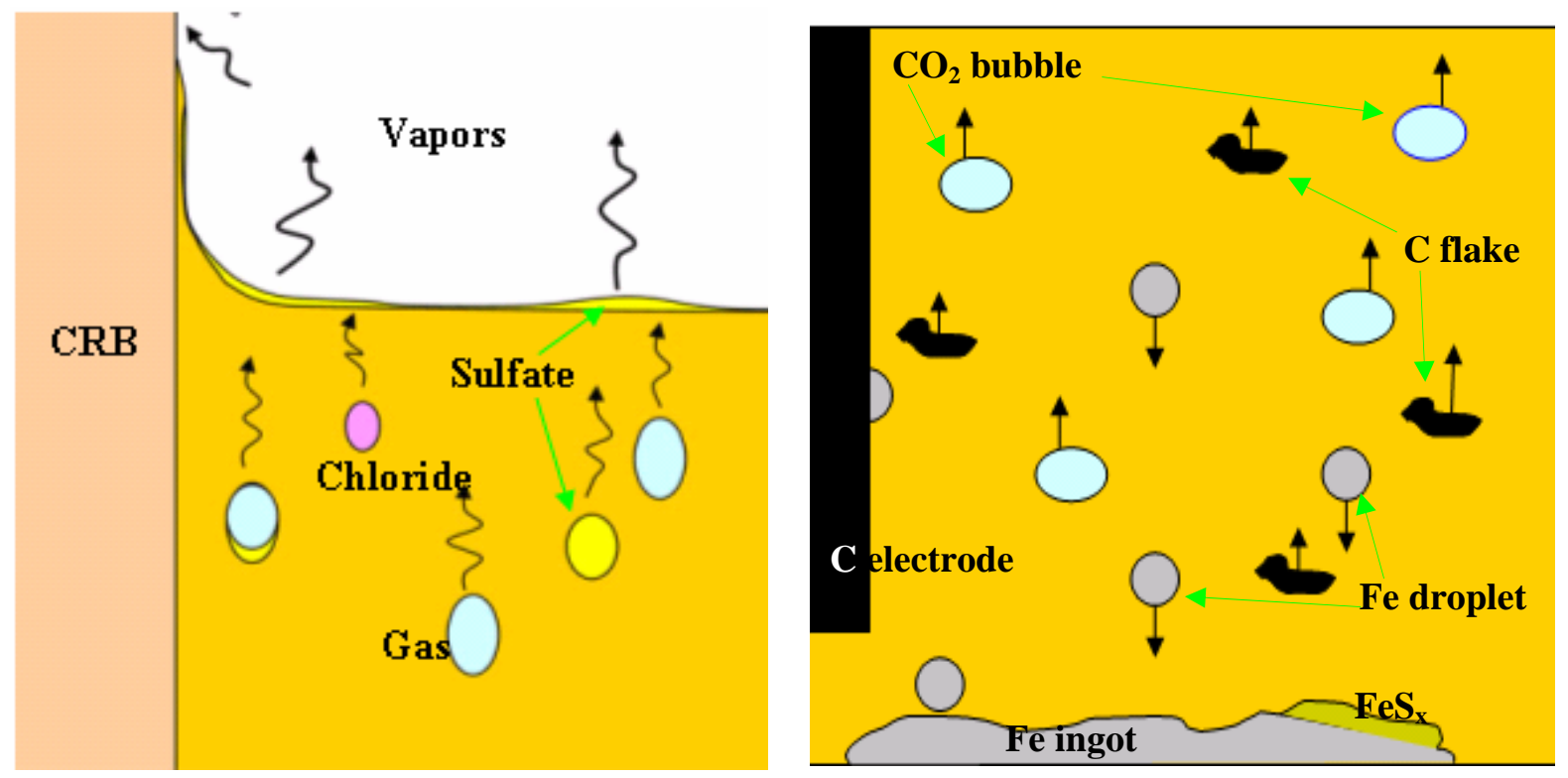

\section{$1200^{\circ} \mathrm{C}$ to $1400^{\circ} \mathrm{C}$}

A fraction of sulfate and chloride phases with Tc/Re salts reach the top surface of the molten glass where they are deposited as a thin layer and evaporate. Salt vapors and volatile components from glass (such as sodium borate) condense on the upper portions of the CRB, on the box lid, and in the off-gas system. Iron oxides in the soil and waste are being reduced to iron metal along with Tc/Re oxides through reaction with remaining graphite flake (starter path) and on the graphite electrodes surface. Iron droplets continue to scavenge and reduce more iron and $\mathrm{Tc} / \mathrm{Re}$ oxides in the melt as convective currents mix the carbon flake and iron. As metallic droplets reach the bottom, they often fuse into an ingot. Iron sulfide may form at the iron-glass interface.

\section{Figure 3.5. A Pictorial Representation of Tc/Re Transport out of the BV Feed/Melt}

When sulfate-rich and chloride-rich inclusions reach the glass melt surface, they gradually evaporate (Figure 3.5 and Table 3.7). Remaining sulfate melt forms patches of yellow salt. The chloride-rich inclusion may convert to gas while still in the glass-forming melt ( $\mathrm{NaCl}$ boils at $\left.1465^{\circ} \mathrm{C}\right)$. The sulfate melt keeps dissolving in molten glass as long as the glass melt remains undersaturated with $\mathrm{SO}_{3}$. However, the $\mathrm{SO}_{3}$ solubility limit in the glass sharply decreases as the temperature approaches $1400^{\circ} \mathrm{C}$. Some glass components, such as alkali borates, also easily volatilize. Volatilization is further enhanced by humid atmosphere. 
Table 3.7. Conceptual Model of the Mechanism of Leachable Technetium Salt Deposition in the Bulk Vitrification Process

Step 5. SIM Reaches Melt Surface and Vapors Contaminate $\mathbf{C R B}^{(\mathrm{a})}$

\begin{tabular}{|c|c|c|c|c|}
\hline \multirow{2}{*}{ Description } & \multirow{2}{*}{ Key Elements } & \multicolumn{2}{|r|}{ Evidence/Basis } & \multirow{2}{*}{$\begin{array}{l}\text { Recommended } \\
\text { Testing }\end{array}$} \\
\hline & & Test & Result & \\
\hline \multirow{4}{*}{$\begin{array}{l}\text { At } 1200 \text { to } 1400^{\circ} \mathrm{C} \text {, the sulfate and chloride } \\
\text { MIS reaches the glass melt surface and } \\
\text { volatilizes. Tc/Re also volatilize directly from } \\
\text { molten glass. The vapors penetrate CRB pores } \\
\text { and condense on cooler surfaces of the CRB, } \\
\text { the hood, and the off-gas system. Without the } \\
\mathrm{Na}_{2} \mathrm{O} \text { from the nitrate and the higher } \\
\text { temperatures seen in the lower CRB region, in } \\
\text { the upper region, Tc/Re are not incorporated in } \\
\text { glass phase and remain in a leachable form. }\end{array}$} & $\begin{array}{l}\text { Tc/Re within the melt } \\
\text { also volatilize } \\
\text { directly and condense } \\
\text { on cooler surfaces. }\end{array}$ & CFT & $\begin{array}{l}\text { Pre-melted glass evolved } \sim 30 \% \text { of Tc } \\
\text { and Re in } 5 \text { hours at } 1200^{\circ} \mathrm{C} .\end{array}$ & \\
\hline & \multirow{2}{*}{$\begin{array}{l}\text { Sulfate/chloride MIS } \\
\text { reaches the surface of } \\
\text { the glass melt and } \\
\text { volatilizes and } \\
\text { condenses. }\end{array}$} & CFT & $\begin{array}{l}\text { Sulfate and chloride collected from CFT } \\
\text { baseline (1-7 wt\% of condensate) and } \\
\text { pre-melted glass (7-18 wt\%). }\end{array}$ & \\
\hline & & $\begin{array}{l}\text { ES- } \\
31 B\end{array}$ & $\begin{array}{l}\text { Re deposition was lower in ES-31B } \\
\text { than in other ES tests with nitrate rich } \\
\text { feed. The distribution of Re in the CRB } \\
\text { was also relatively level from top to } \\
\text { bottom (upper CRB portions were not } \\
\text { elevated). S-109 feed for ES-31B had a } \\
\text { lower S/Na ratio (.0074 vs .018) than } \\
\text { tests with the six-tank composite feed. } \\
\text { Lower sulfate levels may reduce overall } \\
\text { deposition in the CRB, particularly in } \\
\text { the upper portions. }\end{array}$ & \\
\hline & $\begin{array}{l}\text { Iron and Tc/Re } \\
\text { within the melt are } \\
\text { reduced by carbon. } \\
\text { Iron inclusions form } \\
\text { and scavenge } \\
\text { additional Fe and } \\
\text { Tc/Re from the melt. }\end{array}$ & $\begin{array}{l}\text { ES- } \\
32 B\end{array}$ & $\begin{array}{l}\text { Formation of small dispersed iron metal } \\
\text { inclusions, and several large inclusions } \\
\text { with high concentrations of Tc/Re } \\
\text { compared to the bulk glass. }\end{array}$ & $\begin{array}{l}\text { Perform laboratory- } \\
\text { scale melts to } \\
\text { verify scavenging } \\
\text { of Tc/Re from Fe } \\
\text { inclusions under C- } \\
\text { mediated reducing } \\
\text { conditions. }\end{array}$ \\
\hline
\end{tabular}

(a) CFT results were reported by Kim et al. (2005); ES-31C-E test results were reported by Pierce et al. (2005) 

The vapors of MIS precipitate on colder surfaces, such as the box lid or the CRB. Vapor condensation may occur even on a hot refractory surface if the condensate reacts with the CRB components. This may be caused by capillarity (partial pressure of vapors decreases above surfaces of a high negative curvature) or by chemical affinity (the vaporized component dissolves in melts in which it is a low concentration). Once on the CRB in a sufficient quantity, MIS easily penetrates, by capillary suction, through open pores of the castable refractory into the interior of the CRB. This process is facilitated by their low viscosity.

Sodium borate may create a film on the CRB that is further strengthened by the dynamic meniscus. The sodium borate film is quickly saturated by alumina from the refractory; the resulting increase in surface tension brings about a surface tension gradient between the surface film and the bulk melt, pumping more melt upwards ${ }^{(a)}$. This film may protect the CRB to some extent.

\subsection{Feed-Refractory Interface}

The MIS from the melter feed, containing Te/Re, penetrates the CRB open porosity as the interface temperature increases to approximately $750^{\circ} \mathrm{C}$. This happens as soon as the feed contacts the refractory wall (Figure 3.1 and Table 3.3). Appendix D, Section 3.1, demonstrates that CRB coupons submerged in MIS at temperatures of $400^{\circ} \mathrm{C}, 600^{\circ} \mathrm{C}$, and $700^{\circ} \mathrm{C}$ were soaked with molten salt and were destroyed by evolving gases when submerged in MIS at $800^{\circ} \mathrm{C}$. However, the temperature distribution within the CRB should not be ignored. Especially during start up, the feed-glass refractory interface is exposed to a moving temperature gradient. The CRB temperature ranges from ambient to a temperature above $1000^{\circ} \mathrm{C}$.

The penetration of MIS into the CRB proceeds by capillary suction and hydrostatic pressure through the interface between the feed and the wall, filling the open pores of the block. When the nitrates decompose at approximately $700^{\circ} \mathrm{C}, \mathrm{NO}_{\mathrm{x}}$ gas escapes through the pores (Figure 3.2 and Table 3.4) while sulfates, chlorides, borates, and chromates are left behind together with pertechnetates and perrhenates (Figure 3.3 and Table 3.5); $\mathrm{Na}_{2} \mathrm{O}$ from $\mathrm{NaNO}_{3}$ forms with refractory components a viscous melt. Above $800^{\circ} \mathrm{C}$, the Tc/Re compounds are expected to be very volatile, and vapor-phase transport occurs between the residual MIS in the CRB pores and lower temperature regions of the CRB (Figure 3.6). Kim et al. (2005) reported significant Tc/Re volatility from glass feed at temperatures above $800^{\circ} \mathrm{C}$.

When the nitrates decompose, they react with the fine-grained fraction of the CRB material forming crystalline products, such as nepheline $\left(\mathrm{NaAlSiO}_{4}\right)$, and a sodium-aluminosilicate glass-forming melt.

This high-viscosity melt may trap the residual salt that releases gas on decomposing. The gas expands the melt and swells the CRB. Appendix D, Sections 3.3.1 through 3.3.3, presents extreme examples of this phenomenon. A substantial portion of pertechnates and perrhenates from the MIS dissolves in the glass phase, in which it becomes immobilized.

(a) Dynamic meniscus is caused by vigorous convection associated with surface tension gradient that drives the triple-phase line higher than the static force balance would. It can reach tens of mm above the static meniscus, coating the wall with a thin layer of flowing melt. The surface tension gradient is caused by volatilization of surface active components $\left(\mathrm{Na}_{2} \mathrm{O}\right.$ and $\left.\mathrm{B}_{2} \mathrm{O}_{3}\right)$ from the melt and by dissolution of refractory components, such as $\mathrm{Al}_{2} \mathrm{O}_{3}$, that tend to increase surface tension. The bulk melt, which has a lower surface tension, flows into the meniscus area, increasing the height of the meniscus and enhancing corrosion (a phenomenon known as the melt-line corrosion). 


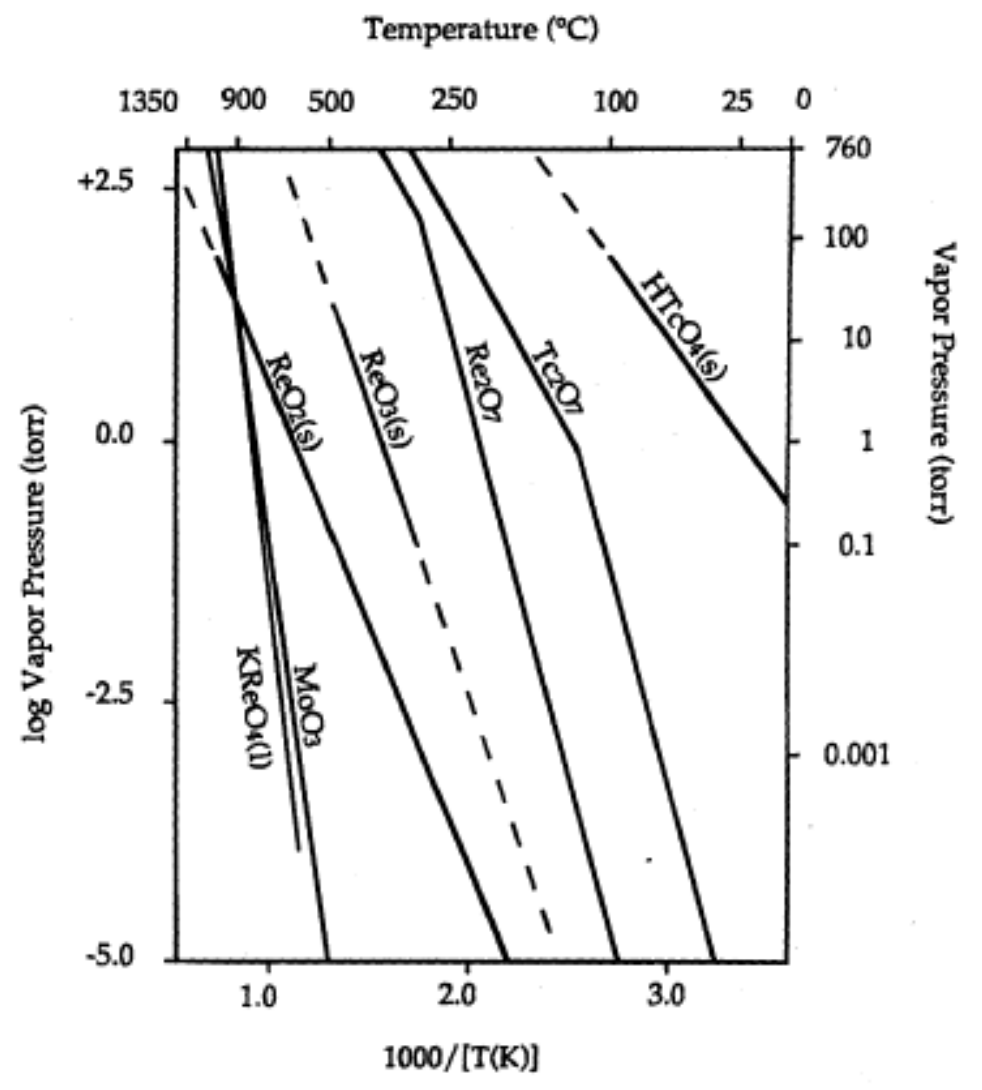

Figure 3.6. Vapor Pressure Versus Temperature for Tc and Re Compounds (Darab and Smith 1996)

\subsection{Capillary Suction}

The rate of penetration of molten salt into refractory pores may be estimated by connecting Darcy's law written in the form

$$
\frac{\Delta P}{L}=\frac{\eta L}{K t}
$$

with the Young-Laplace equation

$$
\Delta P=\frac{2 \sigma}{r}
$$


where $\Delta P=$ suction pressure

$L=$ meniscus distance from the refractory-melt interface

$\eta=$ viscosity

$r=$ pore radius

$K=$ permeability

$t=$ time

$\sigma=$ surface tension.

Eliminating $\Delta P$ from these two equations and rearranging the result, we obtain

$$
L=\left(\frac{2 K \sigma}{r \eta}\right)^{1 / 2} t^{1 / 2}
$$

A rough estimate of the progress of MIS penetration into the CRB is shown in Figure 3.7. The line in Figure 3.7 was obtained from Equation (3.3) with the following values: $\eta \approx 10^{-3} \mathrm{~Pa} \cdot \mathrm{s}, \sigma \approx 0.1 \mathrm{~N} / \mathrm{m}$, $r \approx 5 \times 10^{-5} \mathrm{~m}$, and $K \approx 3 \times 10^{-17} \mathrm{~m}^{2}$, (see Table 5.4).

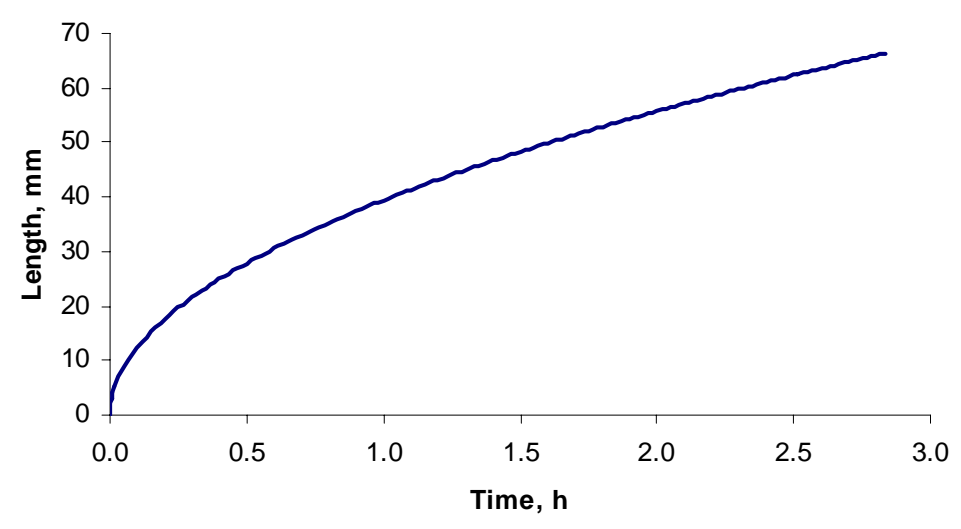

Figure 3.7. Length of MIS Penetration into the CRB (a rough estimate)

The depth of penetration may be limited by a variety of factors. With borate present in the salt melt, the viscosity can increase 100 times, thus slowing down the rate of penetration. A reaction with $\mathrm{SiO}_{2}$ from the CRB and the decreasing temperature deeper in the CRB eventually stops the penetration. Also, the amount of molten salt from the feed is limited once the feed in contact with the refractory wall is depleted of the molten salt. Molten salt penetration from feed is further restricted if, during the BV process, feed is charged away from the wall to minimize its contact with molten salt.

Another important parameter is the fraction of molten salt in the refractory pores. For example, the melter feed used in the ES-31B Test contained enough Re to result in a glass that had a Re concentration of $3.4 \mathrm{ppm}$ if all the Re remained in the glass. If this Re were all contained in the molten LAW simulant, the Re content of the molten salt would be $11 \mathrm{ppm}$. If a portion of CRB filled with 5 mass\% of molten salt, then the fraction of Re left in the refractory may be as high as $0.55 \mathrm{ppm}$ when the salt is decomposed. 


\subsection{Meniscus Area}

Later in the BV melting process, a meniscus is formed at the melt line when a batch is no longer melting in contact with the CRB. Although the salt tends to gather next to the meniscus area, as is often seen in laboratory crucibles, it remains separated from the refractory wall by molten glass, preventing direct contact between the CRB and the sulfate phase. If this condition exists also in the ES melter, the direct suction of the segregated sulfate phase from the meniscus area into the CRB is unlikely to occur.

\subsection{Gaseous Transport}

Consider for simplicity that all Re from an ES test with feed and simulant of compositions given in Table 3.1 and Table 3.2 remains concentrated in a sulfate residue. This residue may contain up to 0.1 mass\% of $\mathrm{Re}_{2} \mathrm{O}_{7}$ as perrhenate. Even more Re or Tc can end up in the CRB as a condensate from vaporized salt segregated on the glass melt surface. As reported by Gibson (1993a, 1993b) and Darab and Smith (1996), Tc and Re compounds, such as $\mathrm{NaReO}_{4}$ and $\mathrm{KReO}_{4}$, and their pertechnetate equivalents, are volatile at relatively low temperatures (see Figure 3.6). These volatile salts can penetrate deep into the porous refractory by gaseous diffusion and convection; deposited ions penetrate into the refractory by surface and intergranular diffusion, following the movement of the temperature gradient.

The depth of penetration by gaseous diffusion can be estimated as follows. Using the kinetic theory of gases, the diffusion coefficient of $\mathrm{KReO}_{4}$ vapors at $900^{\circ} \mathrm{C}$ is $D \sim 10^{-4} \mathrm{~m}^{2} / \mathrm{s}$. The penetration depth is $\delta=3(\pi D t)^{1 / 2}$, yielding $\sim 3 \mathrm{~mm}$ in 1 hour and $\sim 10 \mathrm{~mm}$ in 10 hours. However, the effective diffusion coefficient inside refractory pores can be 10 to 100 times higher because of the constant removal of $\mathrm{KReO}_{4}$ vapors by condensation on the walls. Therefore, it is likely that a front with a sharp drop in Tc/Re concentration is progressing into the refractory wall with a speed controlled by the rate of deposition. Since the deposition proceeds in the nonuniform and time-dependent temperature field, the salt condensation isotherm may also be a rate-controlling factor.

\subsection{Metal Precipitation}

Iron oxides in the soil and waste are reduced to iron metal along with Tc/Re oxides through reaction with remaining graphite flake (starter path) and on the surface of graphite electrodes (Figure 3.5 and Table 3.7):

$$
\begin{aligned}
& 2 \mathrm{Fe}_{2} \mathrm{O}_{3}+3 \mathrm{C} \rightarrow 4 \mathrm{Fe}+3 \mathrm{CO}_{2} \\
& 2 \mathrm{Tc}_{2} \mathrm{O}_{7}+7 \mathrm{C} \rightarrow 4 \mathrm{Tc}+7 \mathrm{CO}_{2}
\end{aligned}
$$

Carbon dioxide escapes to the melt surface in the form of bubbles. Metallic iron makes droplets that sink to the bottom of the melt (Figure 3.8). Metallic Tc/Re alloys with Fe. As iron droplets move through the melt, they continue to scavenge and reduce more Tc/Re oxides in the melt while convective currents mix the graphite flake and iron inclusions. When the droplets reach the bottom, they often fuse, creating an ingot (Figure 3.9 and Figure 3.10). Sulfate dissolved in the melt is reduced to sulfide that is precipitated in the form of FeS at the carbon-glass and iron-glass interfaces (Figure 3.11). 


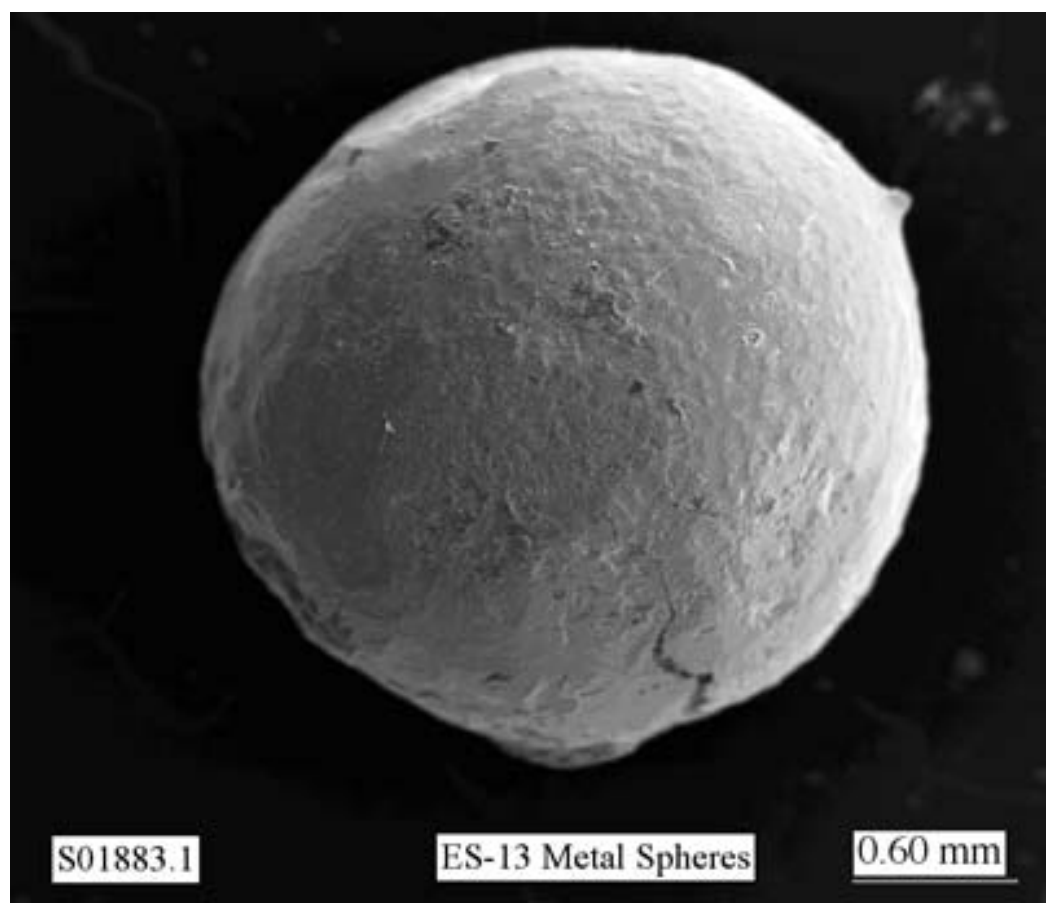

Figure 3.8. Iron Droplet in a BV Glass

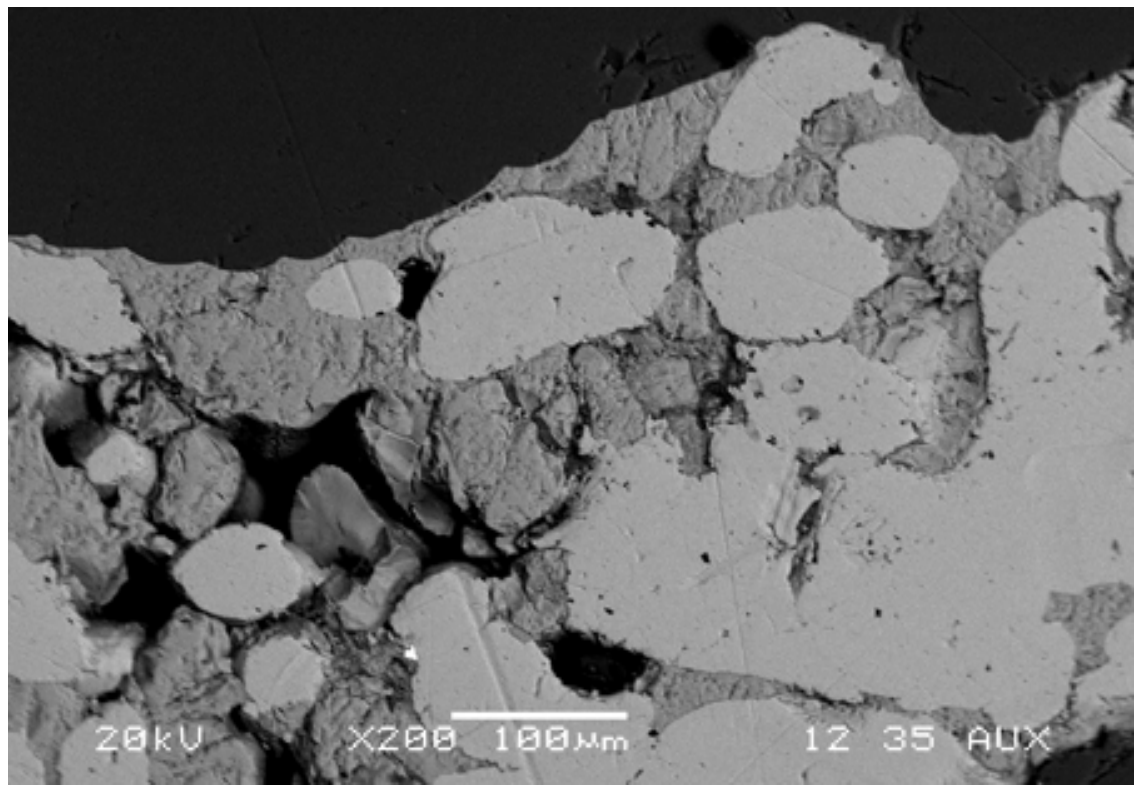

Figure 3.9. An Ingot of Iron Accumulated at the BV Melt Bottom 


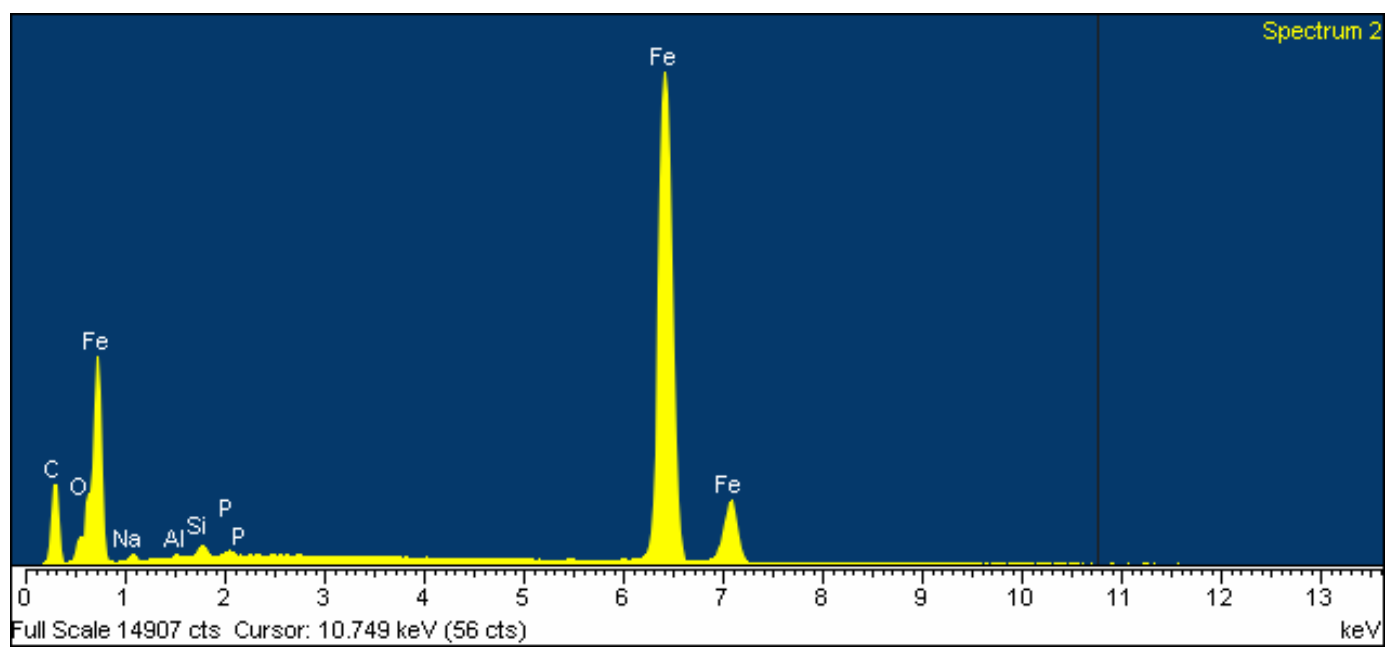

Figure 3.10. A Typical EDS Spectrum of a Metallic Precipitate in a BV Melt

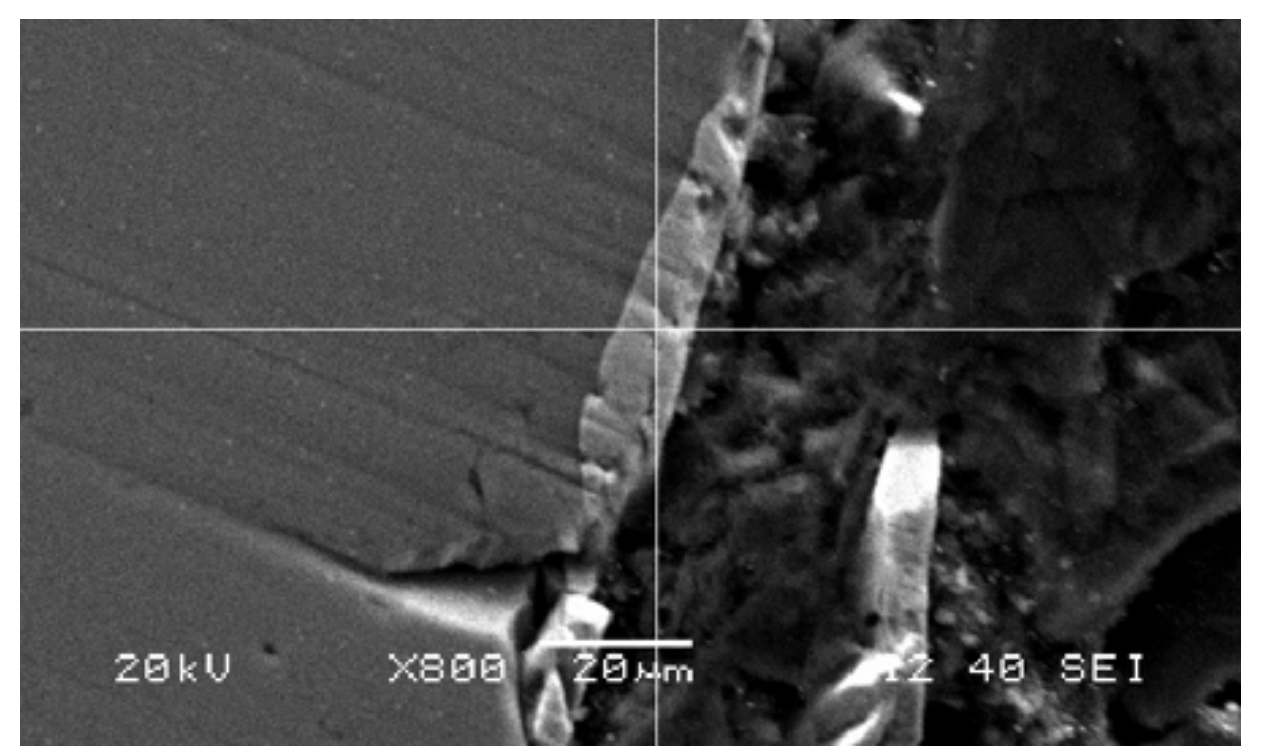

Figure 3.11. An FeS Phase Between Glass (left) and a Carbon Flake (right) 


\subsection{Experimental Methods}

The experimental methods were designed with three major objectives, the first of which was to understand the mechanism and kinetics of Tc/Re transport from the melter feed into the refractory, the second to quantify the extent of Tc/Re deposition as a function of the wall material and the wall temperature, and the third to determine the practicability of incorporating protection methods for reducing Tc/Re transport. Several experimental methods were developed, as described below, to support the inclusion of advanced refractory protection methods into ES tests. These methods complement the methods used in the previous studies as reported in Appendix D.

\subsection{Suspended Refractory Rod Test}

The purpose of this test was to better understand the deposition of condensed vapors on a solid wall or suspended specimen over an axial temperature gradient. A fused silica glass tube was inserted vertically to the upper opening of a box furnace (Figure 4.1). The tube, which contained melter feed doped with Re, was sealed at its lower end. Near the top of the furnace, the tube possessed an axial temperature gradient from the furnace's set temperature to the ambient room temperature above the furnace. In this region, the tube was equipped with a series of measuring K-type thermocouples connected with a Hydra automatic data logging system that monitored the temperature throughout the experiment.

The feed at the bottom of the tube was gradually heated up at a controlled rate of $5^{\circ} \mathrm{C} / \mathrm{min}$. The top portion of the tube could be visually observed to monitor the progress of condensation. Vapors condensed on the tube wall or on a rod of a refractory material suspended in the tube. The tube surface, or the suspended refractory rod, was then analyzed with optical microscopy and scanning electron microscopy-energy dispersive spectroscopy (SEM-EDS). In the case of a rod, both the exposed surface and a fracture surface perpendicular to the exposed surface were examined.

Rod samples were also subjected to extraction of a water-soluble fraction. As described in Pierce et al. (2004), the refractory sample was weighed, placed into a known volume of $0.001 \mathrm{M} \mathrm{HNO}_{3}$ leaching solution, and vacuum saturated at a pressure of $84.6 \mathrm{kPa}\left(12.3 \mathrm{lb} \mathrm{in}^{-2}\right)$ for no less than 4 hours. An aliquot of the saturation solution was removed and analyzed for Re with ICP-MS. The sample was lifted out of the saturation solution, allowed to drip, and spun between 2000 and $5000 \mathrm{rpm}$ in a centrifuge for 1 hour to release non-gravity drainable pore liquid. An aliquot of the centrifuge-extracted liquid was collected and analyzed for Re with ICP-MS. The two-part extraction process (saturation and centrifugation) was repeated until the majority of the soluble Re was leached from each sample, typically accomplished with five consecutive two-part extractions.

\subsection{Partially Immersed Refractory Rod Test}

The purpose of this test was to better understand the reaction of molten salts with refractories and the transport mechanism for Tc/Re into the refractory pores. A refractory rod (12 to $20 \mathrm{~mm}$ in cross-section and 10 to $12 \mathrm{~cm}$ in length) was inserted into a platinum crucible and kept vertical by the platinum lid with a central opening (Figure 4.2). Melter feed enriched in sodium sulfate and $\operatorname{Re}_{2} \mathrm{O}_{7}$ was added to the crucible so that $\sim 25 \mathrm{~mm}$ of the lower end of the rod was immersed in molten glass, and the assembly was gradually heated $\left(5^{\circ} \mathrm{C} / \mathrm{min}\right)$ to the set temperature. The rod was removed from the melt at the end of the 
heat-treatment. Both the exposed surface and a fracture surface perpendicular to the exposed surface were examined optically and by SEM-EDS.
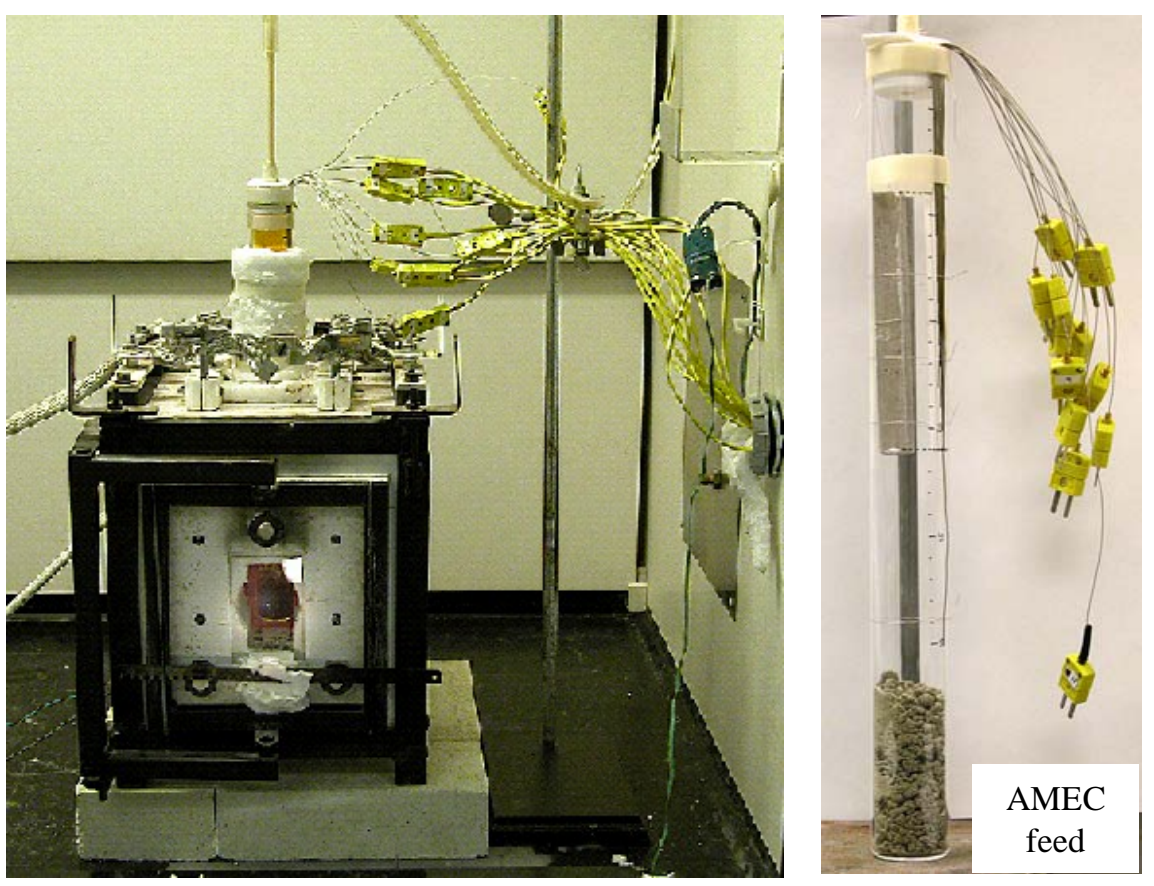

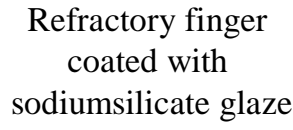

$+$

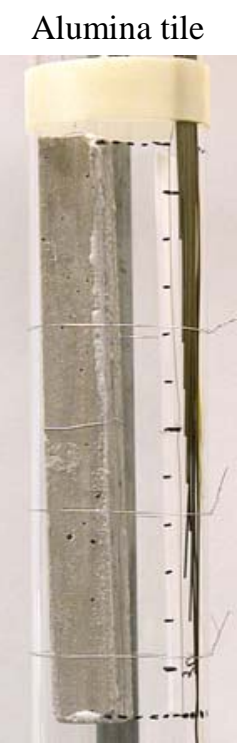

Figure 4.1. Test Assembly for Rhenium Evaporation-Condensation Study
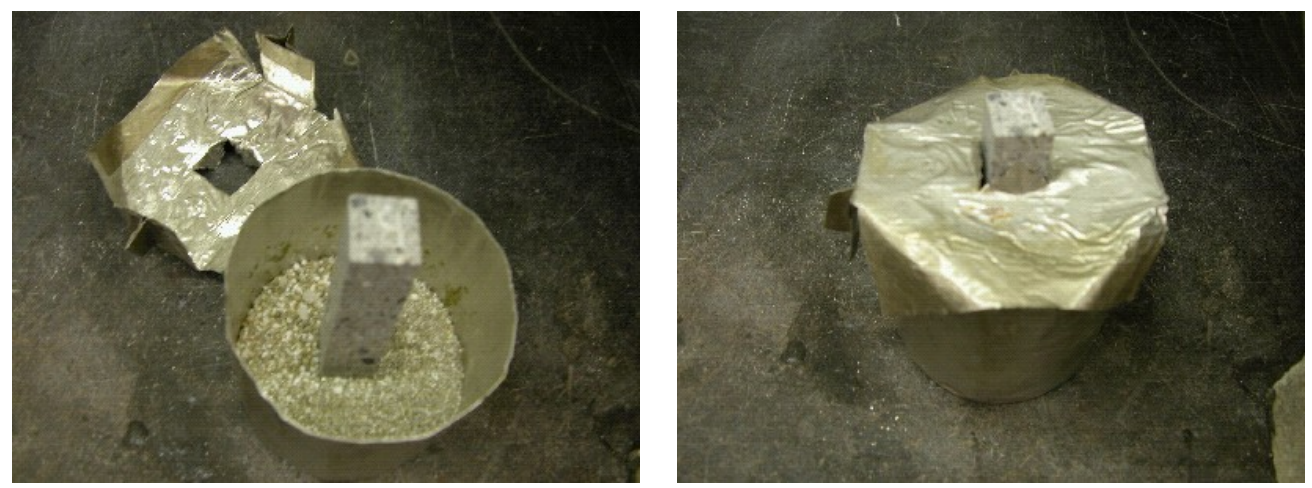

Figure 4.2. Partially Immersed Refractory Rod Setup

\subsection{Simulated Condensate Penetration Test}

The purpose of this scoping test was to study the transport of salts deposited on the refractory surface into the body of the refractory as a function of various parameters, such as time, temperature, and surface pretreatment. This test was a simplified version of the suspended refractory rod test that is more complex and labor intensive. Unlike the suspended rod test, this test did not use the condensate from vaporized 
feed components; instead, it used a simulated condensate placed on a horizontal surface of a refractory coupon. The simulant composition was estimated based on preliminary data obtained from cold finger experiments (Kim et al. 2005) and on the average composition of condensate that precipitated on fused silica glass (Section 5.1.3). The simulant was spiked with $\mathrm{Na}_{2} \mathrm{CrO}_{4}$ as a coloring agent, and the $\mathrm{Re}_{2} \mathrm{O}_{7}$ content was increased to make it easily detectable by EDS. The simulant composition, in mass fractions, was $\mathrm{B}_{2} \mathrm{O}_{3}$ 0.13, $\mathrm{NaF} 0.25, \mathrm{NaCl} 0.25$, KCl 0.05, $\mathrm{Na}_{2} \mathrm{SO}_{4}$ 0.30, $\mathrm{Na}_{2} \mathrm{CrO}_{4} 0.01$, and $\mathrm{Re}_{2} \mathrm{O}_{7} 0.01$.

A 100-g batch of simulated condensate was mixed as a dry powder and milled. An 10-g portion of this powder simulant was spread on a refractory coupon $(\sim 25 \times 25 \times 20 \mathrm{~mm})$ to cover a circle of $\sim 16 \mathrm{~mm}$ in diameter (using a small alumina crucible). Coupons with simulated condensate were placed into a furnace at various temperatures for $30 \mathrm{~min}$. The top surfaces of the samples were examined with optical microscopy. Samples were then fractured through the center of the circular simulated deposit (a groove was made on the bottom of the coupon before the experiment to facilitate the fracture location (see Figure 4.3), and examined to determine the depth of salt penetration.

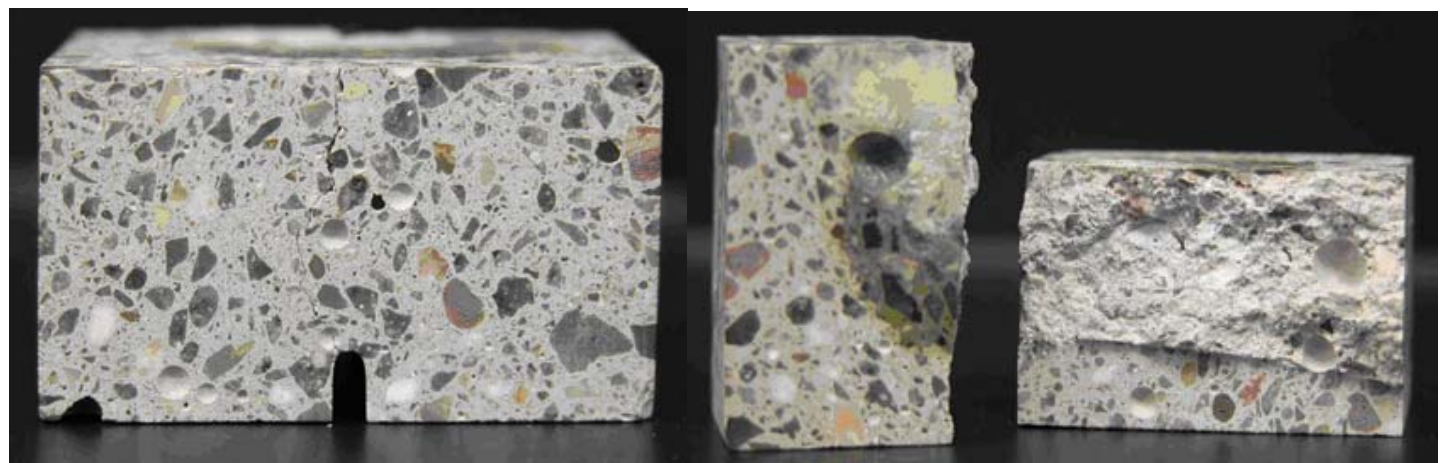

Figure 4.3. Refractory Coupon with a Groove at Bottom Surface (before and after fracturing)

To determine whether any of the simulated salts had soaked into the refractory material, the samples were subjected to salt leach testing where the salts could be extracted from the pores of the refractories. The samples were leached for 1 hour in a mild acid solution to remove the salt simulant from the refractory surface. The leach water was collected for analysis. Then the samples were hydrated with the same mild acid solution in a vacuum desiccator, causing the refractory pores to become saturated. The leach water was collected for analysis. Finally, the samples were placed in an IEC Centra GP8 centrifuge and rotated at $2000 \mathrm{rpm}$ for $30 \mathrm{~min}$ to draw the water from the saturated pores. Samples were put through five cycles of this procedure, and each time the soak water and pore water were collected and retained for analysis.

\subsection{Gas Permeability}

The purpose of this testing was to measure the gas permeability of the various refractory materials. Gas permeability of the refractories is thought to be related to the kinetics of the evaporation-condensation mechanism because it characterizes the pore structure within the solid, particularly the flow path through the solid. Gas-permeability measurements were conducted at Porous Materials Inc. ${ }^{\text {a }}$ using their standard gas permeameter. For castable samples, a 19-mm-thick and 25-mm-diameter sample was used because of its coarse microstructure. Most samples were formed by casting in a cylindrical mold and then cutting off

\footnotetext{
a 20 Dutch Mill Road, Ithaca, New York 14850, USA
} 
the top with a diamond saw after curing. Greystone ${ }^{(a)}$ tile samples were measured in their as-received thickness (6 mm thick).

The gas permeameter used at Porous Materials Inc. seals the inlet and outlet surfaces of the sample with O-rings. Then gas is forced through the sample while the steady-state flow rate through and pressure across the sample are measured. The permeability (Darcy units) was calculated at PNNL using the following expression, which is based upon a compressible gas (see Vangpaisal and Bouazza 2004):

$$
K=\frac{2 \mu Q L P_{2}}{A\left(P_{2}^{2}-P_{1}^{2}\right)}
$$

$$
\text { where } \begin{aligned}
K & =\text { gas permeability }\left(\mathrm{m}^{2}\right) \\
Q & =\text { gas flow rate }\left(\mathrm{m}^{3} / \mathrm{s}\right) \\
P_{1} \text { and } P_{2} & =\text { pressures at the inlet and outlet }(\mathrm{Pa}) \\
L & =\text { thickness of the sample }(\mathrm{m}) \\
A & =\text { area of flow }\left(\mathrm{m}^{2}\right) \\
\mu & =\text { dynamic viscosity of the gas }(\mathrm{Pa} \mathrm{s}) .
\end{aligned}
$$

\subsection{Refractory Corrosion Test}

This test was performed on greystone tile only since the corrosion resistance of the other refractories had been previously established. A strip of greystone tile with a thickness of $6.425 \mathrm{~mm}$ was placed in a Pt crucible with pieces of glass, heated at a rate of $10^{\circ} \mathrm{C} / \mathrm{min}$ to $1350^{\circ} \mathrm{C}$, and held for 22 hours. The glass used in the corrosion test was collected from a previous ES test and had been pre-melted to $1360^{\circ} \mathrm{C}$ to remove any gases and prevent reboil during the corrosion test. After the 22-hour corrosion heattreatment, the strip was removed and sectioned, and its profile was measured with a caliper. For each cut, the width was measured in four or five places to obtain an average corrosion depth. See Appendix D for additional methods of corrosion testing than were used for the CRB.

\subsection{Near Surface Concentration Gradient in the CRB}

To determine the concentration distribution of Tc/Re in the refractory wall at its interface with molten glass, a piece of the ES-31B CRB was chipped off. Material was removed from this CRB sample, layer by layer, by grinding, starting from the interface with melt. The sample was placed in a clean plastic bag and clamped into a mount with the bag opening facing the diamond blade of the rotating disk of the grinder. The hand grinder was modified with a plastic collar (the bottom of a large plastic jug) such that the opening of a plastic bag could be clamped around the collar. The sample's face was pressed to the blade until $\sim 1 \mathrm{~mm}$ of the refractory was removed. The powder from the bag was removed into the sample bottle, and the bag, the collar, and blade were cleaned with a brush. The process was repeated until the desirable distance from the interface was reached. The grinder blade and collar were cleaned each time with deionized (DI) water and dried.

(a) Gray wonderstone unfired (grey) alumina silicate machinable ceramic, manufactured by Graphtek LLC, available at Graphitestore.com. 
The samples were leached in water (added at $2.5 \mathrm{~mL}$ per g of refractory powder) in a Teflon container at $90^{\circ} \mathrm{C}$ for 24 hours. The leachate was filtered and sampled for analysis by inductively coupled plasmamass spectrometry (ICP-MS) (provided by the Southwest Research Institute ${ }^{\mathrm{a}}$ ), and the powder was dried and digested in concentrated nitric acid in a sealed microwave acid digestion vessel. The digested samples were diluted with water and analyzed by ICP-MS to determine the amount of non-leachable Re in the refractory samples.

\subsection{Manufacturing Demonstration Testing}

To assess the practicality of constructing a composite CRB and the compatibility of tiles and CRB materials, especially with respect to thermal stability and interactions, thermal expansion tests were completed on individual materials using a high-temperature dilatometer. In addition, composite samples with either glazes or tile were heat-treated to assess interactions. To prepare tile samples, a rectangular sample of a tile was cut to cover the bottom of a $50 \times 150-\mathrm{mm}$ mold. A layer of Vibrocast 60 PC refractory paste was then poured on top of the tile to create a 25 -mm-thick composite, dried at room temperature for 1 day, removed from the mold, dried at $150^{\circ} \mathrm{C}$ for 4 hours, and ramp-heated to $1000^{\circ} \mathrm{C} 5^{\circ} \mathrm{C} / \mathrm{min}$. On cooling, visual examinations were used to determine compatibility. The composite was checked for adherence of the tile to the CRB and for structural integrity. A qualitative assessment of adherence was made for each sample. Tiles were judged as non-adherent if they separated from the refractory rod in the furnace, were partially adherent if they were bonded but could be removed by hand, and strongly adherent if a screwdriver was required to remove the tile. The bonding of tiles to the CRB was considered important since the MIS and Tc/Re vapors could penetrate CRB if the tile was detached from the CRB during heating and merely mechanically held in place (by the pressure of the feed) with a gap between the tile and the CRB.

\footnotetext{
${ }^{a}$ Mike Dammann, (210) 522-5428.
} 


\subsection{Baseline Refractories}

This section describes the suspended refractory rod test, the immersed refractory rod test, and the simulated condensate penetration test, including their materials, the procedures, and the results. A comparison is made to $1 / 6^{\text {th }}$ scale melter data.

\subsection{Suspended Refractory Rod Test}

\subsubsection{Materials}

Feed for $500 \mathrm{~g}$ of glass, spiked with 0.1 mass\% (1000 ppm) $\mathrm{ReO}_{2}$, was prepared by mixing and subsequent drying of liquid simulant with AMEC soil, $\mathrm{ZrO}_{2}, \mathrm{~B}_{2} \mathrm{O}_{3}$, and $\mathrm{Re}_{2} \mathrm{O}_{7}$. Refractory rods were cut from Vibrocast 60PC (a mullite-based castable material with 17\% porosity) and alumina-zirconia-silica (AZS) UNICOR ${ }^{\circledR} 501$ (an electrofused fully-oxidized alumina-zirconia-silica [AZS] refractory with $1.15 \%$ open porosity; composition in mass\%: $14.5 \mathrm{SiO}_{2}$, $50.0 \mathrm{Al}_{2} \mathrm{O}_{3}$, and $33.5 \mathrm{ZrO}_{2}$ ).

\subsubsection{Procedure}

The basic procedure for this test was to heat feed in the bottom of a fused silica glass tube and to examine the deposits on either the fused silica glass tube or suspended refractory rods at different points along the thermal gradient that formed in the upper portions of the fused silica glass tube. For each test, a portion of the prepared feed $(\sim 75 \mathrm{~g})$ was heated in the fused silica glass tube at $5^{\circ} \mathrm{C} / \mathrm{min}$. The furnace was then held at the set temperature for 0 to 2 hours. After cooling, either the fused silica glass tube or the rod was cut, coated with carbon, and analyzed with SEM-EDS. Initially, deposition on fused silica glass tube (without suspended rods) was carried out by heating feed to temperatures of $800^{\circ} \mathrm{C}, 1000^{\circ} \mathrm{C}$, and $1350^{\circ} \mathrm{C}$. For experiments with refractory rods $(12 \times 12 \times 120 \mathrm{~mm}$ rectangular fingers), the feed material was heated to a set temperature of $1000^{\circ} \mathrm{C}$ for 2 hours. The areas of the refractory fingers that were exposed to a temperature gradient in the range of $200^{\circ} \mathrm{C}$ to $550^{\circ} \mathrm{C}$ were examined after cooling using SEM-EDS.

\subsubsection{Results}

Appendix A displays selected SEM and optical images of the deposits and compositions of individual phases. The main deposits detected on the fused silica-glass tube were $\mathrm{NaCl}$ and $\mathrm{Na}_{2} \mathrm{SO}_{4} ; \mathrm{NaNO}_{3}$ deposits were found when the feed was heated to $800^{\circ} \mathrm{C}$. Rhenium-rich salt $\left(\mathrm{KReO}_{4}\right)$ appeared in SEM photomicrographs in samples taken from portions of the fused silica glass tube that were at temperatures below $530^{\circ} \mathrm{C}$. The Re-rich salt was usually attached to larger deposits of $\mathrm{NaCl}$ (Figure 5.1), less often $\mathrm{Na}_{2} \mathrm{SO}_{4}$ (Figure 5.2) or $\mathrm{NaNO}_{3}$ (Figure 5.3); Figure 5.4 shows a larger agglomeration of $\mathrm{KReO}_{4}$ crystals. The amount of deposit on the tube wall increased with increasing feed test termination temperatures. Figure 5.5 displays the condensate composition on the fused silica-glass tube determined through EDS as a function of temperature. Note that Re is still present above $200^{\circ} \mathrm{C}$ but is not seen in the EDS analysis because it is at a lower relative concentration compared to the $\mathrm{S}$ and $\mathrm{Na}$ that are present in higher amounts at these higher temperatures. 


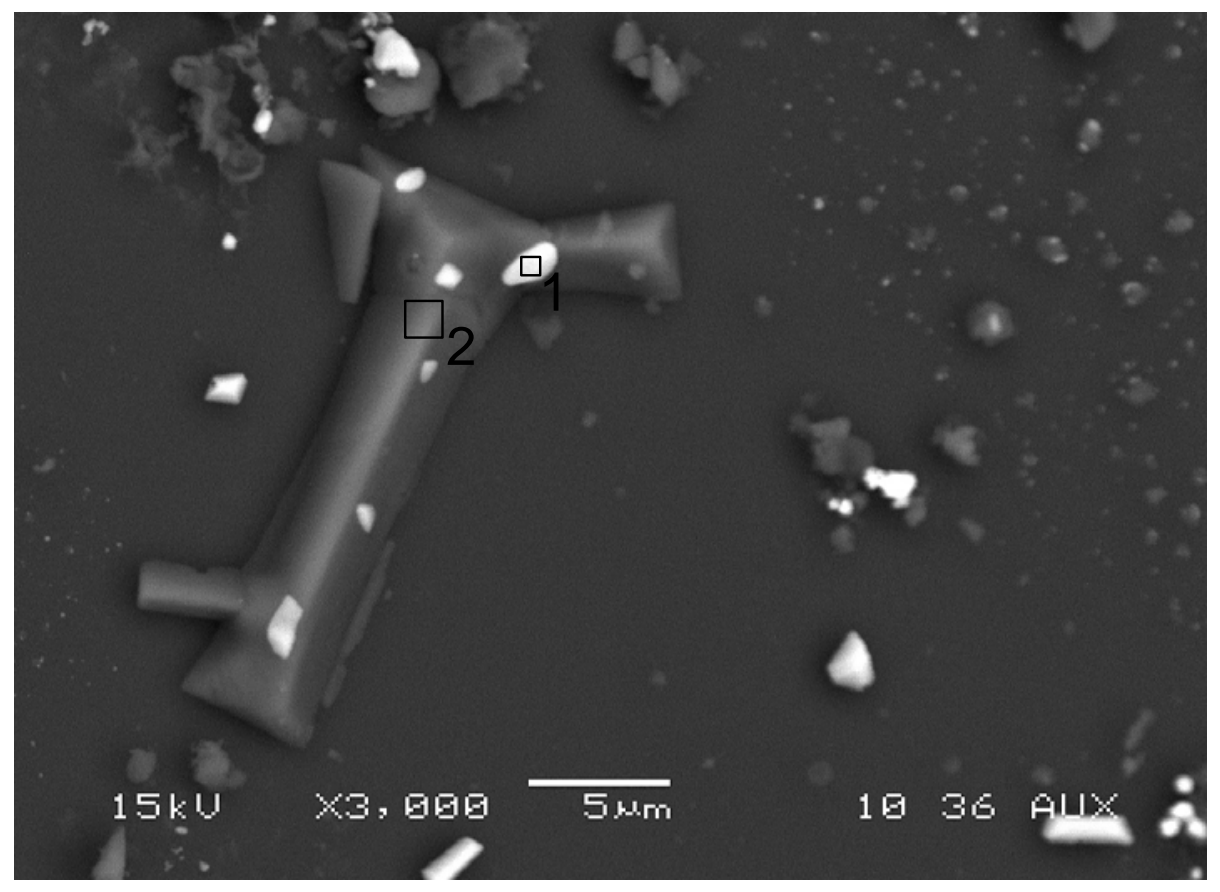

Figure 5.1. Grey $\mathrm{NaCl}$ Crystal (2) and White $\mathrm{KReO}_{4}$ Deposits (1) on Fused Silica Glass Tube at $235^{\circ} \mathrm{C}$ (SEM micrograph, feed heated to $1000^{\circ} \mathrm{C}$ with $2-\mathrm{h}$ hold)

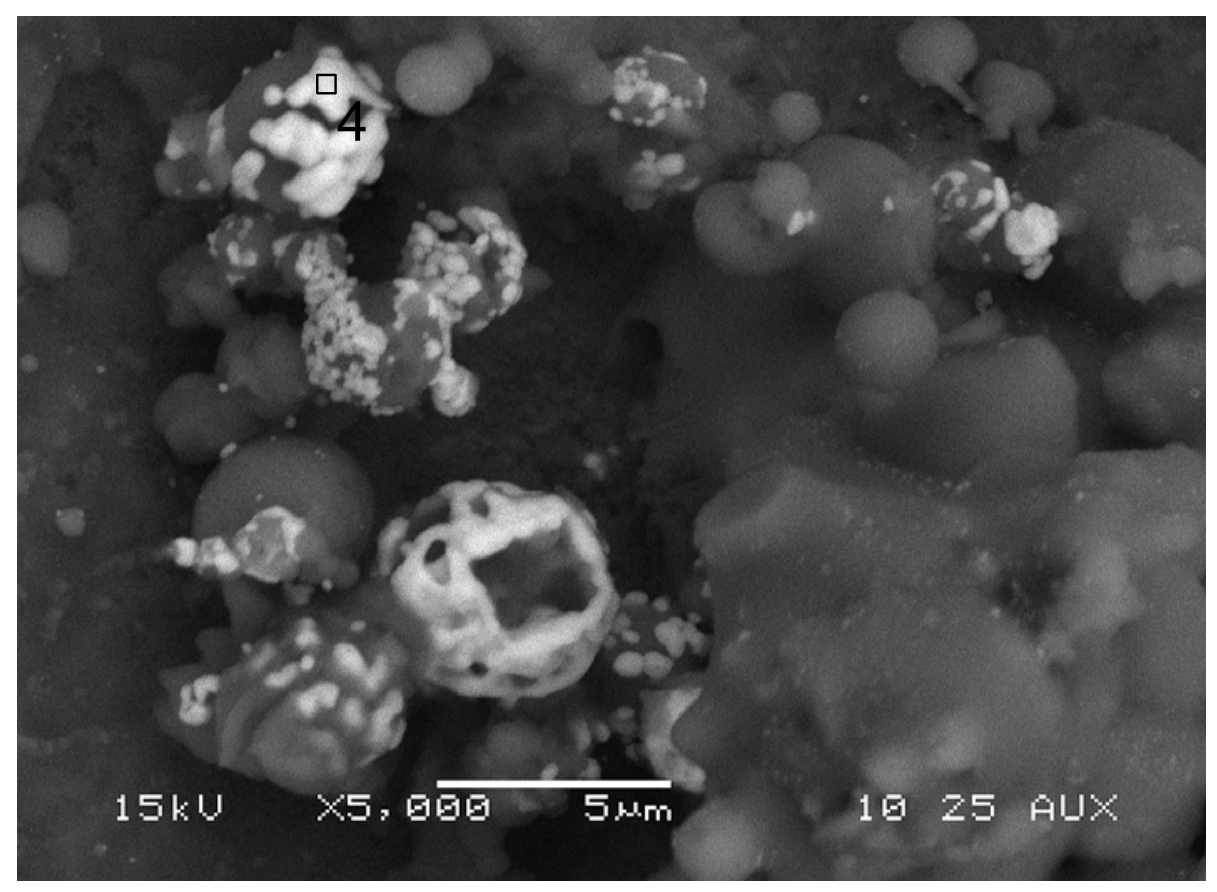

Figure 5.2. White $\mathrm{KReO}_{4}$ Deposits (4) on Spherical $\mathrm{Na}_{2} \mathrm{SO}_{4}$ on Fused Silica Glass Tube at $423^{\circ} \mathrm{C}$ that Appears Corroded by Fluoride Vapors (SEM micrograph, feed heated to $1350^{\circ} \mathrm{C}$ with 2-h dwell) 


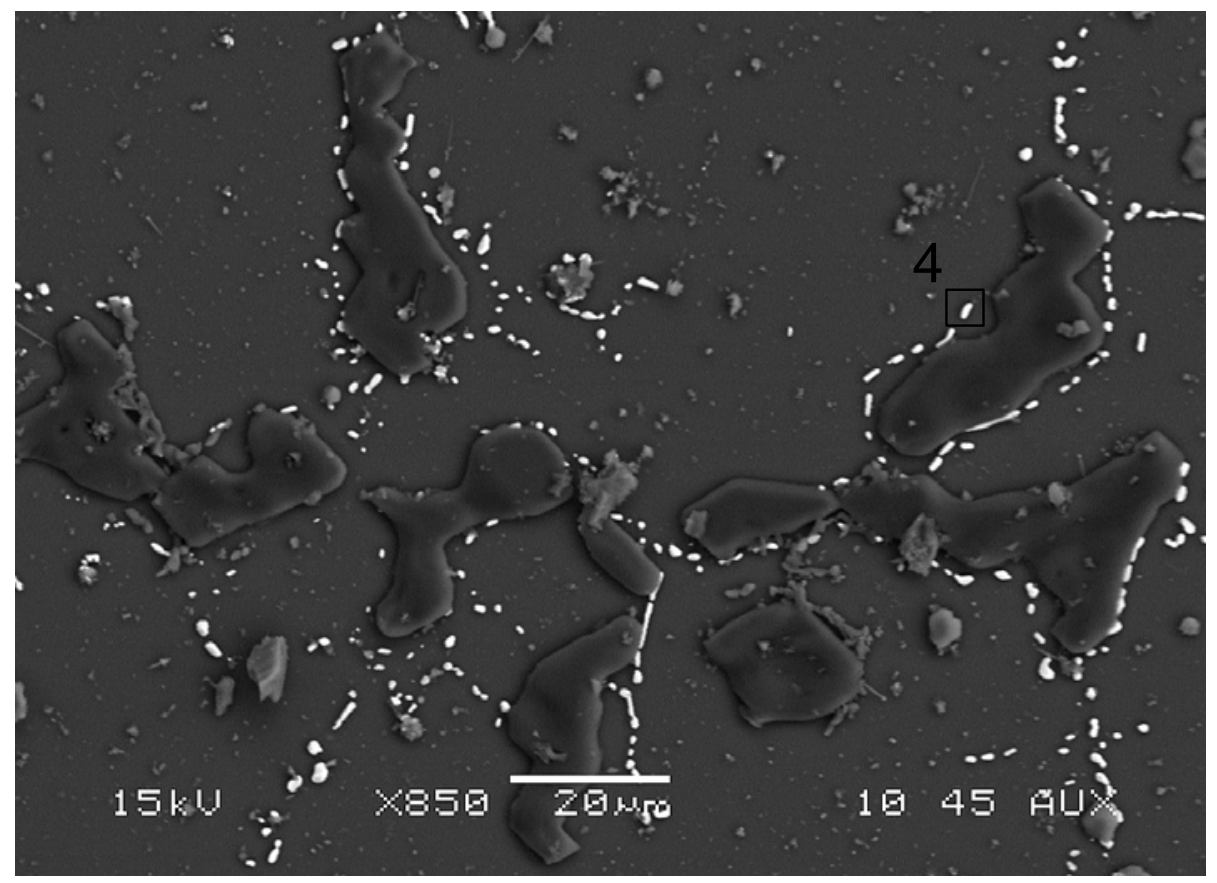

Figure 5.3. White $\mathrm{KReO}_{4}$ Deposits (4) Around Patches of $\mathrm{NaNO}_{3}$ on Fused Silica Glass Tube at $432^{\circ} \mathrm{C}$ (SEM micrograph, feed heated to $800^{\circ} \mathrm{C}$ with 2 -h hold)

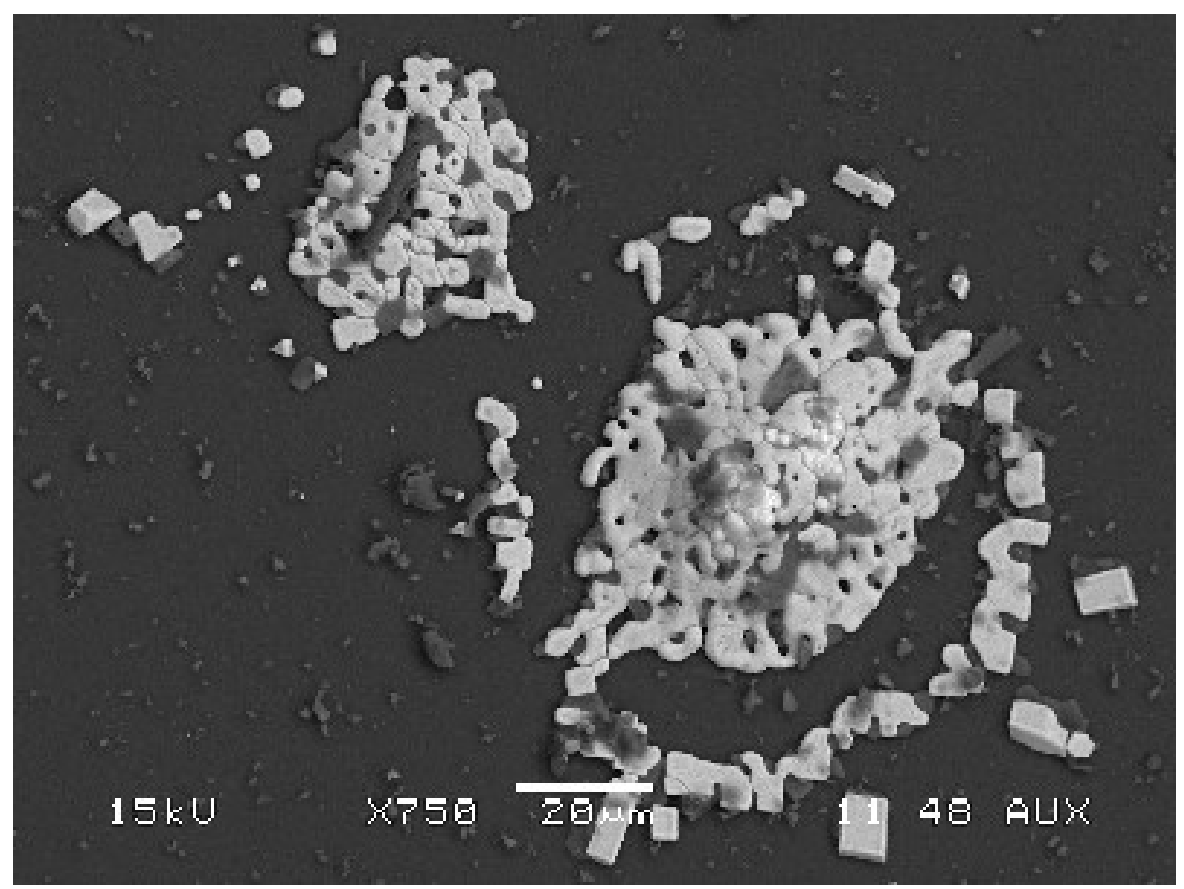

Figure 5.4. Clusters of $\mathrm{KReO}_{4}$ Crystals on Fused Silica Glass Tube at $467^{\circ} \mathrm{C}$ (SEM micrograph, feed heated to $1000^{\circ} \mathrm{C}$ with 2 -h hold) 


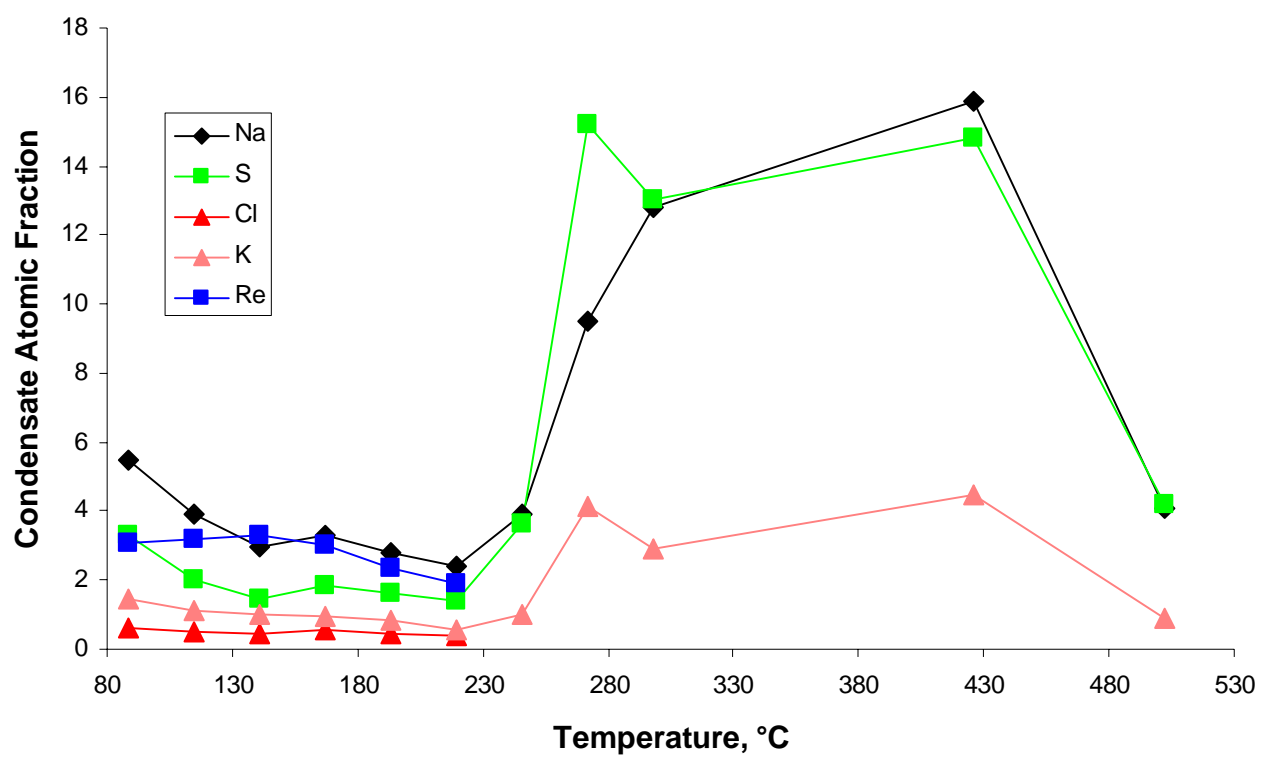

Figure 5.5. Concentration Distribution of Condensate in Fused Silica Glass Tube (feed heated to $1350^{\circ} \mathrm{C}$ with 2 -h hold)

No isolated Re salt deposits were detected with the SEM on untreated refractory surfaces. Pores of untreated Vibrocast 60PC exposed to $442^{\circ} \mathrm{C}$ were filled with chlorides and a small amount of sulfates, but no Re was detected with the SEM. Salt deposits were absent in the fracture surface of the AZS material, indicating that very little salt penetrated into the AZS.

Since Re was not detected on the surface with the SEM, additional refractory leach tests were performed for untreated and glazed Vibrocast 60 and AZS refractory from the suspended rod test. The purpose was to determine if Re was present in the portions of the rods that were exposed to the range of temperatures in which vapors of Re salts were expected to condense. The test is described in Section 4.1.

The results are summarized in Table 5.1. Approximately the same amount of Re was deposited on the untreated samples, whether AZS or Vibrocast 60PC. The sodium silicate glazed sample had slightly less Re deposited on the refractory rod. These tests indicate that the same salts that condense on the surface of the fused silica glass tube also condense on the refractory samples. These salts penetrate into the Vibrocast 60PC refractory carrying Re. Re was not found on the surface of the AZS material, and salts were not found in the AZS fracture surface, but the leach samples showed about the same levels of Re as the Vibrocast 60PC. The location of salt and Re deposits on this material were not determined by the analyses conducted.

Table 5.1. Results of Re Extraction Analysis

\begin{tabular}{||l|c|c|c||}
\hline \hline Refractory & Glaze & T range, ${ }^{\circ} \mathbf{C}$ & Re, ppm \\
\hline AZS & Untreated & 180 to 441 & 0.552 \\
\hline Vibrocast 60 PC & Untreated & 160 to 430 & 0.675 \\
\hline Vibrocast 60 PC & Sodium silicate & 187 to 405 & 0.314 \\
\hline
\end{tabular}




\subsection{Immersed Refractory Rod Test}

\subsubsection{Materials}

For this test, the sulfate content in the feed was increased to 2 mass\% to ensure the presence of a segregated molten sulfate on top of molten glass.

\subsubsection{Procedure}

The assembly was ramped at $5^{\circ} \mathrm{C} / \mathrm{min}$ to the set temperature $\left(900^{\circ} \mathrm{C}, 1000^{\circ} \mathrm{C}, 1100^{\circ} \mathrm{C}, 1200^{\circ} \mathrm{C}, 1300^{\circ} \mathrm{C}\right.$, or $1350^{\circ} \mathrm{C}$ ). Refractory rods ( 12 to $20 \mathrm{~mm}$ in cross-section and 10 to $12 \mathrm{~cm}$ in length) were removed as soon as the set temperature was reached. After cooling, the rods were cast lengthwise into epoxy with about half of the rod submerged. The other half was then chipped away to expose the internal surface for optical and SEM examination.

\subsubsection{Results}

Figure 5.6 shows refractory rods removed at each of the temperatures $900^{\circ} \mathrm{C}$ through $1350^{\circ} \mathrm{C}$. At $900^{\circ} \mathrm{C}$, sulfate was still contained in gas bubbles in the calcined feed; bubbles significantly contributed to the feed volume; the height of the feed in the crucible was $\sim 5 \mathrm{~cm}$. The cross-section of the rod revealed signs of molten salt penetration.

When the heat-treatment was discontinued at $1000^{\circ} \mathrm{C}$, the glass melt was connected, and it contained undissolved grains of the soil and $\mathrm{ZrO}_{2}$; the feed had slumped to a height of $\sim 2 \mathrm{~cm}$, leaving a glass coating on the sides of the rod. Molten salt segregated on the melt surface was examined with X-ray diffraction (XRD), which revealed sodium sulfate with traces of unidentified crystalline phase.

At $1100^{\circ} \mathrm{C}$, the rod surface was visibly corroded by the melt. At $1200^{\circ} \mathrm{C}$ and $1300^{\circ} \mathrm{C}$, the melt was fully homogenized. White dendrites, probably Zr-containing crystals, formed at the melt-refractory interface. Glass below as well as above the melt line aggressively attacked the refractory face, creating a dark layer with loose refractory grains dispersed in it. At $1200^{\circ} \mathrm{C}$, swelling of the submerged portion of the rod became noticeable. The severity of swelling increased with temperature. These results confirm the outcome from the previous study described in Appendix D. 


\begin{tabular}{|c|c|c|}
\hline & $\mathrm{T},{ }^{\circ} \mathrm{C}$ & Observations \\
\hline 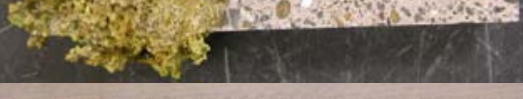 & 900 & $\begin{array}{l}\text { Unmelted feed, penetration } \\
\text { already advanced }\end{array}$ \\
\hline & 1000 & Glass phase connected \\
\hline & 1100 & Corrosion begins \\
\hline & 1200 & Swelling begins \\
\hline & 1300 & Severe swelling \\
\hline$m$ & 1350 & \\
\hline
\end{tabular}

Figure 5.6. Partially Immersed Refractory Rods after Removal from Sulfate-Enriched Glass Melt (the $1350^{\circ} \mathrm{C}$ sample was cross-sectioned to expose swelling - see also Figure 5.7 and Figure 5.8)

A rod heated up to $1350^{\circ} \mathrm{C}$ (Figure 5.7 and Figure 5.8, left) was severely corroded by the melt, exhibiting both material loss through dissolution and a substantial swelling caused by salt penetration and subsequent decomposition. The rod surface above the melt line and below the Pt lid was glazed by glass with islands of crystallized sulfate. Cross-sectioning revealed that the interior area below the melt line was turned almost entirely into sponge-like swollen refractory.

The experiment was repeated with the standard feed composition. The corrosion and swelling were still substantial, but less extensive than with the sulfate-enriched feed (Figure 5.8, right). As Figure 5.8 shows, excess sulfate increased the thickness of the refractory affected by the swelling, indicating that the sulfate melt penetration into the refractory continued even after the nitrates were decomposed; the penetration depth of sulfate increased with increasing sulfate fraction. 


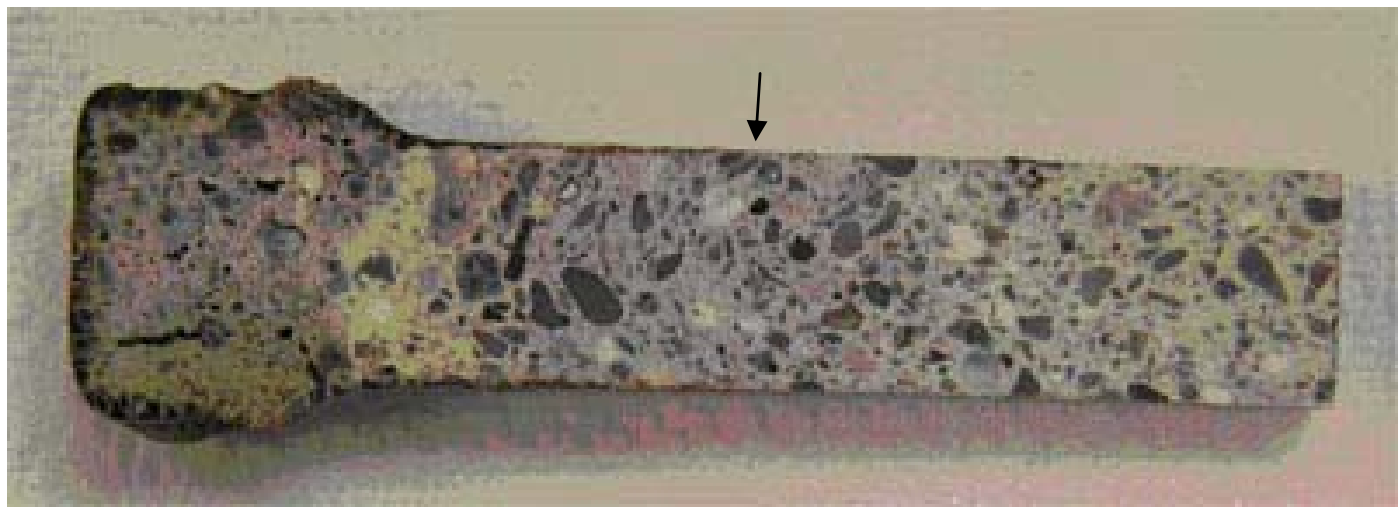

Figure 5.7. Longitudinal Cross-Section of a Partially Immersed $\operatorname{Rod}\left(1350^{\circ} \mathrm{C}\right.$; note the swelling of the immersed portion of rod; the arrow indicates the approximate position of the line to which the dynamic meniscus extended on the rod surface)

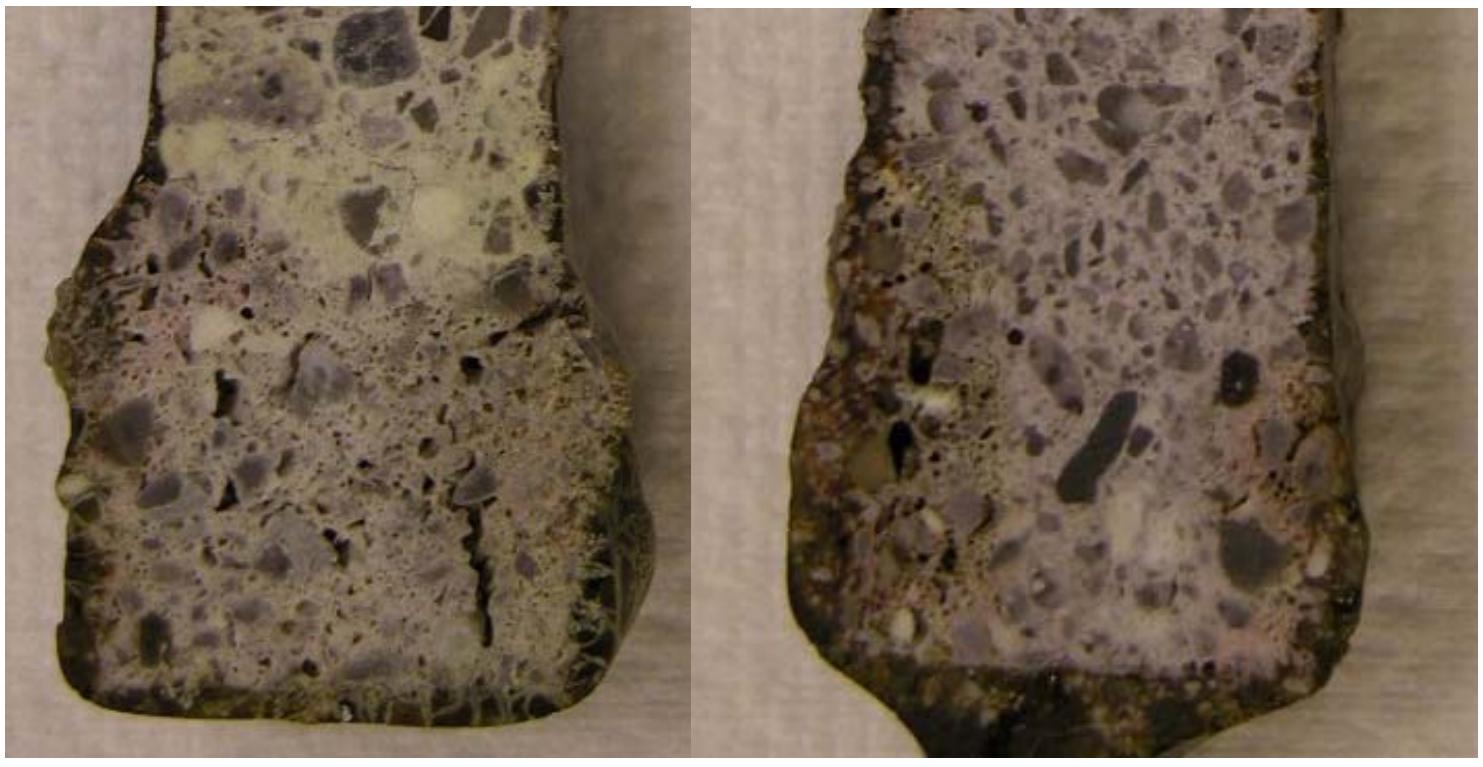

Figure 5.8. The Immersed Part of the Vibrocast Rods with Sulfate Enriched Feed (left, a detail of Figure 5.7), and with normal feed (right).

The results of the SEM examination of fractured rods are plotted in Figure 5.9 through Figure 5.11. The salts are present mainly in the immersed portion of the refractory rods. The penetration occurred at temperatures below $900^{\circ} \mathrm{C}$; there is no evidence of an increased concentration of salts as the temperature increased from $900^{\circ} \mathrm{C}$ to $1200^{\circ} \mathrm{C}$.

Figure 5.10 shows that the fraction of molten salts tends to decrease with increasing distance from the rod surface in the region above the melt line where the rod was exposed to vapors. The measurement was taken at the melt line level where the exposure to feed and melt was fluctuating during the process because of volume changes and foaming. This explains the large variation of data (see the high concentrations of $\mathrm{Na}$ and $\mathrm{S}$ in the $1100^{\circ} \mathrm{C}$ sample as compared to $1000^{\circ} \mathrm{C}$ and $1200^{\circ} \mathrm{C}$ samples). 


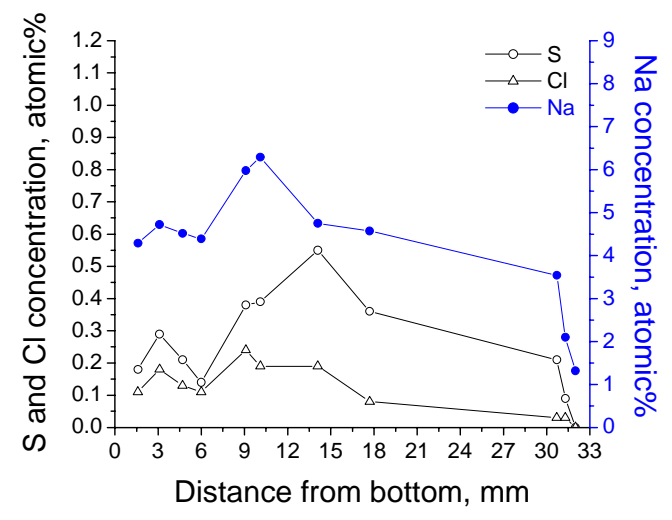

$900^{\circ} \mathrm{C}$

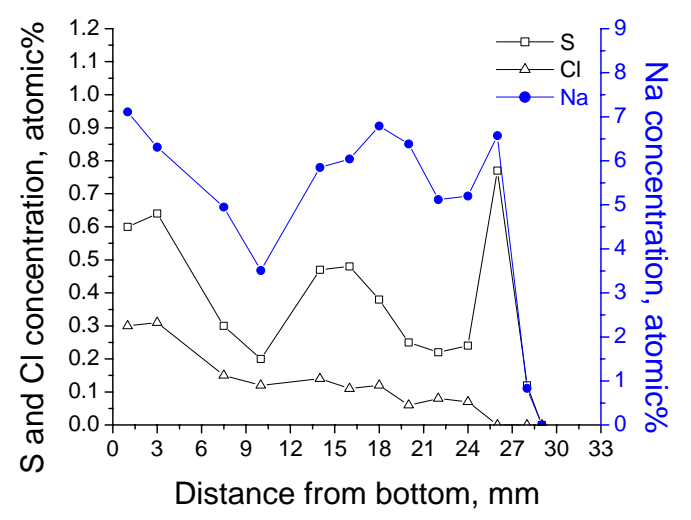

$1100^{\circ} \mathrm{C}$

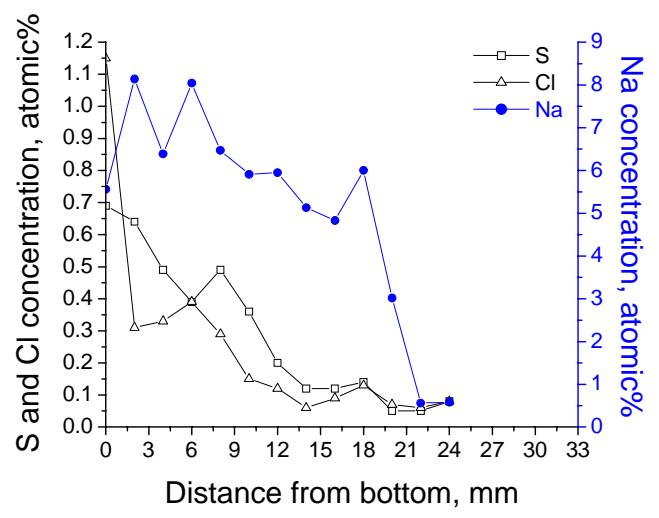

$1000^{\circ} \mathrm{C}$

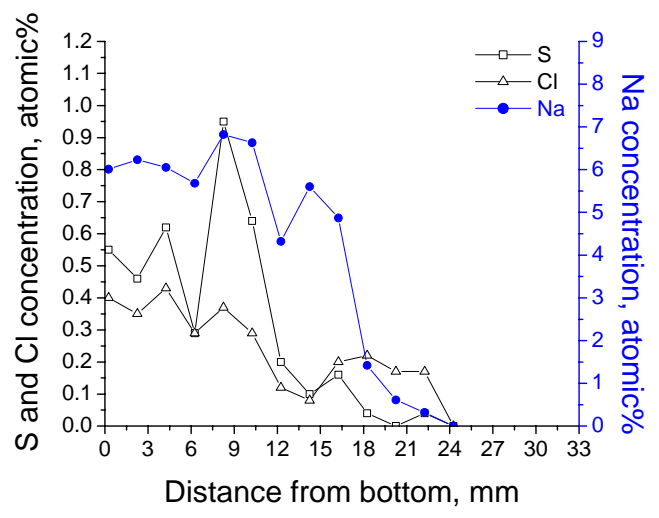

$1200^{\circ} \mathrm{C}$

\section{Figure 5.9. Vertical Concentration Profiles of $\mathrm{S}, \mathrm{Cl}$, and Na from Bottom to Top at the Axis/Center of Immersed Refractory Rod from Vibrocast 60PC after Heat-Treatment at the Temperatures Indicated}

As seen in Figure 5.7, the dynamic meniscus eventually extended 2-4 cm above the melt level and protected the rod from vapor penetration. Thus, the elevated concentrations of salt components in the rod above the melt line occurred before the melt climbed up on the sample sidewalls.

Note a large excess of Na over the fractions of chloride and sulfate (Figure 5.11), indicating that the nitrate was initially the main component of the penetrating melt. The Na atomic fraction in the center of the rod ( $10 \mathrm{~mm}$ from the surface) was $4-5$ at\% (Figure 5.9) and increased at the interface to $5-12$ at $\%$ (Figure 5.10). 


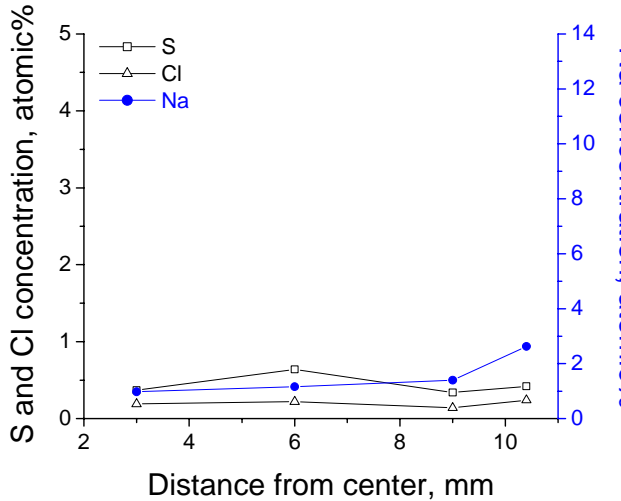

$1000^{\circ} \mathrm{C}, 2.4 \mathrm{~cm}$

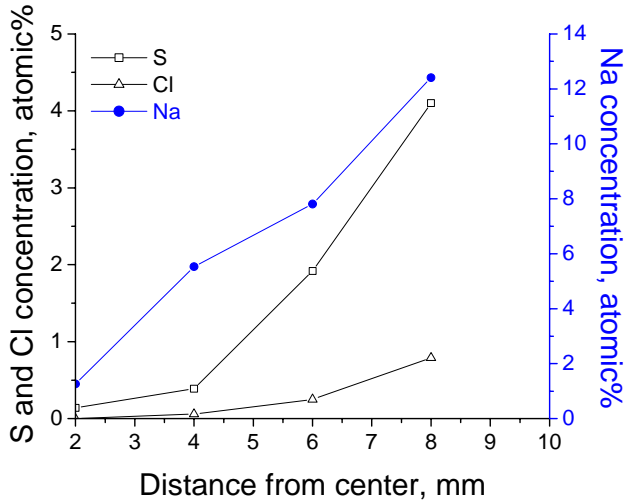

$1100^{\circ} \mathrm{C}, 2.9 \mathrm{~cm}$

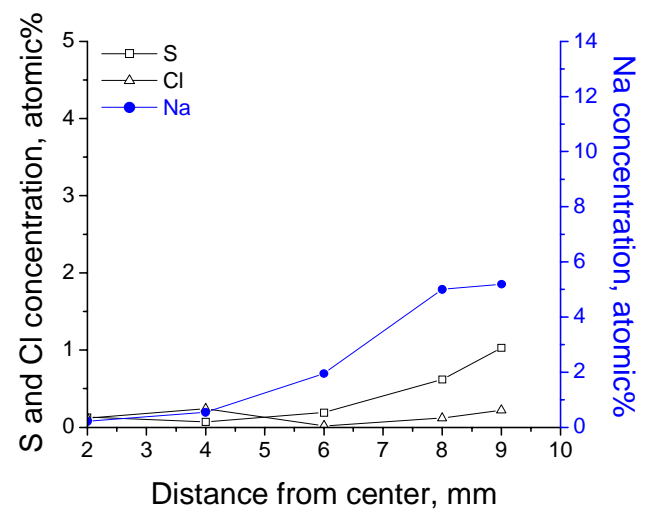

$1200^{\circ} \mathrm{C}, 2.4 \mathrm{~cm}$

Figure 5.10. Horizontal Concentration Profile of S, Cl, and Na at the Indicated Vertical Distance above Bottom; Horizontal Distance is Measured from Center to side of Immersed Refractory Rod Heat-Treated at Temperatures Indicated 


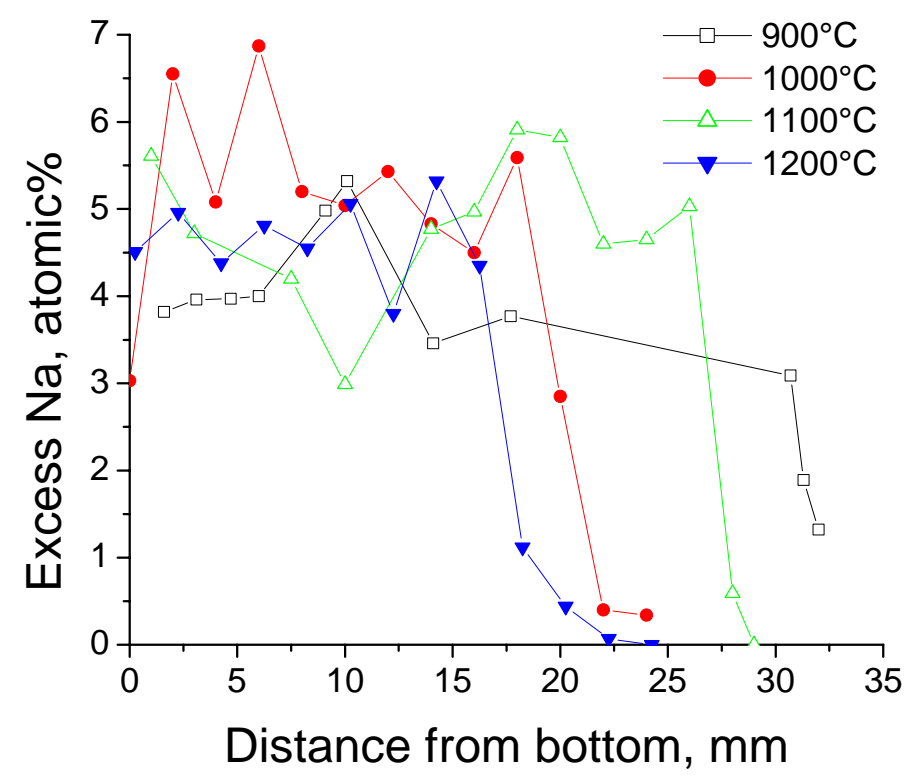

Figure 5.11. Excess of Na over Sulfate and Chloride in Immersed Refractory Rod Heat-Treated at Various Temperatures $(2.4 \mathrm{~cm}$ from bottom)

Taking into account the location and temperature at which penetration, corrosion, and swelling begins, as well as the distribution of deposits (especially sodium) within refractory rods, and the process of glass formation, the following conclusions can be drawn regarding sulfates:

1. Segregated sulfates on the surface of the melt are not likely to penetrate the refractory wall because it is coated by glass that keeps sulfates out of contact. Furthermore, there is no evidence to suggest increased deposits of sulfate in the meniscus area.

2. Increased sulfate content leads to increased damage of the refractory, especially below the melt line. This in turn implies that increased sulfates facilitate the spread of Re into the refractory walls.

3. Sulfates are most likely to penetrate the refractory at lower temperatures (below $900^{\circ} \mathrm{C}$ ) along with nitrates, and they continue to penetrate to some extent after the nitrates are decomposed.

\subsection{Simulated Condensate Penetration Test}

\subsubsection{Materials}

The condensate simulant composition (Table 5.2) was developed based on the results of condensate analyses on the fused silica glass tube and on the cold finger (reported by Kim et al. 2005). The results were similar, but the cold finger also detected borates and fluorides. Rhenium was spiked to a high concentration of 1 mass $\% \mathrm{Re}_{2} \mathrm{O}_{7}$. Chromate was added because of its coloring effect that allowed salt penetration to be discerned visually. The simulant was applied in a dry powdered state (see Section 4.3). Refractories selected for testing were Vibrocast 60PC and AZS. 
Table 5.2. Condensate Simulant Composition

\begin{tabular}{||l|c||}
\hline \hline Component & Mass Fraction \\
\hline $\mathrm{B}_{2} \mathrm{O}_{3}$ & 0.13 \\
\hline $\mathrm{NaF}$ & 0.25 \\
\hline $\mathrm{NaCl}$ & 0.25 \\
\hline $\mathrm{KCl}$ & 0.05 \\
\hline $\mathrm{Na}_{2} \mathrm{SO}_{4}$ & 0.30 \\
\hline $\mathrm{Na}_{2} \mathrm{CrO}_{4}$ & 0.01 \\
\hline $\mathrm{Re}_{2} \mathrm{O}_{7}$ & 0.01 \\
\hline
\end{tabular}

\subsubsection{Procedure}

As specified in Section 4.3, approximately $10 \mathrm{~g}$ of condensate simulant was spread in a circle of $\sim 16 \mathrm{~mm}$ in diameter on an $\sim 25 \times 20 \times 20$-mm coupon of refractory material. Untreated Vibrocast 60PC samples were heat-treated at $400^{\circ}, 700^{\circ}, 800^{\circ}, 900^{\circ}, 1000^{\circ}$, and $1100^{\circ} \mathrm{C}$ for $30 \mathrm{~min}$; AZS samples were heat-treated at $800^{\circ} \mathrm{C}, 1000^{\circ} \mathrm{C}$, and $1100^{\circ} \mathrm{C}$ for $30 \mathrm{~min}$.

\subsubsection{Results}

Condensate simulant placed on baseline Vibrocast 60PC samples and heat-treated at temperatures of $700^{\circ} \mathrm{C}, 800^{\circ} \mathrm{C}$, and $900^{\circ} \mathrm{C}$ partially penetrated into the refractory with some material remaining on the surface. Although ionic salts are generally infinitely miscible in the molten state and crystallize on cooling, the salt layer on the samples after cooling appeared mostly amorphous with distinct segregation of sulfate-chromate melt towards the edge of the circular melt layer. This behavior may be attributed to the presence of borate. The simulated condensate reacted with the refractory at $1000^{\circ} \mathrm{C}$ and $1100^{\circ} \mathrm{C}$, forming a glass phase while volatile components evaporated. At $1100^{\circ} \mathrm{C}$, virtually no salt was left on the sample, and the top surface of the refractory was partly vitrified and swollen because of bubble formation.

SEM examination detected segregated sulfate and chloride phases and sodium alumino-silicate melts and crystals on the coupon surfaces. The morphology of the Vibrocast 60PC coupon surfaces is shown in Figure 5.12. The surface morphology of simulated condensate on the AZS refractory is shown in Appendix B. Appendix B also contains the compositions of individual phases measured by EDS. No salt containing Re was detected.

Examination of fracture surfaces conducted with SEM-EDS (see Appendix B) showed that, starting from $700^{\circ} \mathrm{C}$, the penetration depth of simulated condensate placed on coupons of untreated Vibrocast 60PC decreased as the temperature of isothermal heat-treatment increased. In the coupon heat-treated at $400^{\circ} \mathrm{C}$, $\mathrm{S}, \mathrm{Cl}$, and $\mathrm{F}$ were detected up to $10 \mathrm{~mm}$ below the surface. In the coupon heat-treated at $700^{\circ} \mathrm{C}$, salt containing $\mathrm{S}, \mathrm{Cl}$, and $\mathrm{F}$ was detected $15 \mathrm{~mm}$ below the surface. At $900^{\circ} \mathrm{C}$, the penetration depth was only $7 \mathrm{~mm}$, and only S and $\mathrm{Cl}$ were detected; $\mathrm{F}$ was most likely evaporated. At temperatures of $1000^{\circ} \mathrm{C}$ and $1100^{\circ} \mathrm{C}$, no salts were found below the coupon surface. These results are summarized in Table 5.3. Electrofused AZS Unikor 501 exhibited a 1-mm penetration depth after heat-treatment with simulated condensate at $1000^{\circ} \mathrm{C}$. 


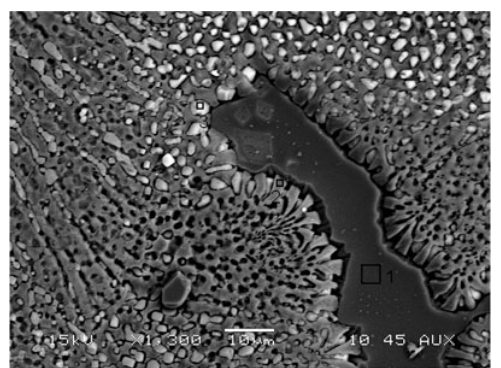

$400^{\circ} \mathrm{C}$

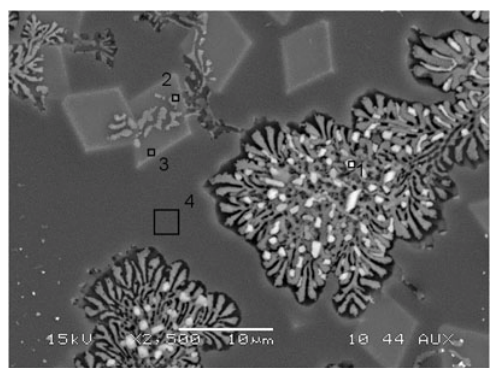

$700^{\circ} \mathrm{C}$

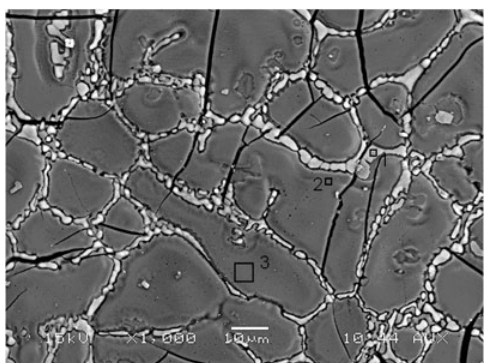

$400^{\circ} \mathrm{C}$

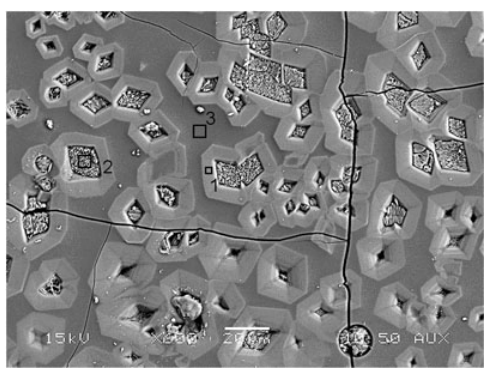

$900^{\circ} \mathrm{C}$

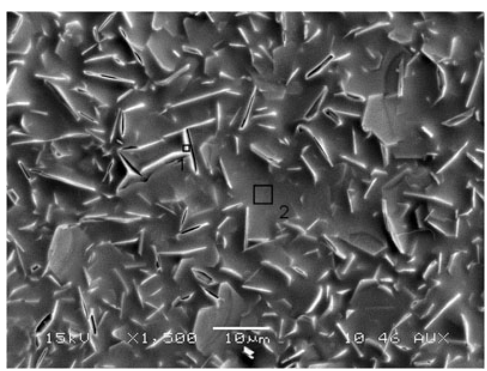

$1100^{\circ} \mathrm{C}$

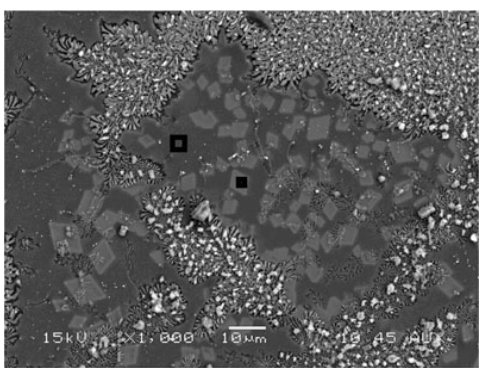

$700^{\circ} \mathrm{C}$

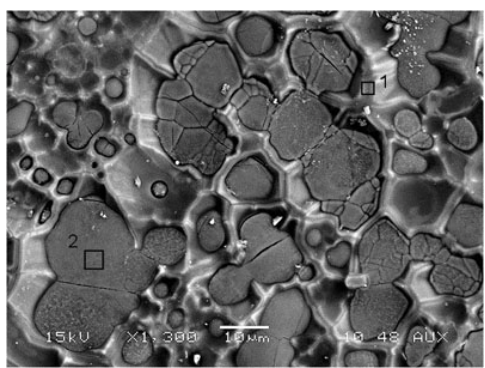

$1000^{\circ} \mathrm{C}$

Figure 5.12. Surface Morphology of Vibrocast 60PC Treated with Condensate Simulant at Various Temperatures

Table 5.3. Simulated Condensate Penetration Test: Summary of Results for Untreated Vibrocast 60PC

\begin{tabular}{|c|c|c||}
\hline $\begin{array}{c}\text { Temperature, } \\
{ }^{\circ} \mathrm{C}\end{array}$ & Salt & $\begin{array}{c}\text { Penetration } \\
\text { Depth, } \mathbf{~ m m}\end{array}$ \\
\hline 400 & $\mathrm{Cl}, \mathrm{F}, \mathrm{S}$ & 10 \\
\hline 700 & $\mathrm{Cl}, \mathrm{F}, \mathrm{S}$ & 15 \\
\hline 900 & $\mathrm{Cl}, \mathrm{S}$ & 7 \\
\hline$\geq 1000$ & $\mathrm{Cl}, \mathrm{S}$ & 0 \\
\hline
\end{tabular}

These tests indicate that MISs with a borate component behave differently than molten salt mixtures with no glass-forming component present. For example, the morphology of solidified MIS with borate exhibits both crystalline and amorphous patterns. However, little is known about mixtures of MIS with borate. MIS readily penetrates into the porous body of CRB where it reacts with a fine-grained fraction, 
forming a viscous glass-forming phase. Evaporation-condensation phenomena further affect the transport of ionic materials within the CRB.

\subsubsection{Gas Permeability}

Figure 5.13 shows the results of gas permeability testing performed on several samples of the baseline Vibrocast 60PC refractory. The untreated sample was cut with a diamond saw on both sides and showed a lower flow rate than the untreated sample with one original cast surface. This difference is contrary to expectation but may have been caused by the presence of residual humidity in a sample that was cut on both ends (no attempt was made to repeat the measurement). The plot also shows that the flow rate through Vibrocast 60PC increased by nearly three orders of magnitude when the sample was heat-treated at $1050^{\circ} \mathrm{C}$. The results of Vibrocast $60 \mathrm{PC}$ permeability measurements are summarized in Table 5.4; the last column shows the impact of treatment relative to the untreated material. The results of the glaze tests are discussed in a subsequent section.

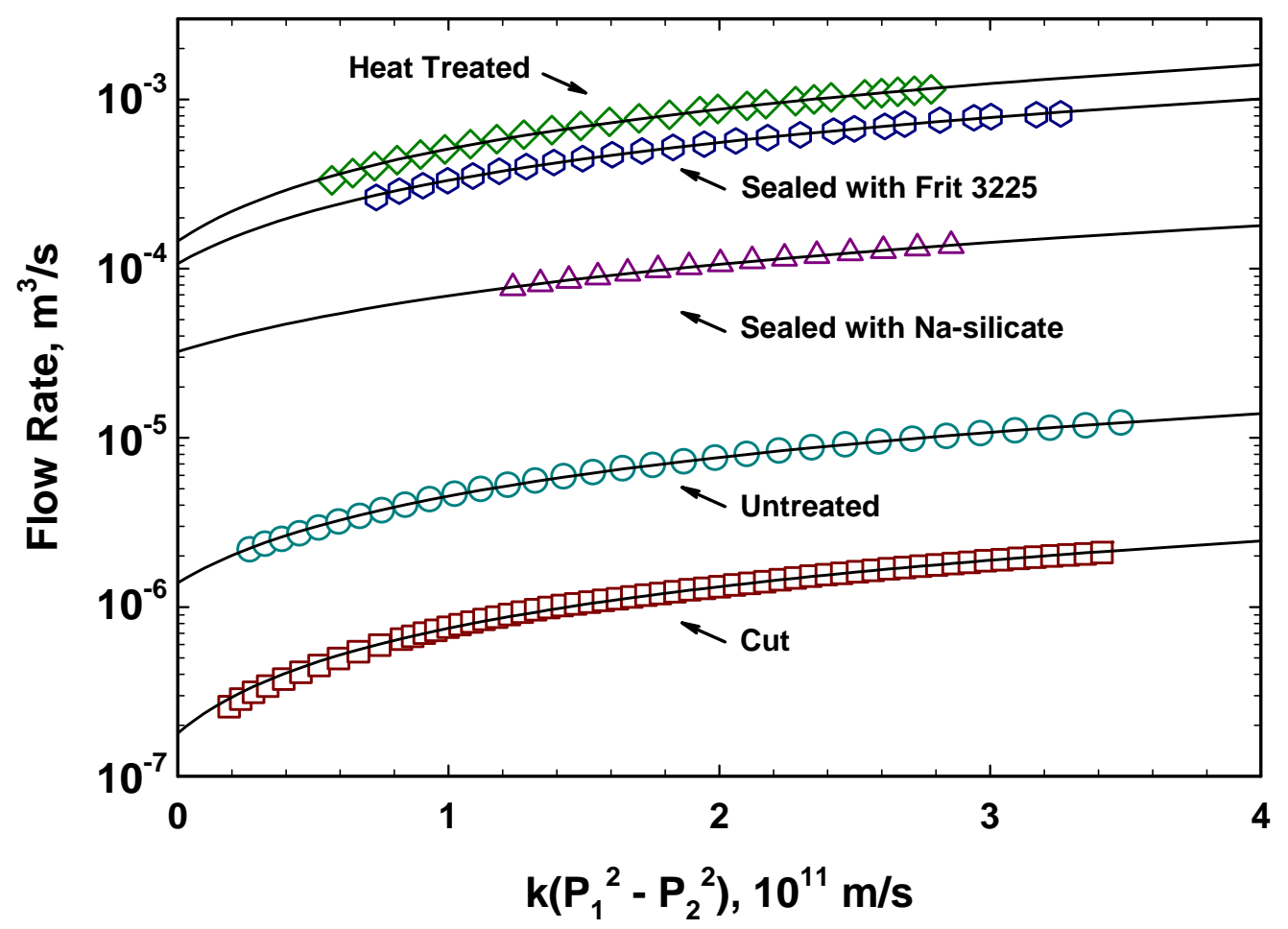

Figure 5.13. Results of Gas Permeability Measurement for Vibrocast 60PC [by Equation (3.1), $\left.k=K A /\left(2 \mu L P_{2}\right)\right]$

\subsection{Comparison to $1 / 6^{\text {th }}$ Scale Melter Data}

As described in Section 3.6, a sample of the refractory wall was taken from the ES Test ES-31B and subjected to layer-by-layer grinding and leaching in DI water at $90^{\circ} \mathrm{C}$ for 24 hours. This sample was removed from the air-inlet side of the CRB in the lower third of the front wall. The approximate location of the sample was $x=70 \mathrm{~cm}$ and $z=27 \mathrm{~cm}$, where $x$ is the horizontal coordinate measured along the longer CRB wall from the exhaust side of the box lid, and $z$ is the vertical coordinate measured down 
from the CRB top. Figure 5.14 shows the results of the leachate analysis. The different sizes of samples collected during the grinding operation resulted in different detection limits for the MS analysis, and a few of the smaller samples were below the detection limit. The samples that were above the detection limit had an average Re mass fraction of $2.2 \times 10^{-8}$. The profile from these data shows no tendency for the soluble amount of Re to decrease with distance from the interface up to $10 \mathrm{~mm}$. Earlier tests (Pierce et al. 2004) showed that the soluble Re concentration decreased significantly at distances $>18 \mathrm{~mm}$ from the interface. Future layer-by-layer grinding tests should be conducted to greater depths with increased sample sizes to provide large enough samples for chemical analysis.

Table 5.4. Gas Permeability of Glazed and Unglazed Vibrocast 60PC

\begin{tabular}{||l|c|c|c|c||}
\hline $\begin{array}{c}\text { Material } \\
\text { Vibrocast 60PC }\end{array}$ & $\begin{array}{c}\text { Surface } \\
\text { Conditions }\end{array}$ & $\begin{array}{c}\text { Maximum Heat } \\
\text { Treatment } \\
\text { Temperature }\end{array}$ & $\begin{array}{c}\text { Gas } \\
\text { Permeability } \\
\text { (Darcy) }\end{array}$ & $\begin{array}{c}\text { Relative } \\
\text { Permeability }\end{array}$ \\
\hline Untreated & As Cast/Cut & $\sim 200^{\circ} \mathrm{C}$ & $3.2 \times 10^{-5}$ & 1.0 \\
\hline Cut & Cut/Cut & $\sim 200^{\circ} \mathrm{C}$ & $5.8 \times 10^{-6}$ & 0.2 \\
\hline Heat-Treated & As Cast/Cut & $\sim 1050^{\circ} \mathrm{C}$ & $3.9 \times 10^{-3}$ & 116.2 \\
\hline Frit 3225 & As Cast/Cut & $\sim 1000^{\circ} \mathrm{C}$ & $2.3 \times 10^{-3}$ & 71.7 \\
\hline Sodium silicate & As Cast/Cut & $\sim 600^{\circ} \mathrm{C}$ & $3.7 \times 10^{-4}$ & 11.7 \\
\hline
\end{tabular}

The leached solids were analyzed to determine the amount of non-leachable Re that was present in the sample. The average mass fraction of Re in these samples was $(6.4 \pm 1.4) \times 10^{-7}$. The samples contained residual solution, the content of which was not measured before drying. To estimate its content, a CRB piece was crushed and mixed with water that was subsequently removed in the same fashion as from the original samples. The water mass fraction, determined on eleven $\sim 1$-g samples, was $0.282 \pm 0.021$. The Re mass fraction in the leachate from the original samples was $(7.9 \pm 2.7) \times 10^{-9}$; this is $\sim 1 \%$ of Re in the analyzed solid CRB. Thus, the mass fraction of insoluble Re in this portion of the CRB was $\sim 6.4 \times 10^{-7}$, i.e., $96 \%$ of total Re (see Figure 5.15, where the results are plotted on a logarithmic scale).

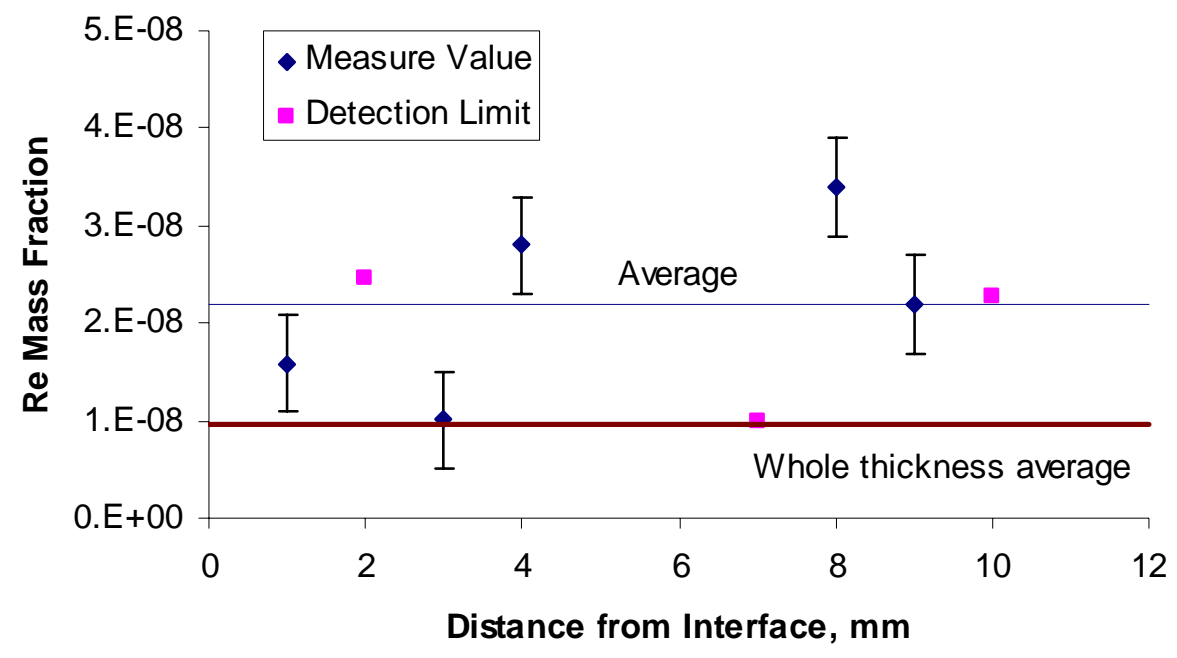

Figure 5.14. Concentration Distribution of Water Soluble Re $\left(\right.$ at $90^{\circ} \mathrm{C}$ ) in the ES-31B Refractory Wall 


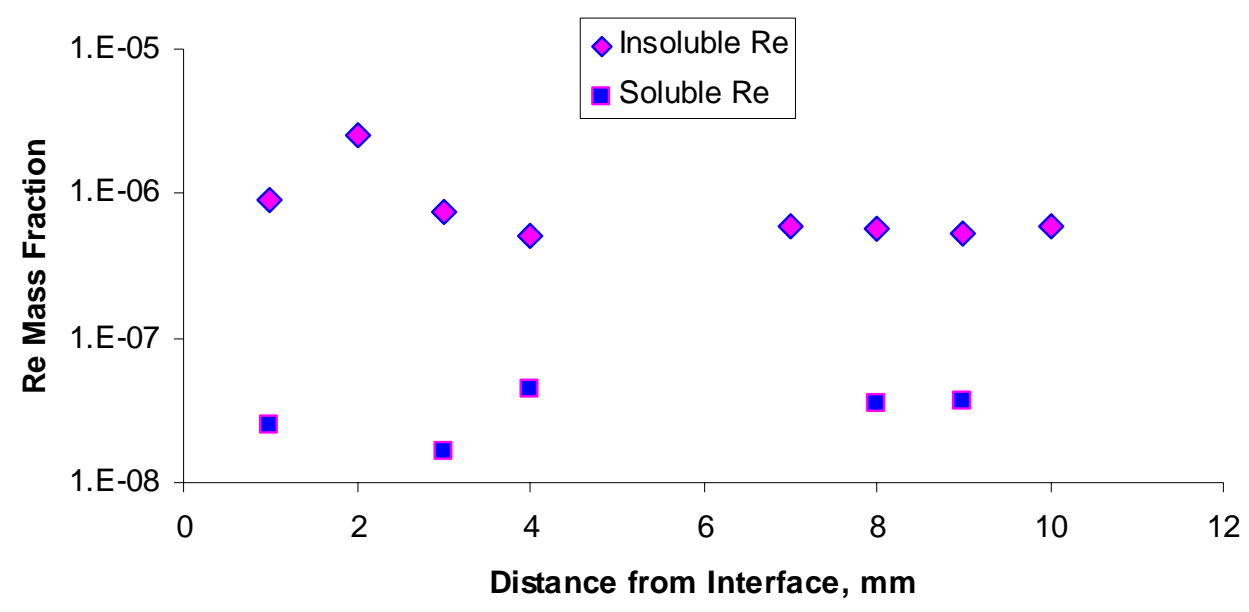

Figure 5.15. Concentration Distribution of Re (leachable and non-leachable) in the ES-31B Refractory Wall

The CRB sample was also analyzed with SEM-EDS for the concentration distribution of LAW components. As Figure 5.16 shows, $\mathrm{Cl}$ and $\mathrm{S}$ were detected up to $15 \mathrm{~mm}$ from the interface (the contact surface with molten glass), and $\mathrm{Na}$ concentration was in a great excess over $\mathrm{S}$ and $\mathrm{Cl}$ concentrations, indicating that its origin was from the nitrate and other salts that had decomposed. No Na was detected beyond the 15-mm distance. Up to 5 at\% Na was found in the CRB by EDS.

The feed used in Test ES-31B was described in a previous report (Hrma et al. 2005). The feed contained 37.5 mass\% of dry LAW simulant (S-109) that contained 27.6 mass\% of Na. Thus, the feed contained 10.3 mass $\%$ of Na from the simulant. The fraction of Re added to the feed was $3.4 \mathrm{mg} / \mathrm{kg}$. Based on these numbers and assuming that only Na from the LAW simulant and all Re was in the MIS, we obtain for the Re/Na mass ratio the value of $3.3 \times 10^{-5}$ and for the atomic ratio $4.1 \times 10^{-6}$. Provided that the Na in CRB came from the MIS, 5 at\% Na found in the CRB sample would be accompanied with the amount of Re corresponding to the Re/Na ratio of the MIS, i.e., $4.1 \times 10^{-6} \times 0.05=2.0 \times 10^{-7}$. In terms of a mass fraction, considering that the Re atomic mass is about eight times larger than the average atomic mass of elements in the CRB, the Re mass fraction in the CRB would be $1.6 \times 10^{-6}$. Considering that the average fraction of $\mathrm{Na}$ in the CRB was 2 to 3 at\%, the expected fraction of Re in the 10-mm CRB layer (measured from the interface with glass) is approximately $8 \times 10^{-7}$. This number appears comparable with the mass fraction of $6.6 \times 10^{-7} \mathrm{Re}$ (soluble plus insoluble) obtained from the layer-by-layer grinding test.

Alternatively, we can estimate that the SIM present in the first $10 \mathrm{~mm}$ of the sample was 7 mass\%. This estimation takes the mass fraction of $6.6 \times 10^{-7}$ Re in the CRB as the starting point, uses the Re/Na mass ratio in MIS from above $\left(3.3 \times 10^{-5}\right)$, and assumes that the Na mass fraction in MIS is $30 \%$ (a value slightly higher than the 27.5 mass\% of $\mathrm{Na}$ in the dry simulant because of the release of all crystalline water and organic carbon). Compare this result with the case of the reverse calculation in Section 2.4 (there we took 5 mass\% of LAW in the CRB and obtained for the Re mass fraction the value of $5.5 \times 10^{-7}$ ( $\left.0.55 \mathrm{ppm}\right)$. These calculations show that the measured Re content in the CRB, though based on very limited data from a single sample, agrees reasonably well with the estimate based on the mass balance. 


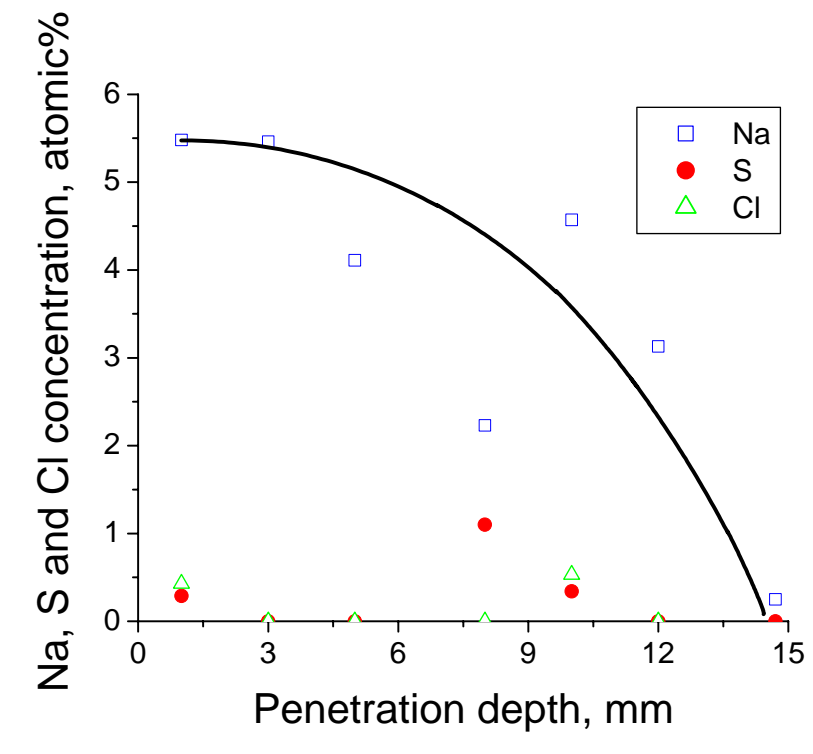

\section{Figure 5.16. Atomic Fractions of $\mathrm{Na}, \mathrm{S}$, and $\mathrm{Cl}$ in $\mathrm{CRB}$ (in ES-31B Test) as Functions of Distance from the Interface with Molten Glass}

In an independent test, a sample of the ES-31B CRB taken right next to the sample used for the above analysis was analyzed for Re over its whole 100 -mm thickness. The amount of soluble Re was determined by conducting extractions at room temperature. The average mass fraction of soluble Re in this sample over the whole 100 -mm thickness was $(9.67 \pm 0.42) \times 10^{-9}$. As Figure 5.14 indicates, this value (shown as the "Whole thickness average" line) is comparable, but slightly lower than, the average soluble concentration found in the ground samples after leaching at $90^{\circ} \mathrm{C}$. This would be consistent with the measured concentration of soluble Re measured for the first $10 \mathrm{~mm}$ to extend to greater depths into the wall before tailing off and reducing the average concentration.

The analysis of another partial wall sample taken from the exhaust side in the upper third of the CRB from Test ES-31B is also available from a previous study (Pierce et al. 2004). This sample contained $18 \mathrm{~mm}$ of the 100 -mm-thick refractory wall as measured from the interface with the glass. It was taken from the top of the vertical CRB corner wall, exhaust side. Its approximate location was $y=33 \mathrm{~cm}$, and $z=5 \mathrm{~cm}$, where $y$ is the horizontal coordinate measured across the CRB box (sample ID is EST-08-05). The sample was subjected to extraction. The soluble mass fraction of Re in this sample was $2 \times 10^{-7}$. This Re content is higher than the fraction of leachable Re extracted from the powdered sample at $90^{\circ} \mathrm{C}$ and lower than the insoluble Re determined by chemical analysis. Comparing these partial results indicates that the distribution of soluble and insoluble Re differs in samples taken from the upper and lower portions of the CRB.

The possibility of insoluble Tc in Test E-32B was also examined. Sample EST-16-01, taken at $x=25 \mathrm{~cm}$, $y=22 \mathrm{~cm}$, and $z=33 \mathrm{~cm}$, was analyzed for soluble Tc over the full 100-mm thickness and found to have a Tc mass fraction of $2.8 \times 10^{-10}$. After the soluble material was extracted, the sample was ground and analyzed by fusing with $\mathrm{KOH}$. Based on the $96 \%$ insoluble Re fraction in the Test ES-31B sample, a proportional insoluble Tc mass fraction would be $7 \times 10^{-9}$. The $\beta$-counting techniques determined that the 
${ }^{99}$ Tc mass fraction of the sample after extraction was below the detection limit of $1 \times 10^{-8}$. This technique did not have a sufficiently low detection limit to assess whether insoluble Tc existed at a ratio similar to that seen for Re in ES-31B. An analytical method with a detection limit two orders of magnitude lower is necessary to perform a better assessment. 


\subsection{Glazed Refractories}

This section describes the suspended refractory rod test, the immersed refractory rod test, and the simulant condensate penetration test, including their materials, the procedures, and the results. Two gas permeability tests are also described.

\subsection{Suspended Refractory Rod Test}

\subsubsection{Materials}

Several frits were considered and evaluated using the simulant condensate penetration test (see

Section 6.3). Based on the test results, two frits were selected for further testing: borosilicate glaze (Ferro Corporation Frit 3225-3 containing 63.06 mass\% $\mathrm{SiO}_{2}$, 8.71 mass $\% \mathrm{Al}_{2} \mathrm{O}_{3}, 22.95$ mass\%, $\mathrm{B}_{2} \mathrm{O}_{3}$, 4.83 mass \% $\mathrm{Na}_{2} \mathrm{O}, 0.24$ mass\% $\mathrm{CaO}$, and 0.21 mass\% $\mathrm{MgO}$ ) and sodium-silicate glaze (73.3 mass\% $\mathrm{SiO}_{2}$ and 23.7 mass $\% \mathrm{Na}_{2} \mathrm{O}$ ). These materials were applied to Vibrocast 60PC test samples.

\subsubsection{Procedure}

For experiments with glazed rods, the feed material was heated to a set temperature of $1000^{\circ} \mathrm{C}$ for 2 hours.

\subsubsection{Results}

Appendix A displays selected SEM and optical images of the deposits and compositions of individual phases. Rhenium salts were detected only on surfaces of Vibrocast 60PC coated with borosilicate glaze (Figure 6.1). The deposits were in the form $\mathrm{NaReO}_{4}$ rather than $\mathrm{KReO}_{4}$ seen on other surfaces, possibly a result of ion exchange with the glaze. No salt deposits were found inside the refractory when the fractured cross sections of both the sodium-silicate and borosilicate-glazed Vibrocast 60PC were examined.

\subsection{Immersed Refractory Rod Test}

Implementing the method described in Section 4.2, the assembly was ramped at $5^{\circ} \mathrm{C} / \mathrm{min}$ to set temperatures from $300^{\circ} \mathrm{C}$ to $1000^{\circ} \mathrm{C}$. Refractory rods were removed as soon as the set temperature was reached. Sodium silicate coating did not visibly affect sulfate penetration into the rod. Borosilicate frit did not affect the melt attack below the melt line but prevented melt spreading above it. Hence, the dynamic meniscus (see the thin layer of dark glass on the refractory rod surface in Figure 5.7) did not occur when the low-surface-tension borosilicate glaze was applied.

\subsection{Simulant Condensate Penetration Test}

\subsubsection{Materials}

Several protective glazes were evaluated: sodium silicate (PQ Corporation aqueous solution with 62.4\% $\mathrm{H}_{2} \mathrm{O}$ ), Ferro Corporation borosilicate Frit 3225-3, Ferro Corporation aluminosilicate Frit 3851-2 (48.66\% $\mathrm{SiO}_{2}, 27.32 \% \mathrm{Al}_{2} \mathrm{O}_{3}, 23.70 \% \mathrm{MgO}$, and 0.32\% CaO), RX Chemical fluorite-containing Frit RX-14 
(containing $\mathrm{CaF}_{2}, \mathrm{SiO}_{2}, \mathrm{Na}_{2} \mathrm{O}, \mathrm{Al}_{2} \mathrm{O}_{3}, \mathrm{MgO}$, and $\mathrm{Fe}_{2} \mathrm{O}_{3}$ at undisclosed proportions), and $\mathrm{ZYP}$ Coatings $\mathrm{Z}$-Guard (60 \% $\mathrm{ZrO}_{2}, 10 \% \mathrm{AlPO}_{4}, 5 \%$ ethanol, and 25\% water); all values are in mass\%. Z-Guard did not qualify for further testing because it did not adhere to the baseline refractory when heated above $300^{\circ} \mathrm{C}$. The aluminosilicate and fluorite frits were disqualified because they did not produce a continuous layer when heated at temperatures $\leq 1100^{\circ} \mathrm{C}$. Table 6.1 summarizes screening test results.

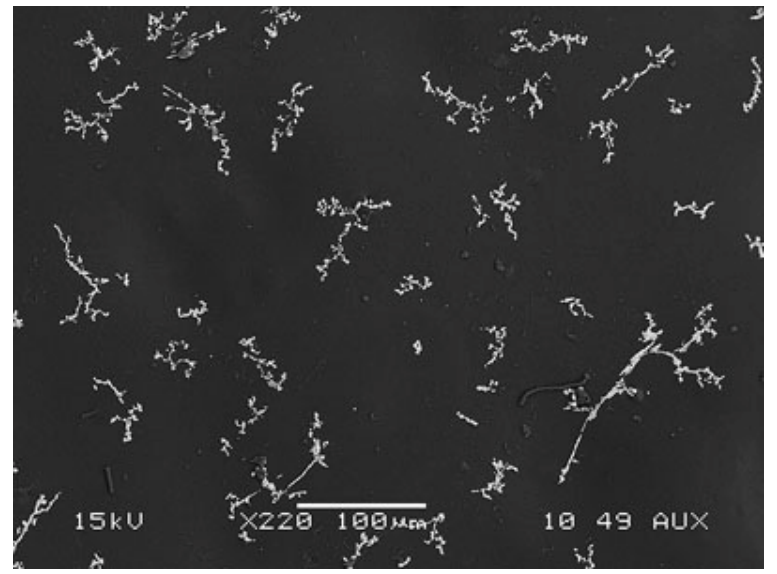

Figure 6.1. $\mathrm{NaReO}_{4}$ Formations on Borosilicate Glaze at $523^{\circ} \mathrm{C}$ (SEM micrograph, feed heated to $1000^{\circ} \mathrm{C}$ with 2-h hold)

Table 6.1. Frit Selections for CRB: Initial Screening Test Results

\begin{tabular}{|l|l|l|c||}
\hline \multicolumn{1}{|c|}{ Glaze } & \multicolumn{1}{|c|}{ Components } & \multicolumn{1}{c||}{ Screening Test Result } & Selected \\
\hline $\begin{array}{l}\text { Sodium Silicate } \\
\text { PQ Corporation }\end{array}$ & $\mathrm{Na}_{2} \mathrm{O}, \mathrm{SiO}_{2}, \mathrm{H}_{2} \mathrm{O}$ & $\begin{array}{l}\text { Foaming tendency } \\
\text { (Section 6.2.2) }\end{array}$ & Yes \\
\hline $\begin{array}{l}\text { Borosilicate Frit 3225-3 } \\
\text { Ferro Corporation }\end{array}$ & $\mathrm{B}_{2} \mathrm{O}_{3}, \mathrm{SiO}_{2}$ & $\begin{array}{l}\text { Glaze continuous at } \\
>1000^{\circ} \mathrm{C}\end{array}$ & Yes \\
\hline $\begin{array}{l}\text { Aluminosilicate Frit 3851-2 Ferro } \\
\text { Corporation }\end{array}$ & $\mathrm{SiO}_{2}, \mathrm{Al}_{2} \mathrm{O}_{3}, \mathrm{MgO}, \mathrm{CaO}$ & $\begin{array}{l}\text { Glaze not continuous at } \\
<1100^{\circ} \mathrm{C}\end{array}$ & No \\
\hline RX Chemical Frit RX-14 & $\begin{array}{l}\mathrm{CaF}_{2}, \mathrm{SiO}_{2}, \mathrm{Na}_{2} \mathrm{O}, \mathrm{Al}_{2} \mathrm{O}_{3}, \\
\mathrm{MgO}_{2}, \mathrm{Fe}_{2} \mathrm{O}_{3}\end{array}$ & $\begin{array}{l}\text { Glaze not continuous at } \\
<1100^{\circ} \mathrm{C}\end{array}$ & No \\
\hline ZYP Coatings Z-Guard & $\mathrm{ZrO}_{2}, \mathrm{AlPO}_{4}$ & $\begin{array}{l}\text { Frit not adheres to CRB at } \\
>300^{\circ} \mathrm{C}\end{array}$ & No \\
\hline
\end{tabular}

\subsubsection{Procedure}

The borosilicate frit was applied on the baseline refractory in the form of a water suspension; it made a continuous glaze when heated at $1000^{\circ} \mathrm{C}$. Preliminary tests conducted with sodium silicate revealed a strong tendency for foaming when heated to temperatures above $240^{\circ} \mathrm{C}$. The final technique used to produce an acceptable glaze was to apply a thin layer of sodium silicate and dry it at $140^{\circ} \mathrm{C}$ for several hours, followed by slow heating to $450^{\circ} \mathrm{C}$ and a faster heating to $800^{\circ} \mathrm{C}$ to obtain smooth glazing. At temperatures of approximately $1000^{\circ} \mathrm{C}$, the sodium silicate glaze began to react with the refractory. All glazed coupons were tested with the simulated condensate at temperatures of $800^{\circ}, 1000^{\circ}$, and $1100^{\circ} \mathrm{C}$. 


\subsubsection{Results}

Molten condensate simulant spread out across the refractory surfaces treated with borosilicate frit (Figure 6.2, left). Sodium silicate appeared to slow or stop molten salt penetration into the pores (Figure 6.2, right—note the dark ring of segregated sulfate-chromate melt). As Figure 6.3 shows, the borosilicate glaze did not protect the large open pores that were exposed when the rod was cut from a refractory block. However, the as-cast refractory block surfaces exposed to the melt during the BV process are generally free of large open pores.
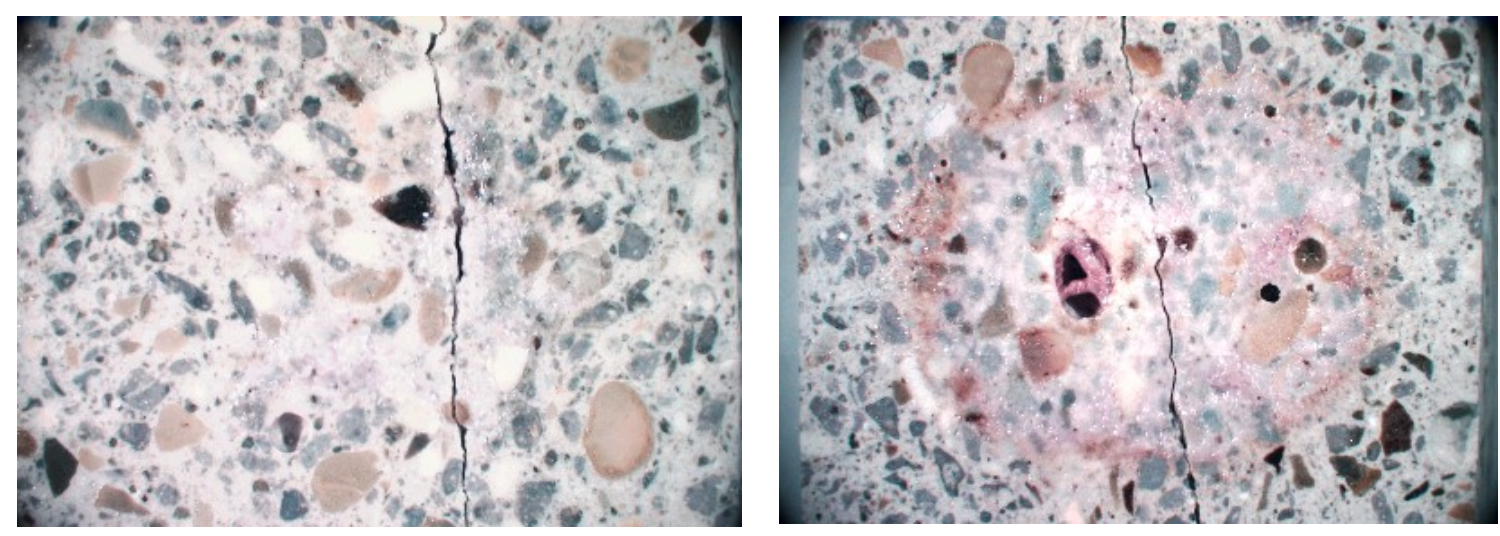

Figure 6.2. Condensate Simulant on Baseline Refractory Coupon $(25 \times 25 \mathrm{~mm})$ Treated with Borosilicate Frit (left) and Sodium Silicate (right) and Heat-Treated at $1100^{\circ} \mathrm{C}$

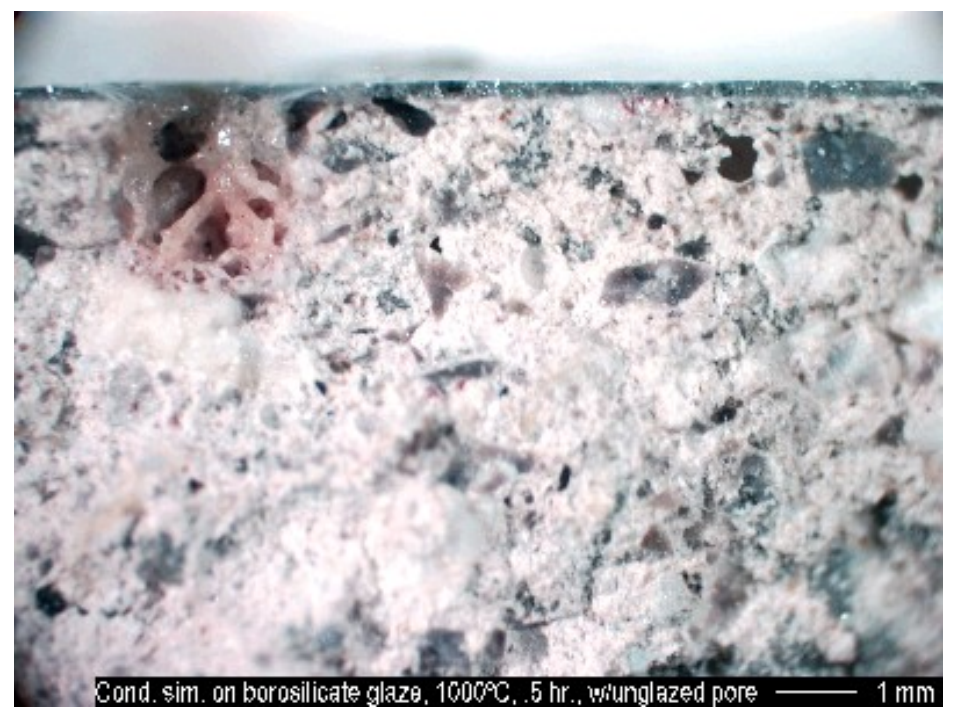

Figure 6.3. Vibrocast 60PC Coated with Borosilicate Glaze and Heat-Treated with Simulated Condensate at $1000^{\circ} \mathrm{C}$ for 5 hours. The glassy glaze coating is apparent at the top right hand side of the photograph. Large pores like those shown in the left center portion of the photograph are not expected in the manufactured surface of the block. 
As Figure 6.4 shows, SEM examination of the glazed samples revealed different surface morphology than that observed with unglazed Vibrocast 60PC. Re salt was detected only on the surface of borosilicate glass (see the white spots around the grey $\mathrm{NaCl}$ areas in Figure 6.5). Compositions of individual phases measured by EDS are given in Appendix B.

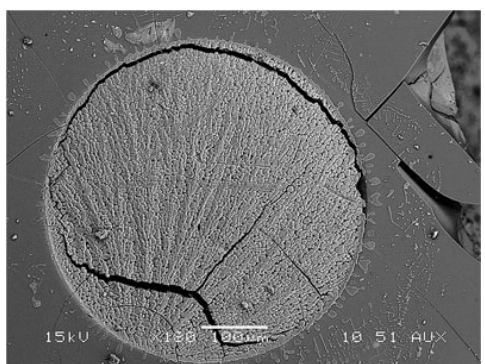

$800^{\circ} \mathrm{C}$

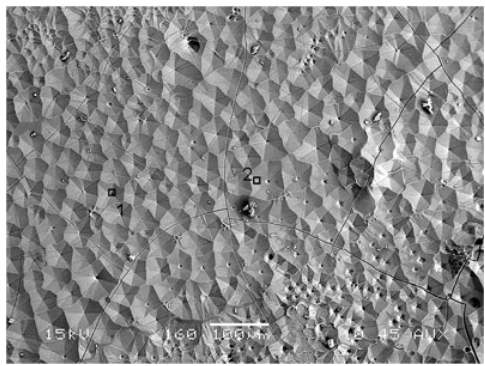

$1000^{\circ} \mathrm{C}$

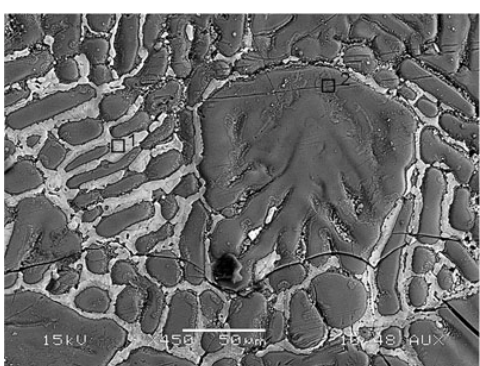

$800^{\circ} \mathrm{C}$

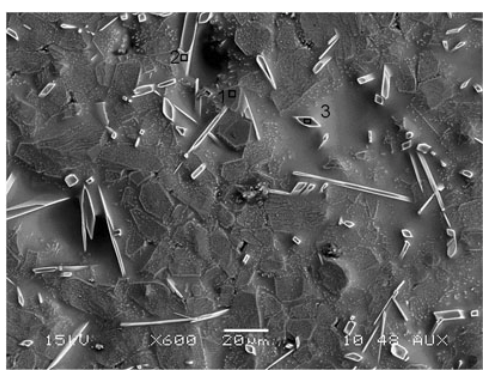

$1100^{\circ} \mathrm{C}$

Figure 6.4. Surface Morphology of Vibrocast 60PC Coated with Sodium Silicate

Glaze and Treated with Condensate Simulant at Various Temperatures

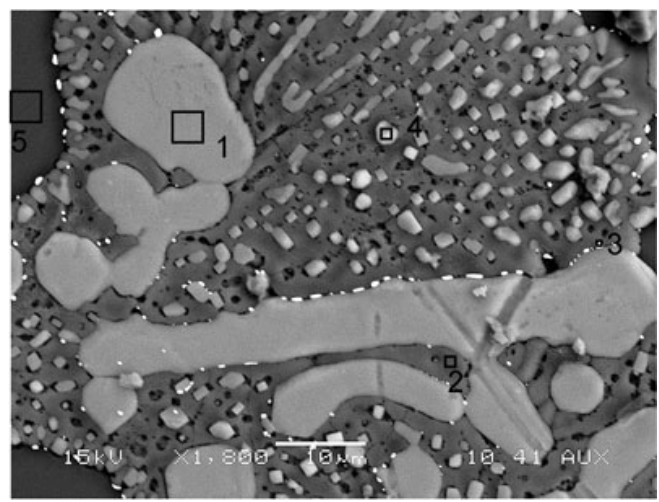

Figure 6.5. Surface Morphology of Vibrocast 60PC Coated with Borosilicate Glaze and Treated with Condensate Simulant at $800^{\circ} \mathrm{C}$

SEM images of fracture cross sectional surfaces are shown in Figure 6.6 and Figure 6.7. According to SEM-EDS data, sulfates and chlorides from simulated condensate penetrated into Vibrocast 60PC coated with sodium silicate glaze on heat-treatment at $800^{\circ} \mathrm{C}$ to the depth of $0.5 \mathrm{~mm}$. Re was detected $0.1 \mathrm{~mm}$ below the surface when the coated coupon was heat-treated at $1000^{\circ} \mathrm{C}$ while the glaze and the $\mathrm{S}$ and $\mathrm{Cl}$ salts penetrated $2 \mathrm{~mm}$ into the refractory surface. The glaze appeared to react with the refractory at a temperature of $1100^{\circ} \mathrm{C}$, and an associated increase in viscosity may have resulted in a shallower 
penetration of only $0.6 \mathrm{~mm}$. No discrete Re particles were found in the $800^{\circ} \mathrm{C}$ or $1000^{\circ} \mathrm{C}$ samples, but the isolated nature of these particles may have made them difficult to find in limited cross sectional areas examined. More SEM images and composition tables are shown in Appendix B.

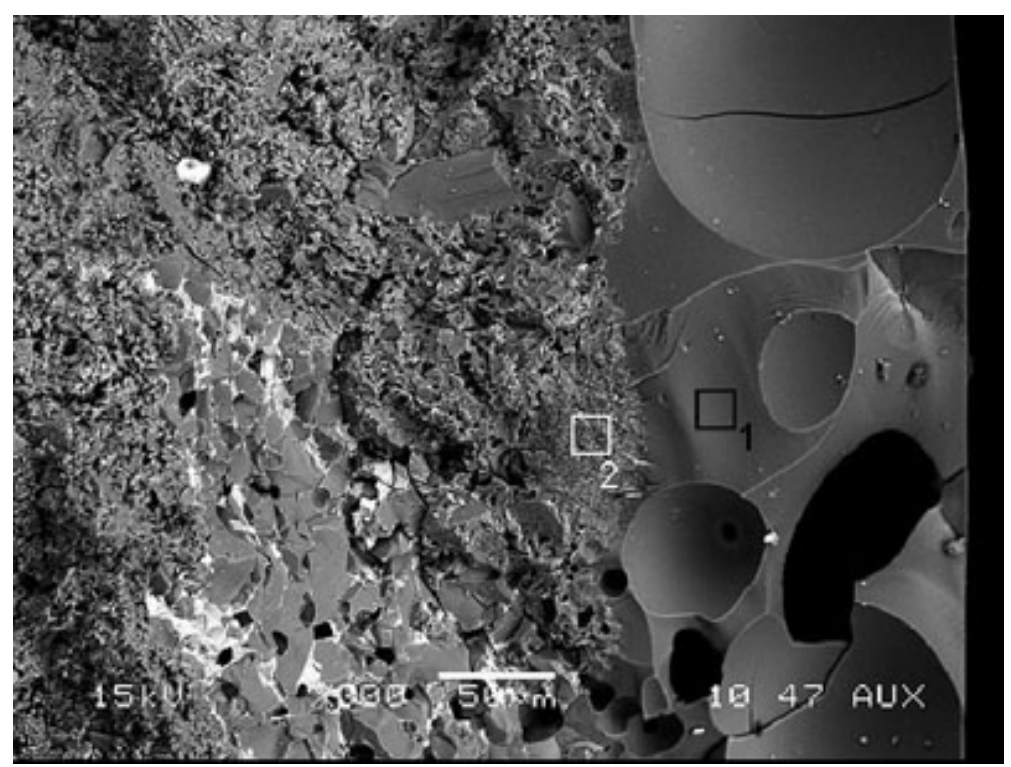

Figure 6.6. Vibrocast 60PC Coated with Sodium Silicate Glaze and Treated with Simulated Condensate at $800^{\circ} \mathrm{C}$

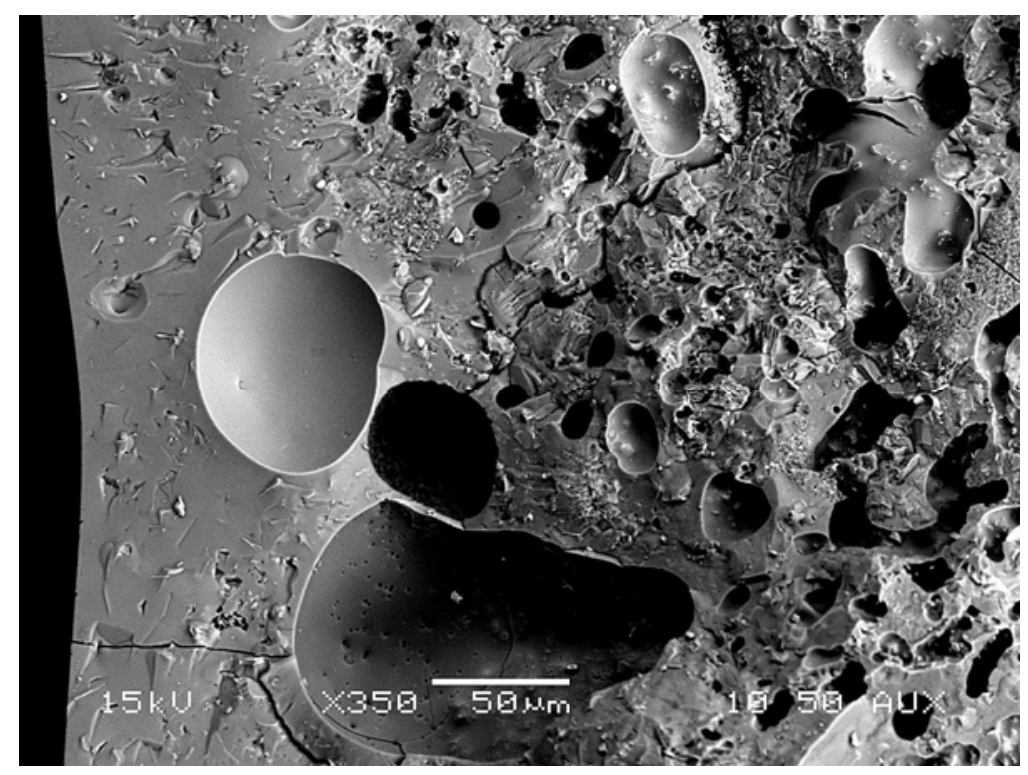

Figure 6.7. Vibrocast 60PC Coated with Sodium Silicate Glaze and Treated with Simulated Condensate at $1100^{\circ} \mathrm{C}$ (there is no distinct interface between glaze, salts, and the refractory) 
No evidence of penetration of simulated condensate was seen on fracture surfaces of Vibrocast 60PC coated with borosilicate glaze (Figure 6.8 and Figure 6.9) heat-treated at $800^{\circ} \mathrm{C}$ and $1000^{\circ} \mathrm{C}$. At $1100^{\circ} \mathrm{C}$, Re deposits were found $2.5 \mathrm{~mm}$ below the surface while the glaze penetrated $3.7 \mathrm{~mm}$ below the surface. See Appendix B for EDS composition tables and more SEM images.

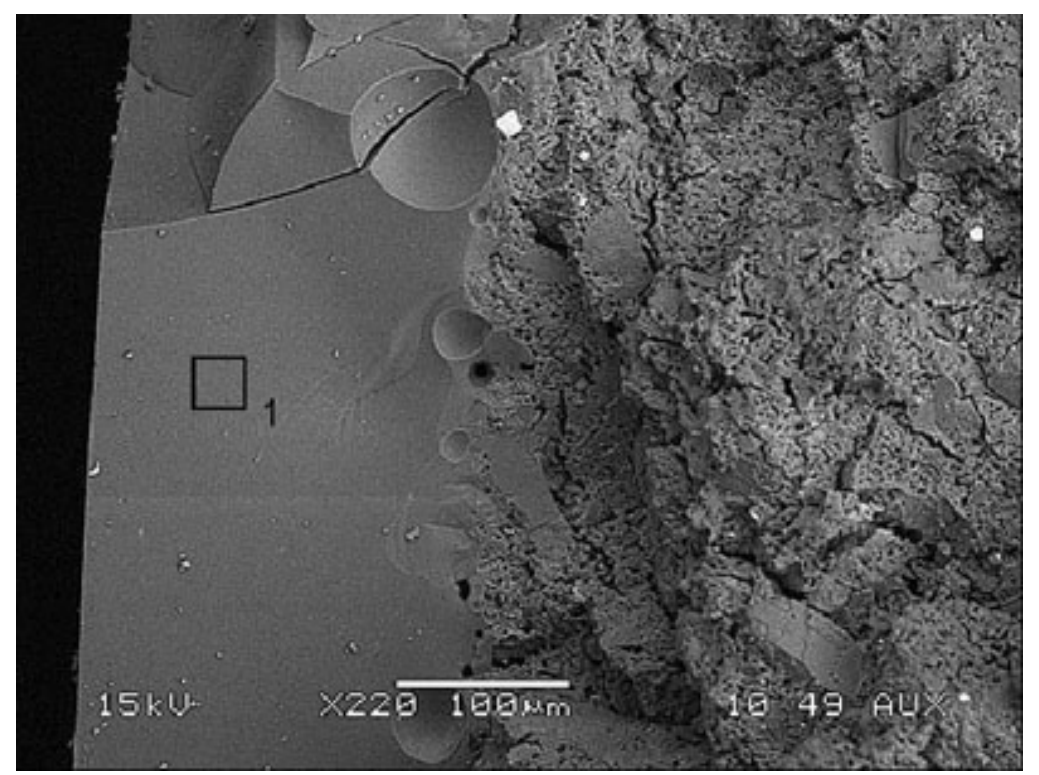

Figure 6.8. Vibrocast 60PC Coated with Borosilicate Glaze and Treated with Simulated Condensate at $800^{\circ} \mathrm{C}$ (note the sharp interface between glaze and the refractory; the glaze protects medium-sized pores and does not penetrate into small pores)

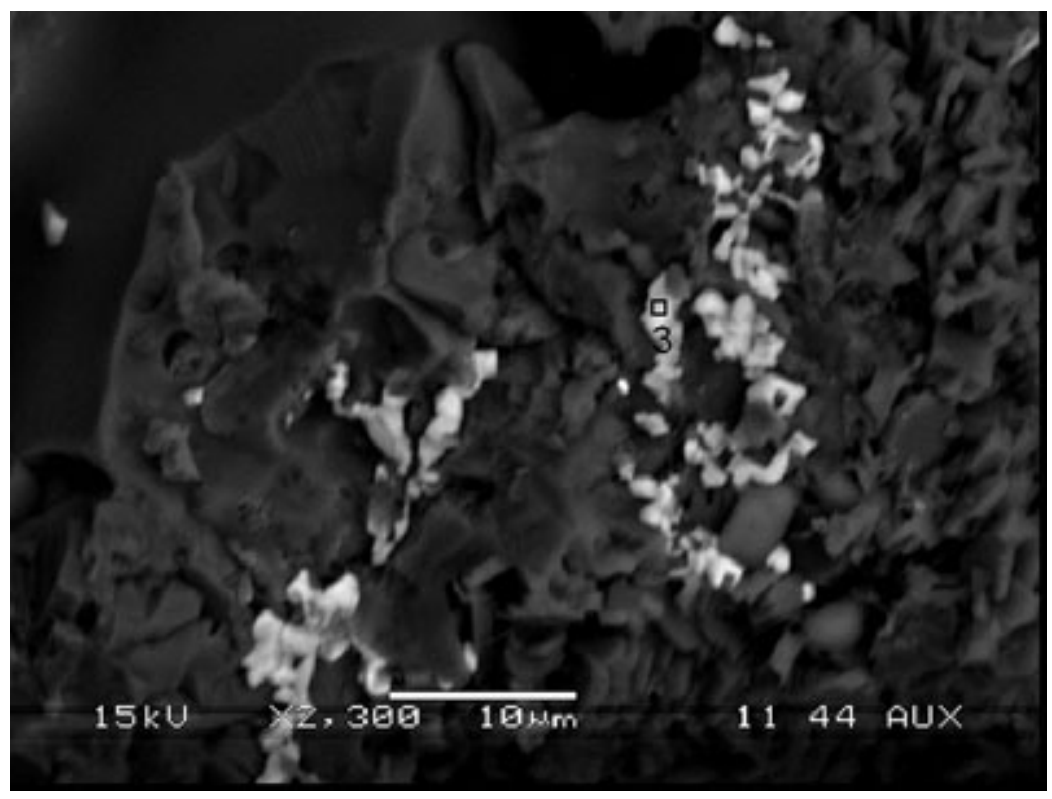

Figure 6.9. Deposits of Re Salt in Vibrocast 60PC Coated with Borosilicate Glaze and Treated with Simulated Condensate at $1100^{\circ} \mathrm{C}$ 
The test results are summarized in Table 6.2. Based on these results, we can conclude that sodium silicate glaze provides limited protection against deposited vapors. Borosilicate glaze prevents the penetration of deposited vapors into the CRB, but traps Re on its surface in a leachable form. Neither glaze protects against the attack of MIS at the feed/CRB contact.

Table 6.2. CRB Glazes: Summary of Test Results

\begin{tabular}{|c|c|c|}
\hline Glaze & $\begin{array}{l}\text { Sodium Silicate } \\
\text { PQ Corporation }\end{array}$ & $\begin{array}{l}\text { Borosilicate Frit 3225-3 } \\
\text { Ferro Corporation }\end{array}$ \\
\hline Components & $\mathrm{Na}_{2} \mathrm{O}, \mathrm{SiO}_{2}, \mathrm{H}_{2} \mathrm{O}$ & $\mathrm{B}_{2} \mathrm{O}_{3}, \mathrm{SiO}_{2}$ \\
\hline CRB compatibility & $\begin{array}{l}\text { Special treatment necessary to } \\
\text { overcome foaming tendency } \\
\text { (Section 6.2.2). }\end{array}$ & $\begin{array}{l}\text { Heating to a temperature }>1000^{\circ} \mathrm{C} \\
\text { necessary for continuous coating. }\end{array}$ \\
\hline Vapor deposition & $\begin{array}{l}\text { Re not detected by EDS on the } \\
\text { glazed surface or inside the } \\
\text { refractory. }\end{array}$ & $\begin{array}{l}\text { Scattered } \mathrm{NaReO}_{4} \text { crystal found only on } \\
\text { the glazed surface. }\end{array}$ \\
\hline Melt attack & $\begin{array}{l}\text { Glaze does not protect CRB against } \\
\text { MIS and molten glass. }\end{array}$ & $\begin{array}{l}\text { Glaze does not protect CRB against MIS } \\
\text { and molten glass, but prevents dynamic } \\
\text { meniscus. }\end{array}$ \\
\hline $\begin{array}{l}\text { Condensate } \\
\text { simulant penetration }\end{array}$ & $\begin{array}{l}\text { Penetration slowed at }<1000^{\circ} \mathrm{C} \text { and } \\
\text { surface sealed at }>1000^{\circ} \mathrm{C} \text {. }\end{array}$ & $\begin{array}{l}\text { Penetration stopped except into large pores } \\
\text { open to the surface. }\end{array}$ \\
\hline
\end{tabular}

\subsection{Gas Permeability}

Two glazed Vibrocast 60PC samples were tested for gas permeability; one sample was coated with sodium silicate glaze and heat-treated at $600^{\circ} \mathrm{C}$, and one was coated with the borosilicate glaze (Frit 3225) and heat-treated at $1000^{\circ} \mathrm{C}$. As shown in Figure 5.13, both glazed samples had a lower flow rate than the uncoated refractory sample heat-treated at $1050^{\circ} \mathrm{C}$. The gazes did not seal the samples because of cracking and incomplete sealing of open pores. These results indicate that glazing decreased the flow rate somewhat, but the heat-treatment temperature was the dominant factor. The permeability data (Table 5.4) led to the same conclusion. The flow rate through the sodium silicate-coated sample was lower than the flow rate through the borosilicate glazed sample, partially thought to be the result of the lower heattreatment temperature of $600^{\circ} \mathrm{C}$. 


\subsection{Refractory Tiles}

Conceptually, tiles applied to the interior of the CRB, with little or no permeability for either Tc gaseous compounds or for molten salt penetration, would block transport into the CRB. Several criteria were chosen for the initial selection of tiles as shown in Table 7.1. Any material exposed directly to the BV process must survive the environment in terms of corrosion resistance and thermal stability, including thermal shock. To control parasitic ohm losses, the electrical conductivity must be substantially less than that of molten glass. The tiles must not cause the BV waste package to be disqualified under the Resource Conservation and Recovery Act (RCRA) disposal criteria. To functionally block the transport of Tc in gaseous compounds, the tiles must have gas permeability significantly less than the CRB. The tile must bond to the castable refractory material until it is covered by molten glass.

Table 7.1. Tile Selection Criteria

\begin{tabular}{||l|l||}
\hline \multicolumn{1}{|c|}{ Criteria } & \multicolumn{1}{c|}{ Limit } \\
\hline Corrosion Resistance & Survival in $1 / 6^{\text {th }}$ scale melter \\
\hline Thermal Stability & Survival in $1 / 6^{\text {th }}$ scale melter \\
\hline Electrical Insulation & Conductivity $<1 \mathrm{~S} / \mathrm{m}$ \\
\hline Non-Hazardous & Non RCRA burial satisfied \\
\hline Low Gas Permeability & $<50 \times \mathrm{CRB}$ \\
\hline CRB Bonding & Adhesion at $1000^{\circ} \mathrm{C}$ \\
\hline Availability & Commercially manufactured \\
\hline \hline
\end{tabular}

\subsection{Manufacturing Demonstration Testing}

As shown in Table 7.1, bonding to the Vibrocast 60 PC CRB is one of the criteria used to judge the usefulness of tiles for the BV technology. The manufacturing demonstration testing was used as the first gate in the screening process for the candidate tiles. Figure 7.1 shows the results of testing. Only two materials, greystone and AZS, remained intact and well bonded after firing to $1000^{\circ} \mathrm{C}$ at $5^{\circ} \mathrm{C} / \mathrm{min}$. 

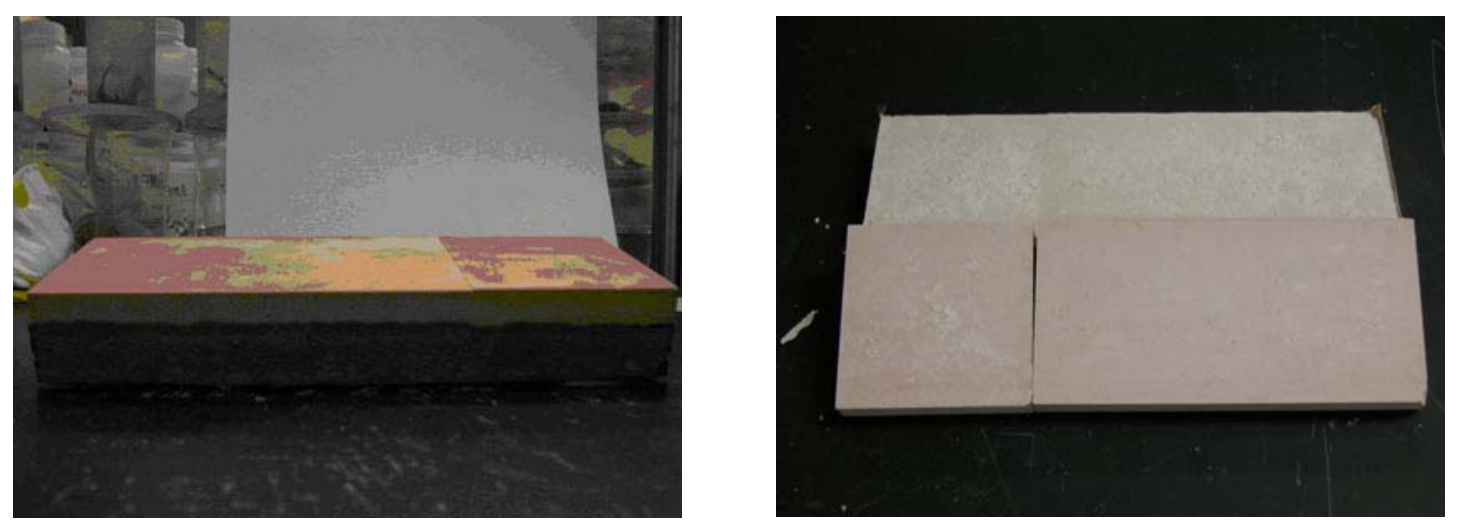

Fired Alumina Silicate
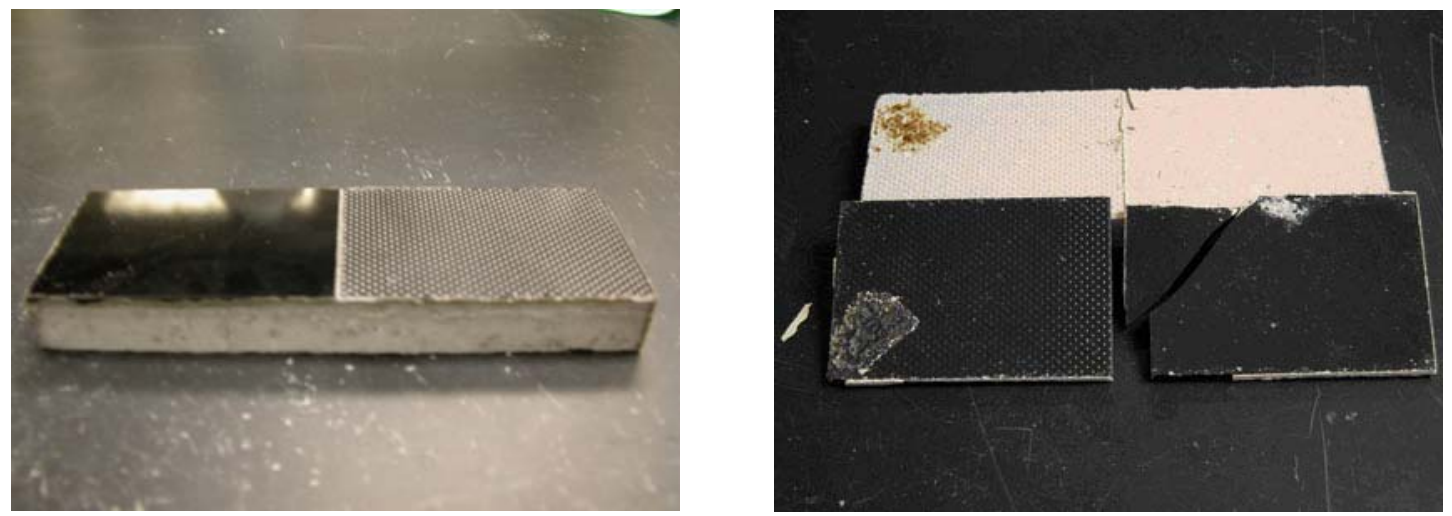

Glass Ceramics
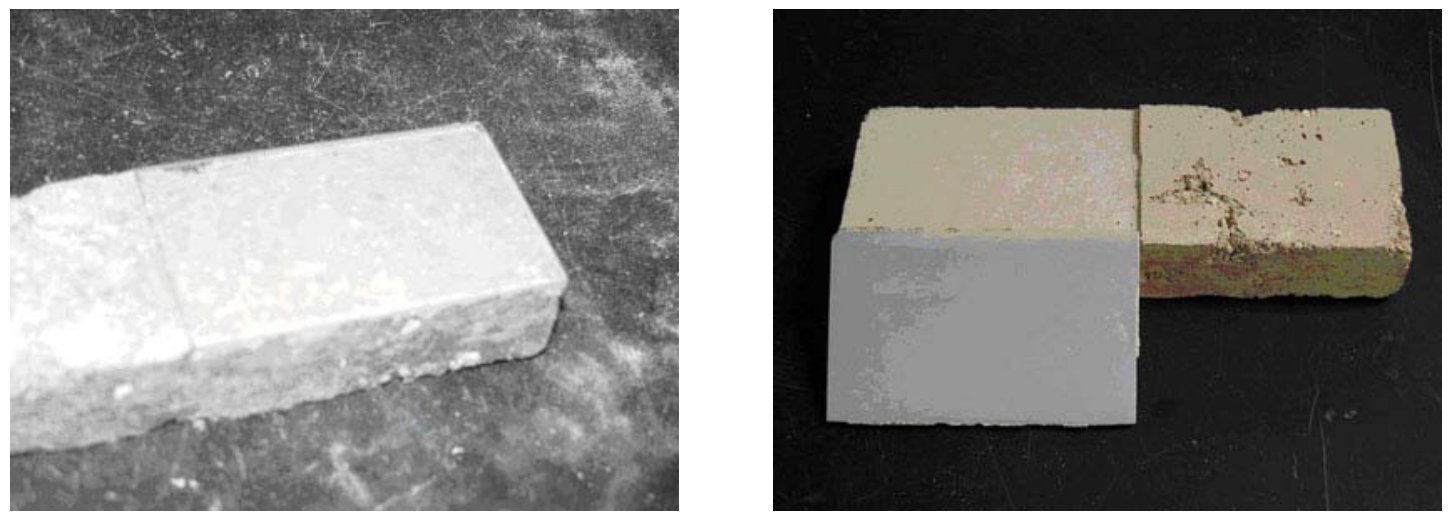

Pyroceram

Figure 7.1. Tiles on Vibrocast 60PC as Cast (left) and after Firing to $1000^{\circ} \mathrm{C}$ (right) 

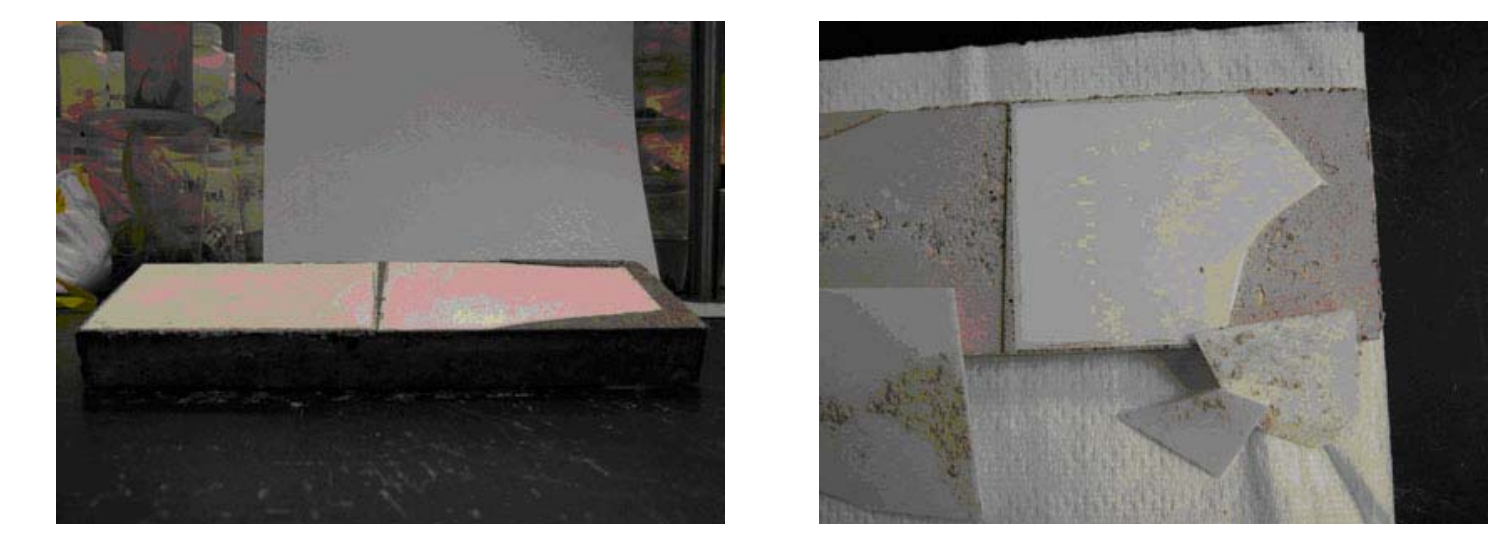

Alumina

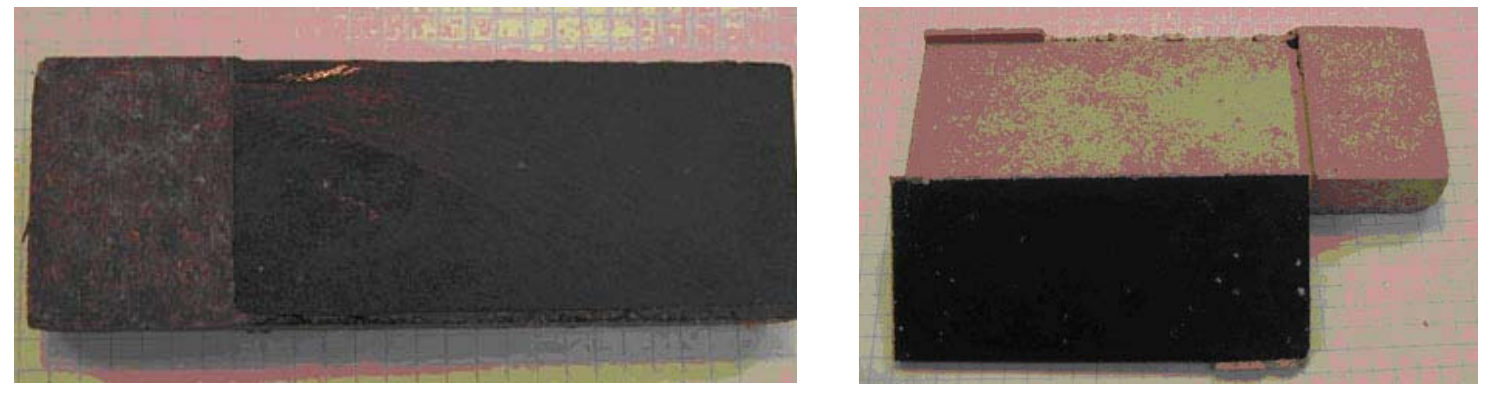

Monofrax K3

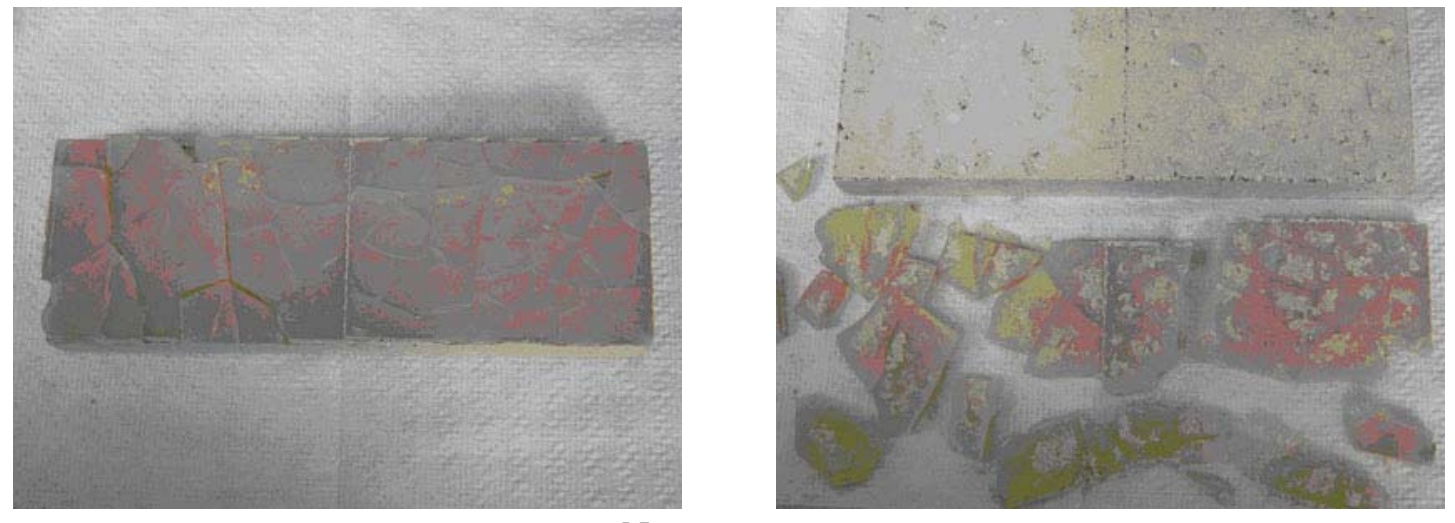

Neoceram

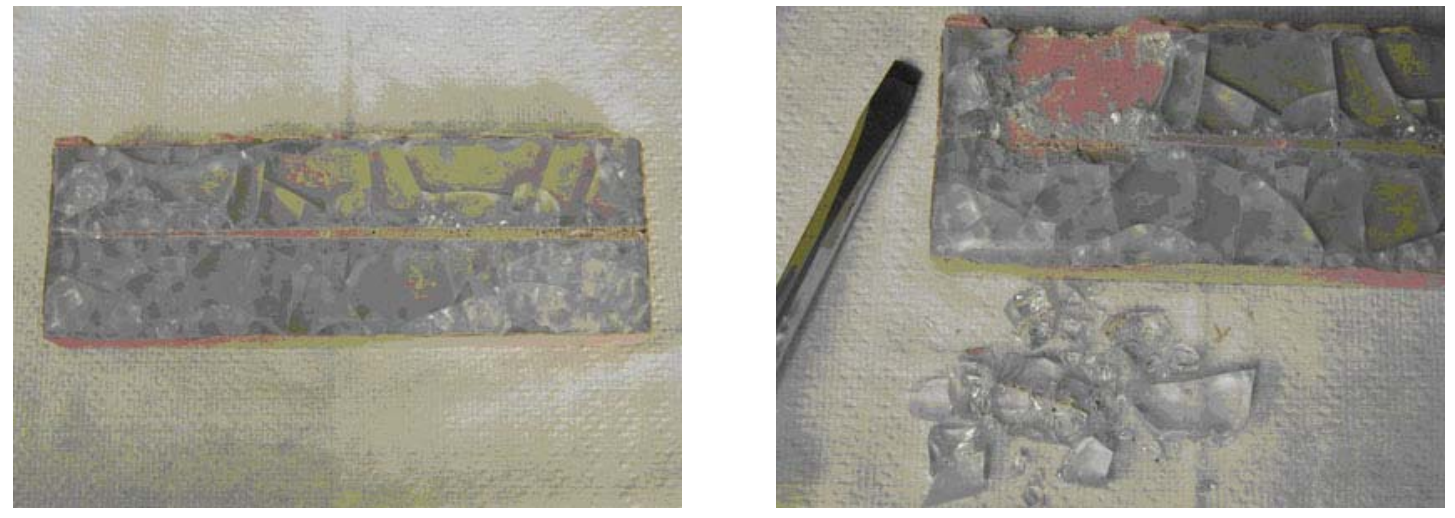

Plate glass

Figure 7.1 (contd) 

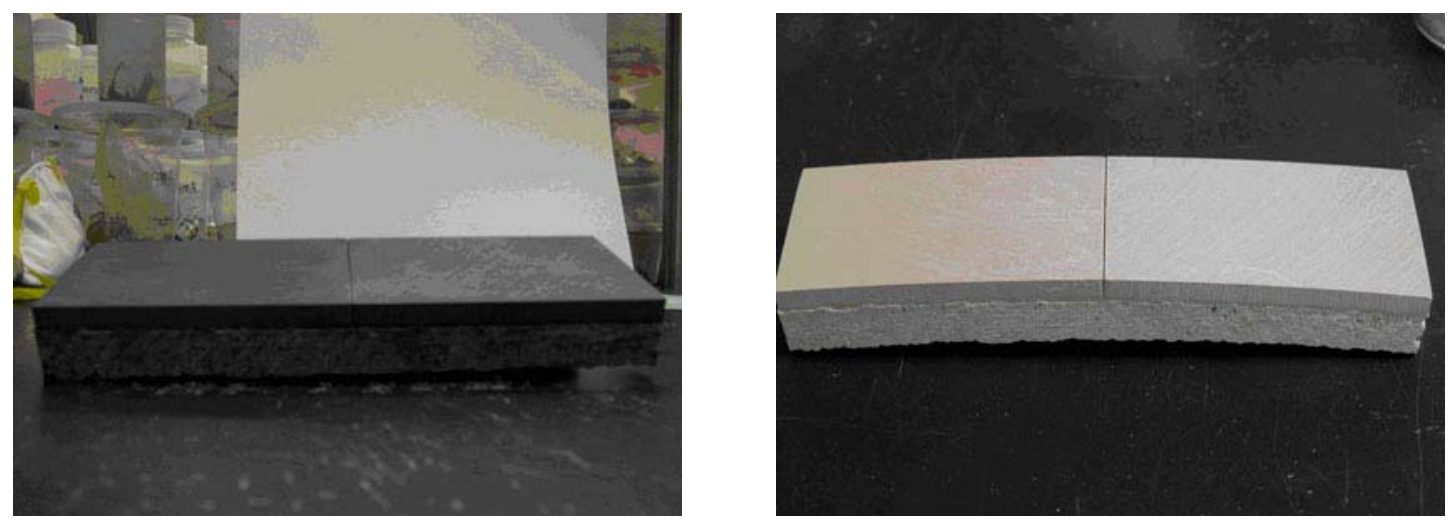

Grey Stone
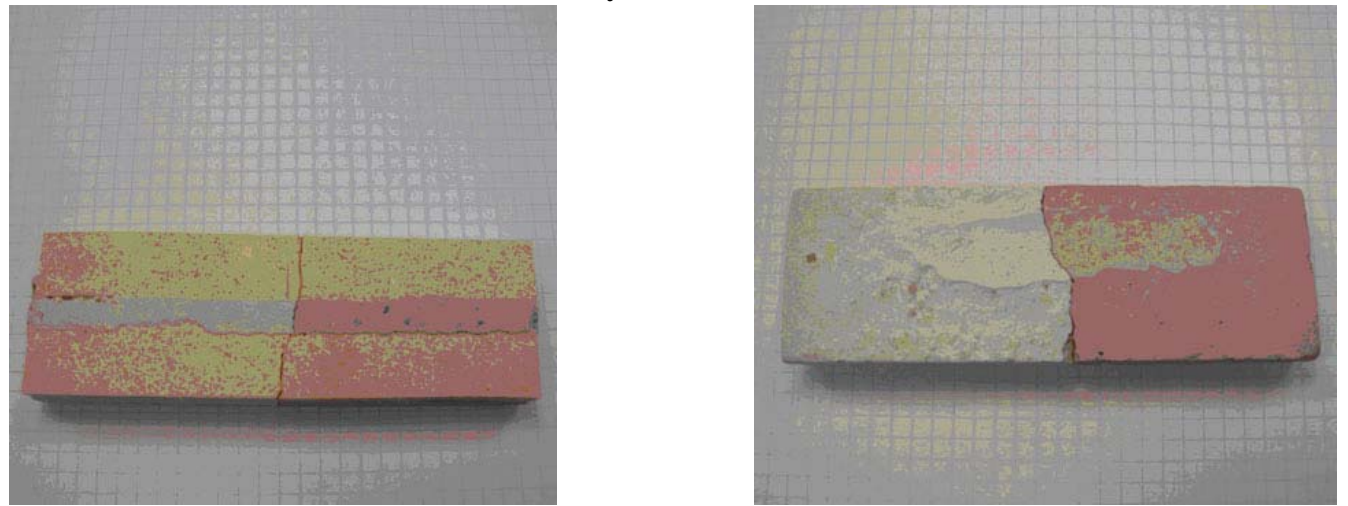

AZS

Figure 7.1 (contd)

All other tiles failed after firing to $1000^{\circ} \mathrm{C}$ at $5^{\circ} \mathrm{C} / \mathrm{min}$ :

- The alumina silicate tile spalled off and showed very few signs of adhesion.

- The glass ceramic tile spalled off and showed only a slight sign of adhesion.

- The pyroceram tile spalled off and showed very little, if any, signs of adhesion.

- The alumina tile was visibly separated around the edges from the castable. Minimal manual force separated the alumina tile from the castable.

- The monofrax tile was separated around the perimeter and could be removed with a small manual force.

- The neoceram tile showed serious cracking and slight adherence of some portions of tile while some had spalled off. The shards were easily removed by hand.

- The plate glass cracked and slumped; it showed fairly good adherence to the castable, yet could be easily removed with a screwdriver and a small applied force.

All attempts to separate the greystone tile from the castable failed; the bonding between the greystone tile and castable was as strong as the materials themselves. A significant arching of the greystone tile on the castable upon heating to $1000^{\circ} \mathrm{C}$ resulted from a large thermal expansion mismatch (Figure 7.2) between greystone and the CRB. The tile expanded by $2.67 \%$ on heating to $1000^{\circ} \mathrm{C}$ (by $\sim 2 \%$ between $600^{\circ} \mathrm{C}$ and 
$855^{\circ} \mathrm{C}$ ) and shrank by only $0.47 \%$ on cooling for a net permanent expansion of $2.2 \%$. After the first thermal cycle of heating to $1000^{\circ} \mathrm{C}$, the tile expanded by a mere $0.11 \%$ on reheating.

Figure 7.3 shows $\mathrm{XRD}$ patterns of greystone. Original greystone is a rock containing pyrophilite $\left(\mathrm{Al}_{2} \mathrm{O}_{3} \cdot 4 \mathrm{SiO}_{2} \cdot \mathrm{H}_{2} \mathrm{O}\right)$, muscovite $\left(\mathrm{K}_{2} \mathrm{O} \cdot 3 \mathrm{Al}_{2} \mathrm{O}_{3} \cdot 6 \mathrm{SiO}_{2} \cdot 2 \mathrm{H}_{2} \mathrm{O}\right)$, and lizardite $\left(3 \mathrm{MgO} \cdot 2 \mathrm{SiO}_{2} \cdot 2 \mathrm{H}_{2} \mathrm{O}\right)$. On firing to $800^{\circ} \mathrm{C}$, the minerals lose a part of their crystalline water. Firing above $800^{\circ} \mathrm{C}$ removed the rest of the water and caused the minerals to decompose to mullite $\left(3 \mathrm{Al}_{2} \mathrm{O}_{3} \cdot 2 \mathrm{SiO}_{2}\right)$, cristobalite $\left(\mathrm{SiO}_{2}\right)$, and glass.

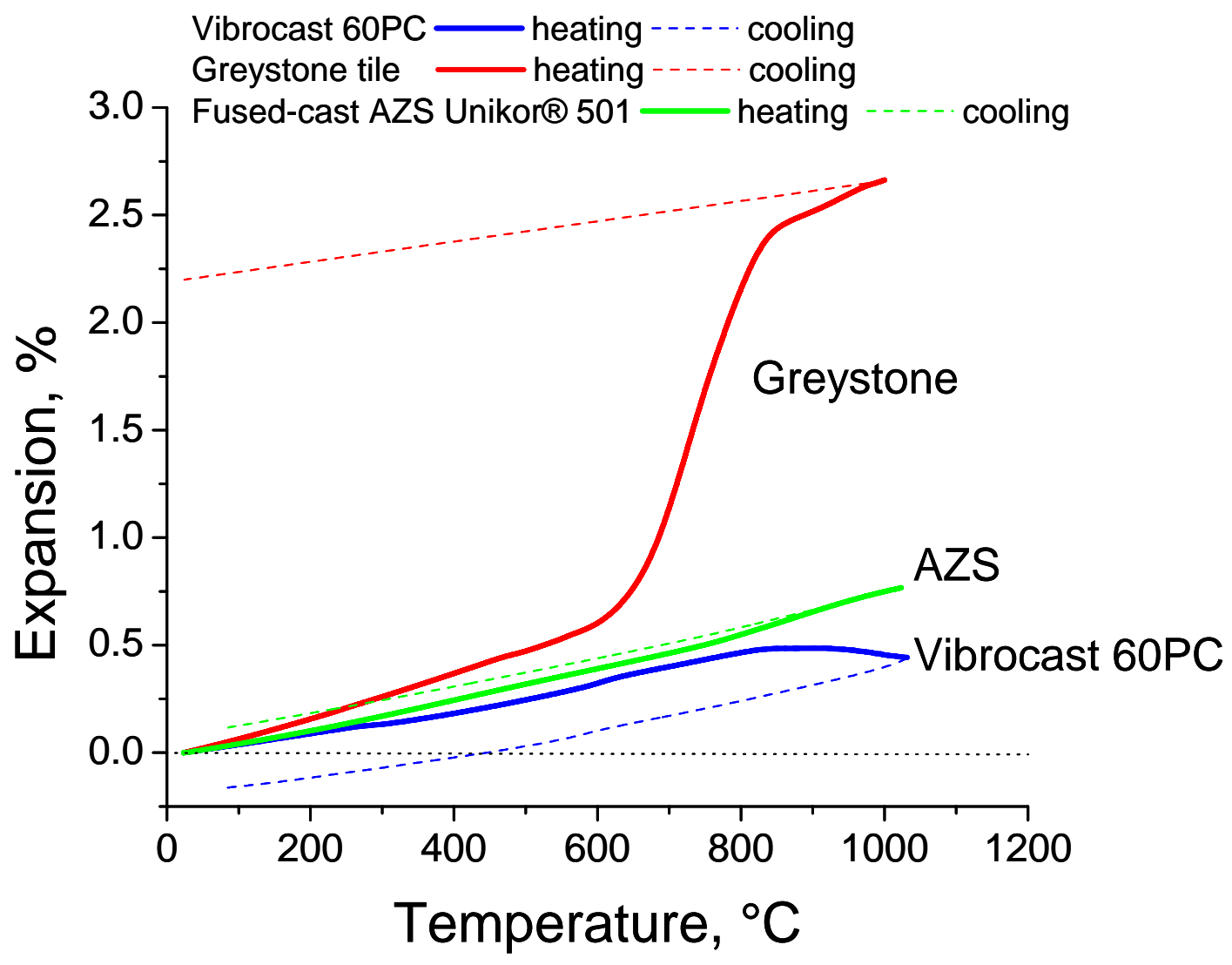

Figure 7.2. Thermal Expansion of Greystone Tile, AZS, and Vibrocast 60PC Specimen (specimens heated and cooled down at $2^{\circ} \mathrm{C} / \mathrm{min}$ ) 


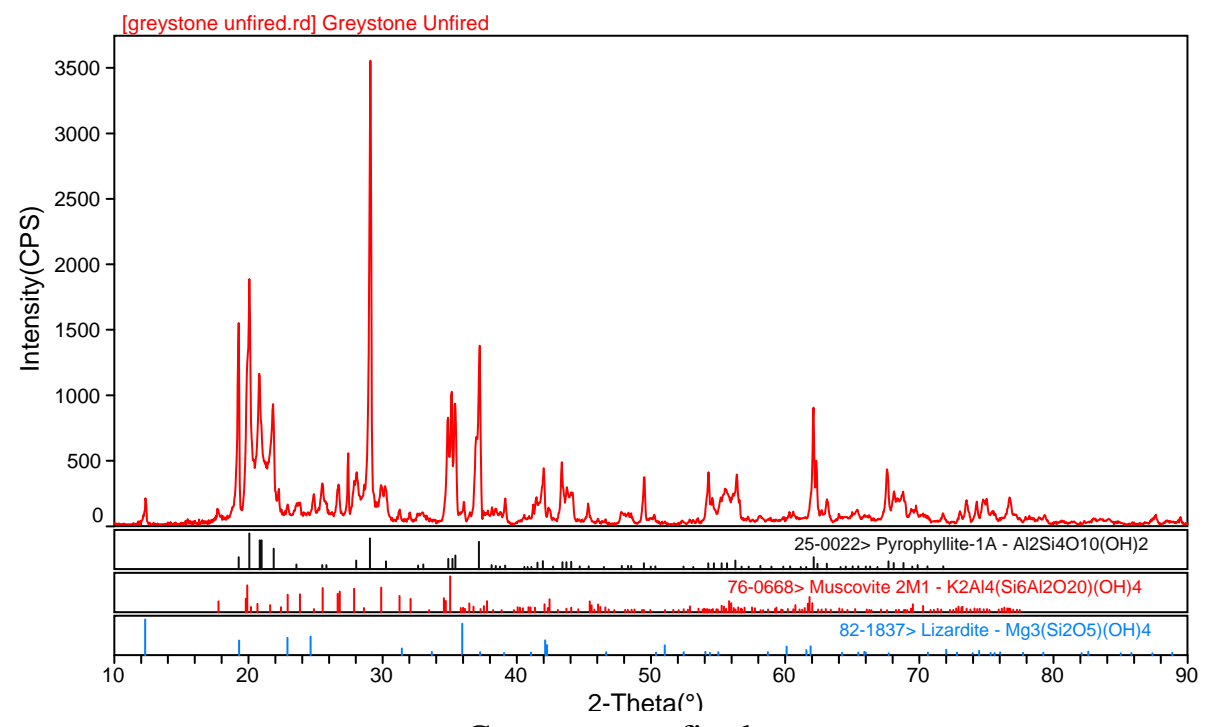

Greystone, unfired

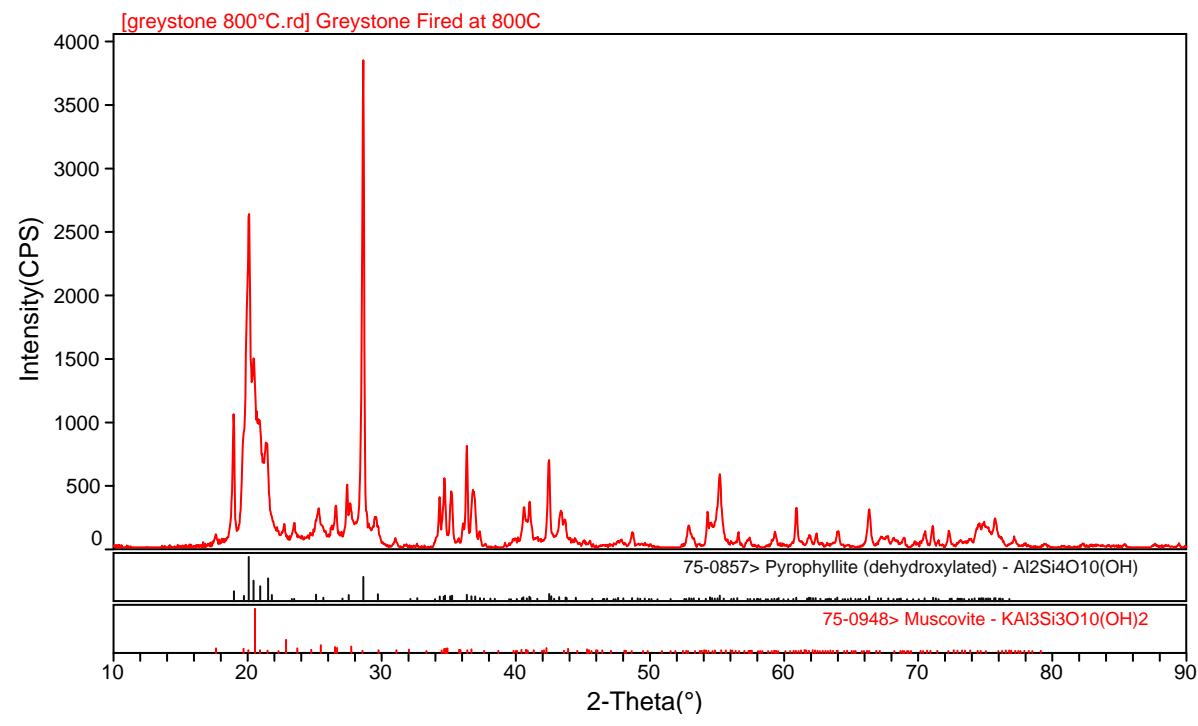

Greystone, fired at $800^{\circ} \mathrm{C}$

Figure 7.3. XRD Pattern of Greystone, Unfired and Fired at $800^{\circ}$ and $1300^{\circ} \mathrm{C}$ 


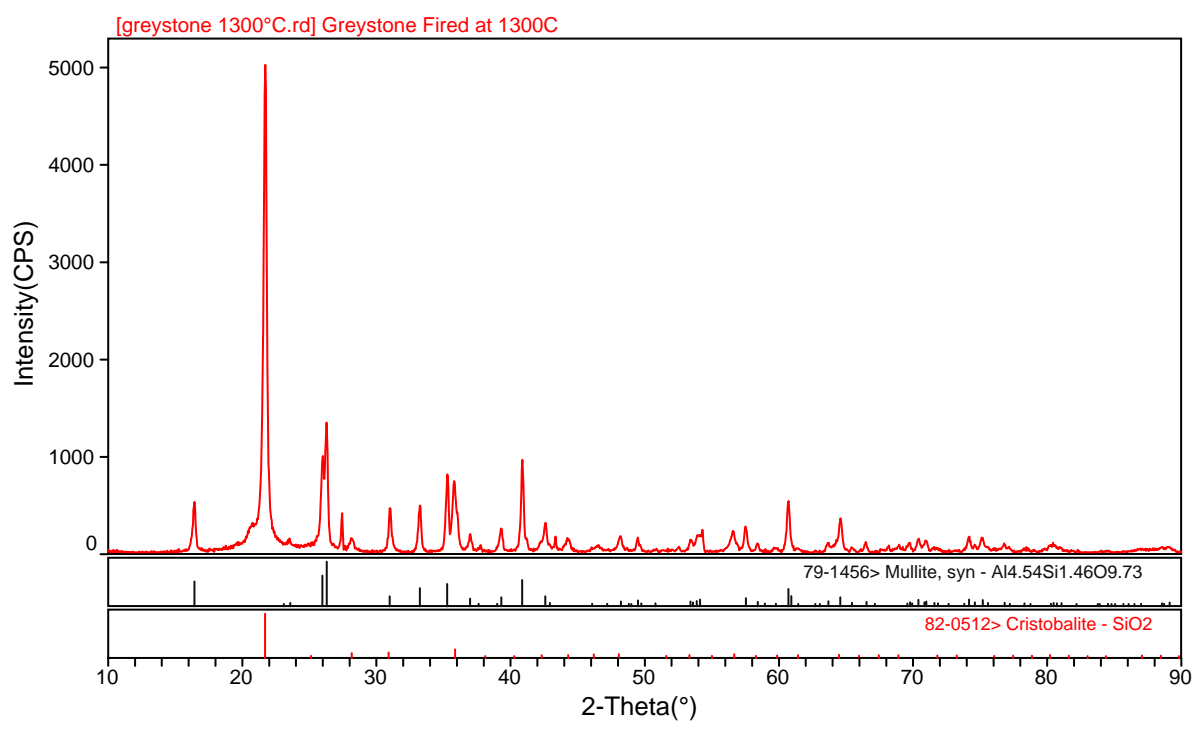

Greystone, fired at $1300^{\circ} \mathrm{C}$

Figure 7.3 (contd)

Vibrocast $60 \mathrm{PC}$ expanded by $0.44 \%$ on heating to $1032^{\circ} \mathrm{C}$. Thermal expansion is $5.07 \times 10^{-6} \mathrm{~K}^{-1}$ at $50^{\circ} \mathrm{C}$ to $265^{\circ} \mathrm{C}$; shrinkage occurs at temperatures greater than $924^{\circ} \mathrm{C}$. Net dimensional change after cooling results in a small shrinkage of $0.16 \%$.

The arching of the grey-stone-CRB couple was avoided by firing the tile to $860^{\circ} \mathrm{C}$ (at $5^{\circ} \mathrm{C} / \mathrm{min}$ ) before bonding. The bonding between the castable and the prefired tile was quite durable (resisted hammer and chisel) after heating to $1000^{\circ} \mathrm{C}$. Ramp heating to $1200^{\circ} \mathrm{C}$ caused a degree of delamination of the tile as Figure 7.4 illustrates.
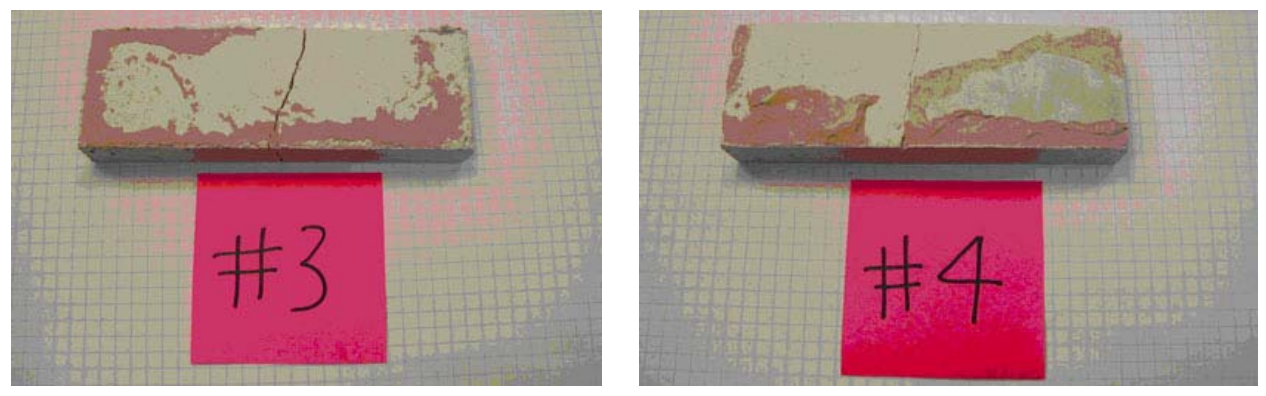

Figure 7.4. Greystone Tile Bonded to CRB after Ramp Heating to $1200^{\circ} \mathrm{C}$, Holding for 8 hours, and Attempting to Remove the Tile with Hammer and Chisel (tiles were prefired $800^{\circ} \mathrm{C}$, \#3 was for 8 hours and $\# 4$ for 1 hour)

After firing the AZS sample to both $1000^{\circ} \mathrm{C}$ and $1200^{\circ} \mathrm{C}$, a hammer and chisel could not break the AZS away from the castable. AZS did not show any signs of arching or delaminating after firing. The AZS Unicor 501 sample expanded by $0.75 \%$ on heating to $1000^{\circ} \mathrm{C}$ and remained $\sim 0.12 \%$ longer after cooling 
compared to the initial sample length (Figure 7.2); this is compatible with the Vibrocast 60PC response to thermal treatment.

Table 7.2 summarizes the results of the bonding experiments. The final manufacturing demonstration test was to fabricate half sections of ES test CRBs using the tiles. Attempts were made to use both the greystone tiles and the AZS tiles for this test. However, U.S. representatives for AZS were only aware of the AZS materials supplied as bricks for glass making, and attempts to cut the AZS bricks into tiles resulted in several damaged saw blades. Further investigation indicated that tiles could be obtained from the manufacturer, but AZS tiles were not available in time to support CRB fabrication. ${ }^{\text {(a) }}$ As a result, only greystone tiles were used for CRB lining manufacturing demonstration tests. Tiles were incorporated into the ES CRB by attaching the tiles to the inner surface of a metal mold and casting Vibrocast 60PC into the mold. One-quarter-inch gaps were left between tiles to act as grout lines. These gaps were filled with Vibrocast 60PC as part of the casting process. Figure 7.5 shows the final CRB after removal from the mold.

Table 7.2. Bonding Between Tiles and Vibrocast 60PC After Ramp Heating to $1000^{\circ} \mathrm{C}$ : Summary of Testing

\begin{tabular}{||l|l|l||}
\hline Tile & Source & Bonding \\
\hline Alumina & Repton & Limited bonding \\
\hline AZS & St. Gobain SEFPRO & Excellent \\
\hline Glass ceramic (Dark Robax) & Abrisa & No bonding; cracking \\
\hline Greystone & Carbon Store & Excellent (cracking of 60PC) \\
\hline Monofrax K3 & Monofrax & Weak bonding \\
\hline Neoceram & Peninsula Glass Co. & Limited bonding; extensive crazing \\
\hline Plate glass & Local Supplier & Severe crazing \\
\hline Pressed sintered Aluminosilicate & Morgan Advanced Ceramics & No bonding \\
\hline Pyroceram & Peninsula Glass Co. & No bonding \\
\hline
\end{tabular}

(a) More recently, we discovered that AZS tiles are made in LePontet, France, by Sait-Gobain SERFPO in standard sizes $150 \times 500 \times 550 \mathrm{~mm}$ and 500×600 mm with 75, 100, and $120 \mathrm{~mm}$ thickness; AZS CorGuard tiles sized $25 \times 300 \times 300 \mathrm{~mm}$ are potentially suitable for CRB lining. 


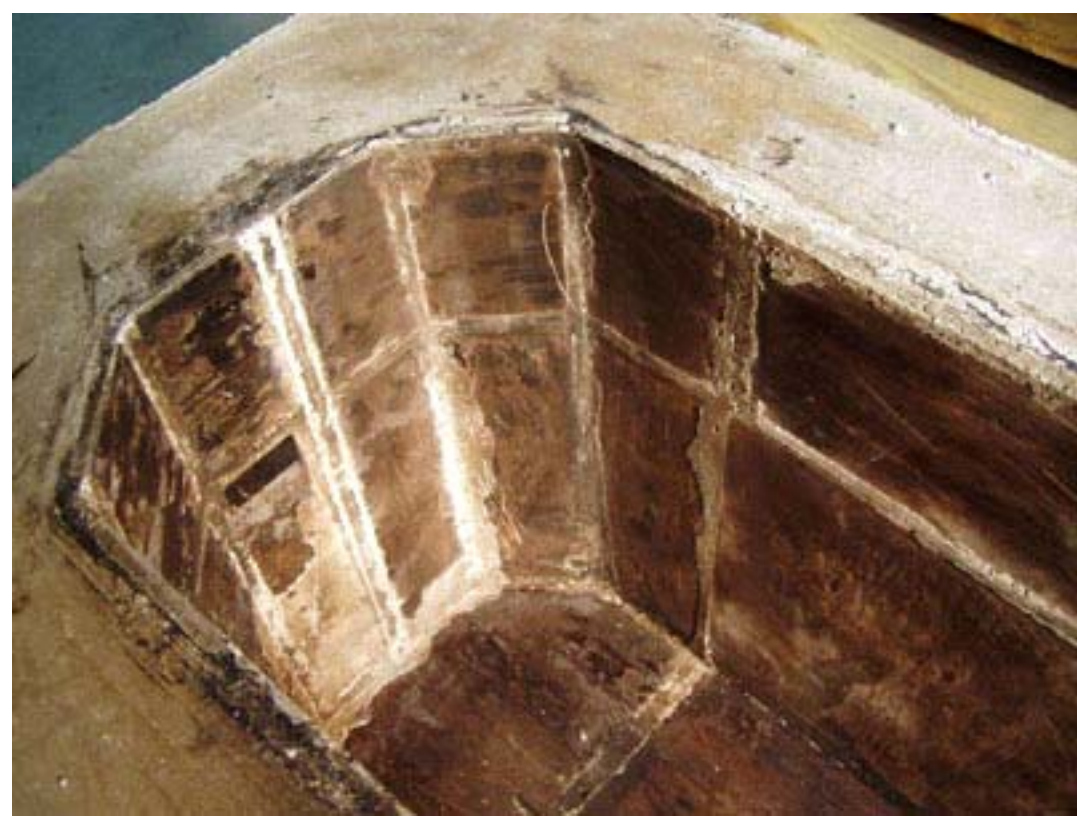

Figure 7.5. Greystone Tile Preparation (tiles were heated in air to $860^{\circ} \mathrm{C}$ to reduce thermal expansion mismatch and were applied to mold with open joints to allow for expansion)

\subsection{Simulant Condensate Penetration Test}

\subsubsection{Materials}

Only the greystone was tested because it was the only material that was available in the form of a tile that also passed the manufacturing demonstration test.

\subsubsection{Procedure}

Greystone tiles were ramped to $800^{\circ}, 1000^{\circ}$, and $1100^{\circ} \mathrm{C}$ at $5^{\circ} \mathrm{C} / \mathrm{min}$ and then left at that temperature for 30 minutes before being ramped back down to room temperature. The tiles were then broken in half with a chisel, and the fractured cross section was examined with the SEM.

\subsubsection{Results}

Figure 7.6 shows greystone tiles after the heat-treatment at $1000^{\circ} \mathrm{C}$. The surface morphology of simulated condensate on plate glass and alumino-silicate tile is shown in Appendix B. The salt formed various configurations of sulfate and chloride melts on the surface of the tile. However, no discrete particles of Re-containing salt were detected. 

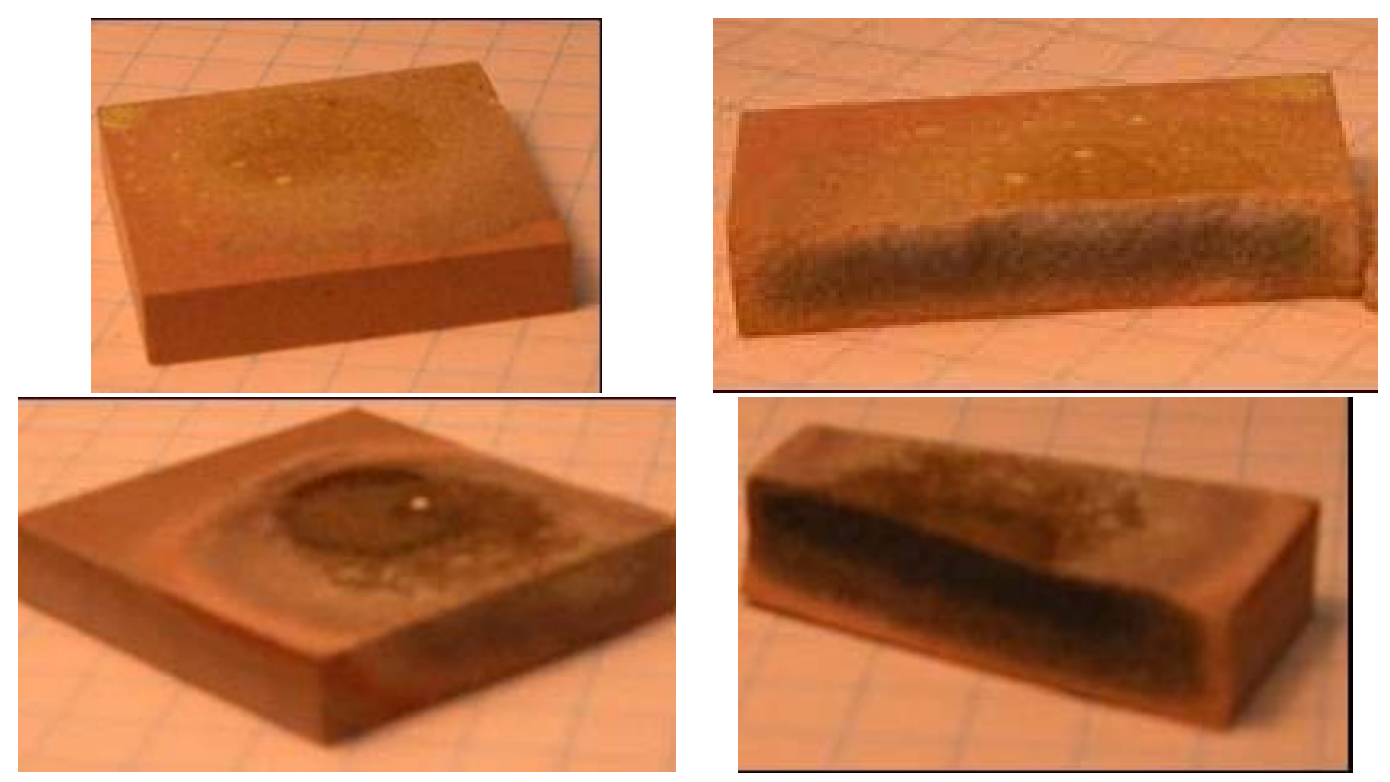

Figure 7.6. Prefired (top) and Unfired (bottom) Greystone Tiles Heat-Treated with Simulated Condensate at $1000^{\circ} \mathrm{C}$

No penetration into the greystone tile (either as-received or prefired) was observed after heat-treatment at $1000^{\circ} \mathrm{C}$; a distinct interface was retained between the simulated condensate and the tile (see Figure 7.7; the bubbles are probably gas exuded from the tile pores).

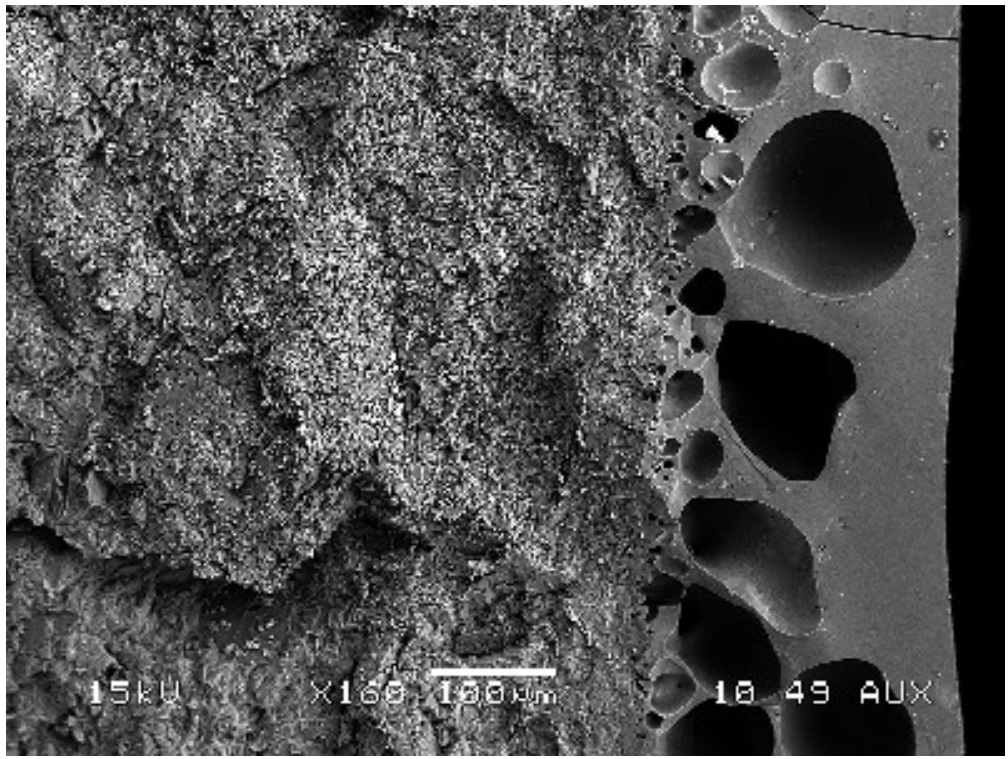

Figure 7.7. Simulated Condensate on Unfired Greystone Tile Heated at $1000^{\circ} \mathrm{C}$ 


\subsection{Gas Permeability, Density, and Porosity}

Materials with theoretical densities in excess of $92 \%$, such as the high-density alumina or fused cast AZS, do not possess interconnected porosity and would not be expected to have measurable gas permeability. Therefore, the gas permeability of AZS was not measured. The greystone tile is expected to have interconnected porosity because of its origin. The calculation of permeability took into account that the greystone tile was only $6 \mathrm{~mm}$ thick (compared to the $19 \mathrm{~mm}$ thick Vibrocast 60PC samples tested).

In Figure 7.8, the gas permeability of the greystone tile both as-received (untreated) and after heating to $600^{\circ} \mathrm{C}$ for 8 hours in air is compared to that of the as-cast Vibrocast 60PC (Figure 5.13). The as-received greystone tile possessed a gas permeability that was almost 4 orders of magnitude less than the Vibrocast 60PC (Table 7.3; the last column shows the ratio of the material's permeability to that of the untreated Vibrocast 60PC). After heat-treatment to $600^{\circ} \mathrm{C}$, the gas permeability of the greystone tile was increased by a factor of 50 but is still much less than even the untreated Vibrocast 60PC. This increase is similar to the effect of heat-treatment on the Vibrocast 60PC. Heat-treatment of the greystone tile causes transformation of the original minerals and phases into new phases and is expected to cause a change in the pore structure within the solid. Evidently this heat-treatment opens up the pore structure. The gas permeability of greystone tile heated to higher temperatures may be greater, but the heat-affected greystone is expected to have significantly lower gas permeability than the Vibrocast 60PC heated to a similar temperature.

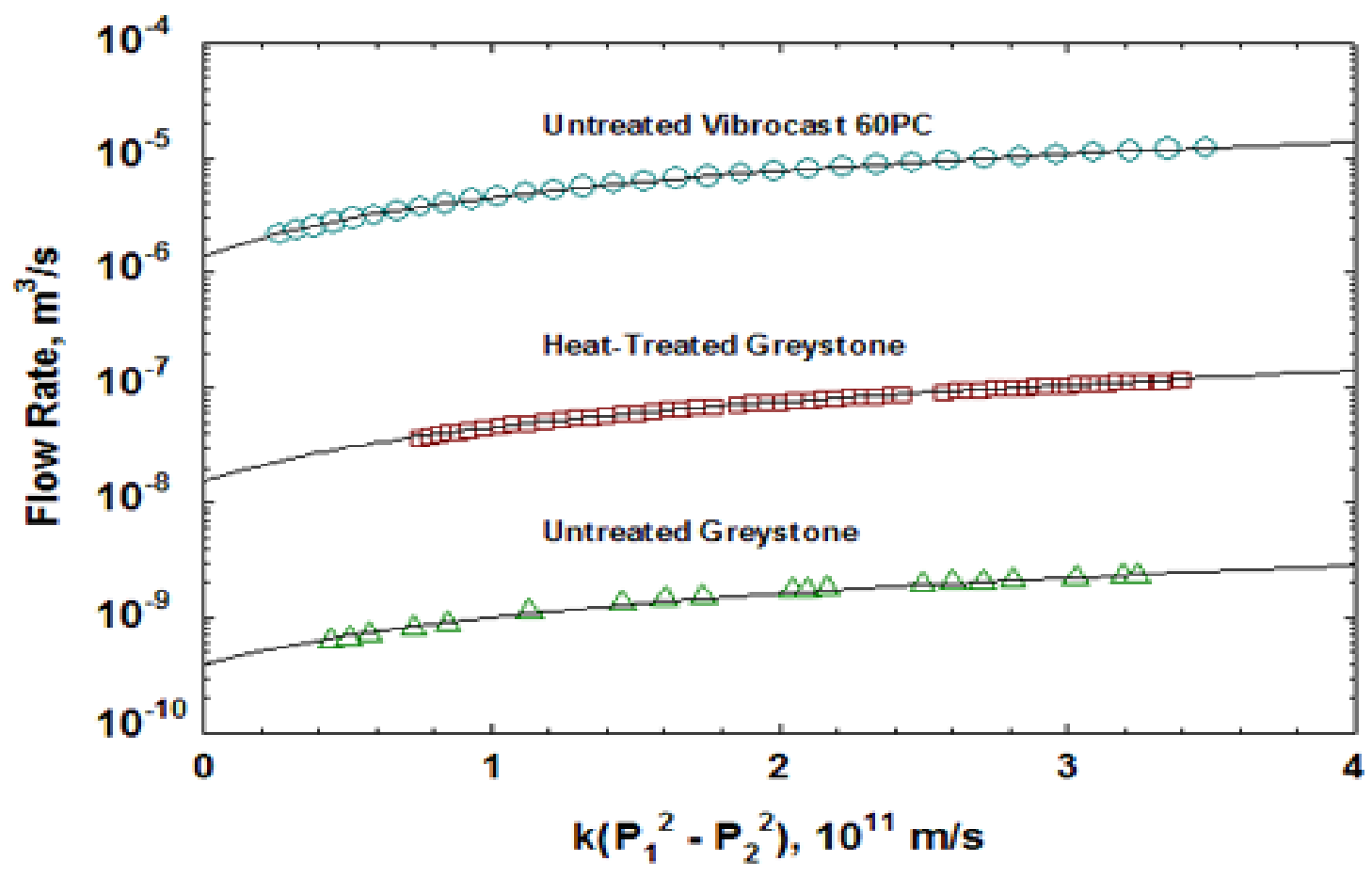

Figure 7.8. Results of Gas Permeability Measurement for Greystone Tile 
Table 7.3. Gas Permeability of Greystone Tile in Comparison to Vibrocast 60PC

\begin{tabular}{|c|c|c|c|c|c|}
\hline \multirow[b]{2}{*}{ Material } & \multirow{2}{*}{$\begin{array}{c}\text { Surface } \\
\text { Condition }\end{array}$} & \multirow{2}{*}{$\begin{array}{c}\text { Maximum } \\
\text { Heat-Treatment } \\
\text { Temperature }\end{array}$} & \multirow{2}{*}{$\begin{array}{c}\text { Gas } \\
\text { Permeability } \\
\text { (Darcy) }\end{array}$} & \multicolumn{2}{|c|}{$\begin{array}{c}\text { Permeability } \\
\text { Relative to Vibrocast 60PC } \\
\text { Heat Treated to Different } \\
\text { Temperatures } \\
\end{array}$} \\
\hline & & & & $\sim 200^{\circ} \mathrm{C}$ & $\sim 1050^{\circ} \mathrm{C}$ \\
\hline Vibrocast 60PC & As Cast/Cut & $\sim 200^{\circ} \mathrm{C}$ & $3.2 \times 10^{-5}$ & 1 & $8.2 \times 10^{-3}$ \\
\hline Vibrocast 60PC & As Cast/Cut & $\sim 1050^{\circ} \mathrm{C}$ & $3.9 \times 10^{-3}$ & $1.2 \times 10^{2}$ & 1 \\
\hline Greystone Tile & Cut/Cut & As received & $6.2 \times 10^{-9}$ & $1.9 \times 10^{-4}$ & $1.6 \times 10^{-6}$ \\
\hline Greystone Tile & Cut/Cut & $600^{\circ} \mathrm{C}$ & $3.0 \times 10^{-7}$ & $9.3 \times 10^{-3}$ & $7.7 \times 10^{-5}$ \\
\hline
\end{tabular}

Greystone density ( $\rho$ ) was determined by measuring tile dimensions and mass. The solid component density $\left(\rho_{\mathrm{S}}\right)$ was measured with helium pycnometer on crushed samples of greystone. The void fraction (porosity) was calculated as $p=1-\rho / \rho_{\mathrm{s}}$. These measurements were performed for the original, i.e., asreceived, tile and tiles fired to temperatures $800^{\circ}$ and $1300^{\circ} \mathrm{C}$. The results are summarized in Table 7.4. The density, porosity, and permeability changes are associated with the solid-state reactions (Figure 7.3) and sintering that the greystone undergoes as the firing temperature increases.

Table 7.4. Bulk Density, Solid Density, and Void Fraction (Porosity) of Greystone as Functions of Temperature

\begin{tabular}{||r|c|c|c||}
\hline \hline${ }^{\circ}{ }^{\circ} \mathbf{C}$ & $\rho, \mathbf{~ k g} / \mathbf{m}^{\mathbf{3}}$ & $\rho_{\mathrm{s}}, \mathbf{~ k g} / \mathbf{m}^{\mathbf{3}}$ & $\boldsymbol{p}=\mathbf{1}-\boldsymbol{\rho} / \boldsymbol{\rho}_{\mathrm{s}}$ \\
\hline 20 & 2727 & 2886 & 0.055 \\
\hline 800 & 2444 & 2608 & 0.063 \\
\hline 1300 & 2357 & 2391 & 0.014 \\
\hline
\end{tabular}

\subsection{Greystone Corrosion Test}

The greystone corrosion test was performed as described in Section 3.5. Figure 7.9 displays the corrosion depth as a function of the distance along the sample. The extent of corrosion was greatest at the bottom where nearly two thirds of the 6.4-mm-thick tile had corroded and lowest near the top surface of the melt. The bottom of the tile edge was visually observed to be corroded by upward drilling bubbles that created the large scatter in the 100-mm-distance data. The tile showed significant amounts of corrosion, but since both sides were exposed to the melt surface, the corrosion of a well bonded tile is expected to be half that seen in these tests. This is because only one side of the tile will be exposed to glass when used to line the CRB. So if one third of the tile corrodes in 22 hours at $1350^{\circ} \mathrm{C}$, the tile would be expected to remain as a liner long enough to protect the refractory for most, if not all, of the BV melt duration. Tile thickness measurements are shown in Appendix C. 


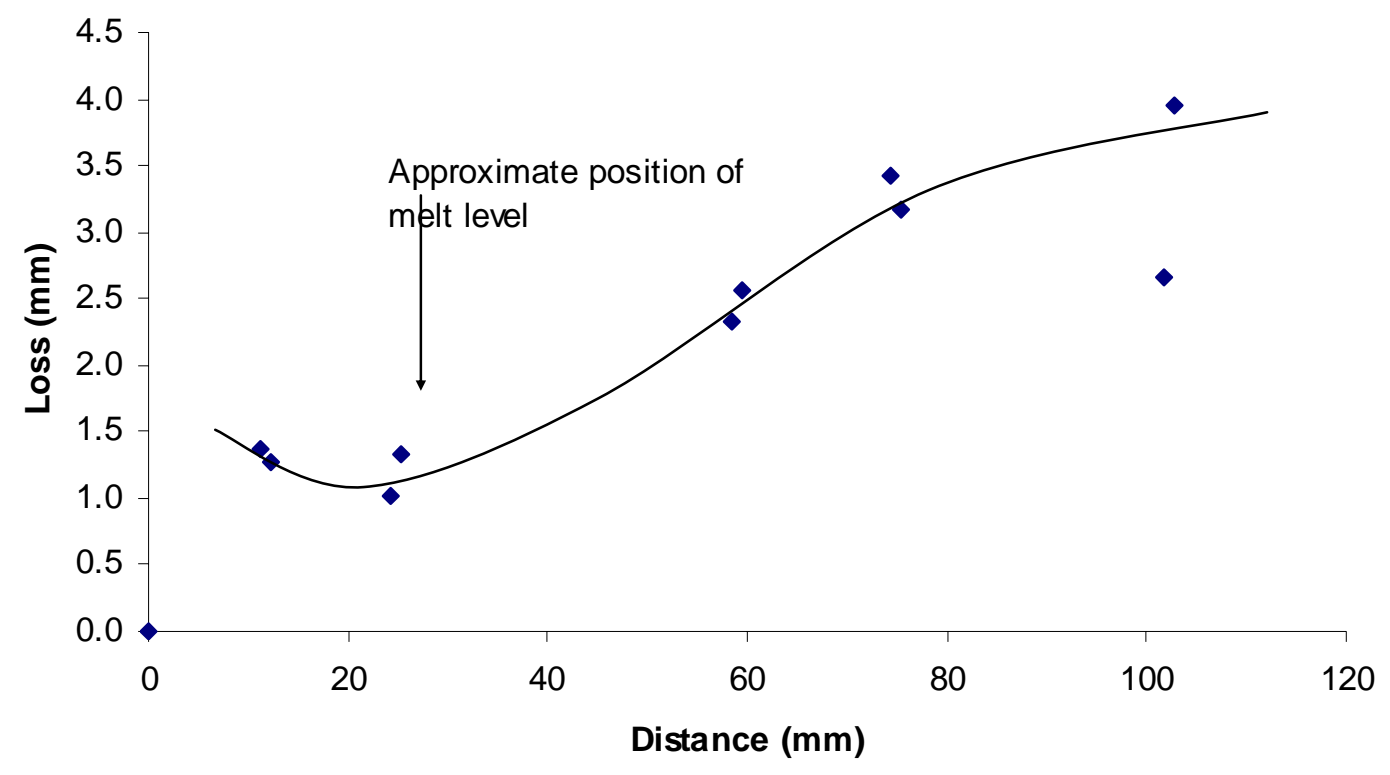

Figure 7.9. Linear Loss of Greystone Tile During 22-h Exposure to Melt at $1350^{\circ} \mathrm{C}$ as a Function of Distance Measured from the Top of the Tile Downward. Starting Thickness of the Tile Was $6.425 \mathrm{~mm}$.

\subsection{Suspended Refractory Rod Test}

\subsubsection{Materials}

Only limited suspended tile rod tests were conducted. Strips $(12 \times 120 \mathrm{~mm})$ were cut from Repton 136 , a high-density alumina tile, to determine how condensed vapors reacted with dense tile materials. Also tested was an electrofused rod cut from an AZS UNICOR® 501 block. The results from AZS were not conclusive and are discussed in Section 4.1.

\subsubsection{Procedure}

For experiments with refractory tiles (cut to $12 \times 120 \mathrm{~mm}$ ), the feed was heated in the fused silica glass tube to a set temperature of $1000^{\circ} \mathrm{C}$ for 2 hours.

\subsubsection{Results}

Appendix A displays selected SEM and optical images of the deposits and compositions of individual phases. Rhenium salts were detected on the high-density alumina tile surface as seen in Figure 7.10. Unlike on a smooth glazed surface (Figure 6.1) on which Re-containing crystals were spread in a nearly uniform pattern, Re deposits are located in areas between grains of the alumina ceramics. This pattern is different also from the Vibrocast 60PC refractory, whose high porosity allowed Re salts to be absorbed on a high surface area. 


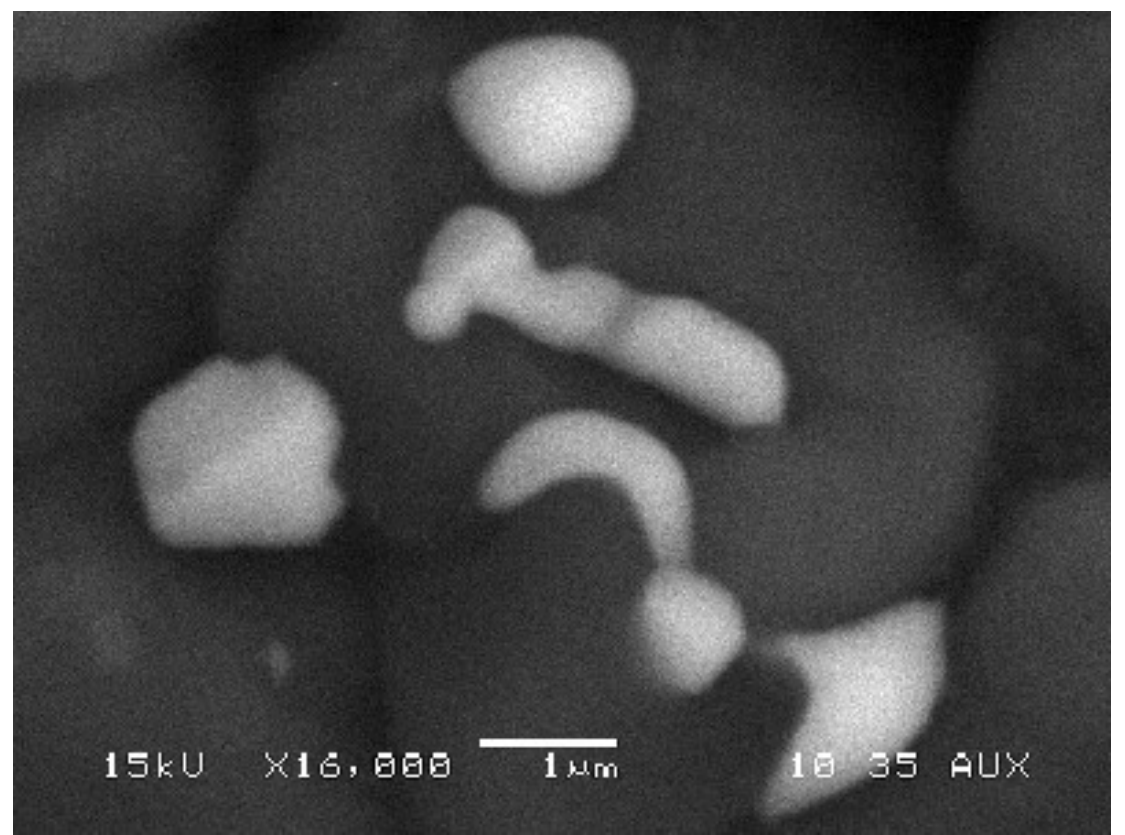

Figure 7.10. $\mathrm{KReO}_{4}$ Formations on Alumina Tile Surface at $354^{\circ} \mathrm{C}$ (SEM micrograph, feed heated to $1000^{\circ} \mathrm{C}$ with $2-\mathrm{h}$ hold)

\subsection{Refractory Tile Summary}

Table 7.5 shows the overall characteristics of the tiles that passed the testing. As mentioned above, AZS tiles have excellent properties; they are dense, corrosion resistant, thermally stable, and bond better with the CRB than the greystone.

Table 7.5. Tiles Deemed Acceptable for Melter Lining: Summary of Testing

\begin{tabular}{||l|l|l||}
\hline \hline Characteristic & Greystone Tile & Fused Cast AZS \\
\hline Corrosion Resistance & Adequate & Excellent \\
\hline Stability & After heat-treatment & Excellent \\
\hline Electrical Insulator & Adequate & Adequate \\
\hline Non-Hazardous & Yes & Yes \\
\hline Gas Permeability & Low & Very Low \\
\hline Available in Tiles & Yes & Yes \\
\hline
\end{tabular}




\subsection{Metal Liner Evaluation}

A metal liner was proposed as an alternative to ceramic glazes and tiles as a shield against technetium penetration into the CRB. This section evaluates whether a metal liner on the wall of a BV system would cause unacceptable electrical shorting between the electrodes.

This task was approached as follows.

- Evaluate the electrical shorting issue for an ES In-Container Vitrification (ICV ${ }^{\mathrm{TM}}$ ) system. This was done so that theoretical calculations could be compared with operating data.

- $\quad$ Assume a simplified parallel electrical resistor method (see Figure 8.1 and Figure 8.2):

- The circuit has two parallel resistors: 1) the main circuit through the glass and 2) from the back of the electrode to the end wall (this is closer than the side wall), through both sides of the liner, and back through the glass behind the other electrode.

- The resistors through the liners are made up of three resistors in series as mentioned in the above bullet. This is simplified as two resistors in series: R2 from the electrode to the wall and from the other wall to the other electrode and R3 through both sides of the liner.

- Assume single-phase heating.

- Assume that the metal liner can either go all the way to the floor or only apply to the plenum space.

- The power dissipated in the liner was obtained as shown in the lists below indicating nomenclature, resistances (see Figure 8.1 for schematic of resistances), and voltages and powers.

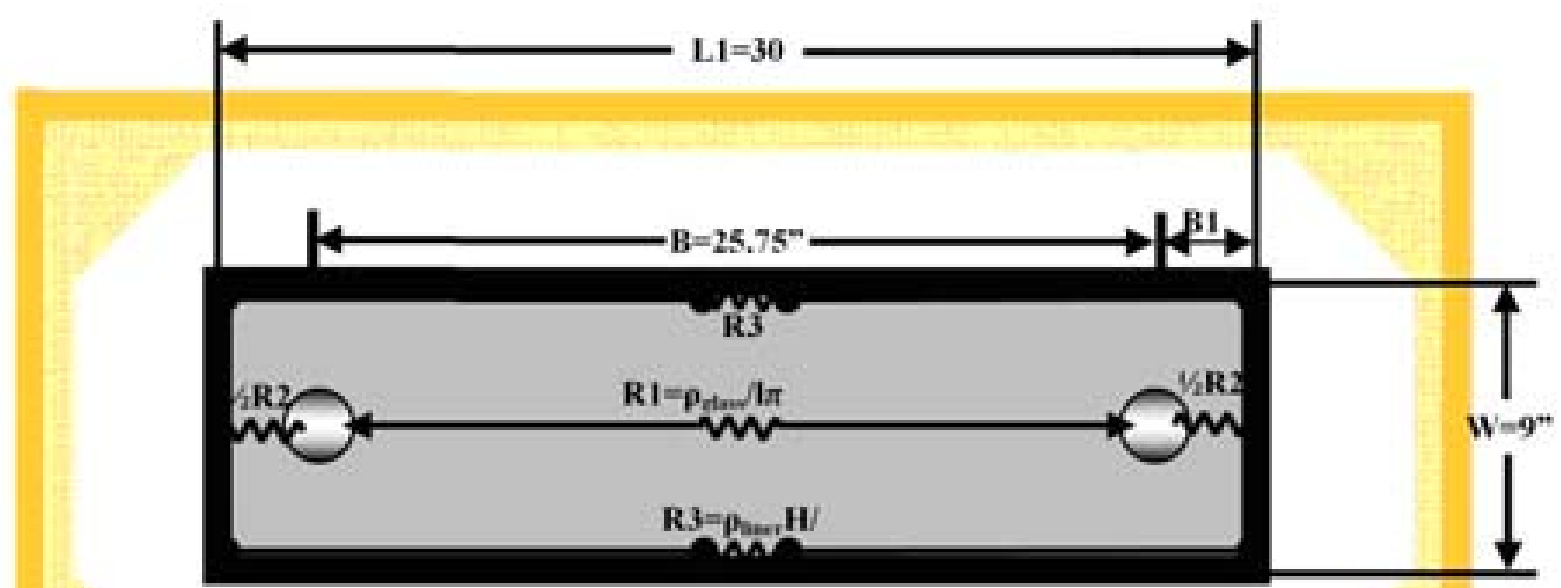

Cast Refractory

$2^{\text {" Refracten Sand }}$

2" Refractury Basa

Figure 8.1. Plan View of ICVTM with Resistor Schematic 


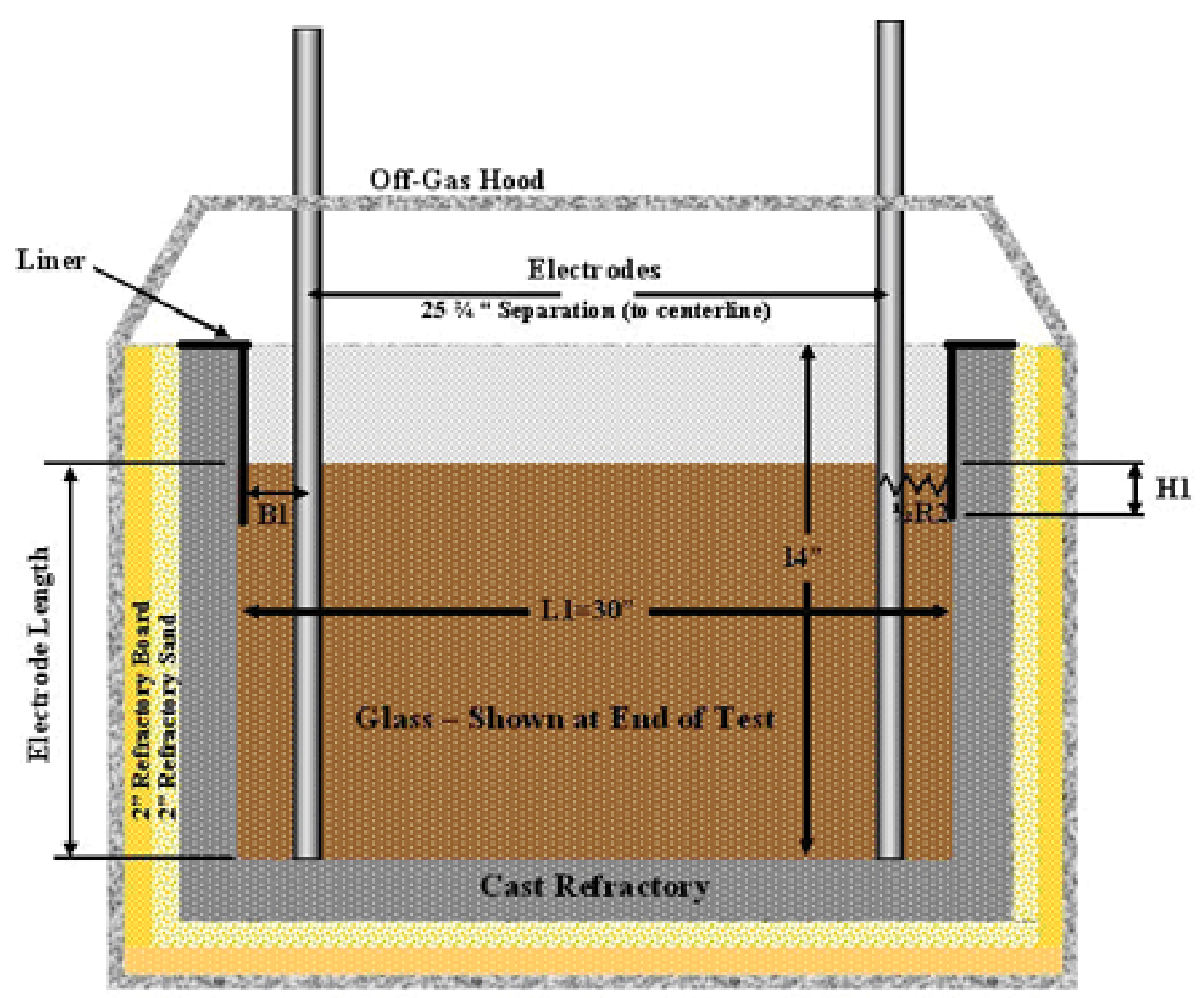

Figure 8.2. Elevation View of ICV ${ }^{\mathrm{TM}}$ with Resistor Schematic

\section{Nomenclature:}

$\mathrm{R}_{\text {Total }}$ total circuit resistance

R1 resistance through the glass between the electrodes

$1 / 2 \mathrm{R} 2$ resistance from one electrode to the wall

R2 sum of resistances from electrodes to walls

R3 resistance through one side of liner

$\mathrm{R} 2,3$ resistance through $\mathrm{R} 2$ and $\mathrm{R} 3$ in series

L1 length of liner

W width of liner

H1 height of liner in contact with the glass

1 length of electrode in the glass

B distance between centerlines of electrodes

B1 distance from centerline of electrode to wall 
A cross sectional area of liner (thickness times height)

E circuit voltage

E2 voltage drop through R2 as fraction of overall voltage

drop through circuit (R2+0.5R3)

$\mathrm{P}$ total power to the BV melter

P1 power dissipated through R1 (glass between electrodes)

P2 power dissipated through R2 (glass between electrodes and walls)

P3 power dissipated through R3 (one side of metal liner)

P23 power dissipated through R2+R3 (glass

between electrodes and walls and liner in series).

Resistances (see Figure 8.1 for schematic of resistances):

$$
\begin{aligned}
& \mathrm{R}_{\text {Total }}=\frac{1}{\frac{1}{\mathrm{R} 1}+\frac{1}{\mathrm{R} 2+\frac{\mathrm{R} 3}{2}}} \\
& \mathrm{R} 1=\frac{\rho \text { glass }}{\pi * l} * \ln \left(\frac{2 b}{d}\right) \\
& \mathrm{R} 2=\frac{\rho_{\text {glass }}}{\pi^{*} H} * \ln \left(\frac{2 * 2 B 1}{d}\right)=\frac{\rho_{\text {glass }}}{\pi^{*} H} * \ln \left(\frac{4 B 1}{d}\right) \\
& \mathrm{R} 3=\frac{\rho_{\text {Liner }} * L_{\text {Liner }}}{A_{\text {Liner }}} \\
& \mathrm{R} 3=\frac{\rho_{\text {Liner }} *(L 1+W)}{H^{*} t_{\text {Liner }}} \\
& \mathrm{R}_{\text {Total }}=\frac{1}{\frac{1}{\rho_{\text {glass }} * \ln \left(\frac{2 b}{d}\right)}+\frac{1}{\frac{\rho_{\text {glass }}}{\pi * H} \ln \left(\frac{4 B 1}{d}\right)+\frac{\rho_{\text {Liner }} *(L 1+W)}{2 * H * t_{\text {Liner }}}}}
\end{aligned}
$$

Note: See Trier (1987, p. 201) for the derivation of R1. In the equation defining R3, $L_{\text {Liner }}=\mathrm{L} 1+\mathrm{W}$ and $A_{\text {Liner }}=H^{*} t_{\text {Liner }}$. 


\section{Voltages and Powers:}

$$
\begin{gathered}
\mathrm{E}=\sqrt{P^{*} R_{\text {Total }}} \\
\mathrm{P} 1=\frac{E^{2}}{R 1} \\
\mathrm{E} 2=E \frac{R 2}{R 2+\frac{1}{2} R 3} \\
\mathrm{P} 23=\frac{E^{2}}{R 23} \\
\mathrm{P} 2=P 23 \frac{R 2}{R 23} \\
\mathrm{P} 3=P 23-P 2
\end{gathered}
$$

As expected, a significant amount of energy shorts from the back of the electrodes to the liner. Sample calculations were run assuming a constant power of $15 \mathrm{~kW}$. If the liner covers the entire wall height, $70 \%$ of the power shorts through the liner. Most of this power is not dissipated in the liner because of its lower resistance. Instead, the majority of the power $(10.5 \mathrm{~kW})$ is dissipated in the glass between the electrodes and the wall. This would result in a cold center of the melt, and the electrodes would most likely destroy the liner at the point of contact.

Other cases were run where the liner is only partially immersed in the glass (Figure 8.3). At 2-inches immersion, $\sim 1 / 3$ of the power goes to the liner. At 1-inch immersion, $\sim 1 / 5$ of the power goes through the liner. This evaluation is probably conservative because of the simplified method used. The percentage of power going through the liner is understated because the energy will not short only to the back wall, but also to the side walls. Moreover, the power will skew to the liner, and the center of the glass will become colder and thus less conductive; consequently, a run-away situation will result. 


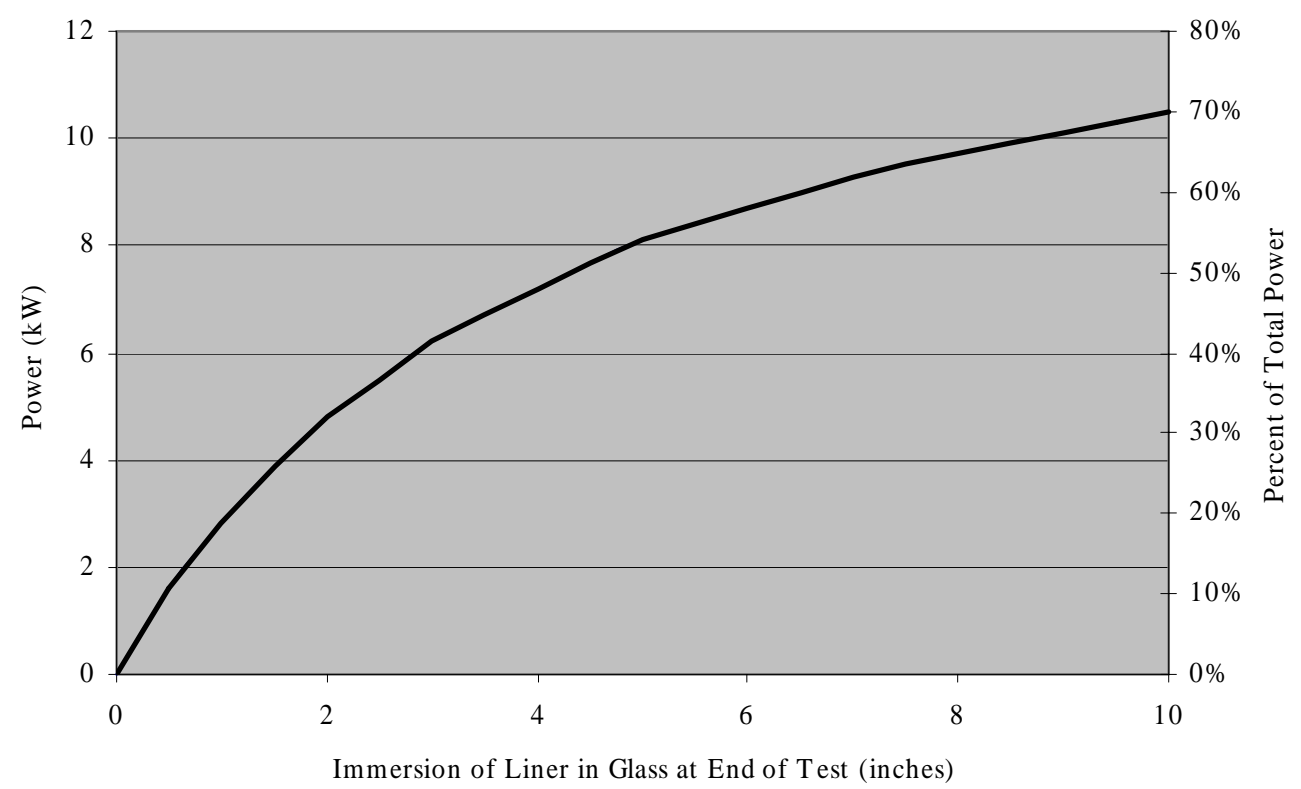

Figure 8.3. Immersion of Metal Liner Versus Power Dissipation in Back of Electrodes at Constant 15-kW Total Power

The amount of power that shorts to the liner is probably acceptable when the liner is immersed 1 inch or less, but maintaining this low level of immersion will be difficult. Another risky solution is to move the electrodes away from the wall and closer to the center of the bath to balance the amount of power between the two parallel circuits. 


\subsection{Conclusions}

The experimental studies and conceptual analyses were performed in three steps.

1. Analyses were conducted on the baseline CRB to help establish what potential mechanisms may be active in the transport of $\mathrm{Tc} / \mathrm{Re}$ to and into the CRB.

2. Tests were conducted to determine the practicality and potential effectiveness of three different approaches aimed at reducing or preventing the Tc/Re deposition of the CRB.

3. A plausible conceptual model was developed for Tc/Re transport during the bulk vitrification process in a CRB.

Laboratory studies aimed at better understanding the Tc/Re transport from LAW feed and glass melts. Both standard and newly designed experimental methods were applied to assess the extent of $\mathrm{Tc} / \mathrm{Re}$ transport to and into the baseline, unprotected CRB. These methods include a suspended refractory rod test, a partially immersed rod test, and a simulated condensate penetration test. The tests were conducted to determine the temperature intervals on which different transport mechanisms were active, the types of materials that form, and the relative concentrations of mobile elements on the surface and in the interior of the baseline refractory material. A gas permeability test was carried out to obtain a quantitative measure of the baseline CRB's resistance to flow. A technique of material removal in thin sections was used on a refractory sample from ES Test ES-31B to determine the distribution of soluble and insoluble Re near the glass/refractory interface. The following conclusions can be drawn from these tests.

- Molten salts from the LAW, mainly sulfates, chlorides, and nitrates, begin to evaporate from BV feeds at temperatures below $800^{\circ} \mathrm{C}$ and condense on solid surfaces at temperatures below $530^{\circ} \mathrm{C}$; potassium perrhenates precipitate from these deposits on cooling.

- Suspended refractory rod tests and tests with simulated condensate indicated that salt vaporized from the BV feed, and glass melt that condensed on cooler surfaces in the CRB would readily wet and penetrate into the unprotected CRB.

- The immersed refractory rod tests showed that molten salt from the feed material would readily penetrate $\geq 10 \mathrm{~mm}$ into the CRB. Feeds with higher concentrations of sulfate resulted in a higher level of swelling and degradation of the CRB refractory at higher temperatures. The excess $\mathrm{Na}$ relative to the sulfur and $\mathrm{Cl}$ in the cross-sectional analysis of the CRB indicated that the sulfate and $\mathrm{NaCl}$ salts penetrate into the refractory with a large volume of sodium nitrate salt. As sodium nitrate decomposes, $\mathrm{Na}_{2} \mathrm{O}$ reacts with the refractory material to form a glass.

- The gas-permeability tests on the baseline CRB showed that the permeability of the unprotected refractory increases by two to three orders of magnitude after heat-treating to $1050^{\circ} \mathrm{C}$. This indicates that the microstructural changes that occur in the CRB when it is heated during the BV process will tend to coarsen the fine porosity and increase the penetration of liquid salts and vapors.

- Chemical analyses of refractory material removed in thin sections from a CRB sample were conducted on a sample taken from a lower section in the CRB in ES Test ES-31B where high temperatures were likely to be reached. These analyses showed that Re penetrated at least $10 \mathrm{~mm}$ into the refractory. The average concentrations of soluble Re and insoluble Re were 0.022 and $0.64 \mathrm{mg} / \mathrm{kg}$ of refractory, respectively, indicating that $96 \%$ of the Re present was in an insoluble form. The concentration profile of both the soluble and insoluble fractions over the first $10 \mathrm{~mm}$ was fairly flat. Sodium penetrated up to $15 \mathrm{~mm}$ into the refractory and was present in great excess over 
the $\mathrm{S}$ and $\mathrm{Cl}$ concentrations. This layer-by-layer analysis provides additional evidence that, in some portions of the refractory, molten salts from the LAW feed penetrate into CRB pores before the sodium nitrate decomposes. As a result, sulfates and chlorides are deposited in the CRB. The $\mathrm{Na}_{2} \mathrm{O}$ from the decomposed nitrates reacts with the CRB to create a durable glass phase that may contain insoluble Tc/Re. A sample taken next to the sample used for the thin-section tests showed that the average soluble Re concentration over the full $100-\mathrm{mm}$ CRB-wall thickness was $0.0097 \mathrm{mg} / \mathrm{kg}$ of refractory. This result indicates that the soluble concentration seen in the first $10 \mathrm{~mm}$ would have to extend deeper into the refractory to account for the mass of material extracted from the full refractory wall.

Three possible approaches aimed at reducing or preventing the deposition of the CRB with soluble Tc/Re were proposed and evaluated:

1. sealing the CRB surface with a glaze

2. lining the CRB with ceramic tiles

3. lining the CRB with metal

Metal liners were deemed unsuitable and were not tested because evaluations showed that they can cause unacceptable distortions of the electric field in the BV system. Therefore, testing focused on refractory glazes and ceramic linings.

Several glaze candidates were screened to determine which glazes adhered to the CRB and produced continuous layers when heated to $1100^{\circ} \mathrm{C}$. The suspended refractory rod test, the partially immersed rod test, and the simulated condensate penetration tests were conducted with selected glazed CRB samples to determine the potential benefits of refractory glazes. Gas permeability tests were also carried out to obtain a quantitative measure of the glazed CRB's resistance to flow. The main conclusions for the glazed samples are:

- Of the glazes investigated, sodium silicate glaze and a low-alkali borosilicate glaze adhered well to the CRB and produced a continuous layer when heated to $1100^{\circ} \mathrm{C}$. These glazes where selected for further testing.

- Suspended refractory rod tests and tests with simulated condensate indicated that the selected glazes can provide partial protection to the CRB from vapor penetration but not from vapor deposition. The glazes slow down molten salt penetration; the borosilicate melt tended to keep the deposited Re salt on the CRB surface in a soluble form.

- The immersed refractory rod tests showed that the glazes did little to reduce the penetration of molten salt below the melt line.

- Gas permeation tests indicated that the glazes resulted in a minor reduction in the gas permeability relative to the baseline $\mathrm{CRB}$ heat-treated to $1050^{\circ} \mathrm{C}$. However, the firing process necessary to form the glaze on the surface would result in a CRB that has much higher permeability than the baseline CRB before heat-treatment, so the net effect on gas permeability during the BV process is not known.

Several refractory tile candidates were screened to determine if they could be applied to the interior of the CRB to potentially reduce the transport of Tc/Re into the refractory. Manufacturing demonstration tests were used to select potential candidates. Suspended rod tests, simulant penetration tests, and refractory corrosion tests were conduced to determine the potential benefits of refractory tiles. Gas permeability tests were also carried out to obtain a quantitative measure of the selected tile's resistance to flow. The main conclusions for the tile samples are: 
- Several tile candidates were tested, but only greystone and AZS remained intact and well bonded after firing to $1000^{\circ} \mathrm{C}$. A net thermal expansion of $2.2 \%$ during firing of the greystone tile caused deformation of the refractory/tile composite. This deformation was avoided by prefiring the greystone tile to $800^{\circ} \mathrm{C}$.

- Half sections of ES CRBs were successfully fabricated with the greystone tiles. Tiles of AZS could not be cut from the bricks available at the time of testing, but AZS tiles that are $25 \mathrm{~mm}$ thick were subsequently identified and should be considered for future CRB lining tests.

- Limited suspended rod tests were conducted with dense tiles. These tests showed that condensed vapors did not penetrate into the dense tiles, and Re salts tended to condense on the surface of the tiles.

- Simulant condensate penetration tests with the greystone tile showed that there was no penetration of the condensate material through the tile.

- The gas permeability of the greystone tiles appeared to increase after heat-treating to $600^{\circ} \mathrm{C}$ but was still several orders below the permeability of the baseline Vibrocast 60PC. The AZS was not tested but, based on its density and microstructure, is expected to have low permeability.

- Refractory corrosion tests that exposed greystone tiles to melt temperatures of $1350^{\circ} \mathrm{C}$ for 22 hours indicate that a 0.25-in.-thick greystone tile would not corrode all the way through during a BV melt.

- Tiles appear to be promising protection method for the CRB and can reduce both vapor penetration and molten salt penetration. However, vapor deposition on the CRB surface above the melt line will occur even with tiles. Greystone tiles were effective, but the AZS tiles that were identified after the testing phase of this study was completed should be examined further.

Extrapolating the results available from this and other laboratory and ES tests leads to a plausible conceptual model for Tc/Re transport into the CRB during the BV process. In the BV process, especially during startup, the feed/glass refractory interface is exposed to a moving temperature gradient that starts at ambient and proceeds to $1200^{\circ} \mathrm{C}$ or greater. Considering the evolution of the temperature field within the CRB, the Tc/Re transport scenario can be outlined as proceeding in the following stages:

- The first step in the melting process is the formation of a molten ionic salt (MIS) in the feed that includes all the Tc/Re within the porosity of the soil and other insoluble grains. This MIS penetrates the CRB open porosity as the interface temperature increases to approximately $700^{\circ} \mathrm{C}$ along with its highly concentrated Tc/Re.

- At approximately $750^{\circ} \mathrm{C}$, the MIS partially decomposes through the loss of $\mathrm{NO}_{\mathrm{x}}$, leaving mainly sulfate and chloride salts. The $\mathrm{Na}_{2} \mathrm{O}$ formed in the decomposition of the nitrates starts to react with insoluble grains in the feed (soil and $\mathrm{ZrO}_{2}$ ), and, to some extent, with the aluminosilicates in the CRB to form viscous liquids that reduce further liquid penetration into the CRB.

- At 800 to $1000^{\circ} \mathrm{C}$, a continuous glass phase starts to form that traps the remains of the MIS in inclusions in the glass.

- At 1000 to $1200^{\circ} \mathrm{C}$, the salt inclusions in the glass slowly dissolve as they rise to the surface. The salt inclusions in the CRB continue to react and form glassy phases that may incorporate some of the Tc/Re but also evaporate and condense in colder portions of the porous CRB, distributing Tc/Re as they condense.

- At 1200 to $1400^{\circ} \mathrm{C}$, the sulfate/chloride MIS reaches the surface of the glass melt and volatilizes. The vapors condense on cooler surfaces in the upper portion of the CRB, the box lid, and the off-gas system. The condensate from the sulfate/chloride MIS will readily penetrate the CRB and deposit 
$\mathrm{Tc} / \mathrm{Re}$ in the upper portions. Without the $\mathrm{Na}_{2} \mathrm{O}$ from the nitrate decomposition and the higher temperatures seen in the lower sections of the box, the Tc/Re deposits in the upper region of the CRB are not incorporated in refractory phase and remain in a leachable form.

- At elevated temperatures, probably above $1200^{\circ} \mathrm{C}$, residual graphite flakes from the starter path react with iron oxides ( $\mathrm{FeO}$ and $\mathrm{Fe}_{2} \mathrm{O}_{3}$ ), reducing them to metallic $\mathrm{Fe}$. A fraction of Tc is also reduced to metal and alloys with Fe. Droplets of molten metal partly remain dispersed in the glass and partly are deposited on the bottom, where they may drill into CRB or form flat ingots.

\section{Path Forward}

The conceptual model of the mechanism of leachable Tc salt deposition in the bulk vitrification process is based on direct and indirect evidence from past studies. Additional testing is needed to fill the gaps in the model, to decrease uncertainty in data and measurements that were predominantly proof-of-principle testing, and to obtain missing data.

- A study is needed to obtain the rate and extent of MIS penetration from the feed into the CRB, both under isothermal conditions and into the CRB with a temperature gradient. The MIS penetration rate and extent, measured with respect to the depth of penetration and the degree of pore filling, can be measured with the submerged rod testing at $T<750{ }^{\circ} \mathrm{C}$. Only very limited data are available for the distribution of MIS components in the CRB from ES testing. The scoping tests that have been performed so far need an improved methodology of dry CRB thin sectioning to be applied to a number of samples selected to represent various positions within the CRB of ES tests.

- The atomic ratios of Re to S and Re to Na, both with the CRB and segregated MIS, should be measured by EDS and chemical analyses on samples taken at various temperatures. If only Re concentration data are available, no conclusions can be made regarding the mode of transport.

- Direct measurements are missing regarding the kinetics of the nitrate decomposition and its reaction with feed refractory components and with the CRB. ${ }^{(a)}$ These data can be obtained from combining several techniques, such as evolved gas analysis (EGA), XRD, and SEM-EDS. Attention needs to be paid to chloride and sulfate behavior during these reactions. Direct evidence is also needed to document the formation of intergranular crystalline and amorphous phases within the CRB as functions of temperature, the volume fraction of MIS in the CRB, the volume reduction to MIS as $\mathrm{NO}_{3}$ decomposes, and the viscosity of amorphous phase in the CRB.

- Particular attention needs to be paid to Tc/Re volatilization and incorporation into the glassy phase in bulk melt and the CRB. Additional data need to be obtained from the cold finger test (CFT) with ground glass quenched at $800^{\circ} \mathrm{C}$ and from pre-melted glass held at $1000^{\circ} \mathrm{C}$ and $1100^{\circ} \mathrm{C}$ to evaluate Tc/Re evolution and condensation.

- The effect of the starting path residue of the formation of metallic inclusions has never been investigated. Data are needed to relate the metal deposition on the BV box bottom and its effect on the CRB to the processing conditions.

(a) Nitrate reactions in commercial batches were studied by Thomason and Wilburn (1960), and Abe et al. (1983), and in HLW melter feeds by Smith et al. (1995), Hrma et al. (2002), Matyas et al. (2004), and Kim et al. (2005). However, the LAW in the BV feed and in the CRB presents a mixture of nitrates reacting with components never covered before in the literature. Therefore, a study of the MIS reactions and $\mathrm{NO}_{\mathrm{x}}$ evolution in the specific $\mathrm{BV}$ environment is desirable. 


\subsection{References}

Abe O, T Utsunomiya, and Y Hoshino. 1983. The Reaction of Sodium Nitrate with Silica.” Bulletin of the Chemical Society of Japan 56, 249-433.

Darab JG, and PA Smith. 1996. “Chemistry of Technetium and Rhenium Species during Low-Level Radioactive Waste Vitrification.” Chem. Mater. 8:1004-1021.

Gibson JK. 1993a. "High Temperature Oxide and Hydroxide Vapor Species of Technetium.” Radochim Acta 60:121-126.

Gibson JK. 1993b. "Mass Spectrometric Identification of Potassium and Cesium Pertecnetates and Bimetallic Technetium-Rhenium Oxide Dimers.” Radiochim. Acta 62, 127-132.

Hrma P, J Matyáš, and DS Kim. 2002 “The Chemistry and Physics of Melter Cold Cap,”

$9^{\text {th }}$ Biennial Int. Conf. On Nucl. And Hazardous Waste Management, Spectrum '02, American Nuclear Society, CD-ROM.

Hrma, P. R., D. M. Strachan, D. S. Kim, M. J. Schweiger, J. V. Crum, R. W. Shimskey, G. J. Sevigny, E. M. Pierce, and M. L. Elliott. 2005. Analyses of Products from Bulk Vitrification Engineering-Scale Tests 31A, 31B, and 32A. Pacific Northwest Laboratory, Richland, WA (draft report).

Kim DS, JD Vienna, PR Hrma, MJ Schweiger, J Matyas, JV Crum, DE Smith, GJ Sevigny, WC Buchmiller, JS Tixier, VJ Yeager, and KB Belew. 2003. Development and Testing of ICV Glasses for Hanford LAW. PNNL-14351, Pacific Northwest National Laboratory, Richland, WA.

Kim D-S, CZ Soderquist, JP Icenhower, BP McGrail, RD Scheele, BK McNamara, LM Bagaasen, MJ Schweiger, JV Crum, JD Yeager, J Matyáš, LP Darnell, HT Schaef, AT Owen, AE Kozelisky, LA Snow, and MJ Steele. 2005. Tc Reductant Chemistry and Crucible Melting Studies with Simulated Hanford Low-Activity Waste. Pacific Northwest National Laboratory, Richland, WA (draft report).

Luey J, and DK Seiler. 1995. Application of In Situ Vitrification in the Soil Subsurface: EngineeringScale Testing. PNL-10485, Pacific Northwest Laboratory, Richland, WA.

Mann FM, BP McGrail, DH Bacon, RJ Serne, KM Krupka, RJ Puigh, R Khaleel, and S Finfock. 2003. Risk Assessment Supporting the Decision on the Initial Selection of Supplemental ILAW Technologies. RPP-17675, Rev. 0, CH2MHILL Hanford Group Inc., Richland, WA.

Matyáš J, P Hrma, and DS Kim. 2004. “Analysis of Feed Melting Processes,” Ceramic Transactions 155, 69-78.

McGrail, BP, EM Pierce, HT Schaef, EA Rodriguez, JL Steele, AT Owen, and DW Wellman. 2003. Laboratory Testing of Bulk Vitrified and Steam-Reformed Low-Activity Waste Forms to Support a Preliminary Resk Assessment for an Integrated Disposal Facility. PNNL-15126, Pacific Northwest National Laboratory, Richland, WA.

Pierce EM, BP McGrail, LM Bagaasen, DW Wellman, JV Crum, KN Geiszler, and SR Baum. 2004. Progress Report on the Laboratory Testing of Bulk Vitrification Cast Refractory. PNNL-14935, Pacific Northwest National Laboratory, Richland, WA. 
Pierce EM, BP McGrail, LM Bagaasen, EA Rodriguez, DW Wellman, KN Geiszler, SR Baum, LR Reed, JV Crum, and HT Schaef. 2005. Laboratory Testing of Bulk Vitrified Low-Activity Waste Forms to Support the 2005 Integrated Disposal Facility Performance Assessment. PNNL-15126, Pacific Northwest National Laboratory, Richland, WA.

Raymond RE, RW Powell, DW Hamilton, WA Kitchen, BM Mauss, and TM Brouns. 2004. "Initial Selection of Supplemental Treatment Technologies for Hanford's Low-Activity Tank Waste.” In: Proceedings of WM'04 Symposia. WM-4524/RPP-19763-FP, CH2M HILL Hanford Group, Inc. Richland, WA.

Sederburg P, and L Thompson. 2004. Quantitative Engineering Scale Testing Plan. 17902-ES-RT1, Rev.1, AMEC Earth and Environmental, Inc. GeoMelt Division, Richland, WA.

Smith PA, JD Vienna, and P Hrma. 1995. “The Effect of Melting Reactions on Laboratory-Scale Waste Vitrification,” Journal of Materials Research 10 2137-2149.

Thomason CV, and FW Wilburn. 1960. “The Application of Differential Thermal Analysis and Thermogravimetric Analysis to the Study of Reactions between Glass Materials: Part 2. Sodium Carbonate System with Minor Batch Additions.” Physics and Chemistry of Glasses 1 52-69.

Tixier JS, JA Stottlemyre, and MT Murphy. 1991. “Vitrified Underground Barriers.” Waste Management 91:603-611.

Trier W. 1987. Glass Furnace. Society of Glass Technology, Sheffield, England.

Vangpaisal T, and A Bouazza. 2004. "Gas Permeability of Partially Hydrated Geosynthetic Clay Liners.” J. of Geotechnical and Geoenvironmental Eng. 130(1):93-102 
Appendix A

Suspended Refractory Rod Test Results 


\section{Appendix A: Suspended Refractory Rod Test Results}

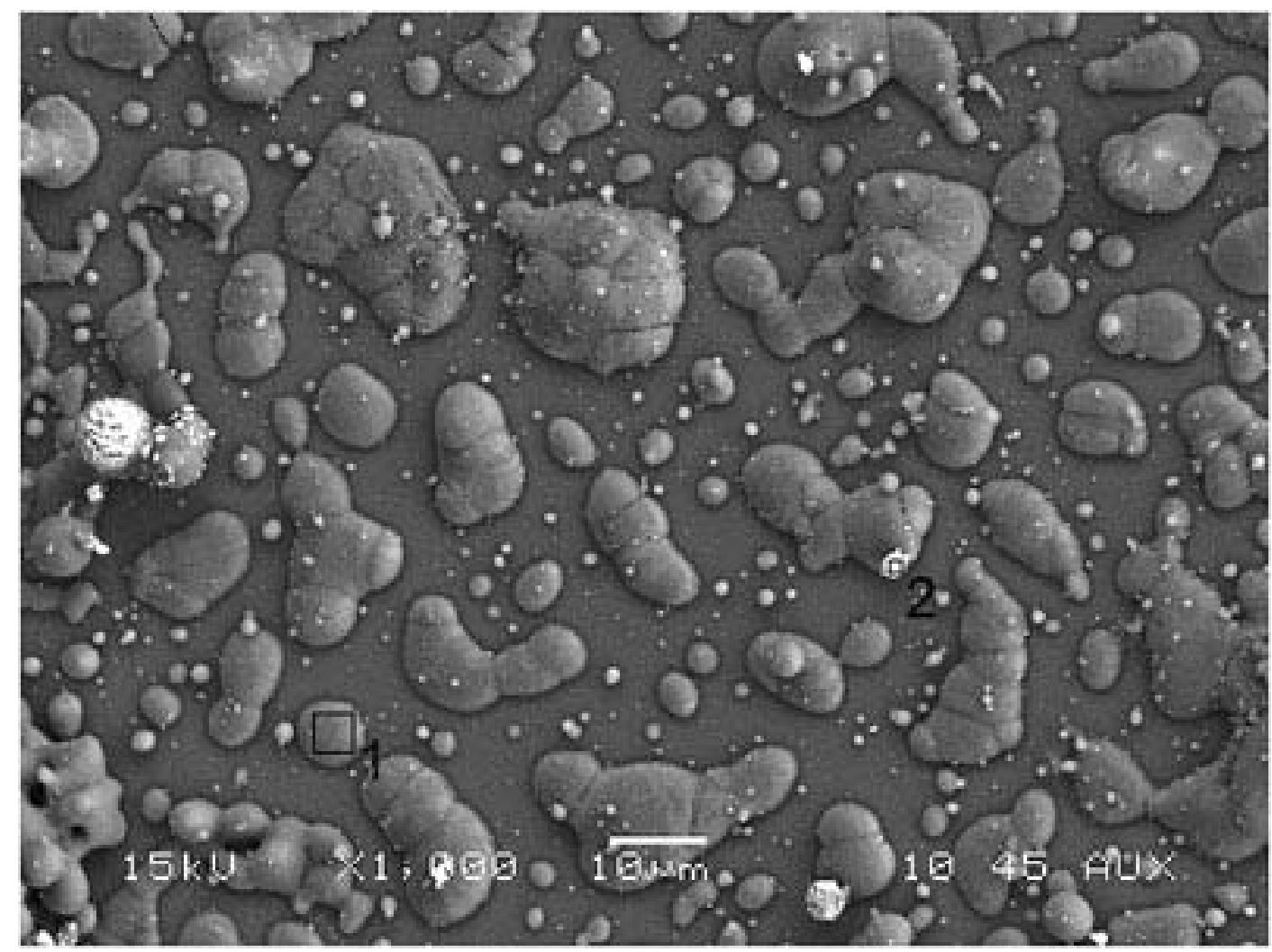

Figure A.1. SEM Micrograph of Condensate Deposit on Fused Silica Glass Wall Tube at $426^{\circ} \mathrm{C}$ (AMEC feed heat-treated at $5^{\circ} \mathrm{C} / \mathrm{min}$ and held at $1350^{\circ} \mathrm{C}$ for 2 hours) 


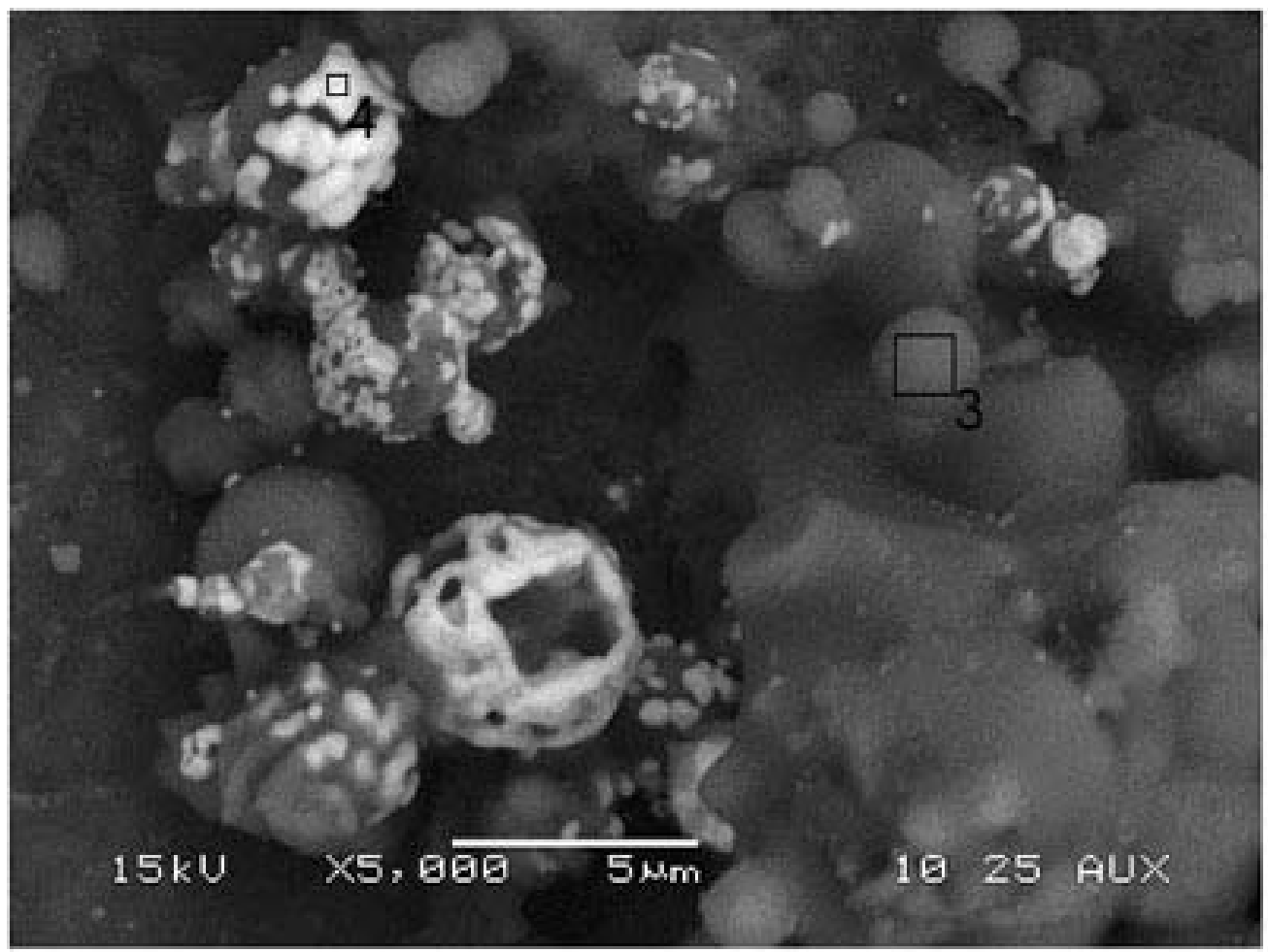

Figure A.2. SEM Micrograph of Condensate Deposit on Fused Silica Glass Wall Tube at $426^{\circ} \mathrm{C}$ (AMEC feed heat-treated at $5^{\circ} \mathrm{C} / \mathrm{min}$ and held at $1350^{\circ} \mathrm{C}$ for 2 hours)

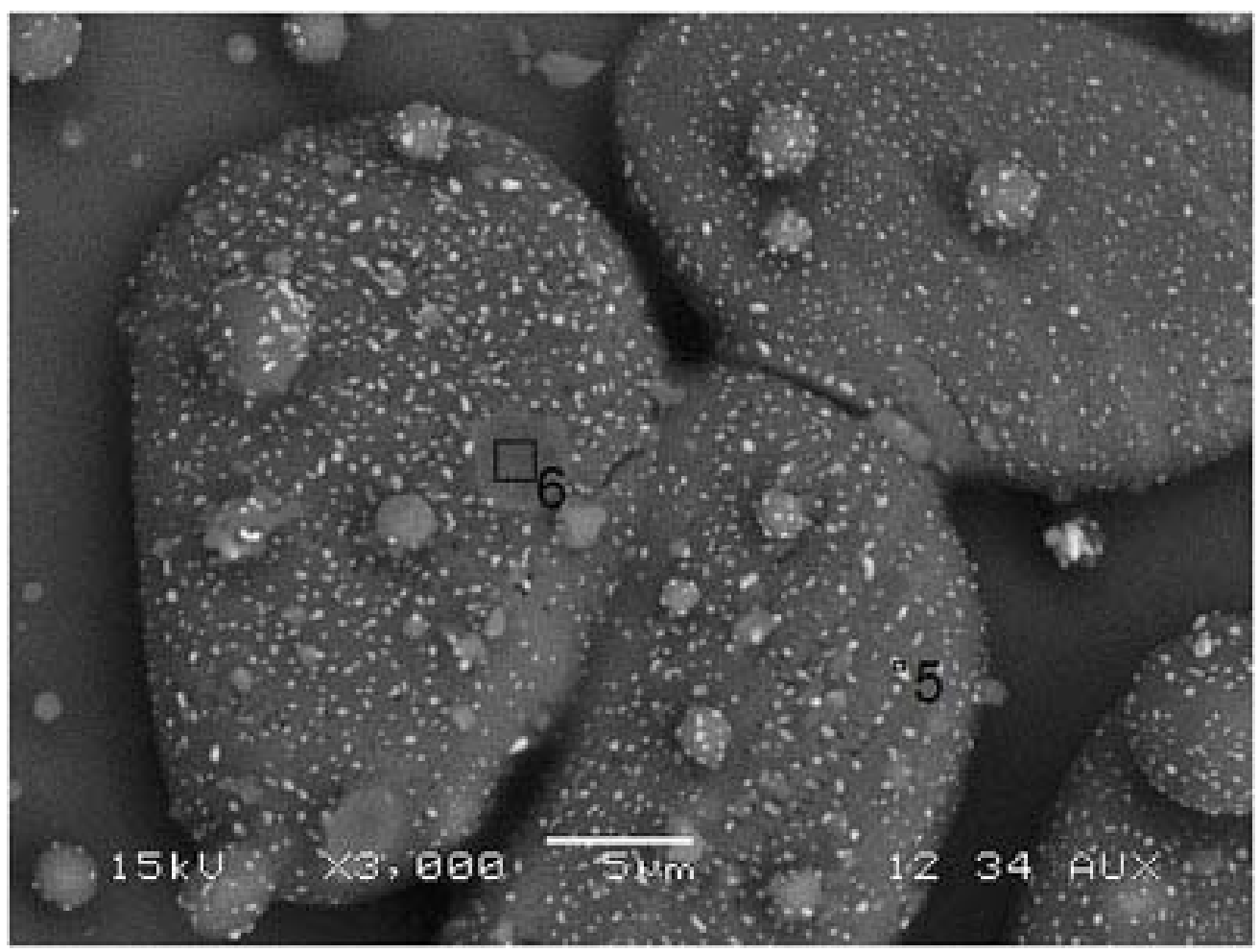

Figure A.3. SEM Micrograph of Condensate Deposit on Fused Silica Glass Wall Tube at $502^{\circ} \mathrm{C}$ (AMEC feed heat-treated at $5^{\circ} \mathrm{C} / \mathrm{min}$ and held at $1350^{\circ} \mathrm{C}$ for 2 hours) 
Table A.1. Composition of Areas 1-6 in Figures A.1 through A.3 (AMEC Feed Heat-Treated at $5^{\circ} \mathrm{C} / \mathrm{min}$ and Held at $1350^{\circ} \mathrm{C}$ for 2 hours)

\begin{tabular}{||l|r|r|r|r|r|r||}
\hline \multirow{2}{*}{ Element } & \multicolumn{1}{|c|}{$\mathbf{1}$} & $\mathbf{2}$ & $\mathbf{3}$ & $\mathbf{4}$ & $\mathbf{5}$ & $\mathbf{6}$ \\
\cline { 2 - 8 } Atomic\% \\
\hline $\mathrm{O}$ & 42.11 & 36.41 & 24.17 & 40.87 & 20.61 & 29.97 \\
\hline $\mathrm{Na}$ & 5.02 & 17.93 & 15.93 & 19.74 & 17.21 & 29.37 \\
\hline $\mathrm{Si}$ & 47.63 & & 36.05 & & & \\
\hline $\mathrm{S}$ & 4.23 & 6.23 & 16.75 & 15.10 & 45.60 & 33.12 \\
\hline $\mathrm{K}$ & & 6.24 & 2.21 & & & \\
\hline $\mathrm{Cr}$ & 1.01 & 10.99 & 4.24 & 9.00 & 12.19 & 7.54 \\
\hline $\mathrm{Re}$ & & & 0.65 & & & \\
\hline
\end{tabular}

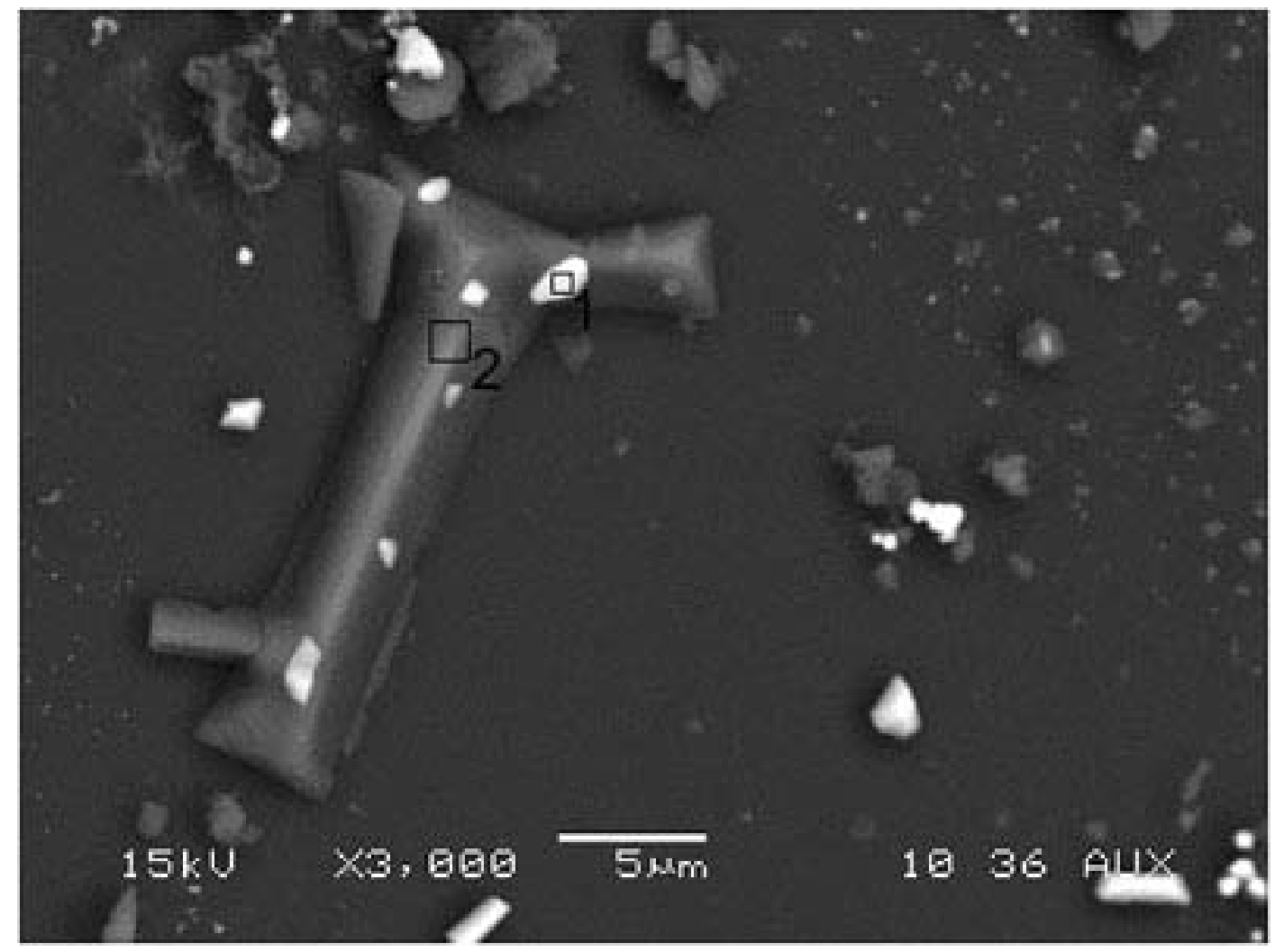

Figure A.4. SEM Micrograph of Condensate Deposit on Fused Silica Glass Wall Tube at $235^{\circ} \mathrm{C}$ (AMEC feed heat-treated at $5^{\circ} \mathrm{C} / \mathrm{min}$ and held at $1000^{\circ} \mathrm{C}$ for 2 hours) 


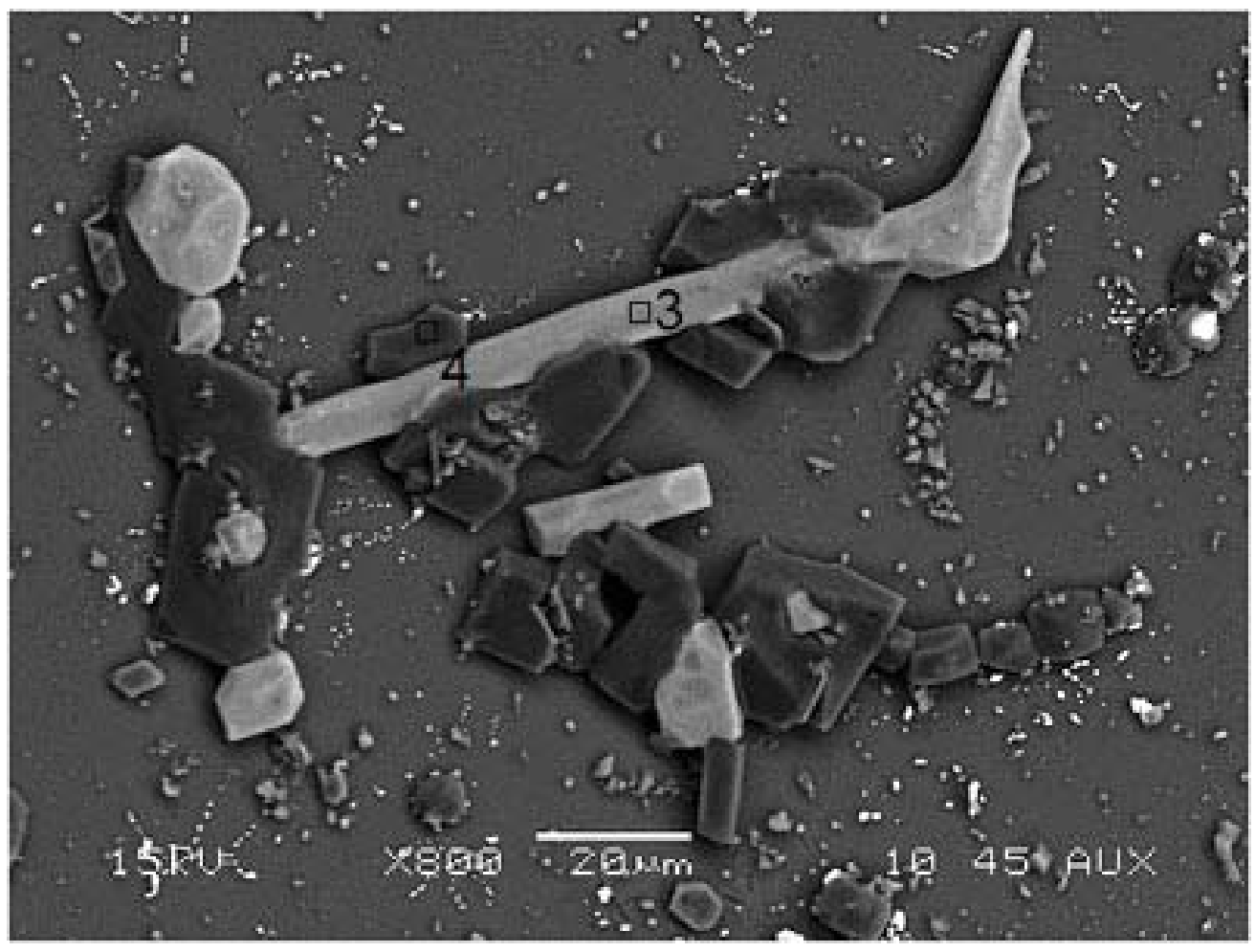

Figure A.5. SEM Micrograph of Condensate Deposit on Fused Silica Glass Wall Tube at $316^{\circ} \mathrm{C}$ (AMEC feed heat-treated at $5^{\circ} \mathrm{C} / \mathrm{min}$ and held at $1000^{\circ} \mathrm{C}$ for 2 hours)

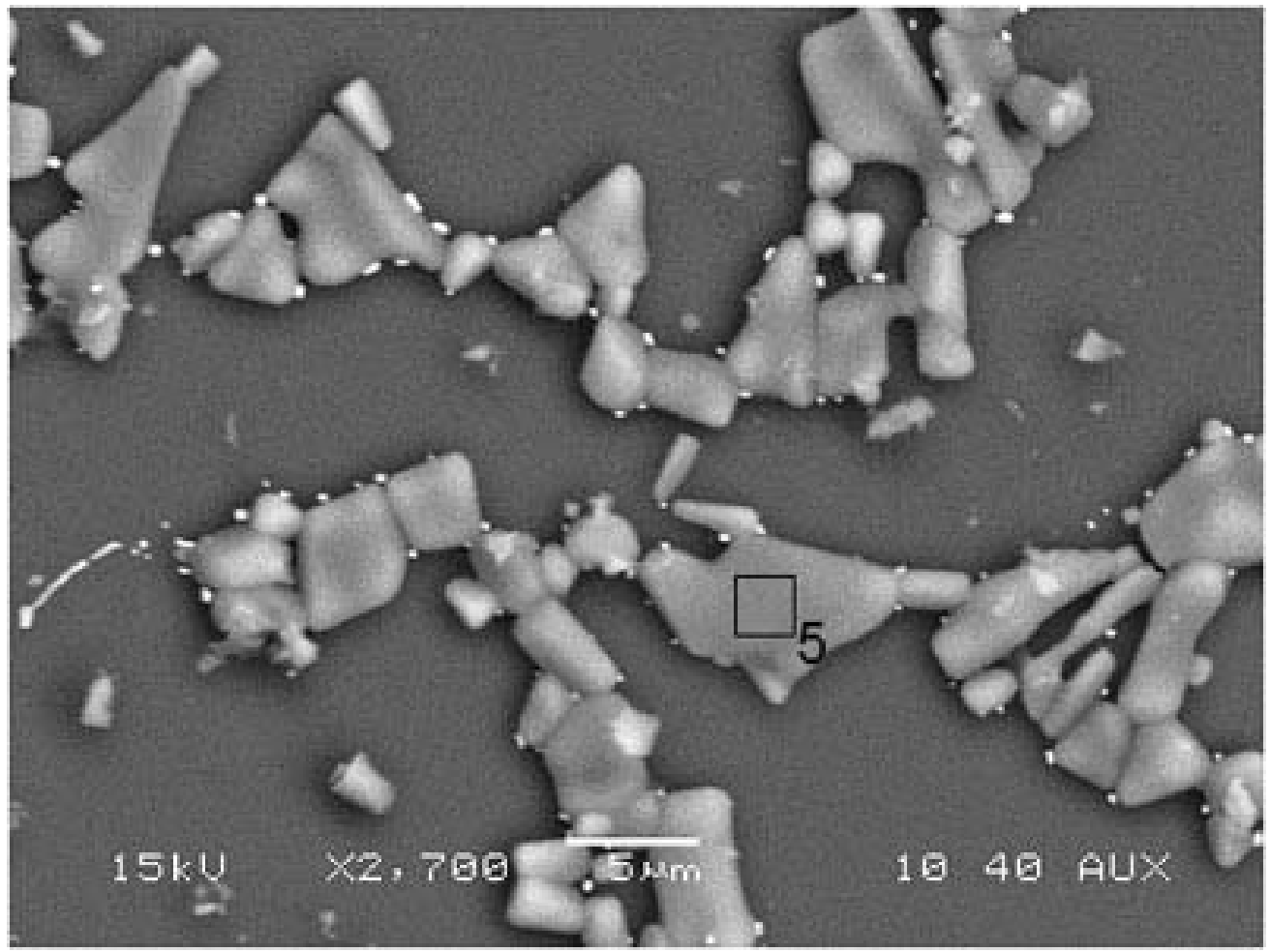

Figure A.6. SEM Micrograph of Condensate Deposit on Fused Silica Glass Wall Tube at $362^{\circ} \mathrm{C}$ (AMEC feed heat-treated at $5^{\circ} \mathrm{C} / \mathrm{min}$ and held at $1000^{\circ} \mathrm{C}$ for 2 hours) 


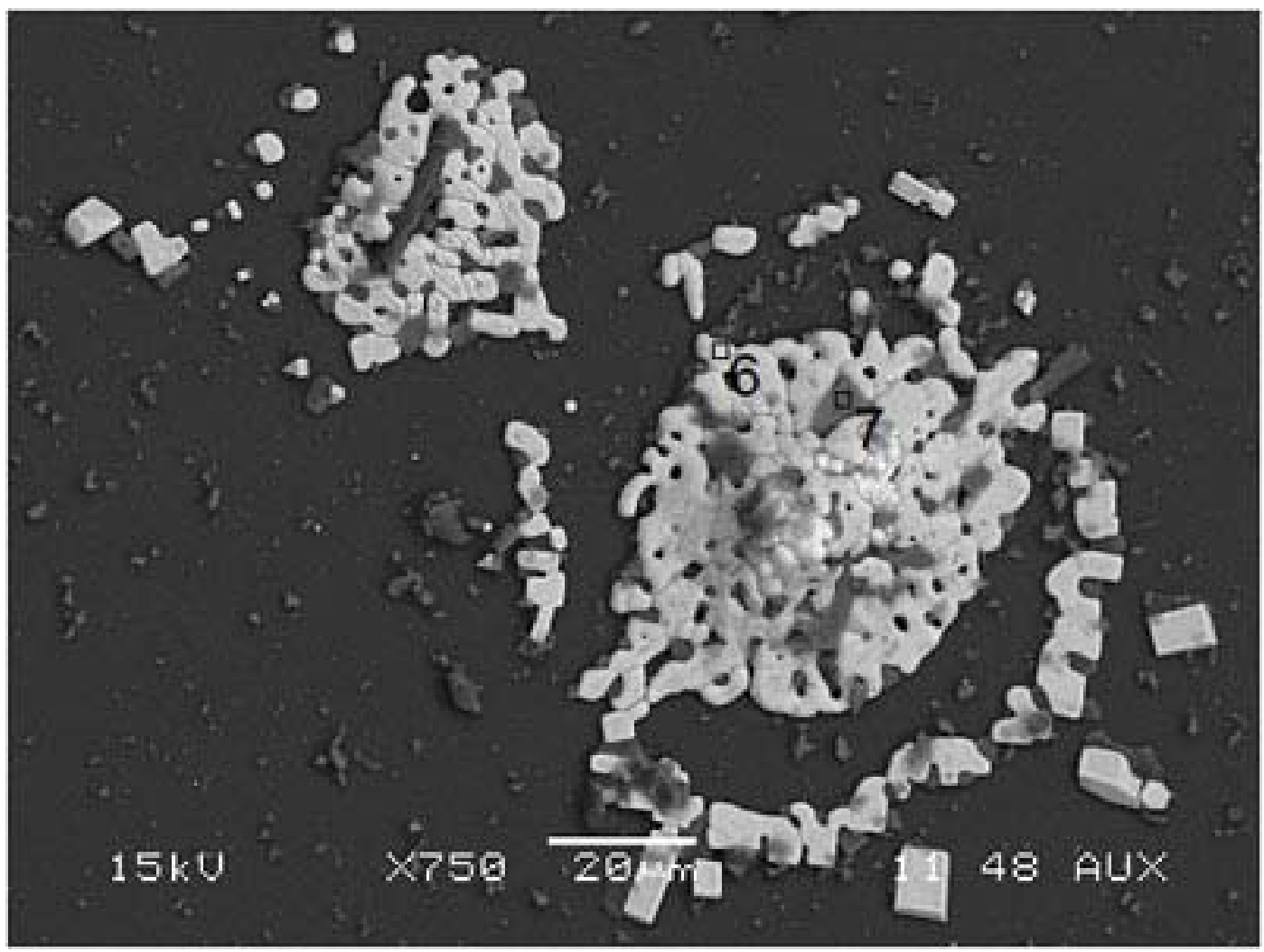

Figure A.7. SEM Micrograph of Condensate Deposit on Fused Silica Glass Wall Tube at $467^{\circ} \mathrm{C}$ (AMEC feed heat-treated at $5^{\circ} \mathrm{C} / \mathrm{min}$ and held at $1000^{\circ} \mathrm{C}$ for 2 hours)

Table A.2. Composition of Areas 1-7 in Figures A.4 through A.7 (AMEC feed heat-treated at $5^{\circ} \mathrm{C} / \mathrm{min}$ and held at $1000^{\circ} \mathrm{C}$ for 2 hours)

\begin{tabular}{||l|r|r|r|r|r|r|r||}
\hline \multirow{2}{*}{ Element } & $\mathbf{1}$ & $\mathbf{2}$ & \multicolumn{1}{|c|}{$\mathbf{3}$} & $\mathbf{4}$ & $\mathbf{5}$ & $\mathbf{6}$ & $\mathbf{7}$ \\
\cline { 2 - 9 } & \multicolumn{7}{|c|}{ Atomic\% } \\
\hline $\mathrm{O}$ & 40.60 & 1.61 & 10.32 & 9.02 & 14.92 & 31.77 & 11.10 \\
\hline $\mathrm{F}$ & & & 1.38 & & & & \\
\hline $\mathrm{Na}$ & 2.26 & 42.38 & 40.93 & 36.06 & 21.73 & 8.05 & 20.80 \\
\hline $\mathrm{Si}$ & & 0.95 & 0.56 & 10.02 & 35.50 & & \\
\hline $\mathrm{S}$ & & & 5.46 & & & & 1.10 \\
\hline $\mathrm{Cl}$ & & 55.06 & 40.58 & 44.91 & 27.85 & 8.54 & 34.41 \\
\hline $\mathrm{K}$ & 26.24 & & 0.78 & & & 22.06 & 12.70 \\
\hline $\mathrm{Re}$ & 30.90 & & & & & 29.58 & 19.89 \\
\hline \hline
\end{tabular}




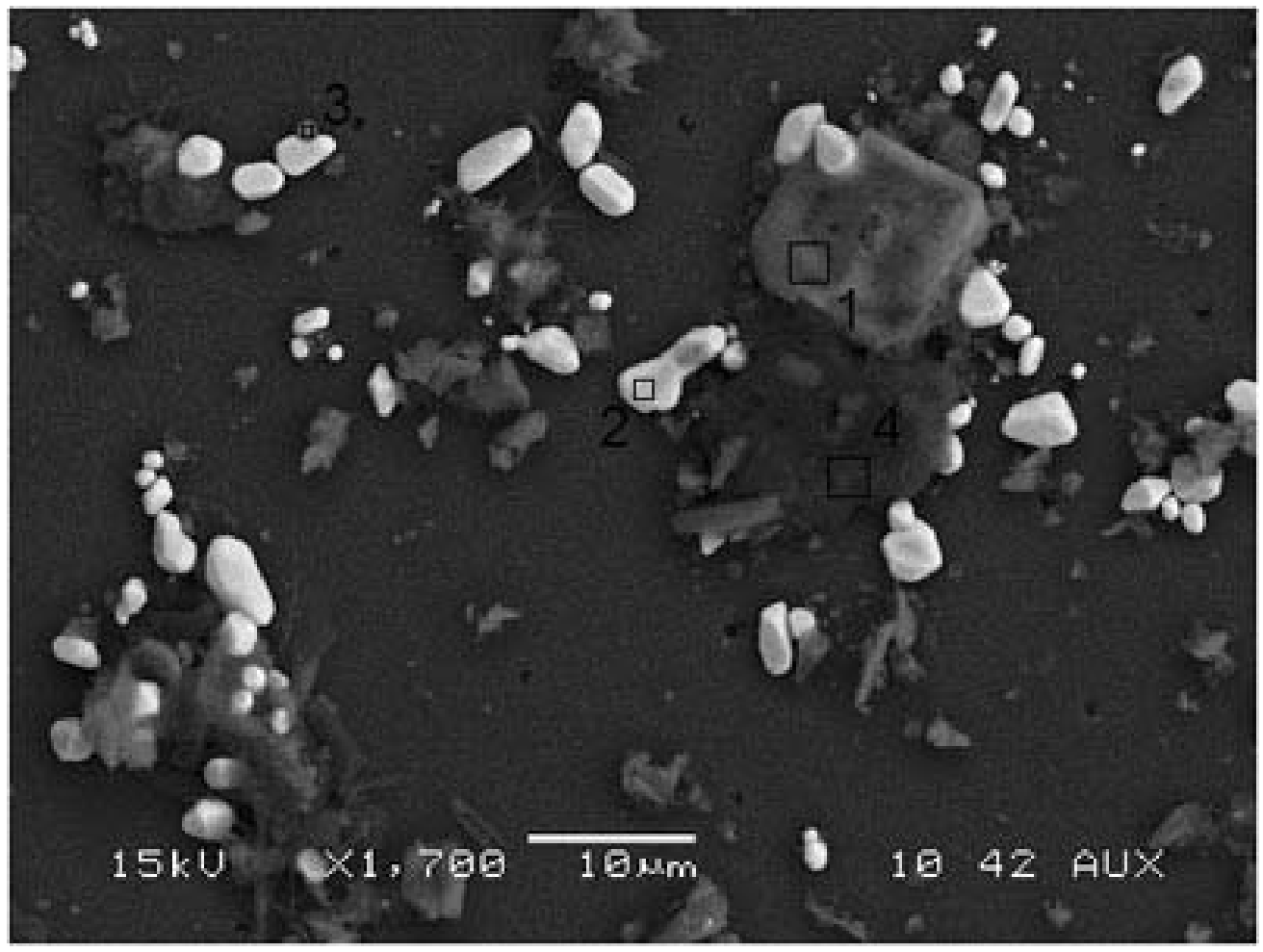

Figure A.8. SEM Micrograph of Condensate Deposit on Fused Silica Glass Wall Tube at $507^{\circ} \mathrm{C}$ (AMEC feed heat-treated at $5^{\circ} \mathrm{C} / \mathrm{min}$ and held at $800^{\circ} \mathrm{C}$ for 2 hours)

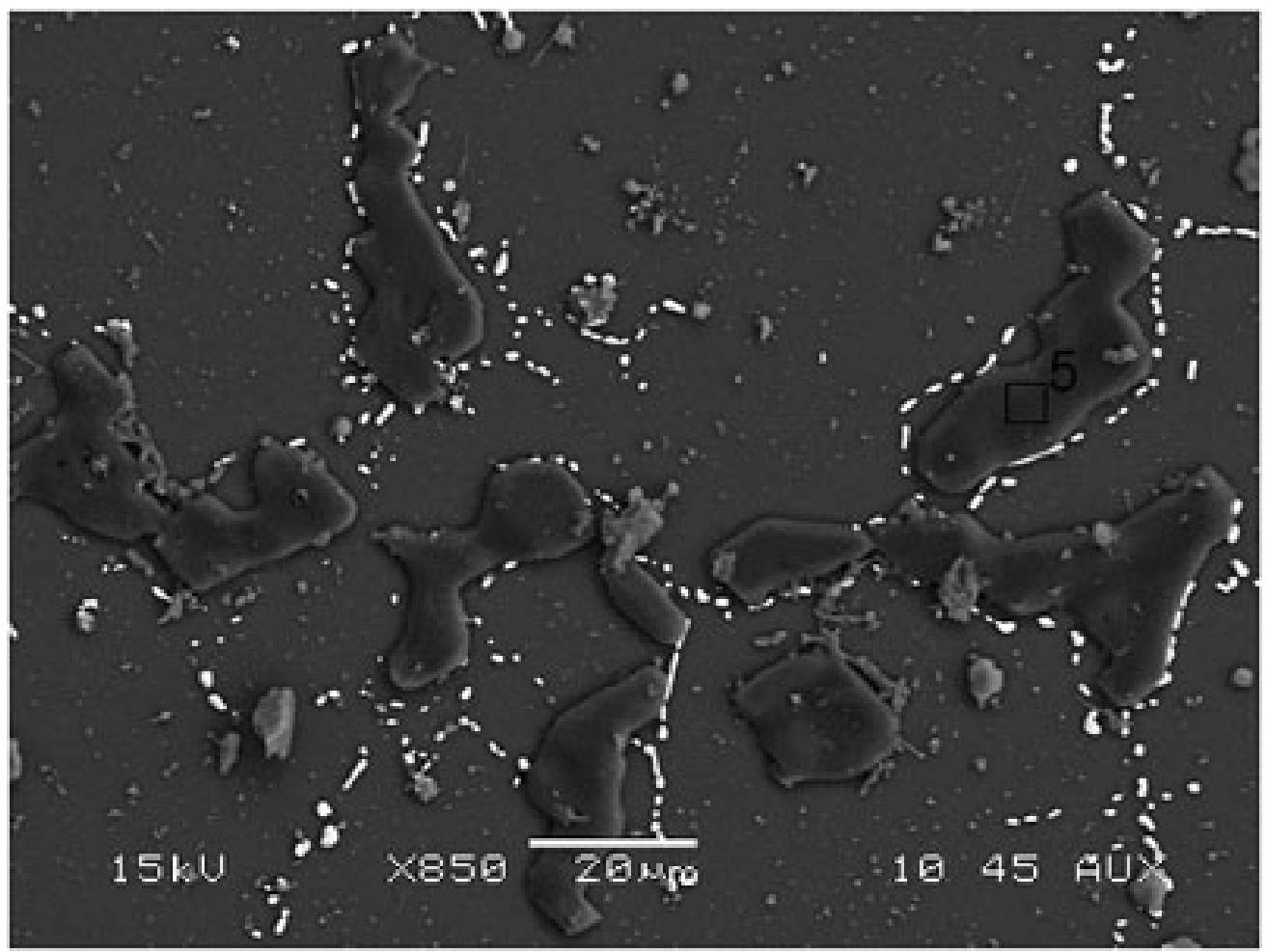

Figure A.9. SEM Micrograph of Condensate Deposit on Fused Silica Glass Wall Tube at $432^{\circ} \mathrm{C}$ (AMEC feed heat-treated at $5^{\circ} \mathrm{C} / \mathrm{min}$ and held at $800^{\circ} \mathrm{C}$ for 2 hours) 
Table A.3. Composition of Areas 1-5 in Figures A.8 and A.9 (AMEC feed heat-treated at $5^{\circ} \mathrm{C} / \mathrm{min}$ and held at $800^{\circ} \mathrm{C}$ for 2 hours)

\begin{tabular}{||l|r|r|r|r|c||}
\hline \multirow{2}{*}{ Element } & \multicolumn{1}{|c|}{$\mathbf{1}$} & $\mathbf{2}$ & \multicolumn{1}{|c||}{$\mathbf{3}$} & \multicolumn{1}{c||}{$\mathbf{4}$} & $\mathbf{5}$ \\
\cline { 2 - 7 } & \multicolumn{5}{|c|}{ Atomic\% } \\
\hline $\mathrm{N}$ & & & & 2.73 & 12.00 \\
\hline $\mathrm{O}$ & 0.79 & 37.55 & 7.84 & 30.71 & 29.93 \\
\hline $\mathrm{Na}$ & 43.64 & 1.73 & 33.72 & 19.34 & 16.16 \\
\hline $\mathrm{Si}$ & 1.05 & 23.05 & 11.80 & 13.48 & 37.76 \\
\hline $\mathrm{S}$ & & & & & \\
\hline $\mathrm{Cl}$ & 54.52 & 0.41 & 46.34 & & 0.68 \\
\hline $\mathrm{K}$ & & 16.25 & 0.30 & 17.83 & 1.70 \\
\hline $\mathrm{Re}$ & & 21.01 & & 15.91 & 1.77 \\
\hline \hline
\end{tabular}

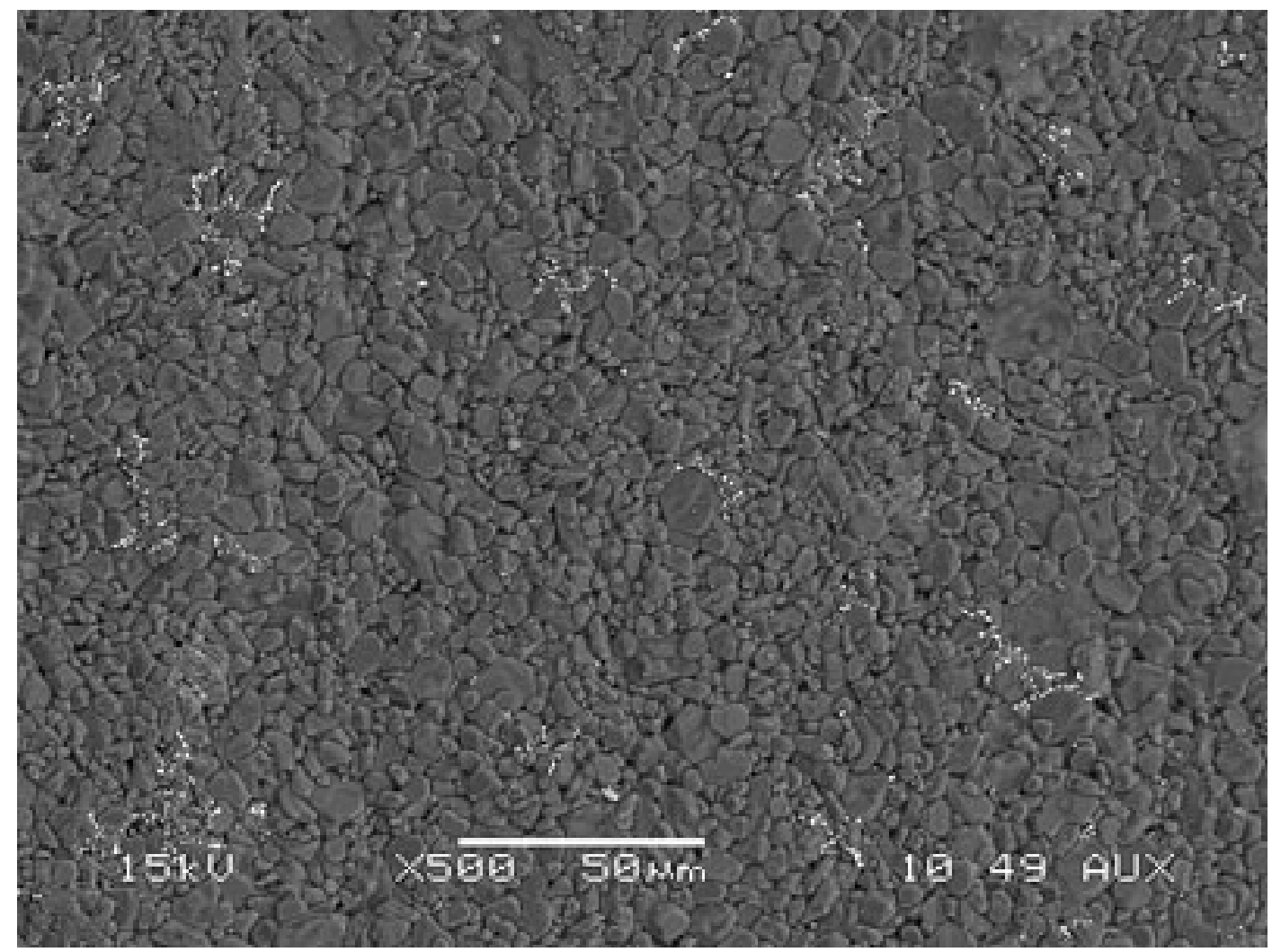

Figure A.10. SEM Micrograph of Condensate Deposit on Alumina Tile Surface at $329^{\circ} \mathrm{C}$ (AMEC feed heat-treated at $5^{\circ} \mathrm{C} / \mathrm{min}$ and held at $1000^{\circ} \mathrm{C}$ for 2 hours) 


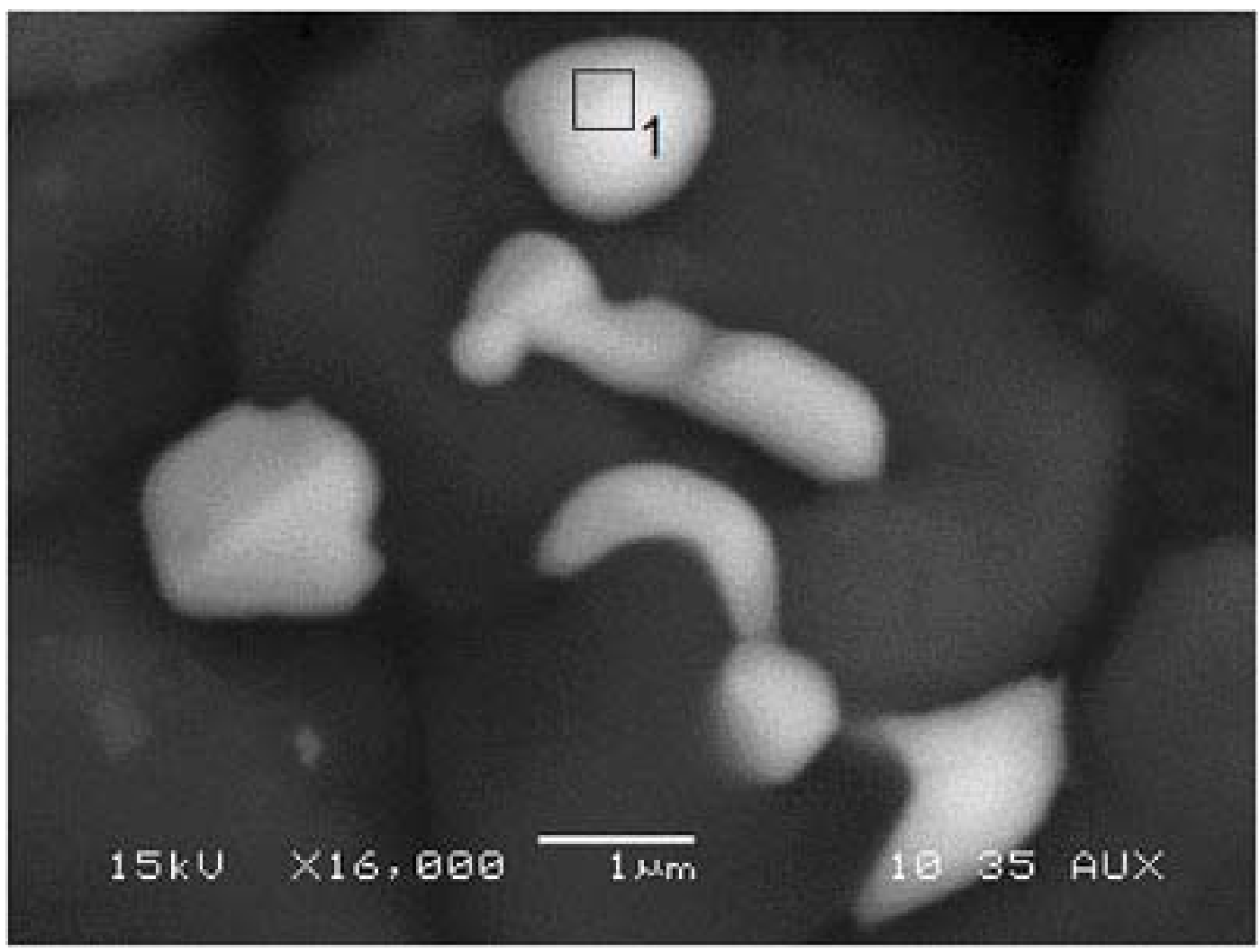

Figure A.11. SEM Micrograph of Condensate Deposit on Alumina Tile Surface at $354^{\circ} \mathrm{C}$ (AMEC feed heat-treated at $5^{\circ} \mathrm{C} / \mathrm{min}$ and held at $1000^{\circ} \mathrm{C}$ for 2 hours)

Table A.4. Composition of Area 1 in Figure A.11 (AMEC feed heat-treated at $5^{\circ} \mathrm{C} / \mathrm{min}$ and held at $1000^{\circ} \mathrm{C}$ for 2 hours)

\begin{tabular}{||l|c||}
\hline \multirow{2}{*}{ Element } & $\mathbf{1}$ \\
\cline { 2 - 2 } & Atomic\% \\
\hline $\mathrm{O}$ & 39.43 \\
\hline $\mathrm{Al}$ & 26.63 \\
\hline $\mathrm{K}$ & 12.30 \\
\hline $\mathrm{Re}$ & 21.64 \\
\hline
\end{tabular}




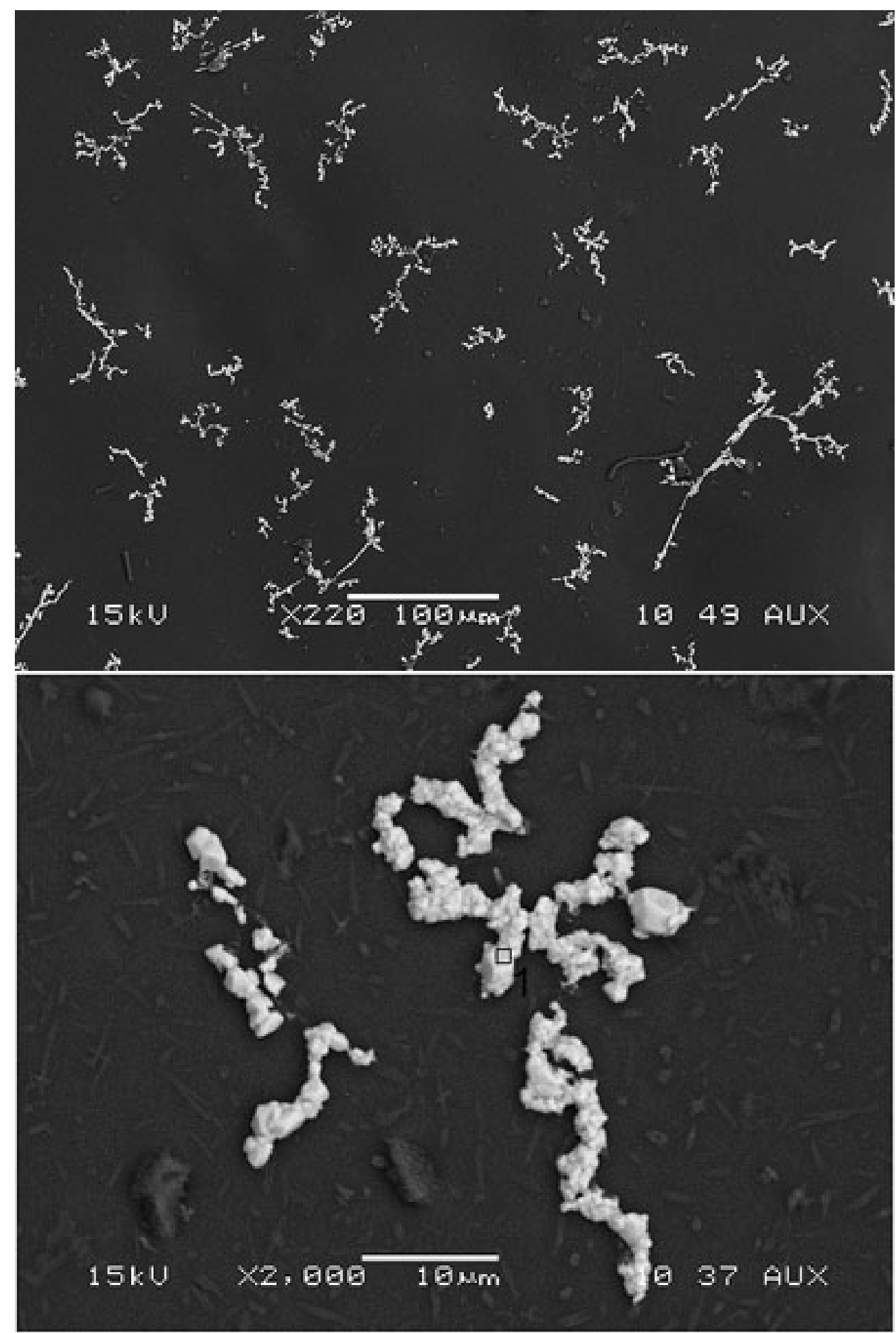

Figure A.12. SEM Micrograph of Condensate Deposit on Borosilicate Glaze Surface at $523^{\circ} \mathrm{C}$ (AMEC feed heat-treated at $5^{\circ} \mathrm{C} / \mathrm{min}$ and held at $1000^{\circ} \mathrm{C}$ for 2 hours) 


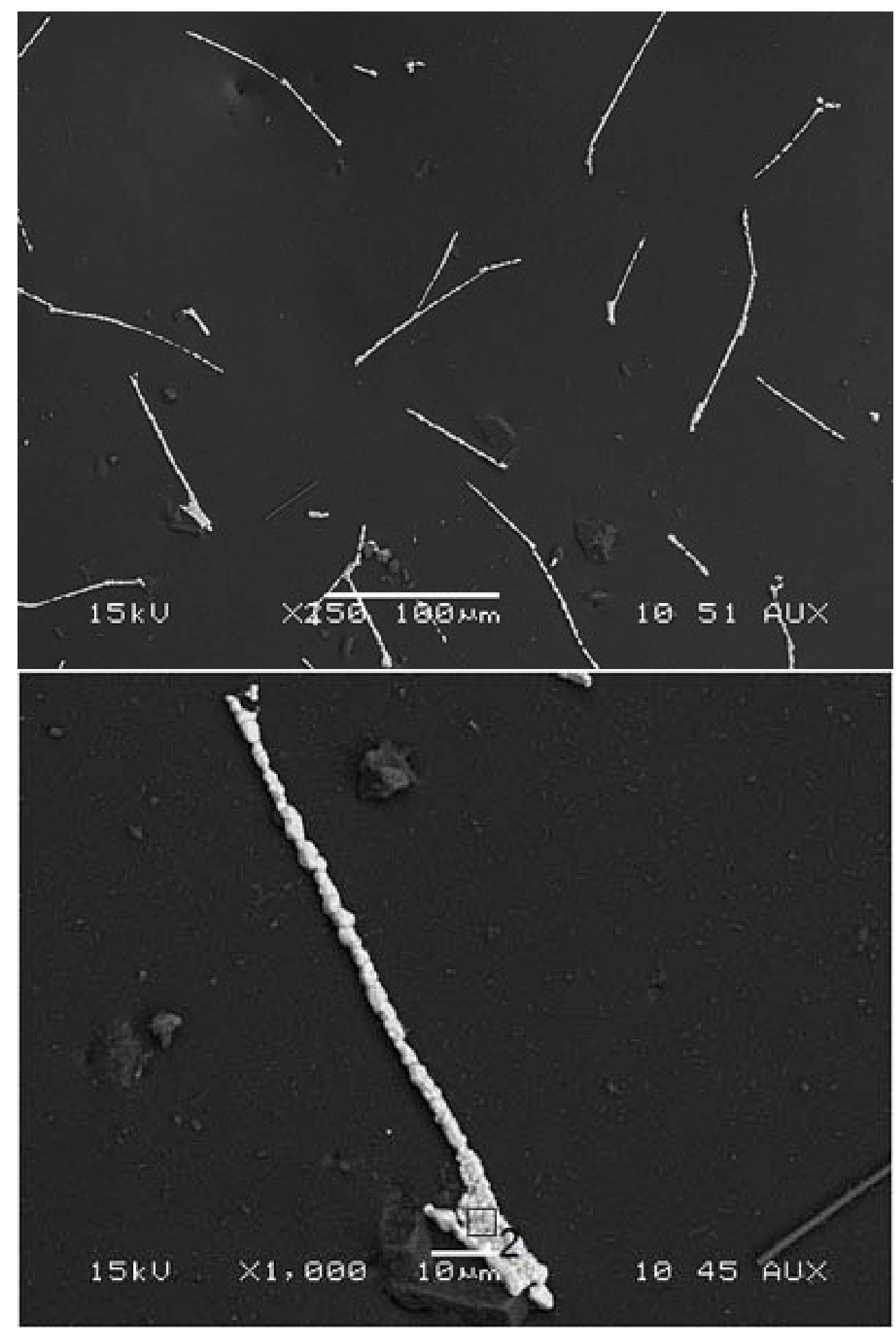

Figure A.13. SEM Micrograph of Condensate Deposit on Borosilicate Glaze Surface at $523^{\circ} \mathrm{C}$ (AMEC feed heat-treated at $5^{\circ} \mathrm{C} / \mathrm{min}$ and held at $1000^{\circ} \mathrm{C}$ for 2 hours) 


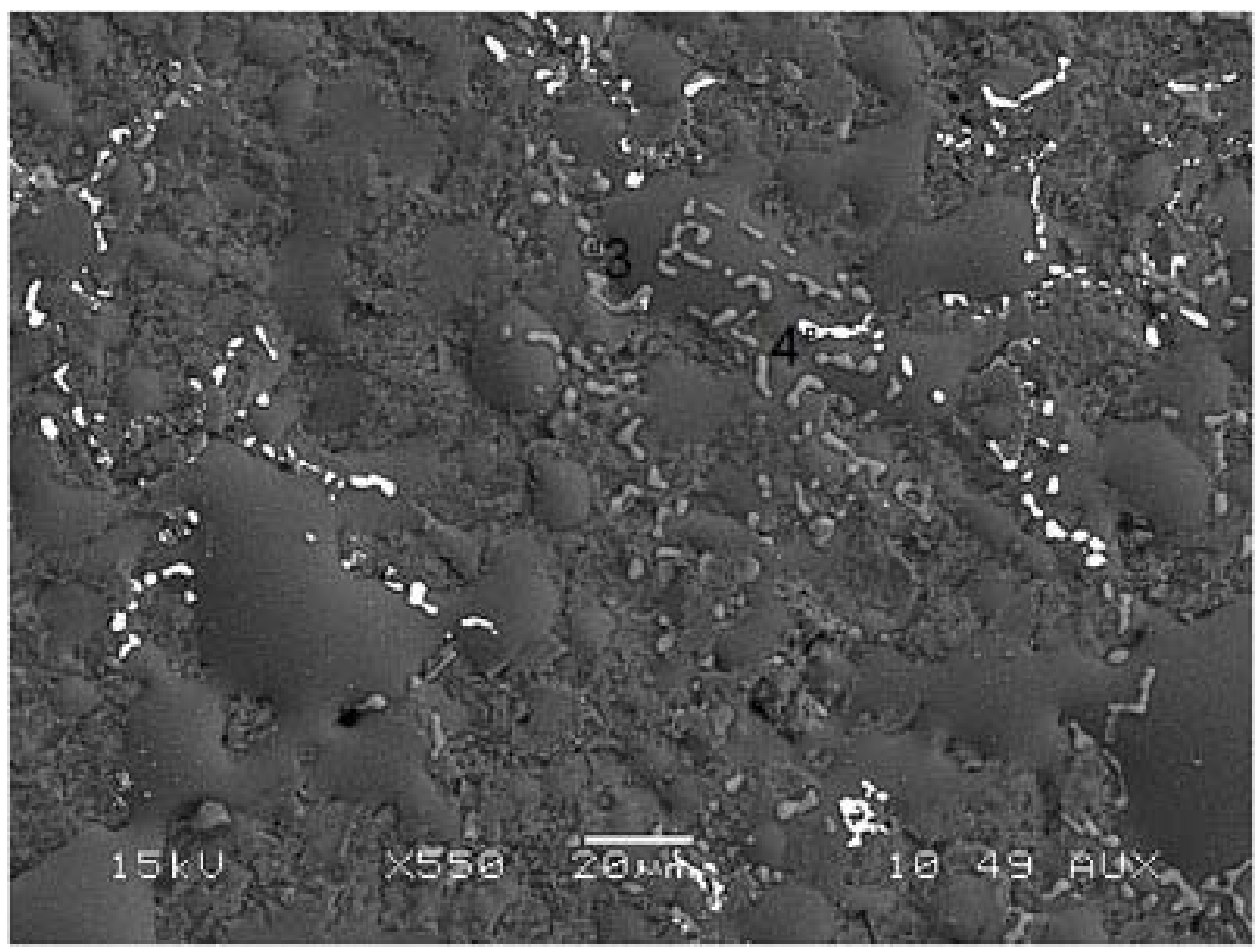

Figure A.14. SEM Micrograph of Condensate Deposit on Borosilicate Glaze Surface at $458^{\circ} \mathrm{C}$ (AMEC feed heat-treated at $5^{\circ} \mathrm{C} / \mathrm{min}$ and held at $1000^{\circ} \mathrm{C}$ for 2 hours)

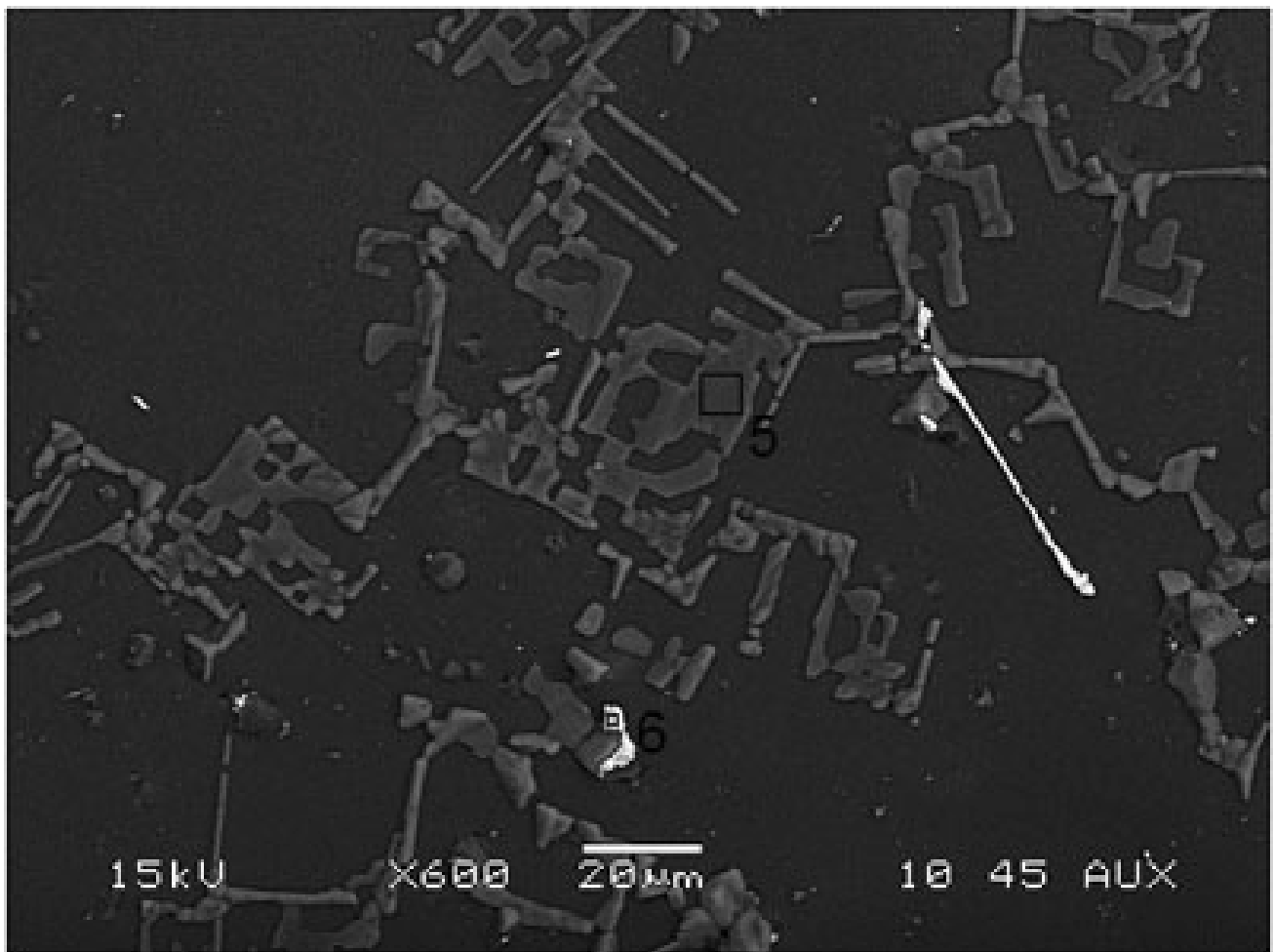

Figure A.15. SEM Micrograph of Condensate Deposit on Borosilicate Glaze Surface at $363^{\circ} \mathrm{C}$ (AMEC Feed Heat-Treated at $5^{\circ} \mathrm{C} / \mathrm{min}$ and Held at $1000^{\circ} \mathrm{C}$ for 2 hours) 
Table A.5. Composition of Areas 1-6 in Figures A.12 Through A.15 (AMEC feed heat-treated at $5^{\circ} \mathrm{C} / \mathrm{min}$ and held at $800^{\circ} \mathrm{C}$ for 2 hours)

\begin{tabular}{||l|c|r|r|r|r|r||}
\hline \multirow{2}{*}{ Element } & $\mathbf{1}$ & $\mathbf{2}$ & \multicolumn{1}{c|}{$\mathbf{3}$} & $\mathbf{4}$ & $\mathbf{5}$ & $\mathbf{6}$ \\
\cline { 2 - 7 } & \multicolumn{7}{|c||}{ Atomic\% } \\
\hline $\mathrm{O}$ & 47.90 & 44.53 & 10.55 & 42.43 & 13.89 & 44.56 \\
\hline $\mathrm{Na}$ & 21.65 & 24.08 & 35.73 & 19.32 & 19.43 & 23.27 \\
\hline $\mathrm{Al}$ & & & 2.80 & 7.75 & 5.34 & \\
\hline $\mathrm{Cl}$ & & & 10.84 & & 36.13 & \\
\hline $\mathrm{K}$ & 0.28 & & 0.23 & & 0.47 & \\
\hline $\mathrm{Ti}$ & & & 0.36 & & & \\
\hline $\mathrm{Re}$ & 30.17 & 31.39 & & 28.98 & & 32.17 \\
\hline
\end{tabular}

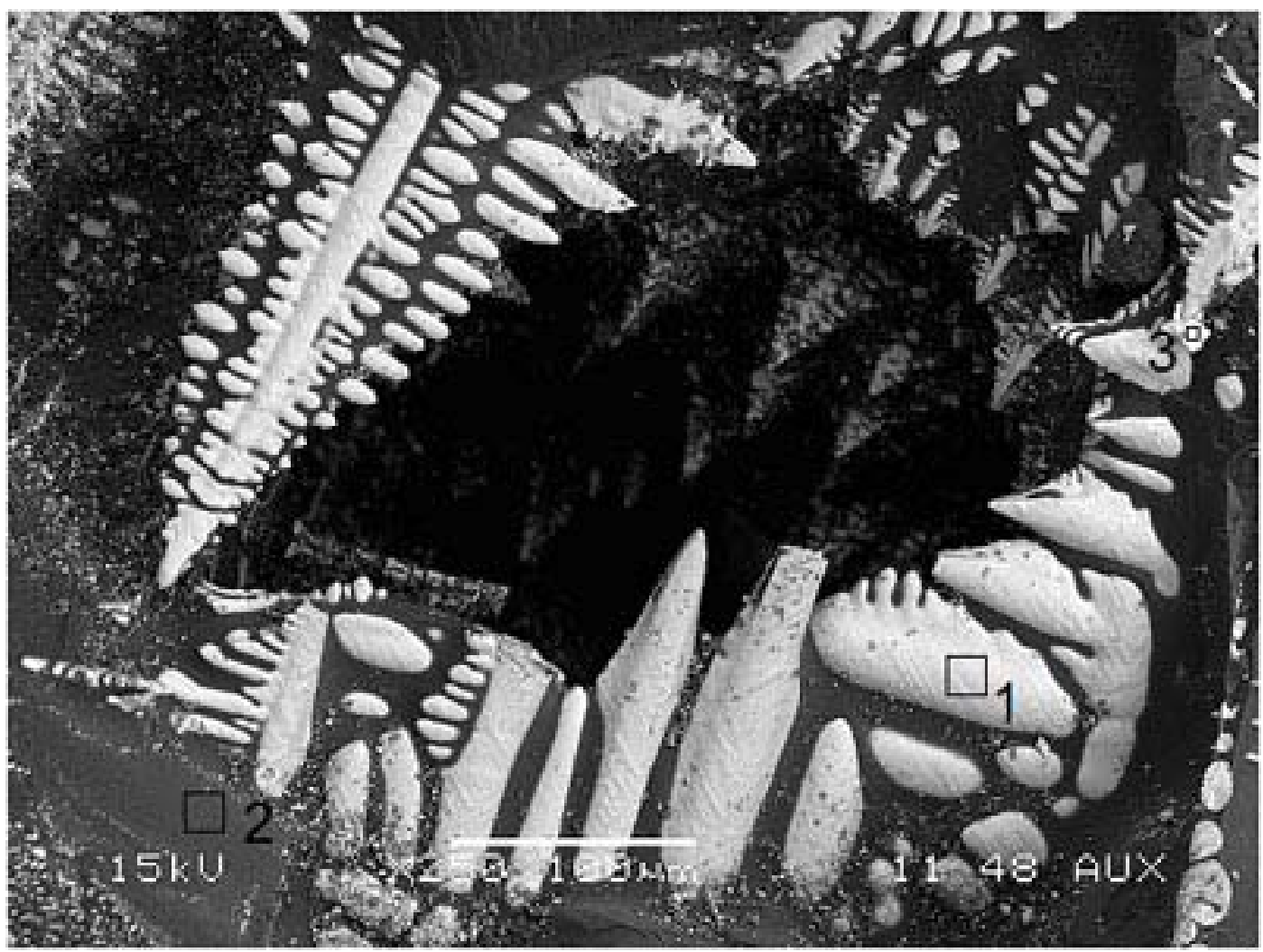

Figure A.16. SEM Micrograph of ELECTROFUSED CAST AZS UNICOR ${ }^{\circledR} 501$ at $441^{\circ} \mathrm{C}$ (AMEC feed heat-treated at $5^{\circ} \mathrm{C} / \mathrm{min}$ and held at $1000^{\circ} \mathrm{C}$ for 2 hours) 
Table A.6. Composition of Areas 1-3 in Figure A.16 (AMEC feed heat-treated at $5^{\circ} \mathrm{C} / \mathrm{min}$ and held at $1000^{\circ} \mathrm{C}$ for 2 hours)

\begin{tabular}{|c|c|c|c|}
\hline \multirow[b]{2}{*}{ Element } & 1 & 2 & 3 \\
\hline & \multicolumn{3}{|c|}{ Atomic\% } \\
\hline $\mathrm{O}$ & 37.68 & 35.83 & 49.51 \\
\hline $\mathrm{Na}$ & 2.28 & 0.87 & \\
\hline $\mathrm{Al}$ & 5.52 & 40.75 & 9.35 \\
\hline $\mathrm{Si}$ & 11.02 & 15.15 & 3.36 \\
\hline $\mathrm{Zr}$ & 43.50 & 7.40 & 37.78 \\
\hline
\end{tabular}

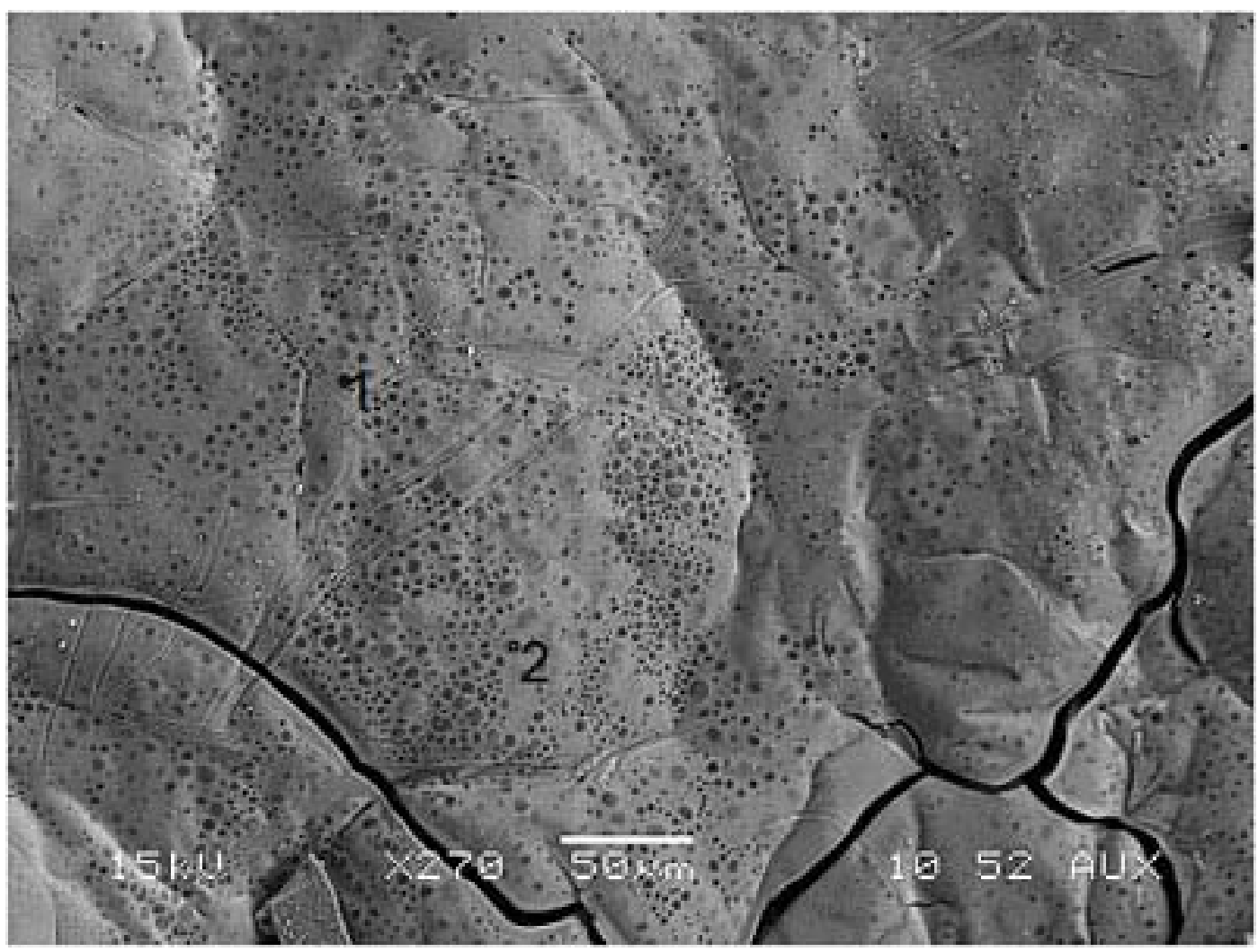

Figure A.17. SEM Micrograph of Sodium Silicate Glaze Surface at $537^{\circ} \mathrm{C}$ (AMEC feed heat-treated at $5^{\circ} \mathrm{C} / \mathrm{min}$ and held at $1000^{\circ} \mathrm{C}$ for 2 hours)

Table A.7. Composition of Area 1 and 2 in Figure A.17 (AMEC feed heat-treated at $5^{\circ} \mathrm{C} / \mathrm{min}$ and held at $1000^{\circ} \mathrm{C}$ for 2 hours)

\begin{tabular}{||l|r|r||}
\hline \multirow{2}{*}{ Element } & \multicolumn{1}{|c|}{$\mathbf{1}$} & \multicolumn{1}{|c|}{$\mathbf{2}$} \\
\cline { 2 - 3 } & \multicolumn{2}{|c|}{ Atomic\% } \\
\hline $\mathrm{O}$ & 35.22 & \multicolumn{1}{c|}{20.50} \\
\hline $\mathrm{Na}$ & 4.94 & 4.09 \\
\hline $\mathrm{Al}$ & 0.75 & 0.71 \\
\hline $\mathrm{Si}$ & 58.79 & 74.42 \\
\hline $\mathrm{K}$ & 0.29 & 0.29 \\
\hline
\end{tabular}




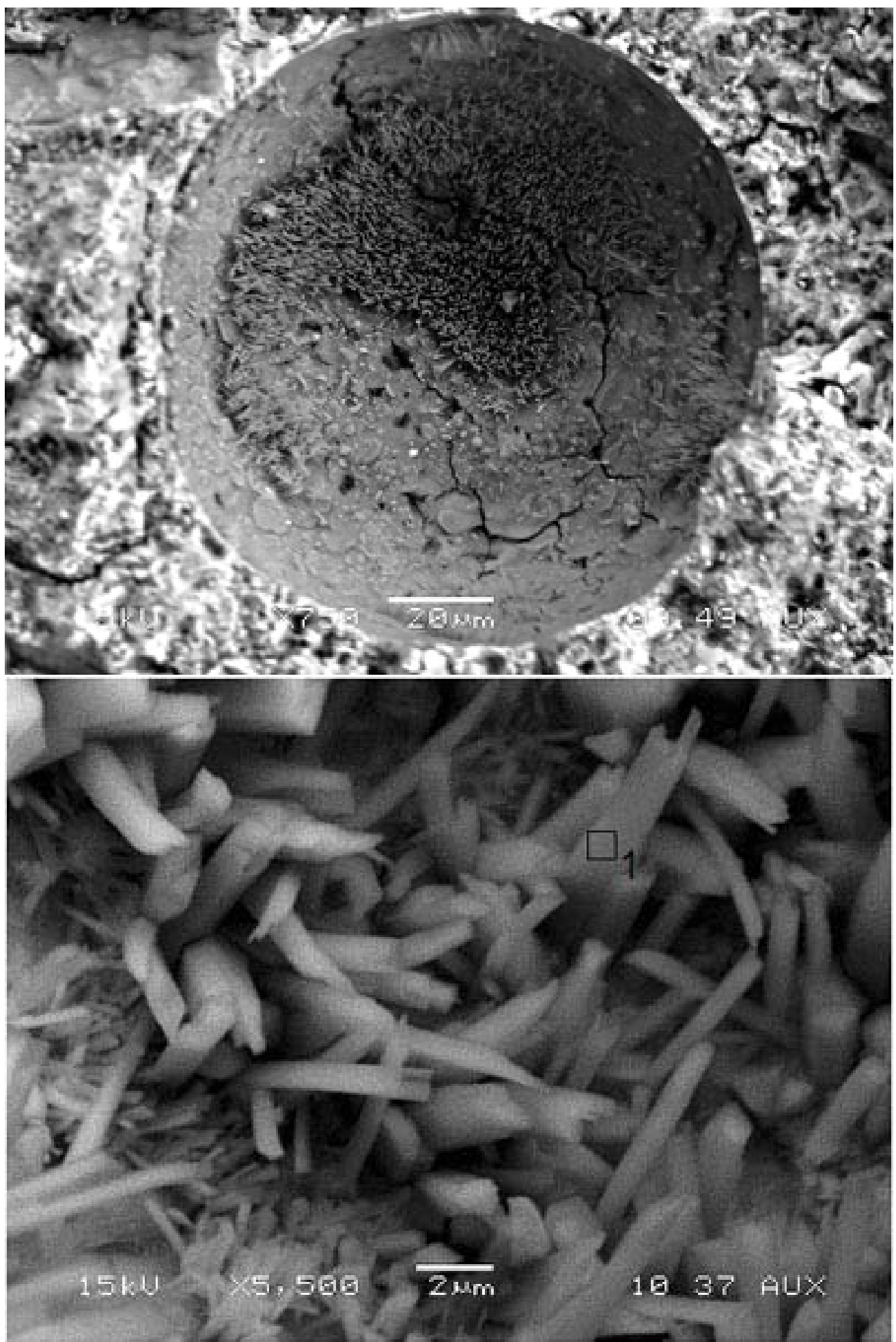

Figure A.18. SEM Micrograph of Untreated VIBROCAST 60PC Side Surface Fractured at $442^{\circ} \mathrm{C}$ (AMEC feed heat-treated at $5^{\circ} \mathrm{C} / \mathrm{min}$ and held at $1000^{\circ} \mathrm{C}$ for 2 hours) 
Table A.8. Composition of Area 1 in Figure A.18 (AMEC feed heat-treated at $5^{\circ} \mathrm{C} / \mathrm{min}$ and held at $1000^{\circ} \mathrm{C}$ for 2 hours)

\begin{tabular}{||l|r||}
\hline \multirow{2}{*}{ Element } & \multicolumn{1}{|c|}{$\mathbf{1}$} \\
\cline { 2 - 2 } & Atomic\% \\
\hline $\mathrm{O}$ & 25.30 \\
\hline $\mathrm{Na}$ & 0.33 \\
\hline $\mathrm{Al}$ & 64.99 \\
\hline $\mathrm{Si}$ & 4.02 \\
\hline $\mathrm{S}$ & 0.18 \\
\hline $\mathrm{Cl}$ & 0.52 \\
\hline $\mathrm{Ca}$ & 4.66 \\
\hline
\end{tabular}

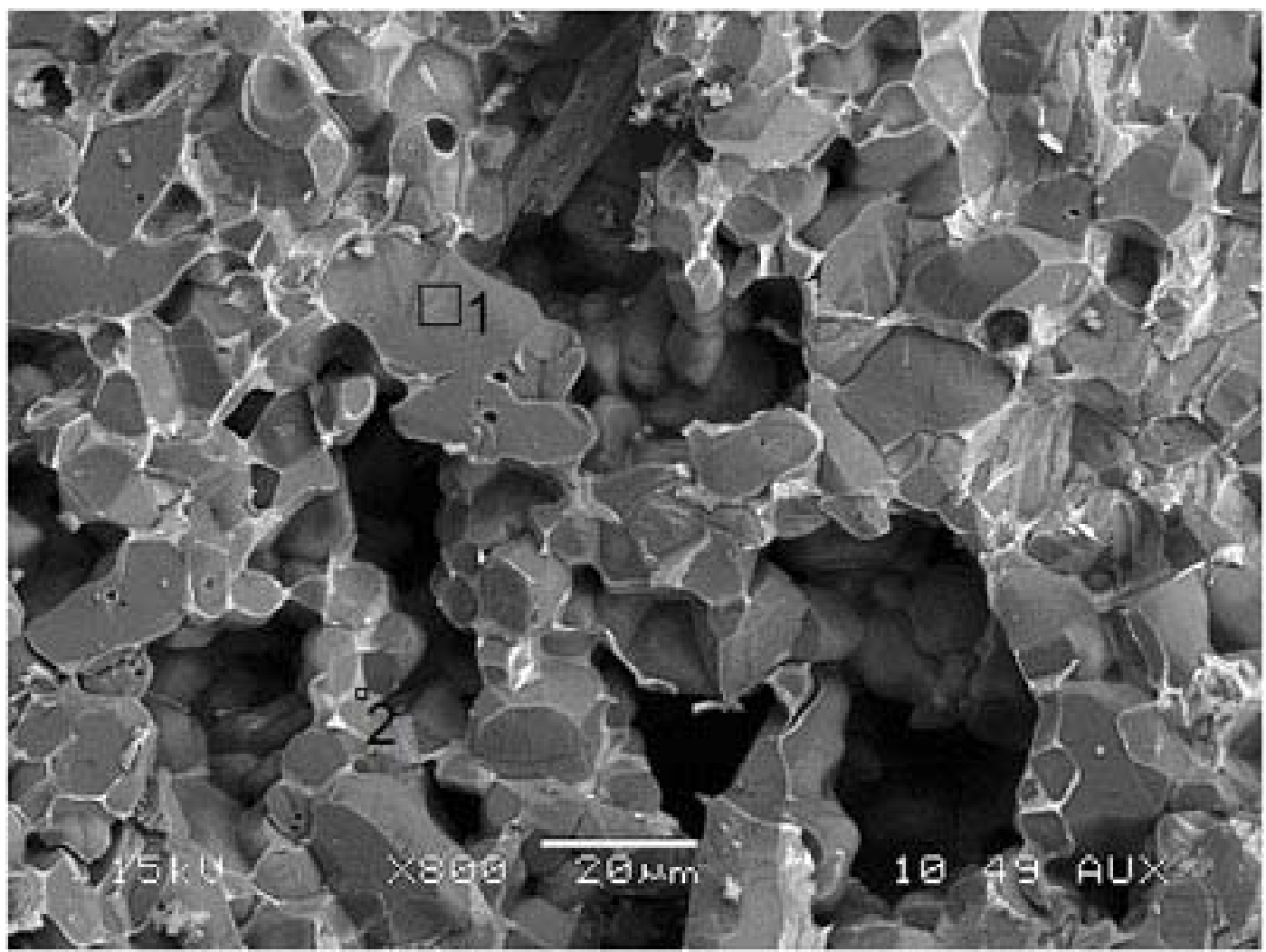

Figure A.19. SEM Micrograph of VIBROCAST 60PC Coated with Sodium Silicate Glaze Side Surface Fractured at $442^{\circ} \mathrm{C}$ (AMEC feed heat-treated at $5^{\circ} \mathrm{C} / \mathrm{min}$ and held at $1000^{\circ} \mathrm{C}$ for 2 hours) 
Table A.9. Composition of Area 1 and 2 in Figure A.19 (AMEC feed heat-treated at $5^{\circ} \mathrm{C} / \mathrm{min}$ and held at $1000^{\circ} \mathrm{C}$ for 2 hours)

\begin{tabular}{||l|r|r||}
\hline \multirow{2}{*}{ Element } & \multicolumn{1}{|c||}{$\mathbf{1}$} & \multicolumn{1}{c|}{$\mathbf{2}$} \\
\cline { 2 - 3 } & \multicolumn{2}{|c|}{ Atomic\% } \\
\hline $\mathrm{O}$ & 40.30 & 19.77 \\
\hline $\mathrm{Al}$ & 58.06 & 71.44 \\
\hline $\mathrm{Si}$ & 1.23 & 4.33 \\
\hline $\mathrm{P}$ & & 0.41 \\
\hline $\mathrm{K}$ & & 0.91 \\
\hline $\mathrm{Ti}$ & 0.25 & 1.38 \\
\hline $\mathrm{Fe}$ & 0.15 & 1.76 \\
\hline
\end{tabular}



Figure A.20. SEM Micrograph of ELECTROFUSED CAST AZS UNICOR ${ }^{\circledR} 501$ Side Surface Fractured at $441^{\circ} \mathrm{C}$ (AMEC feed heat-treated at $5^{\circ} \mathrm{C} / \mathrm{min}$ and held at $1000^{\circ} \mathrm{C}$ for 2 hours; see below the round object located in the center right) 


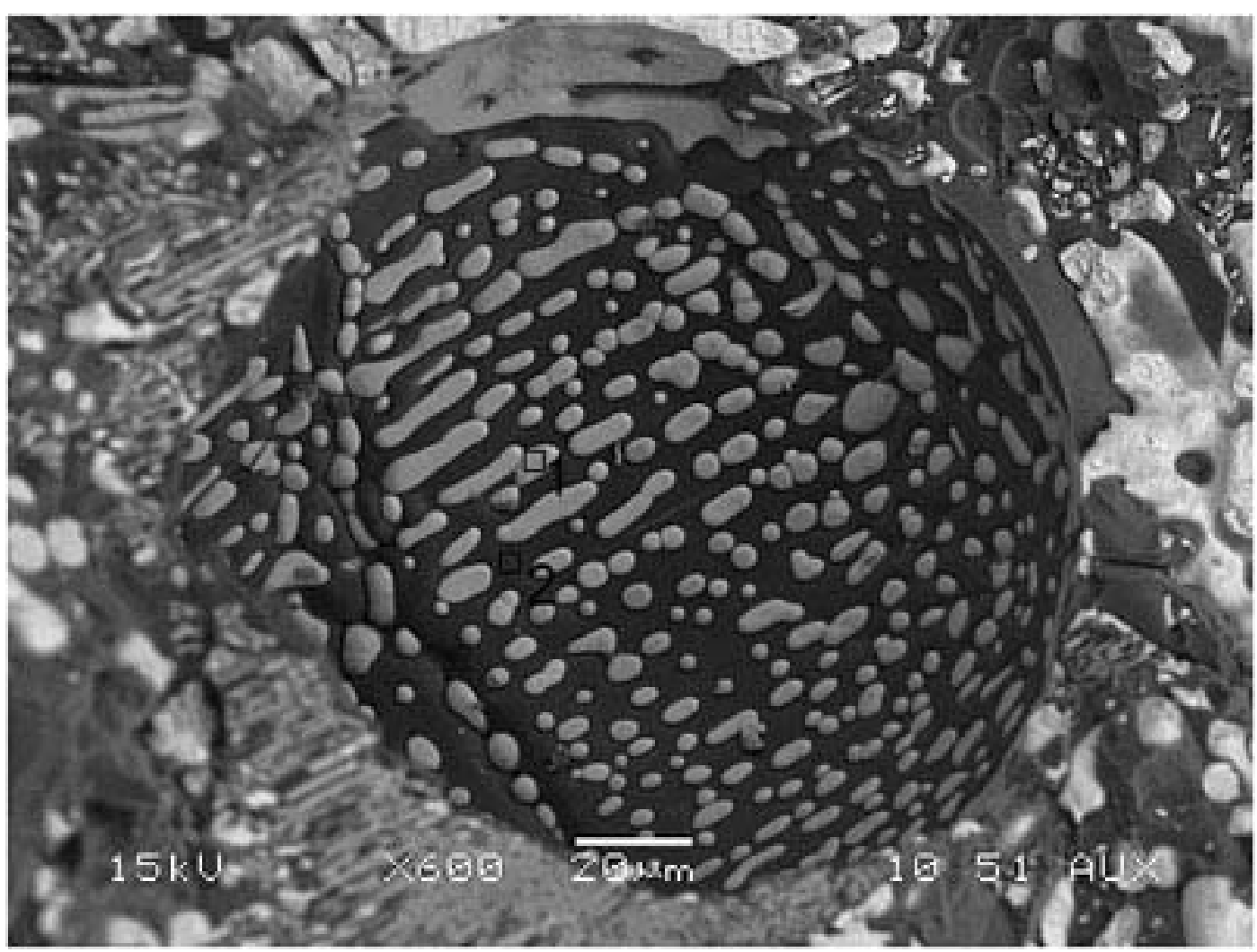

Figure A.20 (contd)

Table A.10. Composition of Area 1 and 2 in Figure A.20 (AMEC feed heat-treated at $5^{\circ} \mathrm{C} / \mathrm{min}$ and held at $1000^{\circ} \mathrm{C}$ for 2 hours)

\begin{tabular}{|l|r|r|}
\hline \multirow{2}{*}{ Element } & \multicolumn{1}{|c|}{$\mathbf{1}$} & \multicolumn{1}{|c|}{$\mathbf{2}$} \\
\cline { 2 - 3 } & \multicolumn{2}{|c|}{ Atomic\% } \\
\hline $\mathrm{O}$ & 51.28 & 43.4 \\
\hline $\mathrm{Na}$ & 0.83 & \\
\hline $\mathrm{Al}$ & 7.14 & 55.9 \\
\hline $\mathrm{Si}$ & 11.58 & \\
\hline $\mathrm{Zr}$ & 29.18 & 0.71 \\
\hline
\end{tabular}




\section{Optical Microscopy Observations}
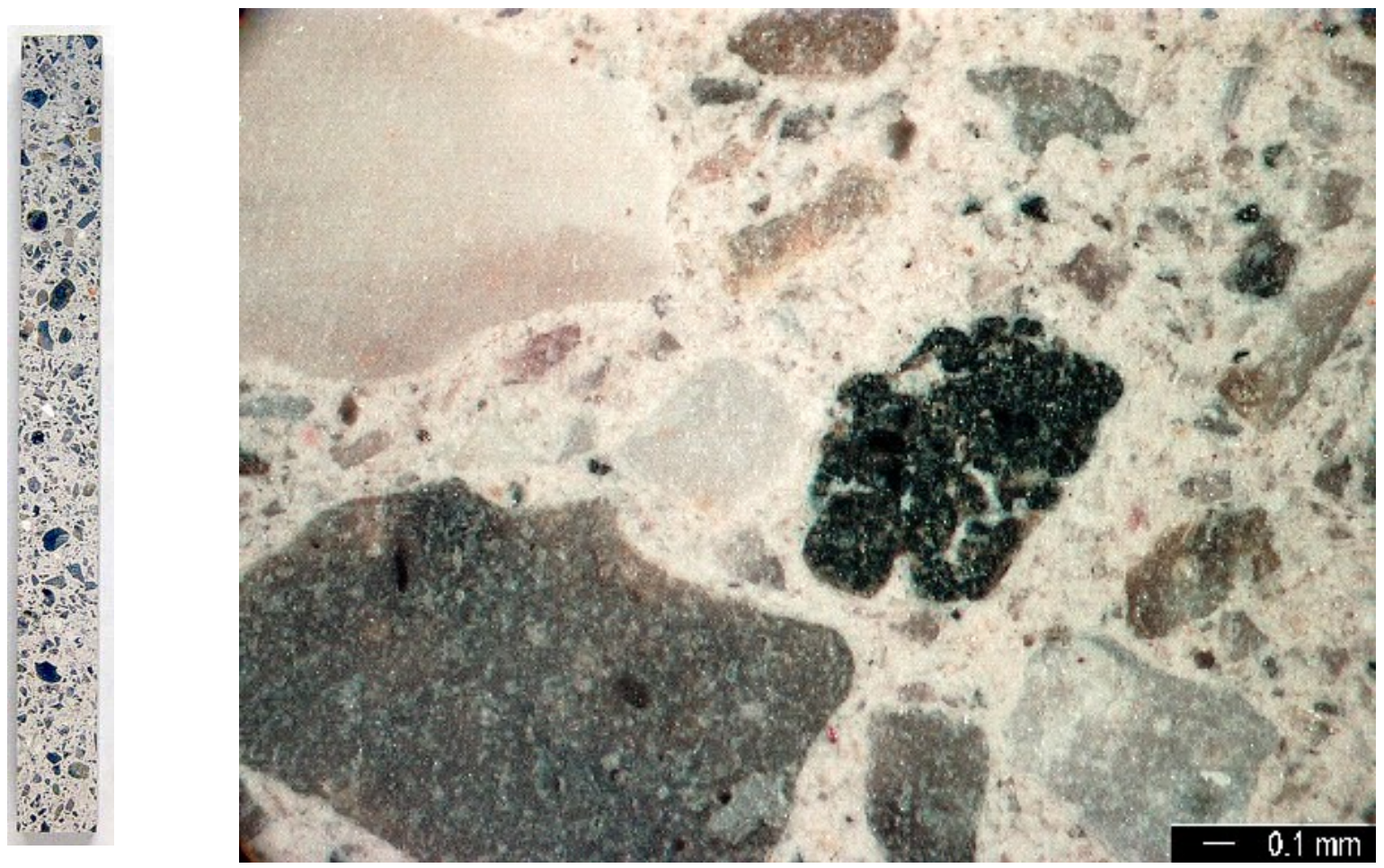

Figure A.21. Optical Micrograph of Untreated VIBROCAST 60PC (AMEC feed heat-treated at $5^{\circ} \mathrm{C} / \mathrm{min}$ and held at $1000^{\circ} \mathrm{C}$ for 2 hours)
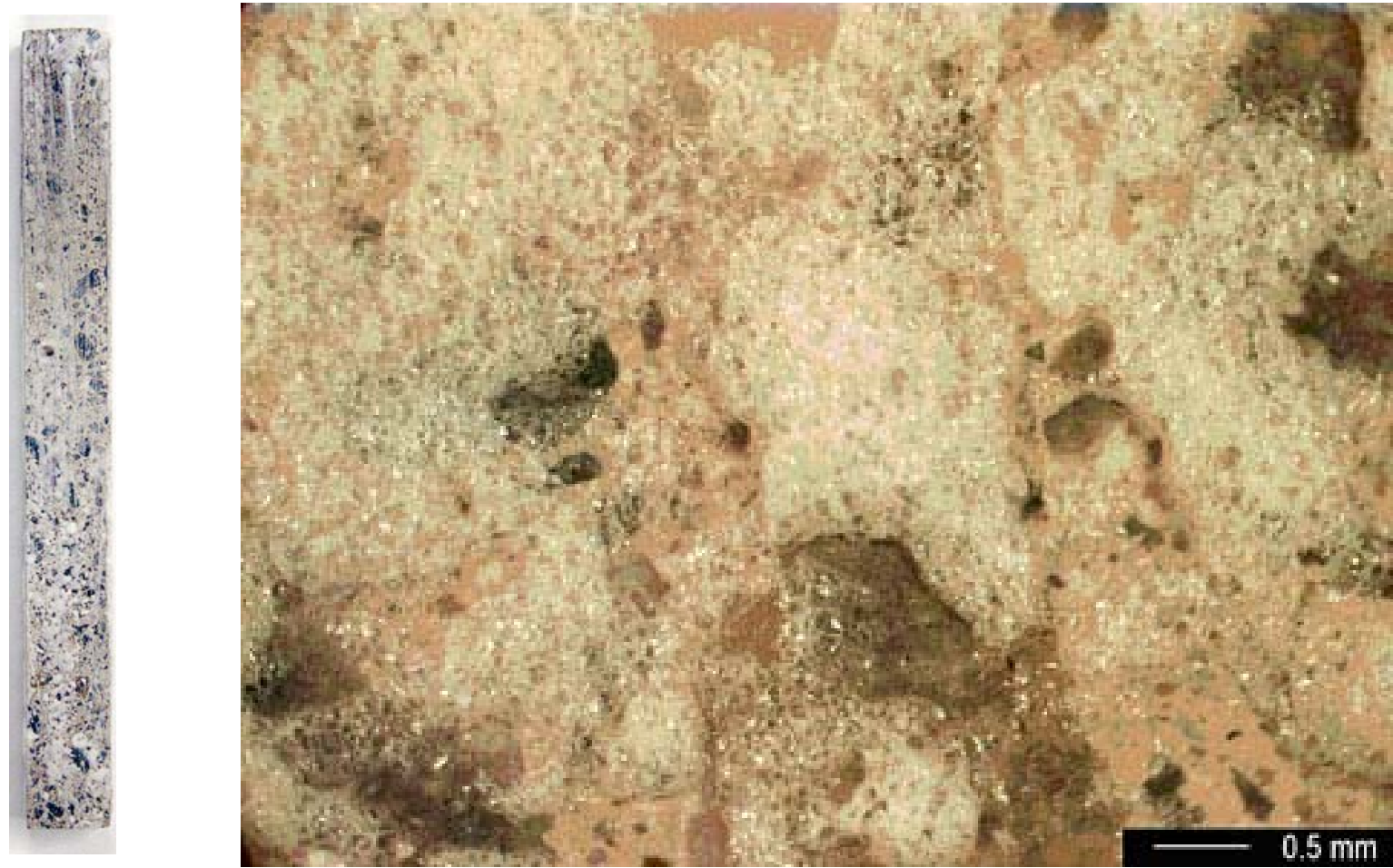

Figure A.22. Optical Micrograph of VIBROCAST 60PC Coated with Sodium Silicate Glaze (AMEC feed heat-treated at $5^{\circ} \mathrm{C} / \mathrm{min}$ and held at $1000^{\circ} \mathrm{C}$ for 2 hours) 

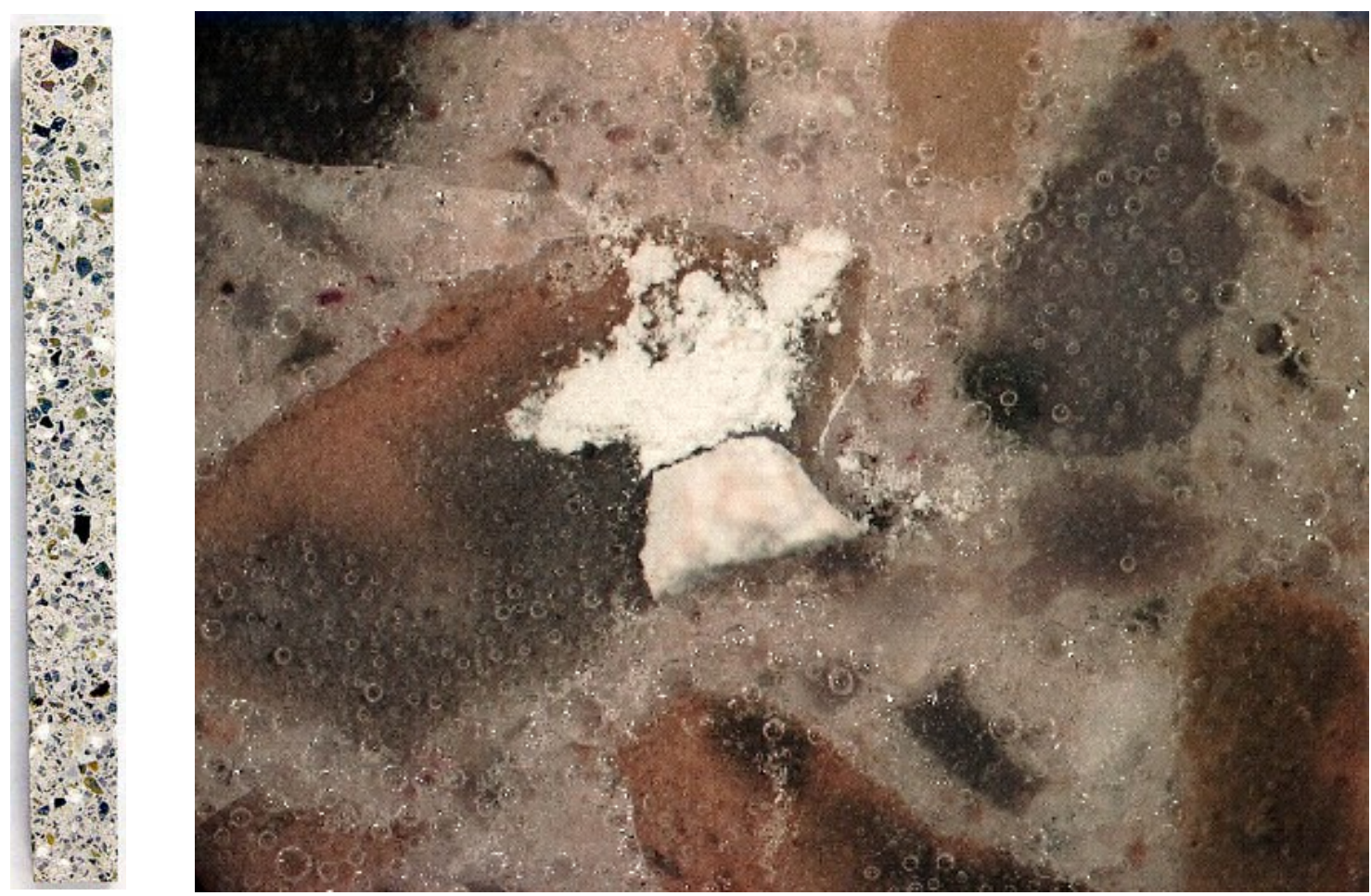

Figure A.23. Optical Micrograph of VIBROCAST 60PC Coated with Borosilicate Glaze (AMEC feed heat-treated at $5^{\circ} \mathrm{C} / \mathrm{min}$ and held at $1000^{\circ} \mathrm{C}$ for 2 hours)

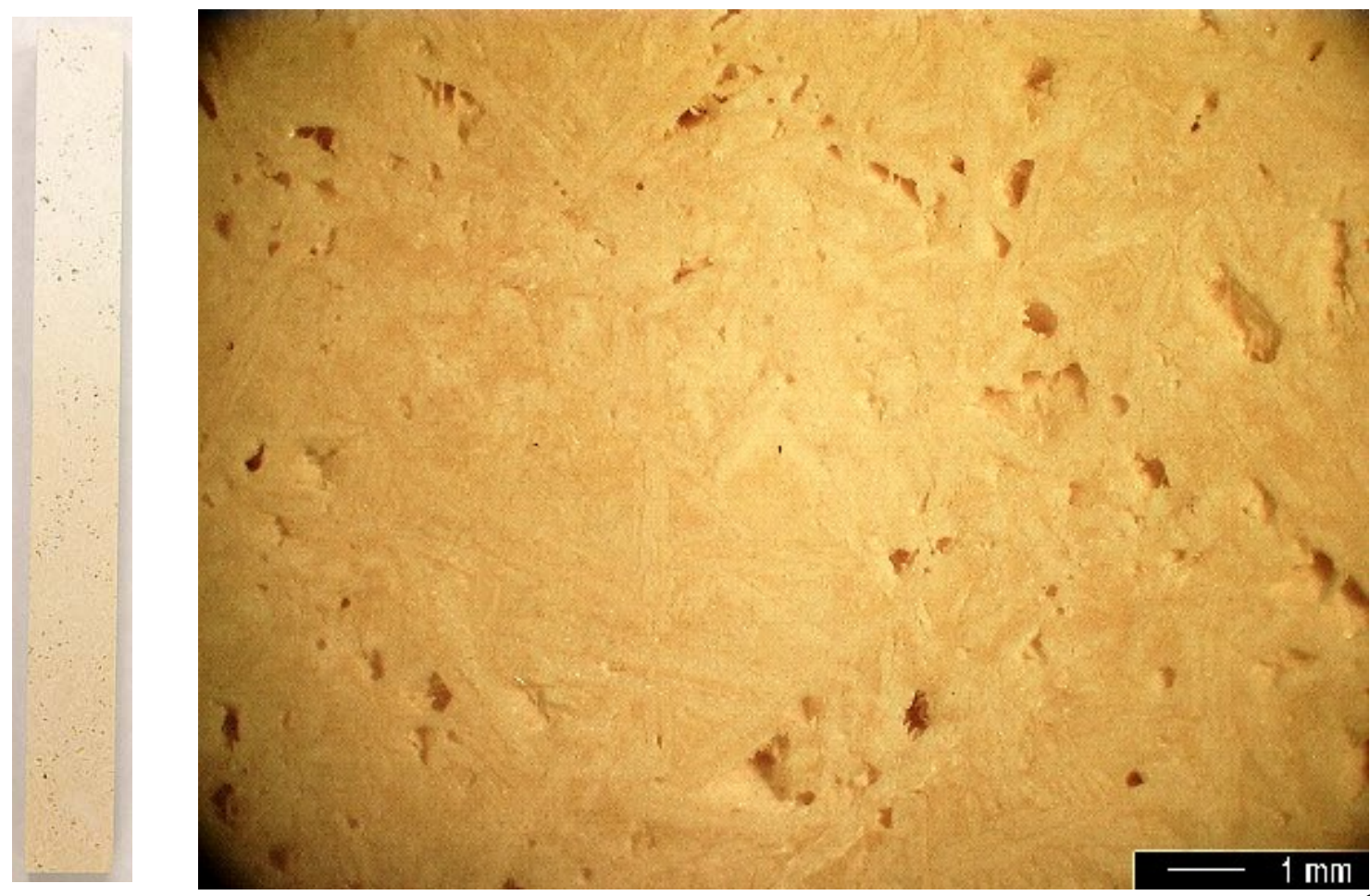

Figure A.24. Optical Micrograph of untreated ELECTROFUSED CAST AZS UNICOR ${ }^{\circledR}$ 501 (AMEC feed heat-treated at $5^{\circ} \mathrm{C} / \mathrm{min}$ and held at $1000^{\circ} \mathrm{C}$ for 2 hours) 

Appendix B

Simulant Condensate Penetration Test Results 


\section{Appendix B: Simulant Condensate Penetration Test Results}

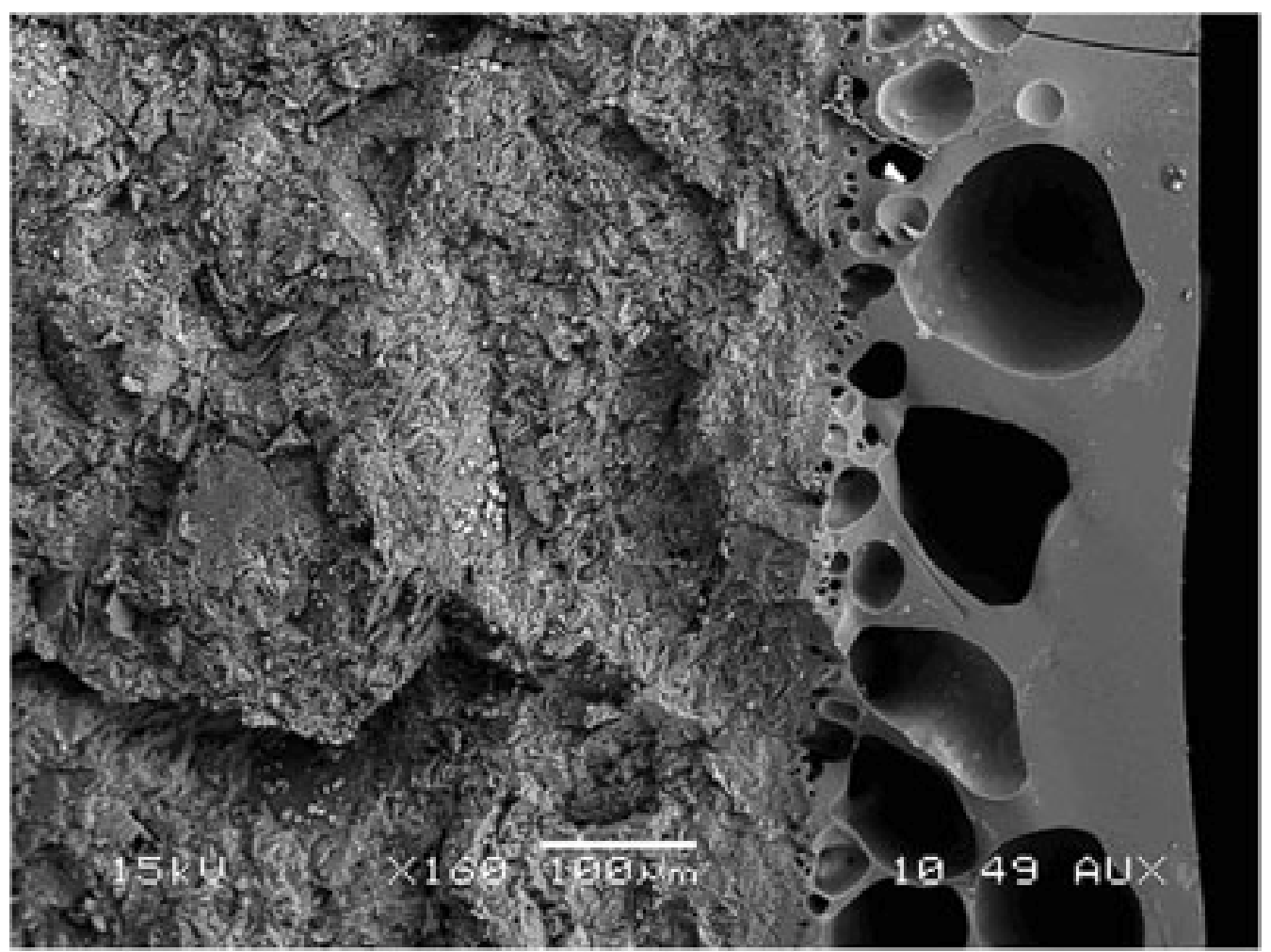

Figure B.1. SEM Micrograph of Cross-Sectioned Prefired Alumina Silicate Tile at $1000^{\circ} \mathrm{C}$ 


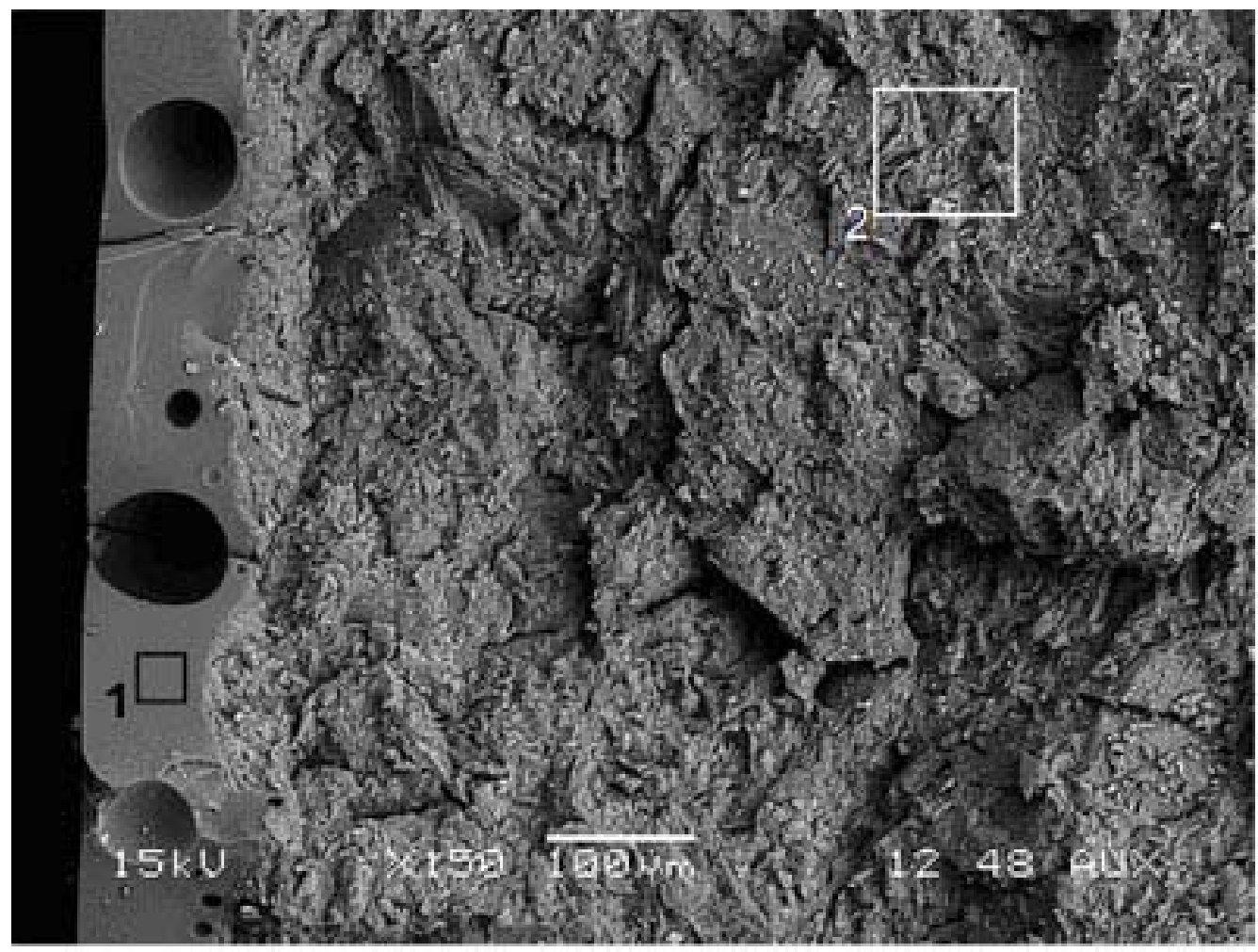

Figure B.2. SEM Micrograph of Cross-Sectioned Prefired Alumina Silicate Tile at $1000^{\circ} \mathrm{C}$

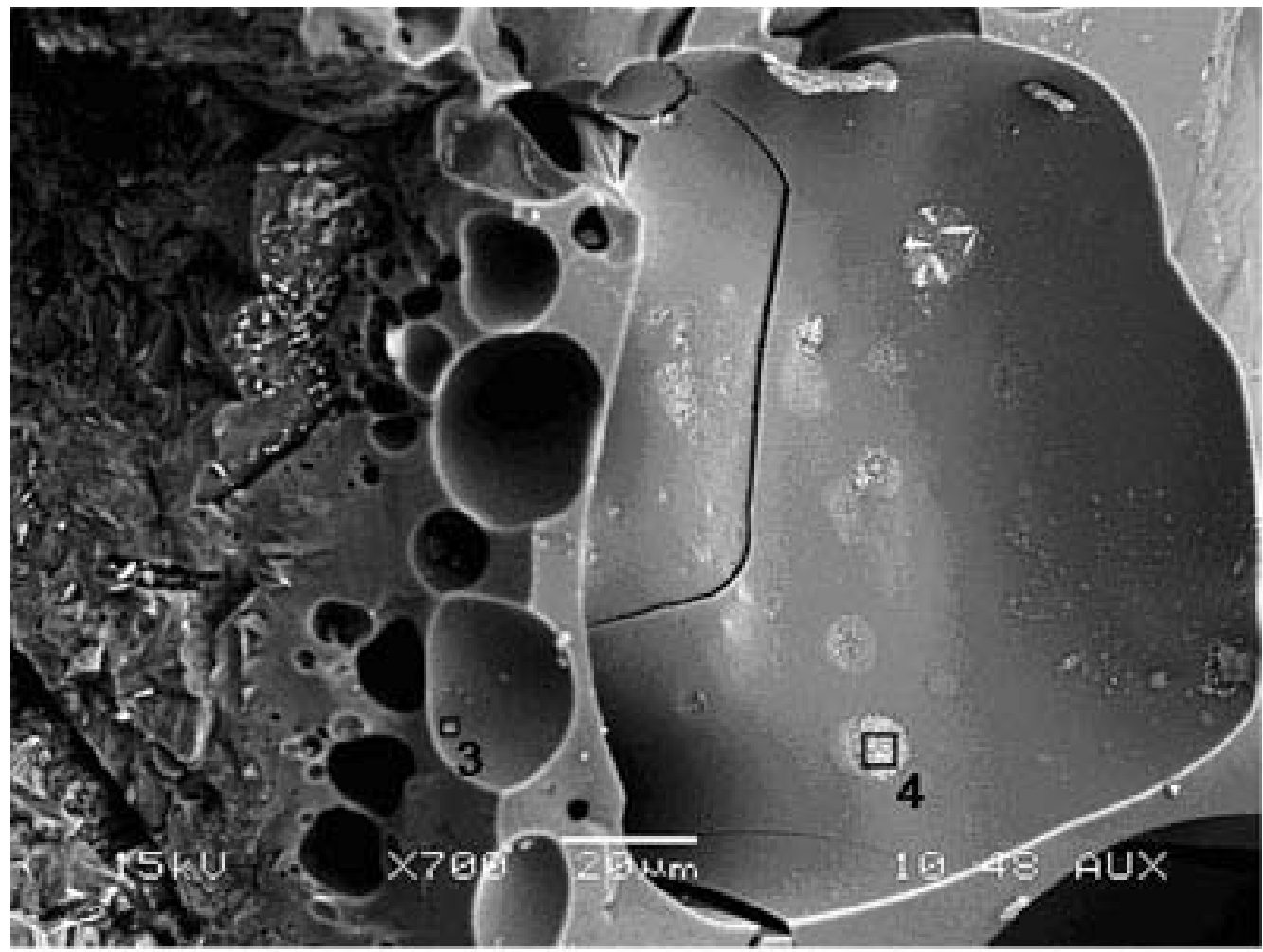

Figure B.3. SEM Micrograph of Cross-Sectioned Non-Prefired Alumina Silicate Tile at $1000^{\circ} \mathrm{C}$ 
Table B.1. Composition of Areas 1-4 in Figures B.2 and B.3

\begin{tabular}{||l|r|r|r|r||}
\hline \multirow{2}{*}{ Element } & $\mathbf{1}$ & \multicolumn{1}{|c|}{$\mathbf{2}$} & \multicolumn{1}{|c||}{$\mathbf{3}$} & \multicolumn{1}{|c||}{$\mathbf{4}$} \\
\cline { 2 - 5 } & \multicolumn{4}{|c||}{ Atomic\% } \\
\hline $\mathrm{C}$ & 14.26 & 17.76 & 13.81 & 19.18 \\
\hline $\mathrm{O}$ & 32.40 & 31.63 & 27.75 & 21.21 \\
\hline $\mathrm{Na}$ & 0.91 & 0.39 & 5.38 & 4.03 \\
\hline $\mathrm{Al}$ & 17.76 & 17.04 & 16.14 & 14.37 \\
\hline $\mathrm{Si}$ & 33.86 & 31.55 & 31.48 & 32.27 \\
\hline $\mathrm{Cl}$ & & & 4.46 & 0.56 \\
\hline $\mathrm{K}$ & 0.44 & 0.57 & 0.99 & 8.38 \\
\hline $\mathrm{Ti}$ & 0.15 & 0.57 & & \\
\hline $\mathrm{Fe}$ & 0.22 & 0.48 & & \\
\hline \hline
\end{tabular}

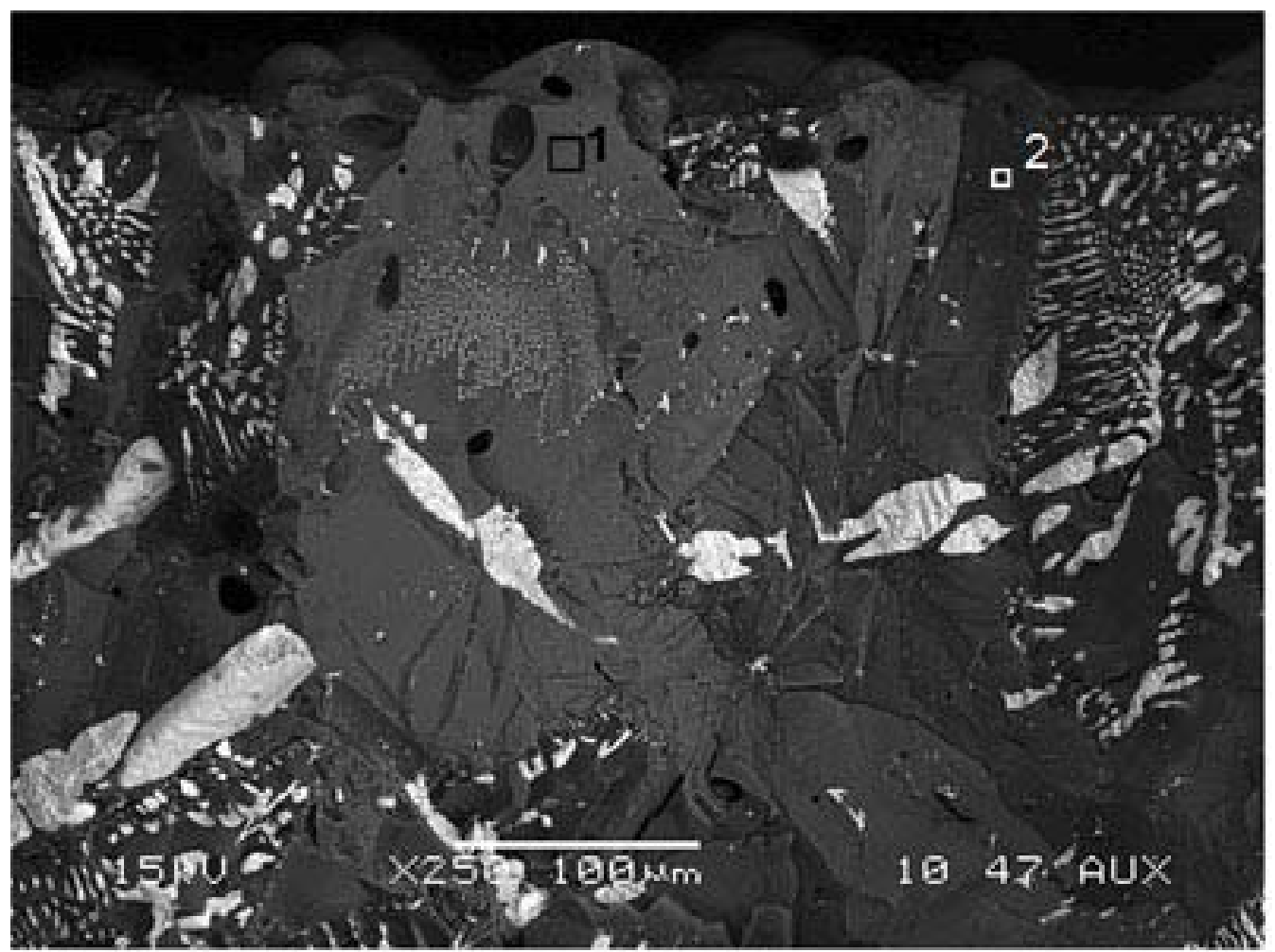

Figure B.4. SEM Micrograph of Cross-Sectioned Electrofused AZS Unikor 501 at $1000^{\circ} \mathrm{C}$ 


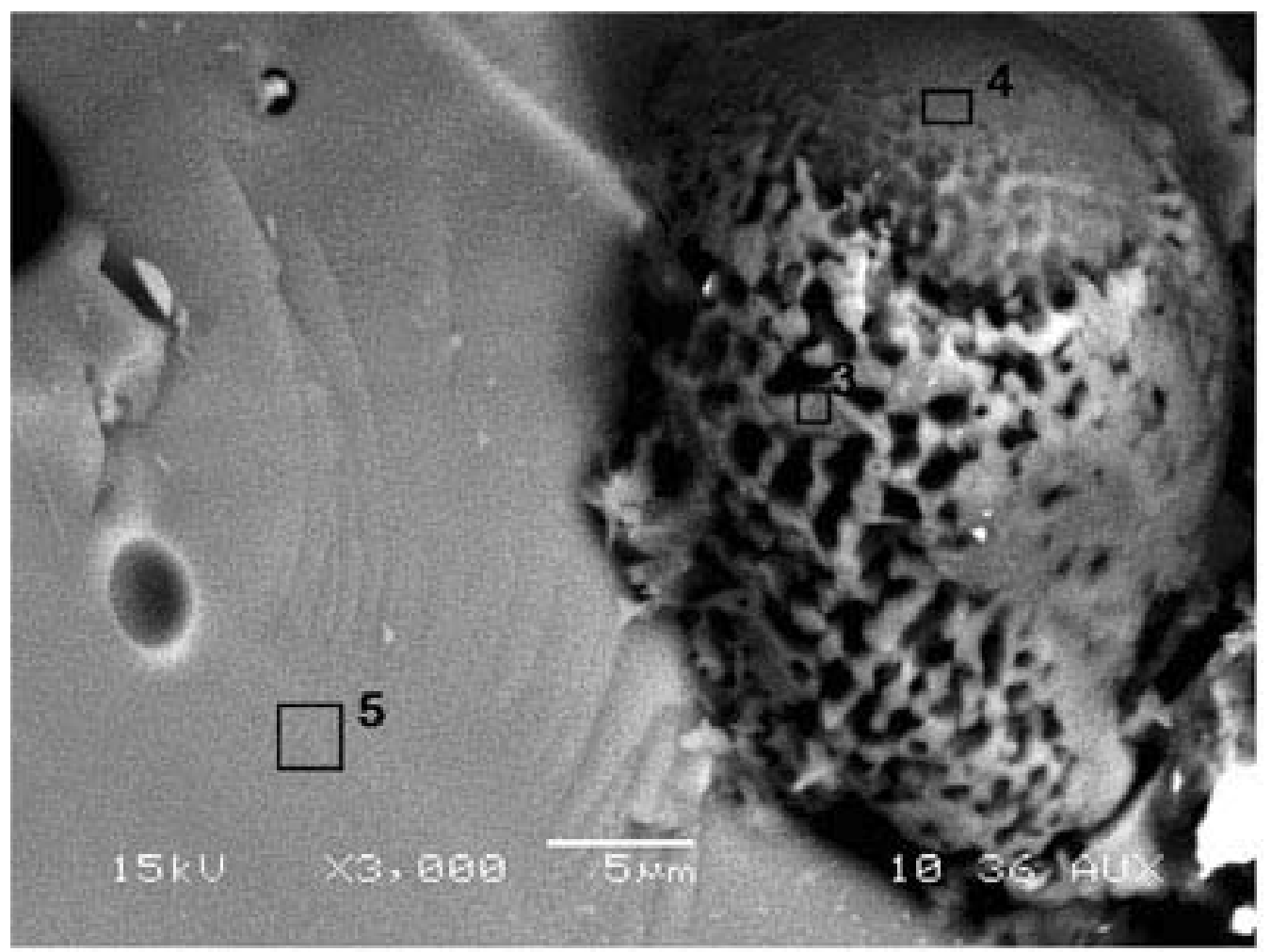

Figure B.5. SEM Micrograph of Cross-Sectioned Electrofused AZS Unikor 501 at $1000^{\circ} \mathrm{C}$

Table B.2. Composition of Areas 1-5 in Figures B.4 and B.5

\begin{tabular}{||l|r|r|r|r|r||}
\hline \multirow{2}{*}{ Element } & $\mathbf{1}$ & $\mathbf{2}$ & \multicolumn{1}{|c|}{$\mathbf{3}$} & $\mathbf{4}$ & $\mathbf{5}$ \\
\cline { 2 - 6 } & \multicolumn{5}{|c||}{ Atomic\% } \\
\hline $\mathrm{O}$ & 30.23 & 39.78 & 21.8 & 39.04 & 25.78 \\
\hline $\mathrm{Al}$ & 11.29 & 1.35 & 30.09 & 34.4 & 2.10 \\
\hline $\mathrm{Si}$ & 7.58 & 50.83 & 0.56 & 0.25 & 13.80 \\
\hline $\mathrm{Zr}$ & 13.49 & 2.65 & 0.78 & 0.08 & 54.37 \\
\hline $\mathrm{S}$ & 22.45 & 5.39 & & & 1.05 \\
\hline $\mathrm{Cl}$ & 7.54 & & 20.82 & 24.68 & 0.82 \\
\hline $\mathrm{K}$ & 1.43 & & 1.23 & 0.13 & 1.21 \\
\hline $\mathrm{Ca}$ & 1.46 & & 1.32 & 1.13 & \\
\hline $\mathrm{Cr}$ & 1.35 & & & & \\
\hline $\mathrm{Fe}$ & 1.76 & & & 0.28 & 0.37 \\
\hline
\end{tabular}




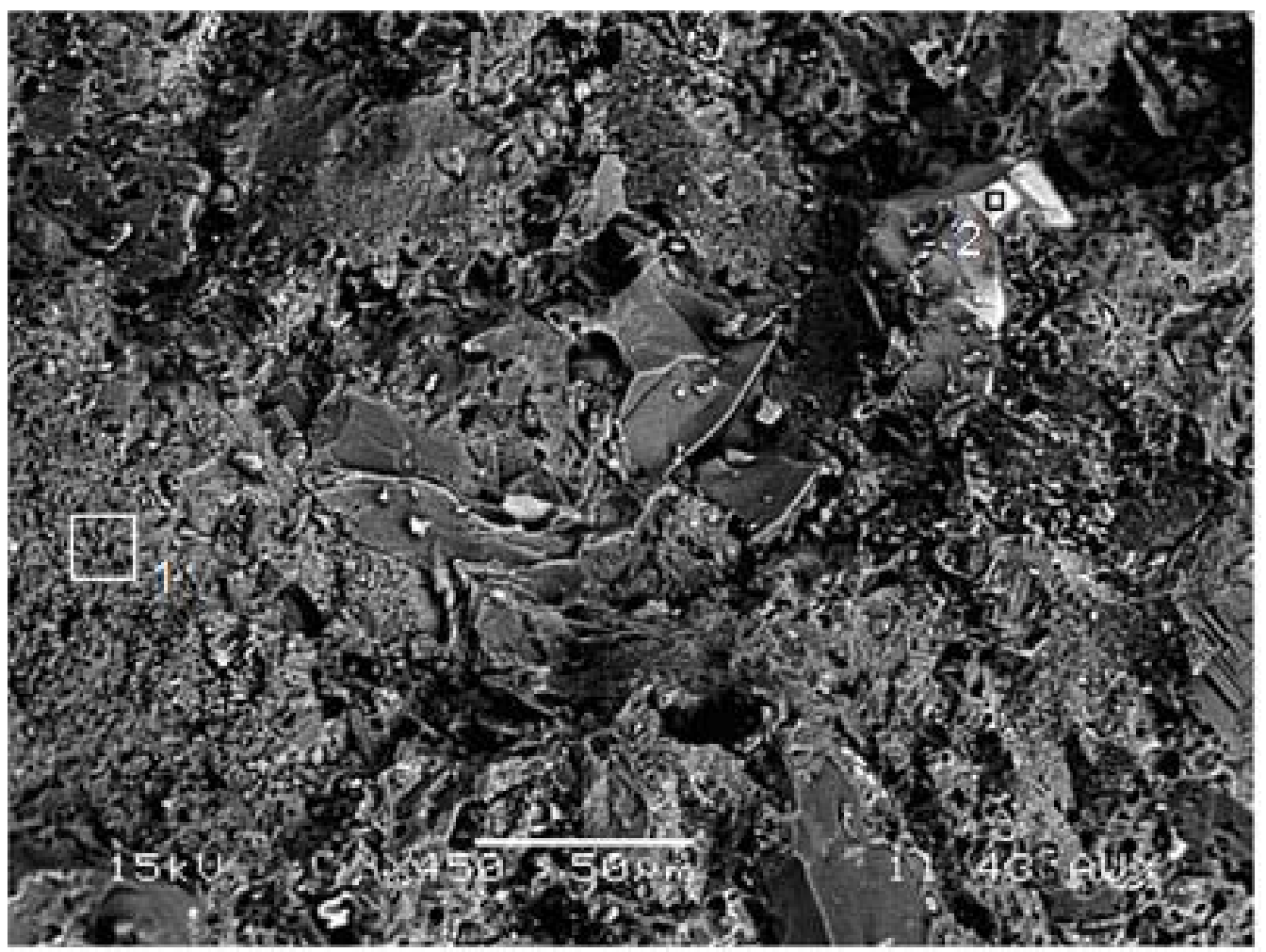

Figure B.6. SEM Micrograph of Cross-Sectioned Untreated Vibrocast 60PC at $700^{\circ} \mathrm{C}$

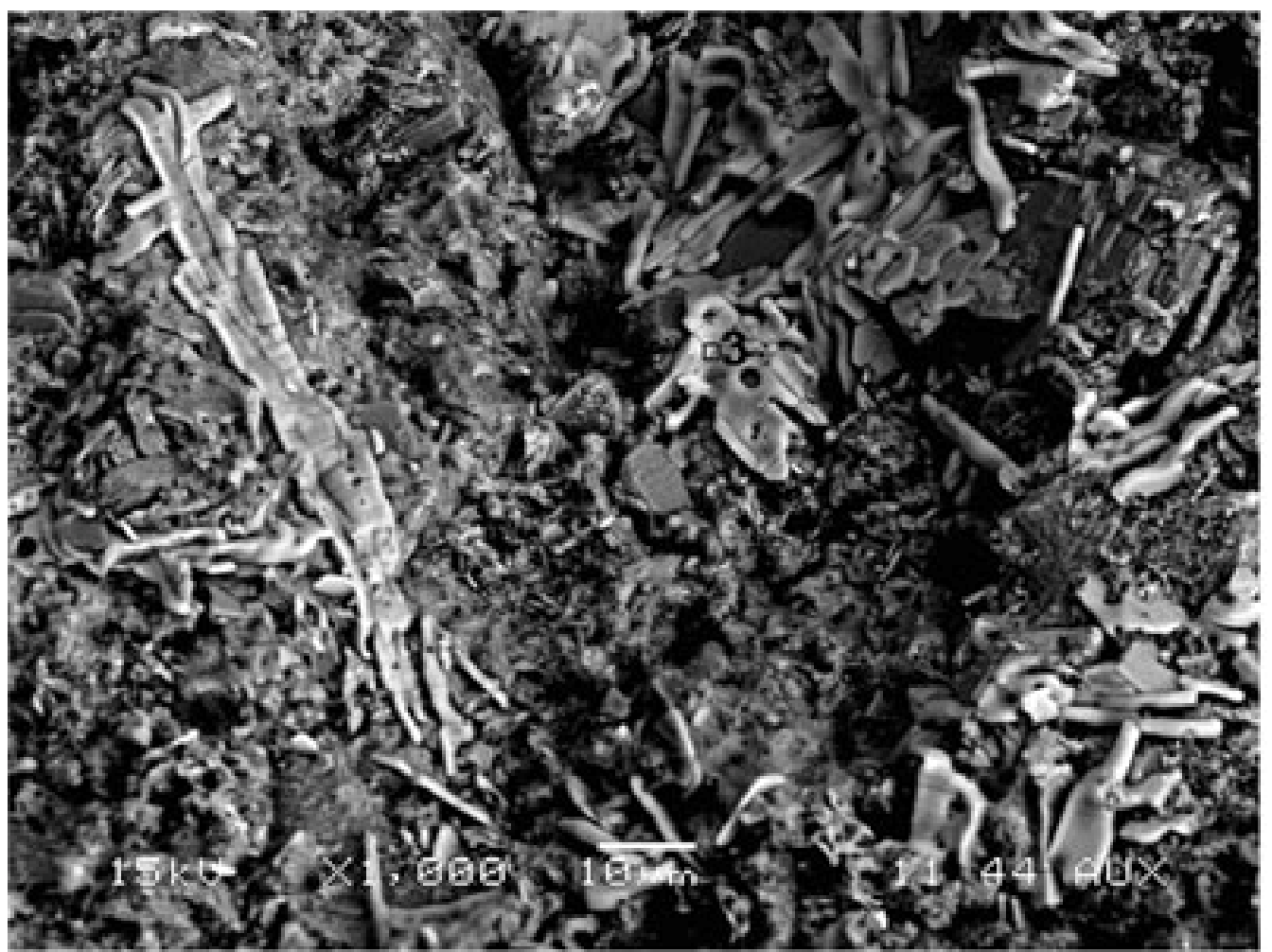

Figure B.7. SEM Micrograph of Cross-Sectioned Untreated Vibrocast 60PC at $700^{\circ} \mathrm{C}$ 


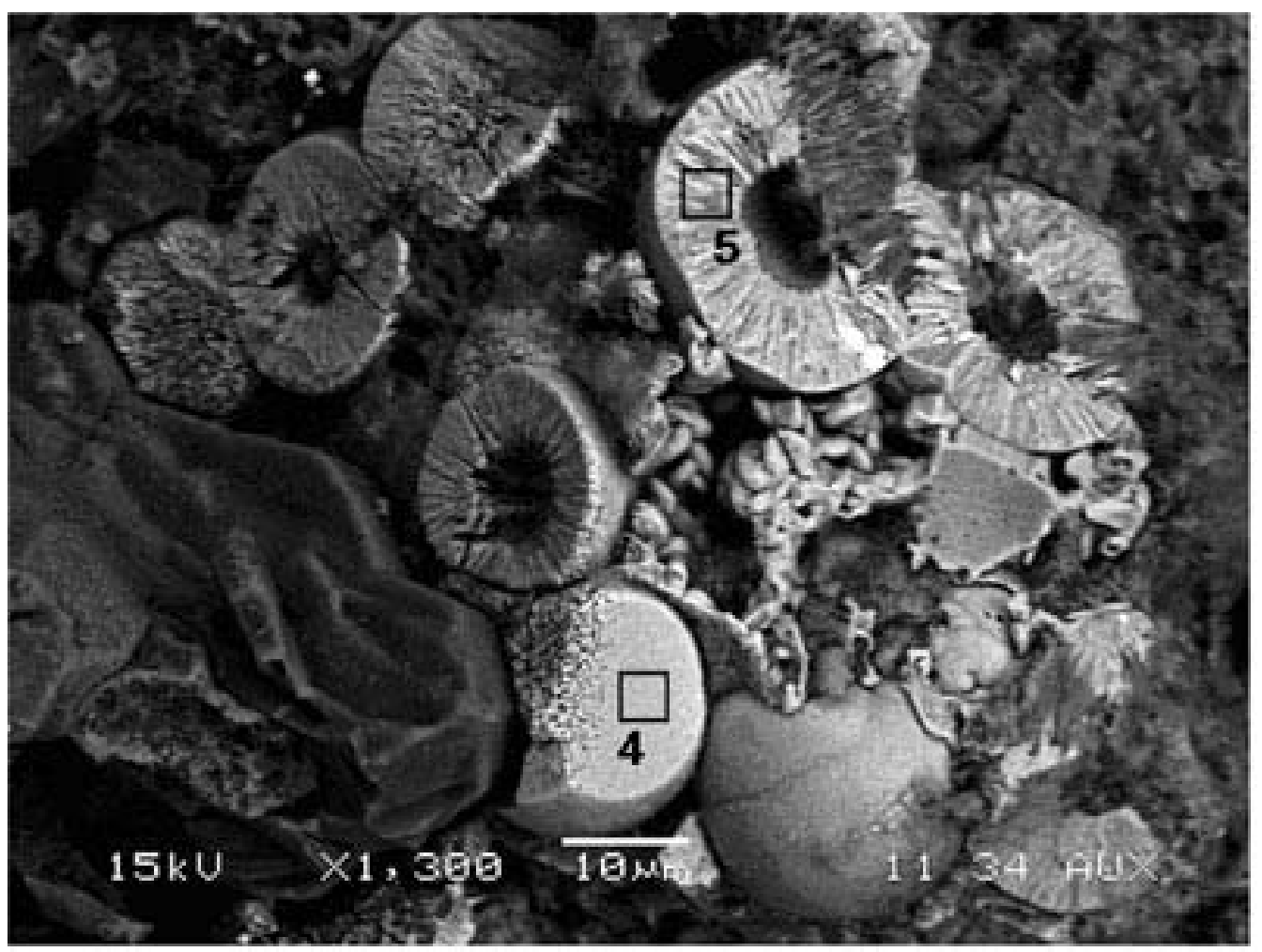

Figure B.8. SEM Micrograph of Cross-Sectioned Untreated Vibrocast 60PC at $700^{\circ} \mathrm{C}$

Table B.3. Composition of Areas 1-5 in Figures B.6 through B.8

\begin{tabular}{||l|r|r|r|r|r||}
\hline \multirow{3}{*}{ Element } & \multicolumn{1}{|c|}{$\mathbf{1}$} & $\mathbf{2}$ & \multicolumn{1}{|c|}{$\mathbf{3}$} & \multicolumn{1}{c||}{$\mathbf{4}$} & $\mathbf{5}$ \\
\cline { 2 - 7 } & \multicolumn{5}{|c||}{ Atomic\% } \\
\hline $\mathrm{O}$ & 32.19 & 45.25 & 50.96 & 34.82 & 35.74 \\
\hline $\mathrm{Na}$ & 0.73 & 3.04 & 1.47 & & \\
\hline $\mathrm{Al}$ & 3.84 & 5.97 & 5.77 & 8.36 & 2.79 \\
\hline $\mathrm{Si}$ & 19.44 & 15.17 & 16.37 & 2.87 & 4.72 \\
\hline $\mathrm{P}$ & & & & 2.25 & 1.66 \\
\hline $\mathrm{Zr}$ & 0.04 & & & & \\
\hline $\mathrm{S}$ & 1.17 & 0.39 & & 5.97 & 1.76 \\
\hline $\mathrm{Cl}$ & 1.28 & 0.80 & & & \\
\hline $\mathrm{K}$ & & 0.65 & & 0.66 & 0.33 \\
\hline $\mathrm{Ca}$ & 0.92 & 0.19 & 18.00 & 1.28 & 0.49 \\
\hline $\mathrm{Ti}$ & 1.33 & 20.58 & & 0.18 & \\
\hline $\mathrm{Fe}$ & 0.61 & & & 34.09 & 46.87 \\
\hline
\end{tabular}




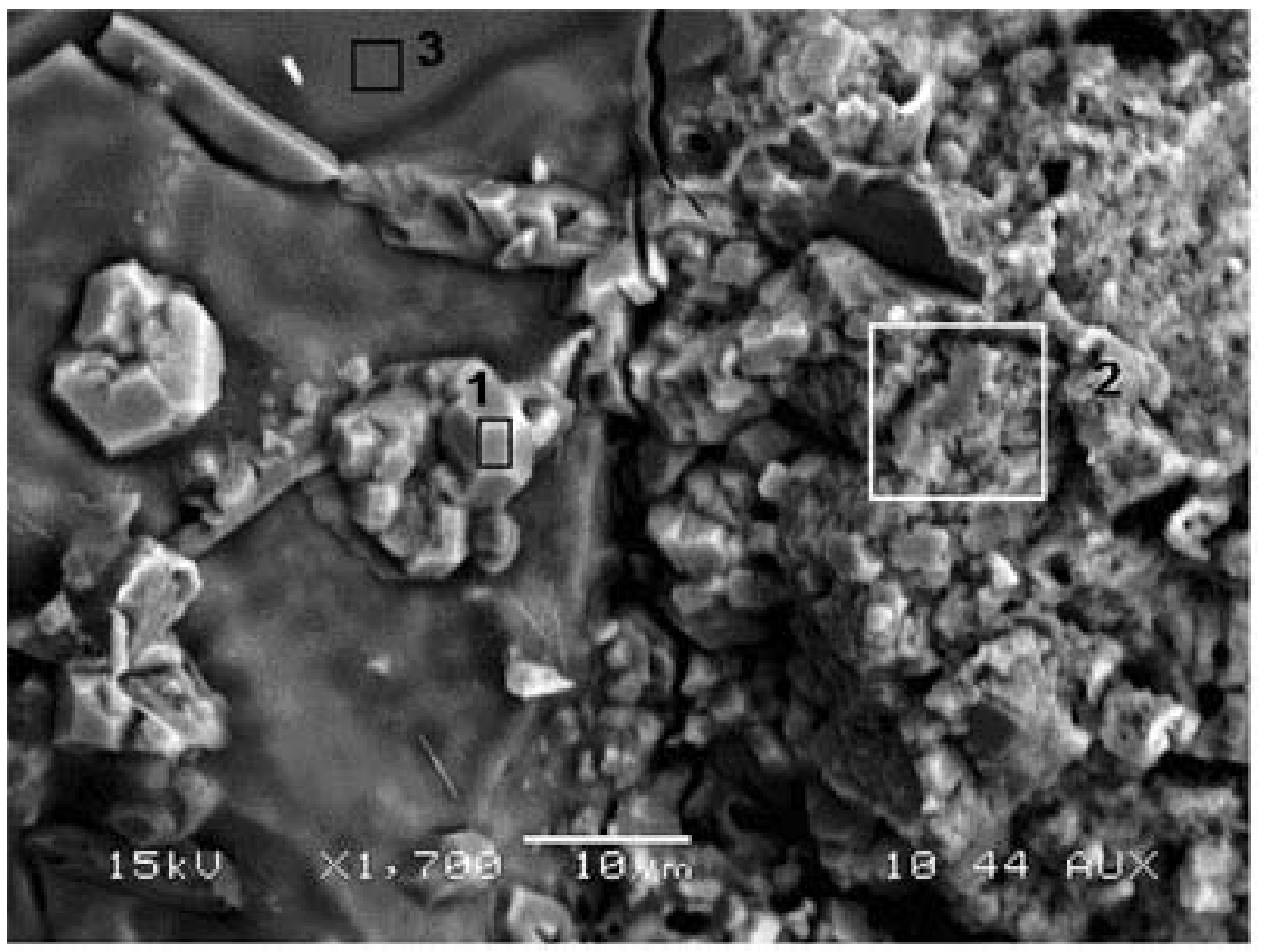

Figure B.9. SEM Micrograph of Cross-Sectioned Untreated Vibrocast 60PC at $900^{\circ} \mathrm{C}$

Table B.4. Composition of Areas 1-3 in Figure B.9

\begin{tabular}{|c|c|c|c|}
\hline \multirow[b]{2}{*}{ Element } & 1 & 2 & 3 \\
\hline & \multicolumn{3}{|c|}{ Atomic\% } \\
\hline $\mathrm{O}$ & 14.74 & 32.44 & 34.49 \\
\hline $\mathrm{Na}$ & 1.99 & 10.74 & 0.88 \\
\hline $\mathrm{Al}$ & 8.76 & 20.65 & 1.76 \\
\hline $\mathrm{Si}$ & 70.08 & 25.85 & 62.61 \\
\hline$S$ & 0.56 & 1.92 & 0.06 \\
\hline $\mathrm{Cl}$ & 0.82 & 4.42 & \\
\hline $\mathrm{K}$ & 1.23 & 0.73 & 0.20 \\
\hline $\mathrm{Ca}$ & 1.83 & 3.25 & \\
\hline
\end{tabular}




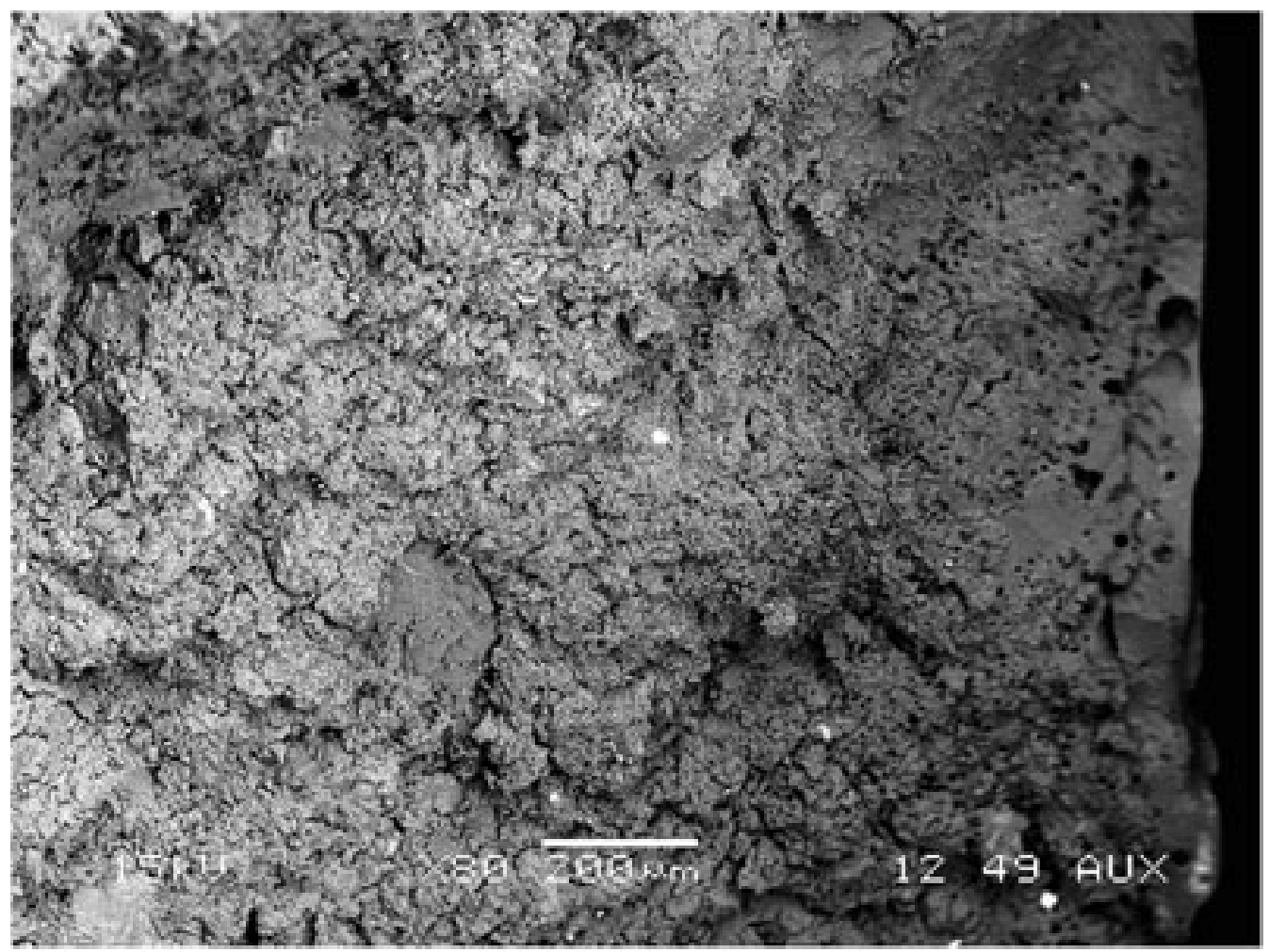

Figure B.10. SEM Micrograph of Cross-Sectioned Untreated Vibrocast 60PC at $1000^{\circ} \mathrm{C}$

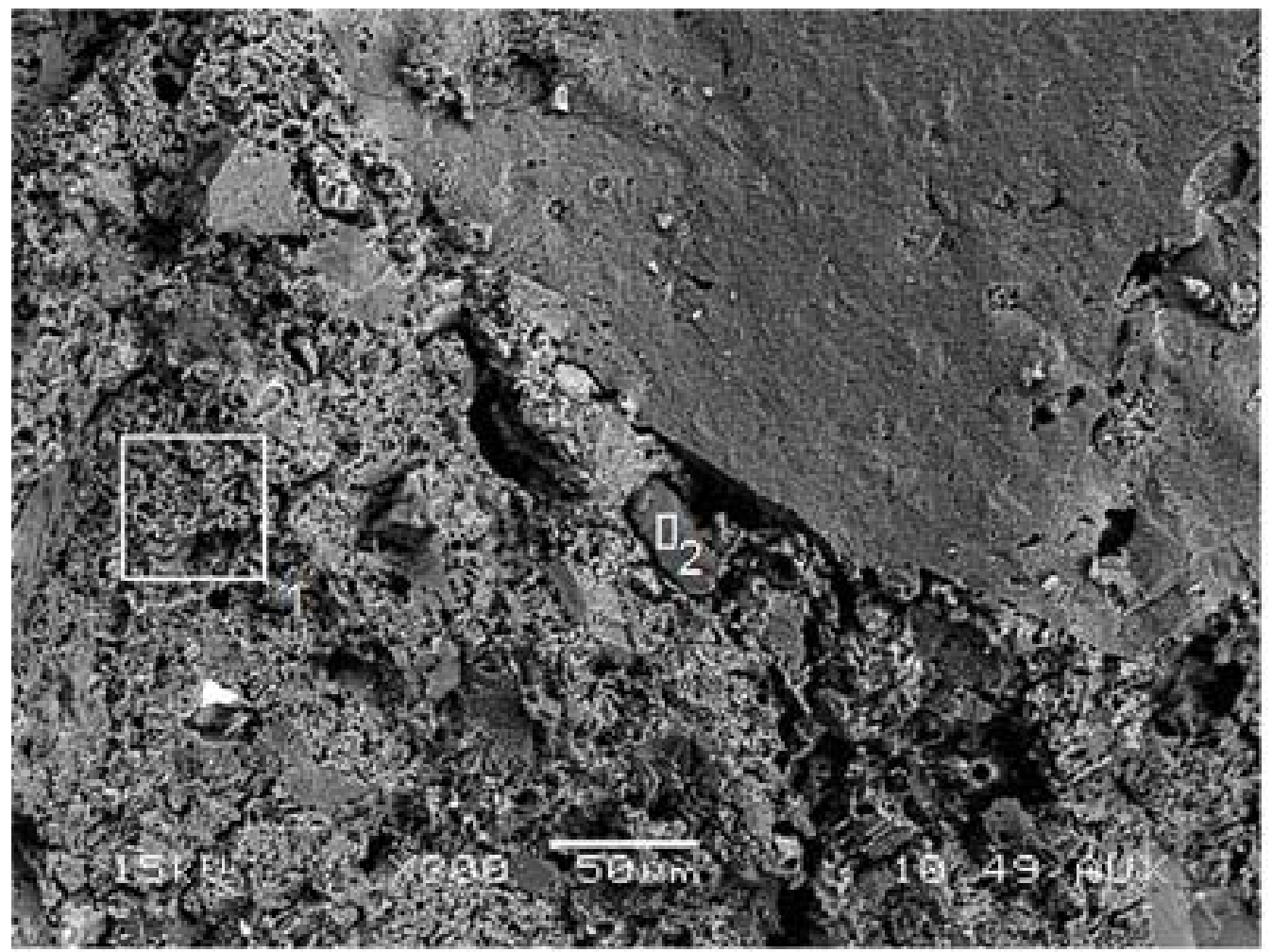

Figure B.11. SEM Micrograph of Cross-Sectioned Untreated Vibrocast 60PC at $1000^{\circ} \mathrm{C}$ 
Table B.5. Composition of Areas 1 and 2 in Figure B.11

\begin{tabular}{||l|r|r||}
\hline \multirow{2}{*}{ Element } & \multicolumn{1}{|c|}{$\mathbf{1}$} & \multicolumn{1}{c|}{$\mathbf{2}$} \\
\cline { 2 - 3 } & \multicolumn{2}{|c|}{ Atomic\% } \\
\hline $\mathrm{O}$ & 34.25 & 35.73 \\
\hline $\mathrm{Na}$ & 0.28 & 0.14 \\
\hline $\mathrm{Mg}$ & 0.59 & \\
\hline $\mathrm{Al}$ & 28.09 & 32.46 \\
\hline $\mathrm{Si}$ & 31.07 & 27.35 \\
\hline $\mathrm{P}$ & 0.51 & \\
\hline $\mathrm{Ca}$ & 4.31 & 2.39 \\
\hline $\mathrm{K}$ & & 0.16 \\
\hline $\mathrm{Ti}$ & 0.24 & 1.31 \\
\hline $\mathrm{Fe}$ & 0.66 & 0.45 \\
\hline
\end{tabular}



Figure B.12. SEM Micrograph of Cross-Sectioned Untreated Vibrocast $60 \mathrm{PC}$ at $1100^{\circ} \mathrm{C}$ 
Table B.6. Composition of Areas 1 and 2 in Figure B.12

\begin{tabular}{||l|r|r||}
\hline \multirow{2}{*}{ Element } & \multicolumn{1}{|c|}{$\mathbf{1}$} & \multicolumn{1}{|c|}{$\mathbf{2}$} \\
\cline { 2 - 3 } & \multicolumn{2}{|c|}{ Atomic\% } \\
\hline $\mathrm{O}$ & 33.74 & 35.47 \\
\hline $\mathrm{Na}$ & 1.76 & 2.47 \\
\hline $\mathrm{Al}$ & 34.81 & 29.70 \\
\hline $\mathrm{Si}$ & 27.19 & 26.27 \\
\hline $\mathrm{K}$ & 0.52 & 0.52 \\
\hline $\mathrm{Ca}$ & 0.32 & 4.44 \\
\hline $\mathrm{Ti}$ & 1.06 & 0.47 \\
\hline $\mathrm{Fe}$ & 0.60 & 0.66 \\
\hline
\end{tabular}

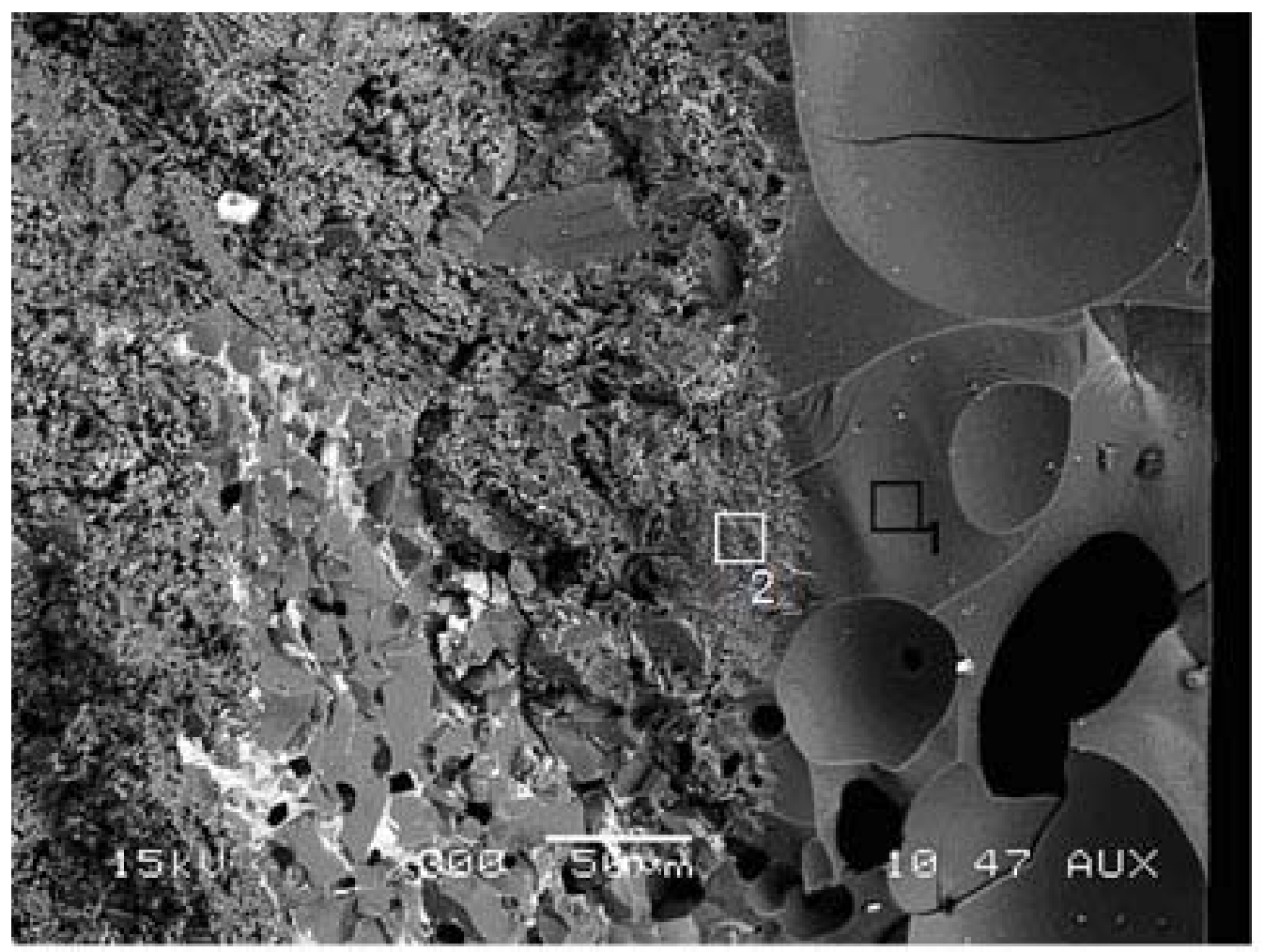

Figure B.13. SEM Micrograph of Cross-Sectioned Vibrocast 60PC Coated with Sodium Silicate Glaze at $800^{\circ} \mathrm{C}$ 


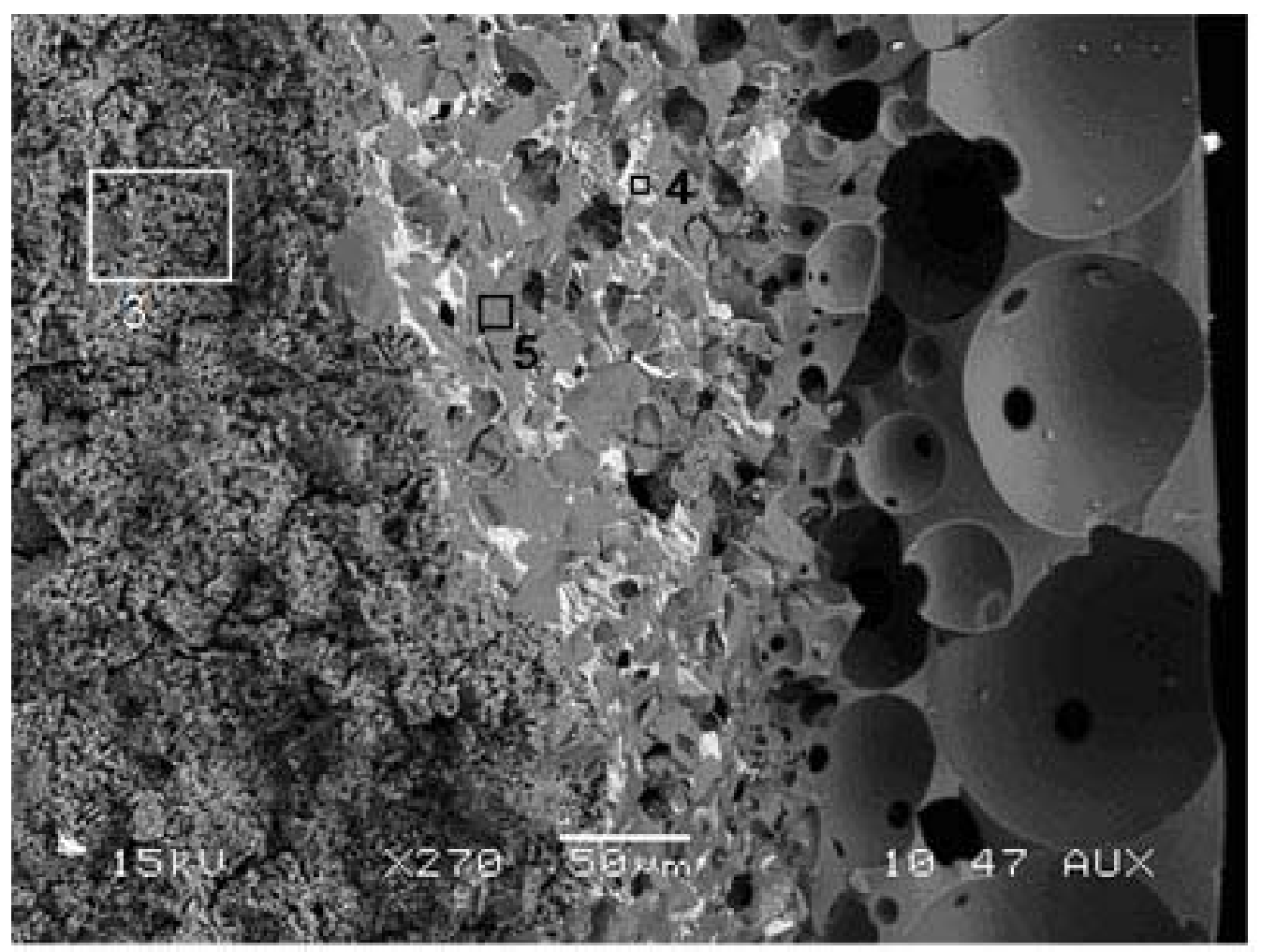

Figure B.14. SEM Micrograph of Cross-Sectioned Vibrocast 60PC Coated with Sodium Silicate Glaze at $800^{\circ} \mathrm{C}$

Table B.7. Composition of Areas 1-5 in Figures B.13 and B.14

\begin{tabular}{||l|r|r|r|r|r||}
\hline \multirow{2}{*}{ Element } & $\mathbf{1}$ & $\mathbf{2}$ & \multicolumn{1}{|c|}{$\mathbf{3}$} & \multicolumn{1}{c||}{$\mathbf{4}$} & \multicolumn{1}{|c||}{$\mathbf{5}$} \\
\cline { 2 - 6 } & \multicolumn{5}{|c|}{ Atomic\% } \\
\hline $\mathrm{O}$ & 43.04 & 38.94 & 35.23 & 3.35 & 16.97 \\
\hline $\mathrm{Na}$ & 17.07 & 16.38 & 2.61 & 1.41 & 9.23 \\
\hline $\mathrm{Al}$ & 19.71 & 22.01 & 31.51 & 2.53 & 18.87 \\
\hline $\mathrm{Si}$ & 14.65 & 16.72 & 27.29 & 1.26 & 11.18 \\
\hline $\mathrm{Zr}$ & 0.46 & 0.27 & 0.14 & & \\
\hline $\mathrm{S}$ & 0.70 & 0.68 & & & \\
\hline $\mathrm{Cl}$ & 0.63 & 1.61 & 0.24 & & 0.76 \\
\hline $\mathrm{K}$ & 1.73 & 1.56 & 0.58 & & \\
\hline $\mathrm{Ca}$ & 0.94 & 0.85 & 1.96 & & \\
\hline $\mathrm{Ti}$ & 0.48 & 0.48 & 0.13 & 33.65 & 3.68 \\
\hline $\mathrm{Fe}$ & 0.60 & 0.50 & 0.30 & 57.79 & 39.31 \\
\hline
\end{tabular}




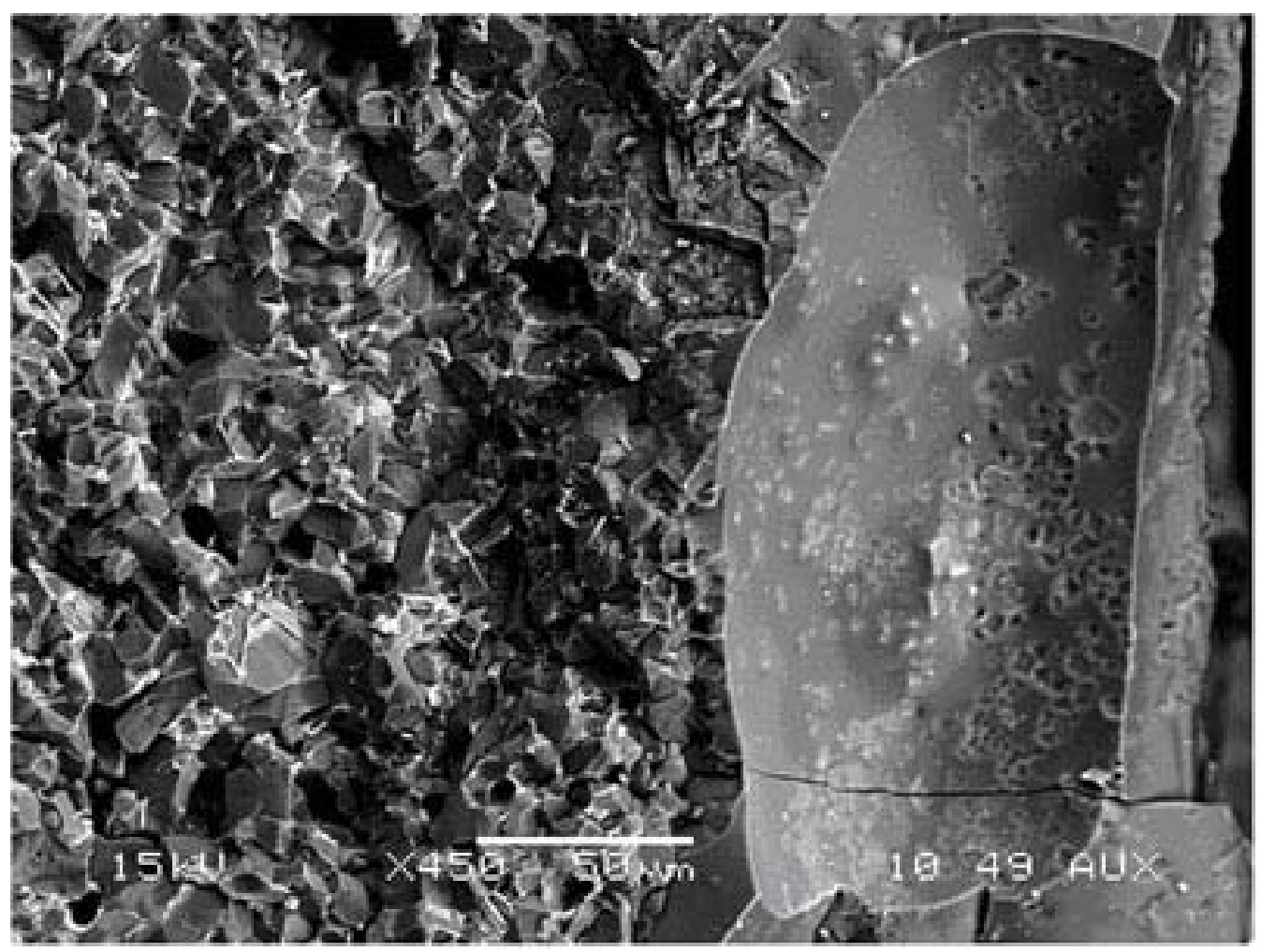

Figure B.15. SEM Micrograph of Cross-Sectioned Vibrocast 60PC Coated with Sodium Silicate Glaze at $1000^{\circ} \mathrm{C}$

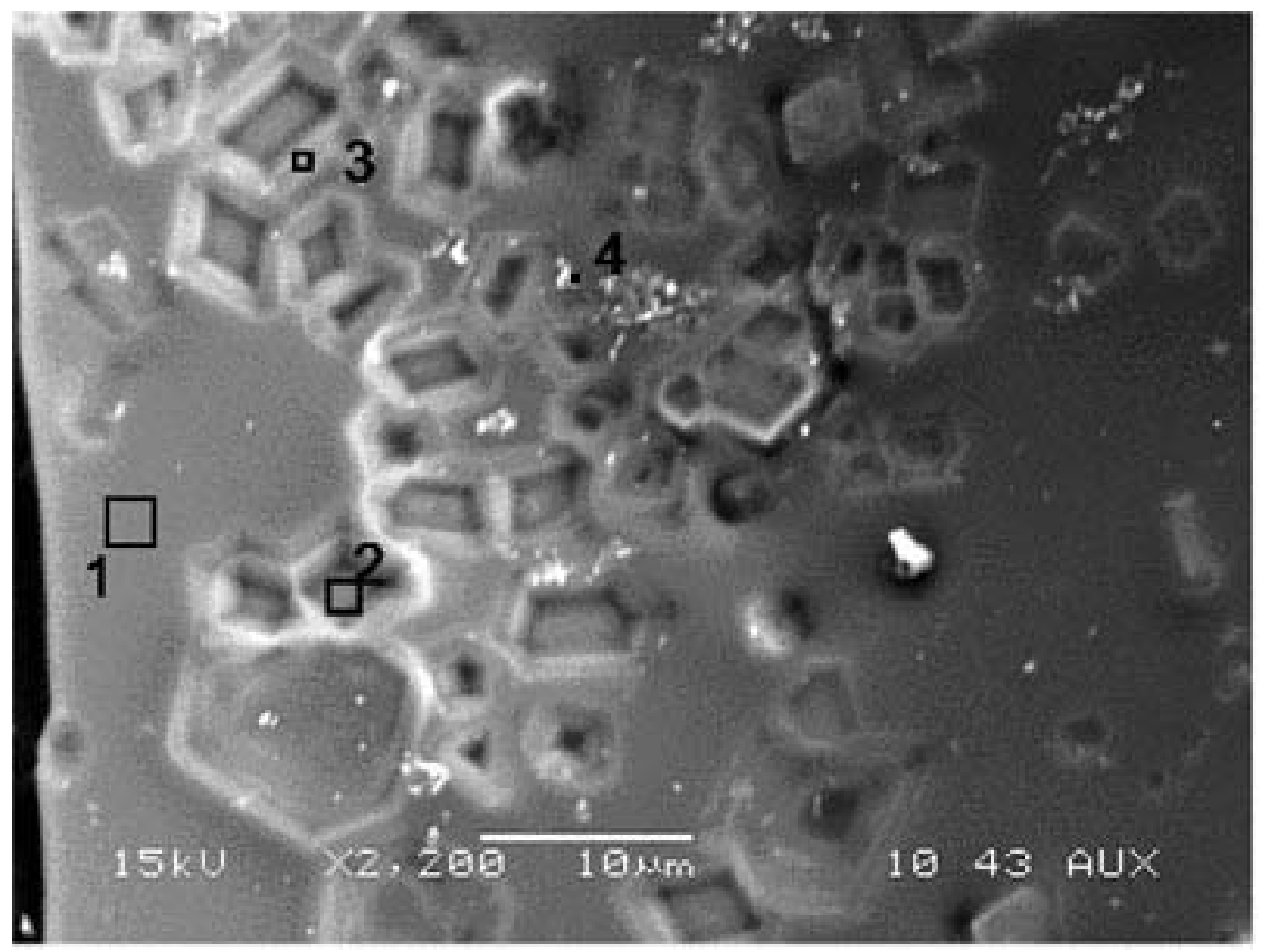

Figure B.16. SEM Micrograph of Cross-Sectioned Vibrocast 60PC Coated with Sodium Silicate Glaze at $1000^{\circ} \mathrm{C}$

B.12 
Table B.8. Composition of Areas 1-4 in Figure B.16

\begin{tabular}{||l|r|r|r|r||}
\hline \multirow{2}{*}{ Element } & $\mathbf{1}$ & \multicolumn{1}{|c|}{$\mathbf{2}$} & \multicolumn{1}{|c|}{$\mathbf{3}$} & \multicolumn{1}{|c|}{$\mathbf{4}$} \\
\cline { 2 - 5 } & \multicolumn{4}{|c|}{ Atomic\% } \\
\hline $\mathrm{O}$ & 42.64 & 35.28 & 39.90 & 41.06 \\
\hline $\mathrm{Na}$ & 10.50 & 10.94 & 7.60 & 8.14 \\
\hline $\mathrm{Mg}$ & & & & 2.35 \\
\hline $\mathrm{Al}$ & 22.29 & 20.48 & 23.47 & 21.90 \\
\hline $\mathrm{Si}$ & 18.99 & 24.30 & 22.13 & 12.59 \\
\hline $\mathrm{Zr}$ & 0.19 & & 0.27 & 0.52 \\
\hline $\mathrm{S}$ & 1.00 & 3.78 & 1.28 & 0.36 \\
\hline $\mathrm{Cl}$ & 1.53 & 2.65 & 2.31 & 0.41 \\
\hline $\mathrm{K}$ & 0.67 & 0.34 & 0.64 & 0.63 \\
\hline $\mathrm{Ca}$ & 1.13 & 2.22 & 1.26 & 0.60 \\
\hline $\mathrm{Ti}$ & 0.55 & & 0.67 & 0.65 \\
\hline $\mathrm{Cr}$ & 0.08 & & & 5.97 \\
\hline $\mathrm{Fe}$ & 0.43 & & 0.45 & 4.00 \\
\hline $\mathrm{Re}$ & & & & 0.82 \\
\hline \hline
\end{tabular}



Figure B.17. SEM Micrograph of Cross-Sectioned Vibrocast 60PC Coated with Sodium Silicate Glaze at $1100^{\circ} \mathrm{C}$ 


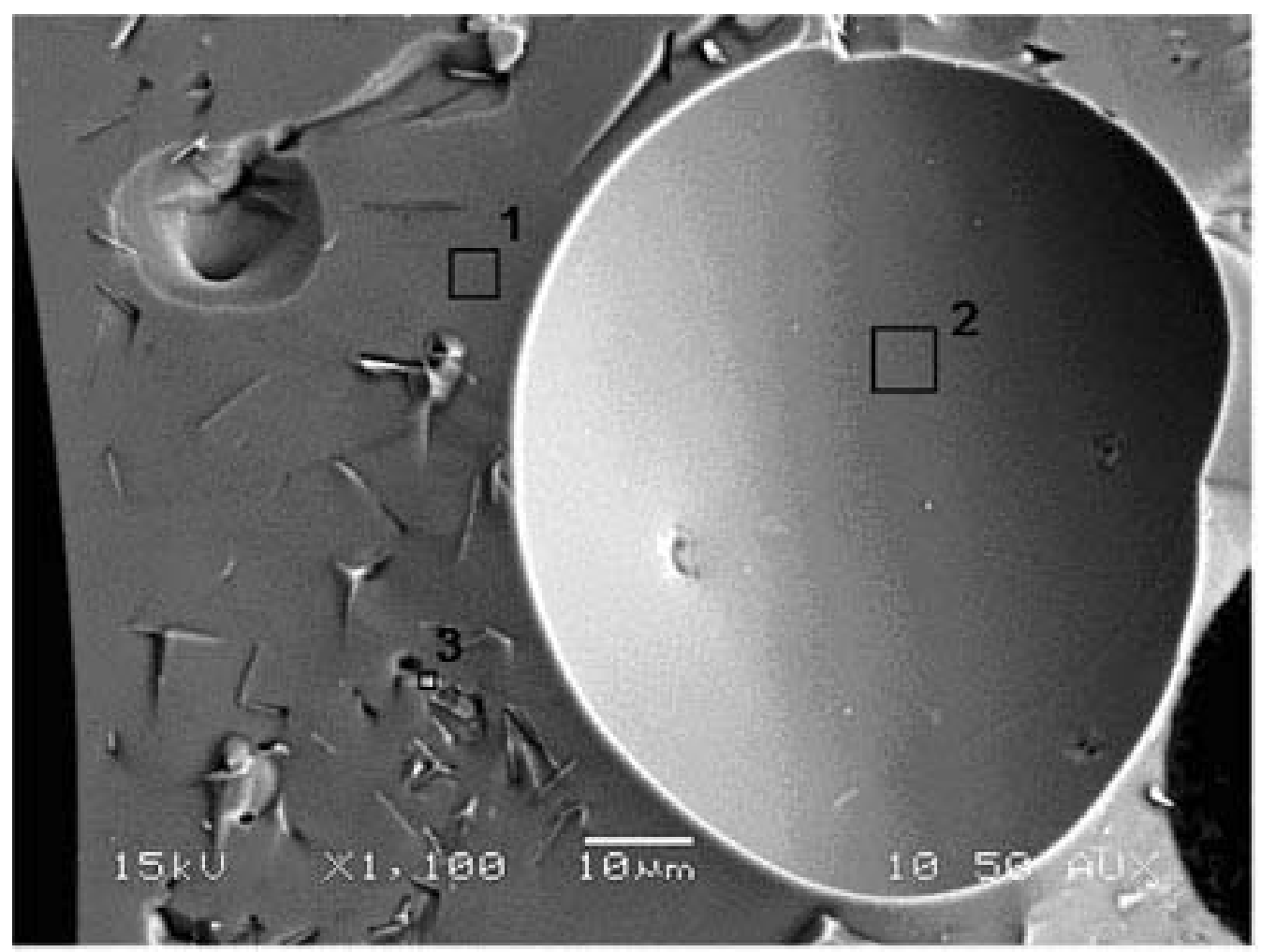

Figure B.18. SEM Micrograph of Cross-Sectioned Vibrocast 60PC Coated with Sodium Silicate Glaze at $1100^{\circ} \mathrm{C}$

Table B.9. Composition of Areas 1-3 in Figure B.18

\begin{tabular}{||l|r|r|r||}
\hline \multirow{2}{*}{ Element } & $\mathbf{1}$ & \multicolumn{1}{|c||}{$\mathbf{2}$} & \multicolumn{1}{|c|}{ Atomic\% } \\
\cline { 2 - 4 } & \multicolumn{3}{|c|}{} \\
\hline $\mathrm{O}$ & 43.59 & 43.23 & 47.08 \\
\hline $\mathrm{Na}$ & 10.84 & 10.04 & 4.52 \\
\hline $\mathrm{Al}$ & 21.57 & 21.75 & 30.80 \\
\hline $\mathrm{Si}$ & 20.01 & 20.40 & 14.71 \\
\hline $\mathrm{Zr}$ & 0.32 & 0.49 & 0.29 \\
\hline $\mathrm{S}$ & 0.22 & 0.44 & 0.13 \\
\hline $\mathrm{Cl}$ & 0.31 & 0.40 & 0.14 \\
\hline $\mathrm{K}$ & 0.72 & 0.75 & 0.40 \\
\hline $\mathrm{Ca}$ & 1.49 & 1.56 & 0.95 \\
\hline $\mathrm{Ti}$ & 0.53 & 0.54 & 0.39 \\
\hline $\mathrm{Fe}$ & 0.40 & 0.39 & 0.60 \\
\hline \multicolumn{4}{|l}{} \\
\hline
\end{tabular}




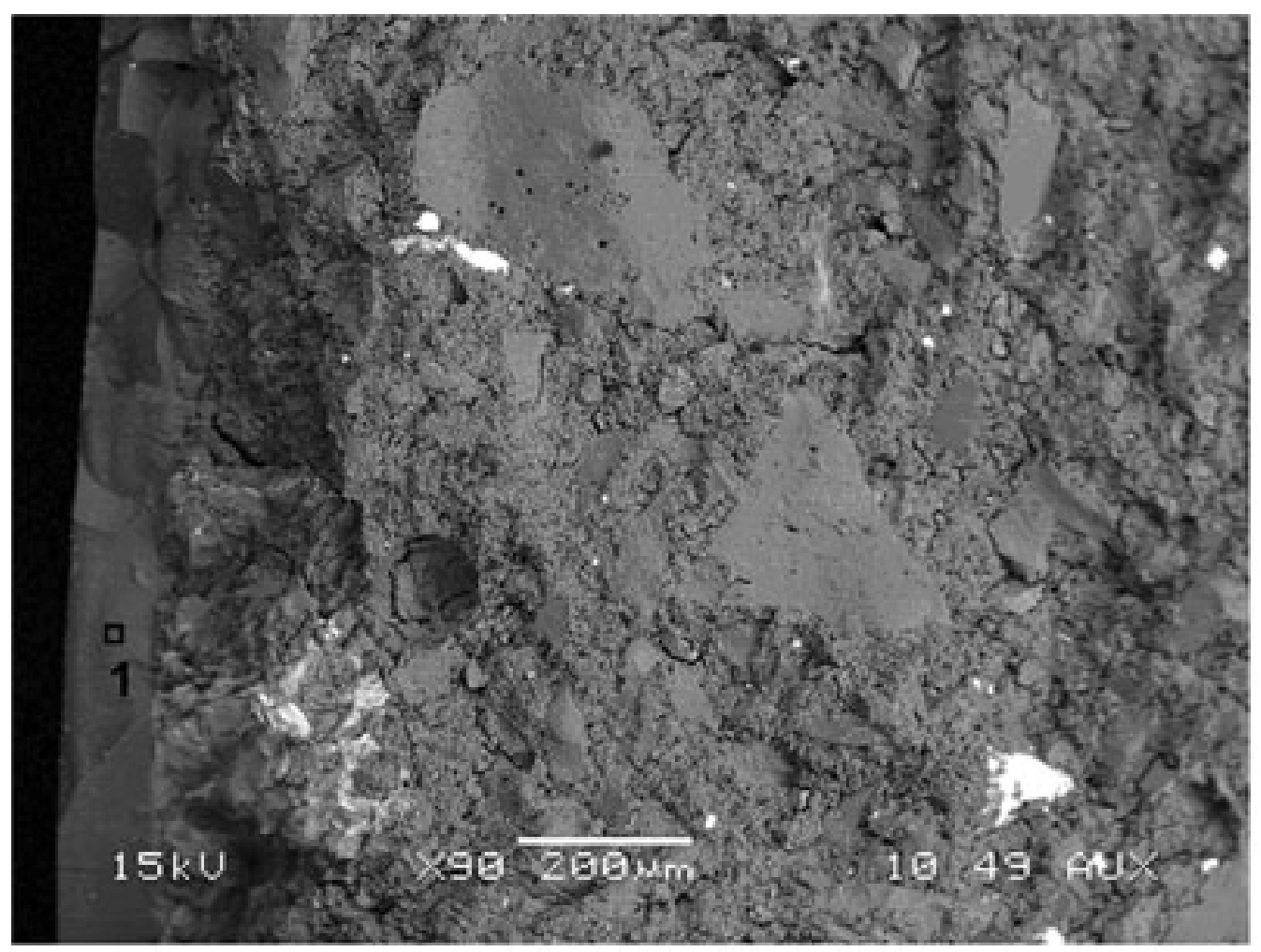

Figure B.19. SEM Micrograph of Cross-Sectioned Vibrocast 60PC Coated with Borosilicate Glaze at $800^{\circ} \mathrm{C}$

Table B.10. Composition of Area 1 in Figure B.19

\begin{tabular}{||l|c||}
\hline \multirow{2}{*}{ Element } & \multicolumn{1}{c|}{$\mathbf{1}$} \\
\cline { 2 - 2 } & Atomic\% \\
\hline $\mathrm{O}$ & 45.93 \\
\hline $\mathrm{Na}$ & 2.08 \\
\hline $\mathrm{Al}$ & 3.69 \\
\hline $\mathrm{Si}$ & 47.36 \\
\hline $\mathrm{S}$ & 0.08 \\
\hline $\mathrm{K}$ & 0.56 \\
\hline $\mathrm{Ti}$ & 0.09 \\
\hline $\mathrm{Fe}$ & 0.21 \\
\hline
\end{tabular}




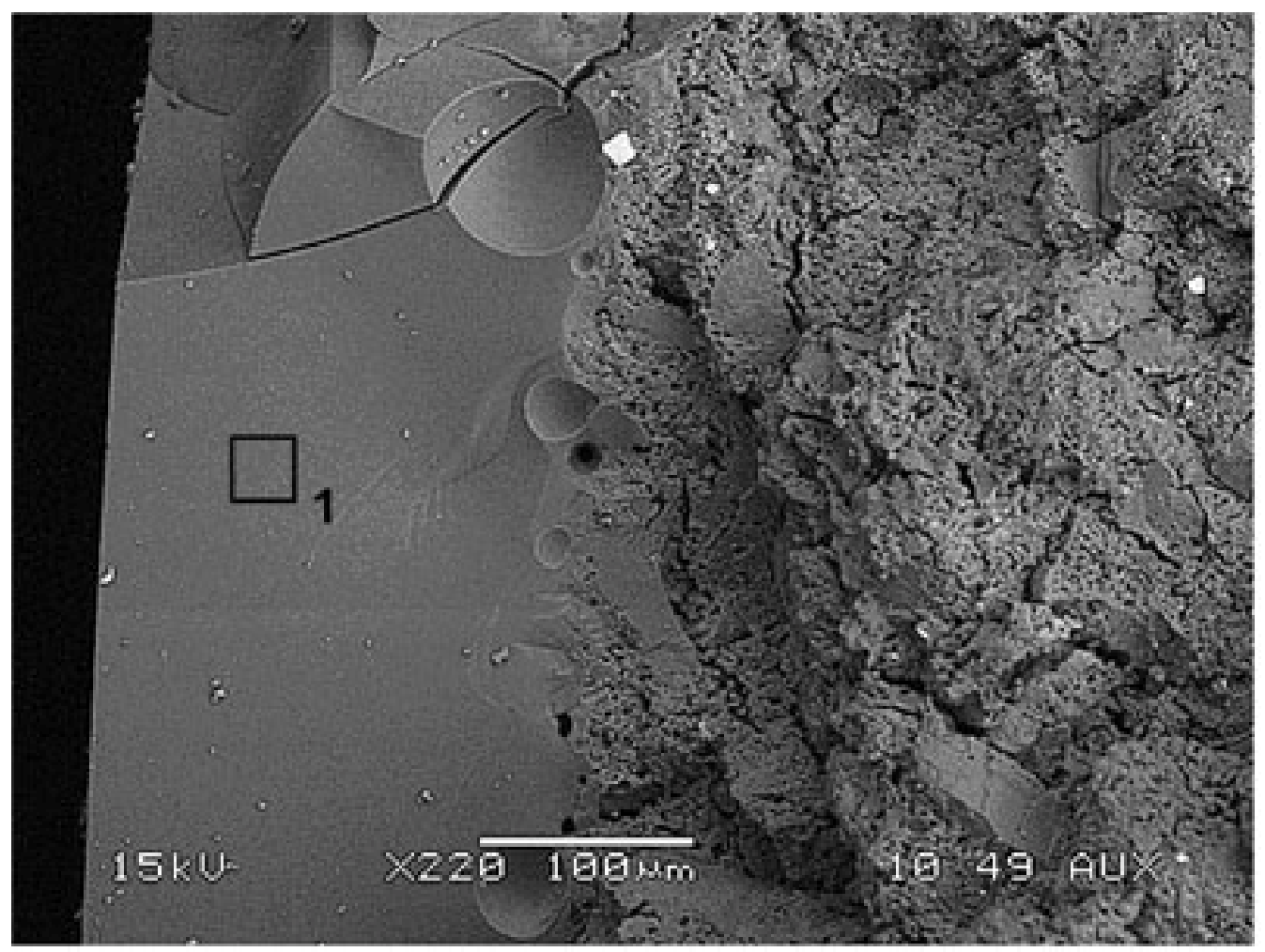

Figure B.20. SEM Micrograph of Cross-Sectioned Vibrocast 60PC Coated with Borosilicate Glaze at $1000^{\circ} \mathrm{C}$

Table B.11. Composition of Area 1 in Figure B.20

\begin{tabular}{||l|c||}
\hline \multirow{2}{*}{ Element } & \multicolumn{1}{|c|}{} \\
\cline { 2 - 2 } & Atomic\% \\
\hline $\mathrm{O}$ & 36.97 \\
\hline $\mathrm{Na}$ & 9.42 \\
\hline $\mathrm{Mg}$ & 0.38 \\
\hline $\mathrm{Al}$ & 12.76 \\
\hline $\mathrm{Si}$ & 37.60 \\
\hline $\mathrm{S}$ & 0.10 \\
\hline $\mathrm{Cl}$ & 0.19 \\
\hline $\mathrm{K}$ & 1.31 \\
\hline $\mathrm{Ca}$ & 0.98 \\
\hline $\mathrm{Ti}$ & 0.29 \\
\hline
\end{tabular}




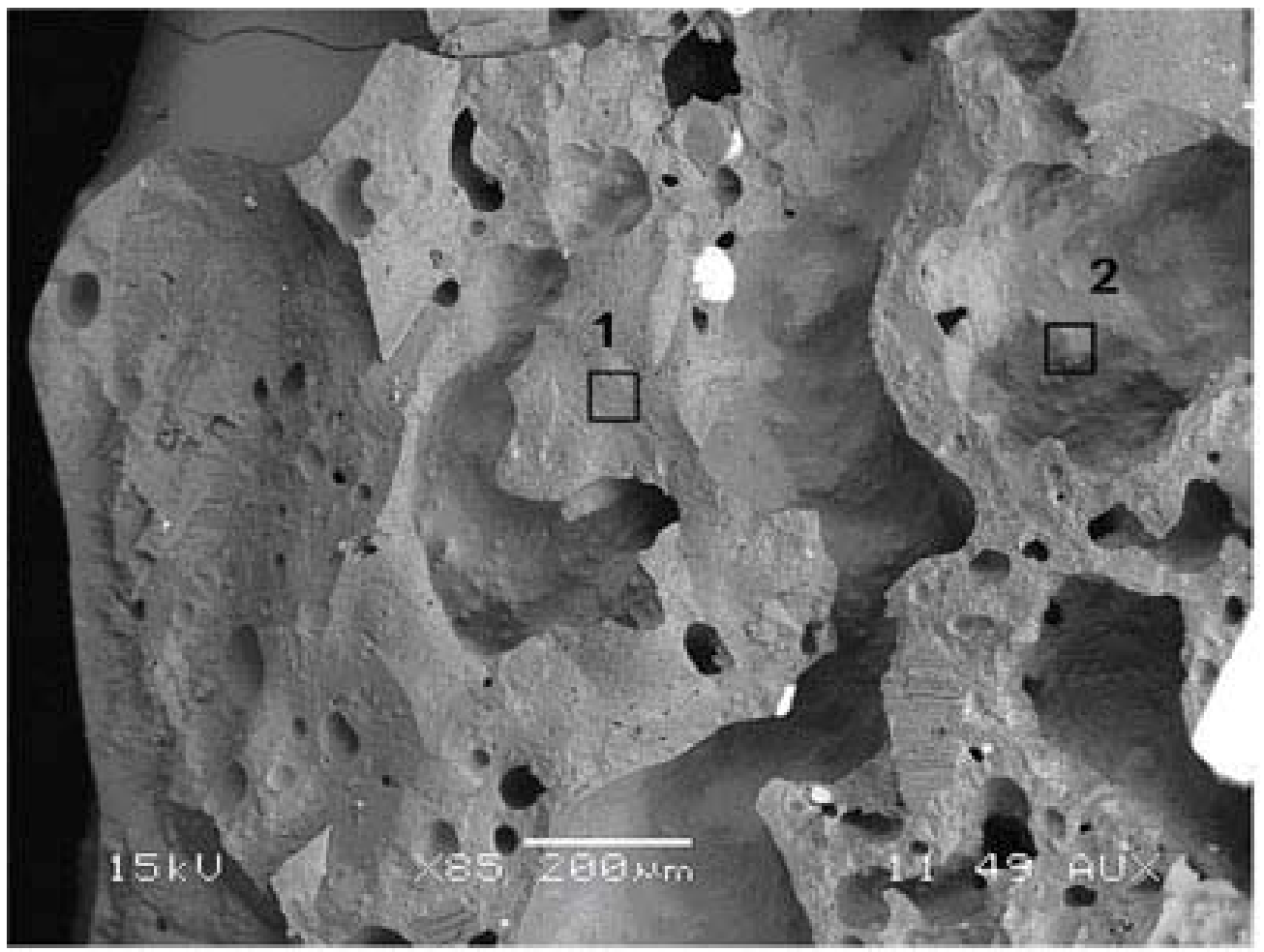

Figure B.21. SEM Micrograph of Cross-Sectioned Vibrocast 60PC Coated with Borosilicate Glaze at $1100^{\circ} \mathrm{C}$

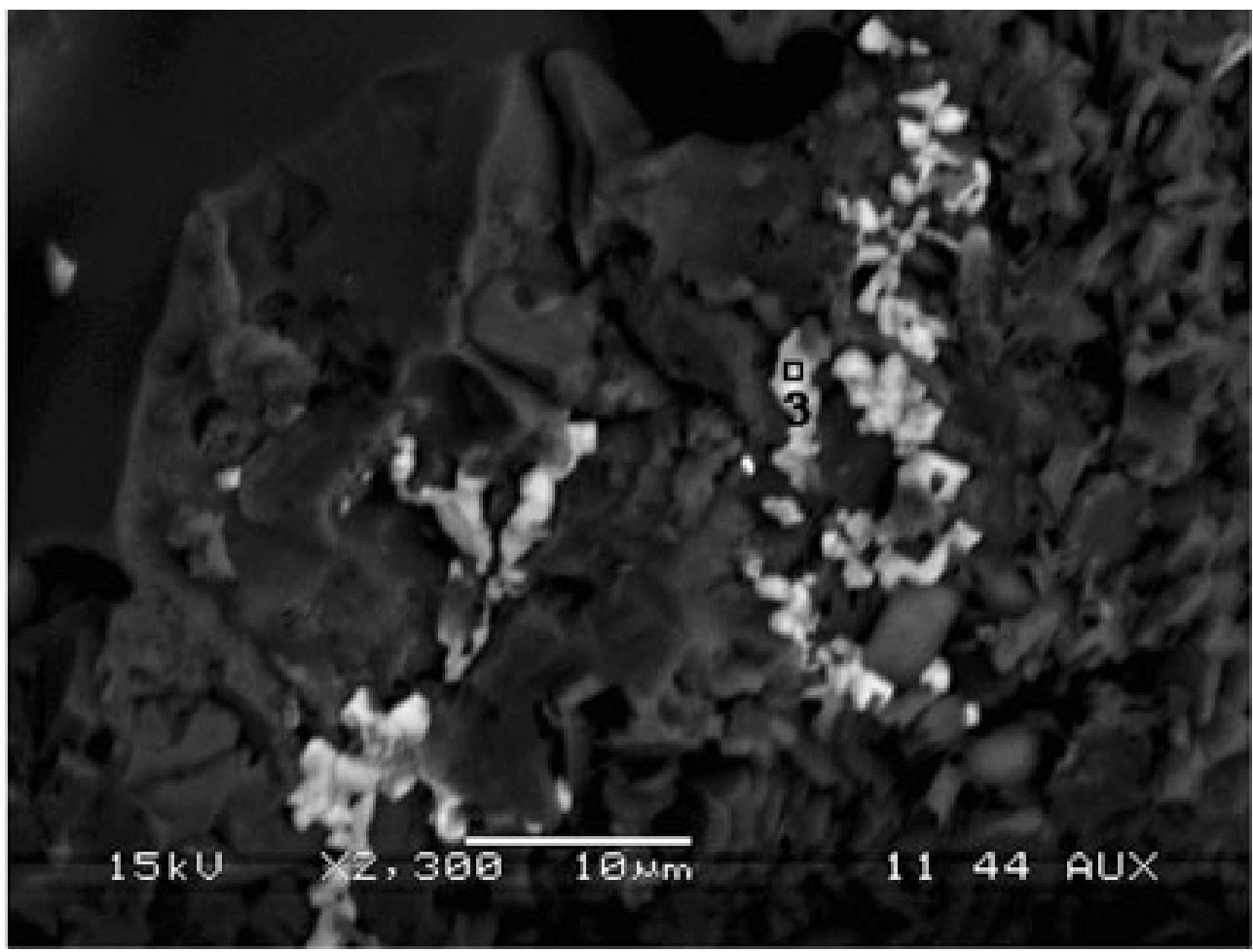

Figure B.22. SEM Micrograph of Cross-Sectioned Vibrocast 60PC Coated with Borosilicate Glaze at $1100^{\circ} \mathrm{C}$ 
Table B.12. Composition of Areas 1-3 in Figures B.21 and B.22

\begin{tabular}{|c|c|c|c|}
\hline \multirow[b]{2}{*}{ Element } & 1 & 2 & 3 \\
\hline & \multicolumn{3}{|c|}{ Atomic\% } \\
\hline $\mathrm{O}$ & 39.67 & 40.85 & 34.36 \\
\hline $\mathrm{Na}$ & 2.29 & 7.06 & 1.69 \\
\hline $\mathrm{Al}$ & 31.44 & 22.68 & 15.06 \\
\hline $\mathrm{Si}$ & 24.22 & 25.14 & 16.23 \\
\hline $\mathrm{P}$ & & 0.44 & \\
\hline $\mathrm{S}$ & & 0.14 & \\
\hline $\mathrm{Cl}$ & 0.06 & 0.31 & 8.20 \\
\hline $\mathrm{K}$ & 0.25 & 0.57 & \\
\hline $\mathrm{Ca}$ & 0.44 & 1.99 & 9.56 \\
\hline $\mathrm{Ti}$ & 1.08 & 0.35 & \\
\hline $\mathrm{Fe}$ & 0.54 & 0.48 & \\
\hline $\operatorname{Re}$ & & & 14.91 \\
\hline
\end{tabular}


Appendix C

Greystone Tile Corrosion Data 


\section{Appendix C: Greystone Tile Corrosion Data}

The table shows measured values of the thickness of a greystone tile corroded in molten glass and then sectioned to measure the loss due to dissolution. Four to five measurements were taken on each section.

\begin{tabular}{||c|c|c|c|c|c|c|c||}
\hline \hline \multirow{2}{*}{$\begin{array}{c}\text { Distance } \\
\text { from top } \\
\text { (mm) }\end{array}$} & $\mathbf{1}$ & $\mathbf{2}$ & $\mathbf{3}$ & $\mathbf{4}$ & $\mathbf{5}$ & Average & SD \\
\hline 0 & 6.450 & 6.420 & 6.410 & 6.420 & - & 6.425 & 0.017 \\
\hline 11.3 & 5.110 & 5.010 & 5.170 & 4.900 & - & 5.048 & 0.118 \\
\hline 12.8 & 4.870 & 5.130 & 5.440 & 5.230 & 5.120 & 5.158 & 0.206 \\
\hline 24.2 & 5.380 & 5.120 & 5.290 & 5.560 & 5.700 & 5.410 & 0.227 \\
\hline 25.2 & 4.940 & 5.080 & 5.150 & 5.240 & 5.040 & 5.090 & 0.113 \\
\hline 58.5 & 3.960 & 3.960 & 4.000 & 4.080 & 4.500 & 4.100 & 0.229 \\
\hline 59.5 & 4.080 & 3.800 & 3.660 & 3.860 & 3.920 & 3.864 & 0.155 \\
\hline 74.4 & 3.040 & 2.840 & 2.970 & 3.210 & 2.950 & 3.002 & 0.137 \\
\hline 75.4 & 3.290 & 3.320 & 2.940 & 3.590 & 3.160 & 3.260 & 0.238 \\
\hline 101.7 & 4.430 & 4.210 & 3.480 & 3.310 & 3.420 & 3.770 & 0.512 \\
\hline 102.7 & 2.820 & 2.830 & 2.290 & 2.270 & - & 2.553 & 0.315 \\
\hline
\end{tabular}

C. 1 
Appendix D

Castable Refractory Block Material Selection for the Bulk Vitrification Process 


\title{
Appendix D
}

\section{Castable Refractory Block Material Selection for the Bulk Vitrification Process}

\author{
P. R. Hrma, M. J. Schweiger, J. Matyáš, D. N. Tran, J. V. Crum, D. S. Kim,
}

N. H. Wong, and K. B. Minister 



\section{Abbreviations and Acronyms}

$\begin{array}{ll}\text { APEL } & \text { Applied Processing Engineering Laboratory } \\ \text { BV } & \text { bulk vitrification } \\ \text { CRB } & \text { castable refractory block } \\ \text { DTA } & \text { differential thermal analysis } \\ \text { EDS } & \text { energy dispersive spectroscopy } \\ \text { EGA } & \text { evolved gas analysis } \\ \text { ES } & \text { engineering-scale } \\ \text { GDL } & \text { Glass Development Laboratory } \\ \text { LAW } & \text { low-activity waste } \\ \text { MIS } & \text { molten ionic salt } \\ \text { MS } & \text { mass spectrometry } \\ \text { PNNL } & \text { Pacific Northwest National Laboratory } \\ \text { TGA } & \text { thermogravimetric analysis } \\ \text { VHT } & \text { vapor hydration test } \\ \text { XRD } & \text { X-ray diffraction }\end{array}$




\section{Contents}

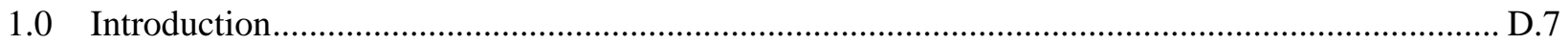

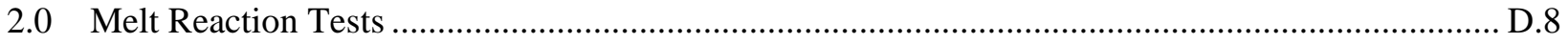

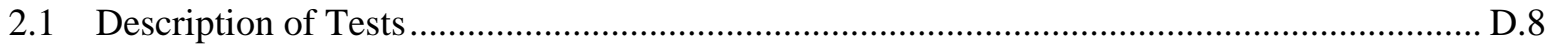

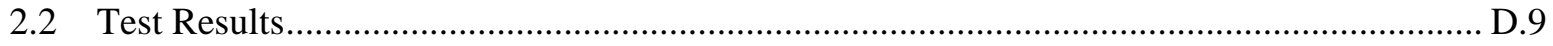

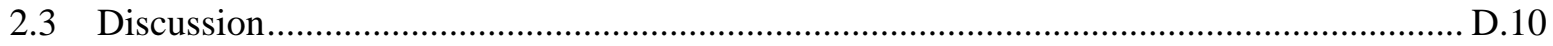

3.0 Refractory-Melt Interaction ............................................................................................ D.13

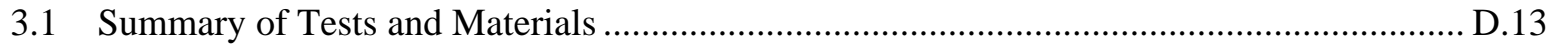

3.2 Molten Ionic Salt (MIS) Permeability Test .................................................................... D.15

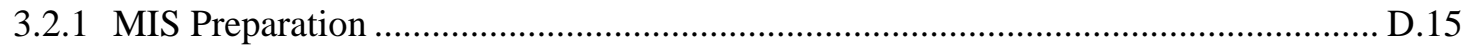

3.2.2 Test Materials, Assembly, and Procedure ............................................................ D.16

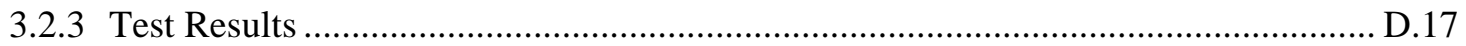

3.3 Molten Glass Permeability Test........................................................................... D.21

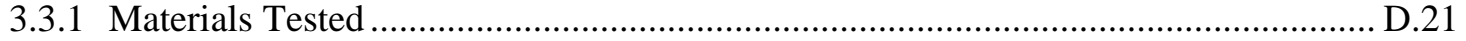

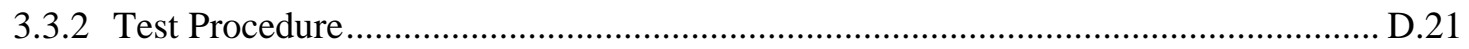

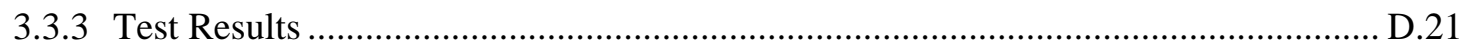

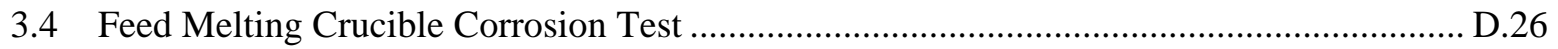

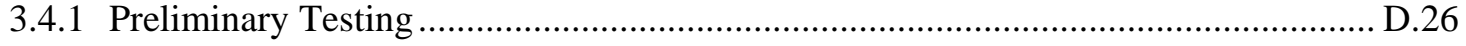

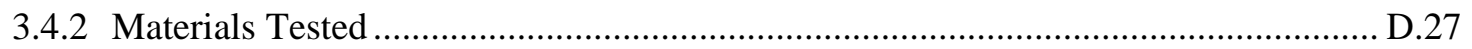

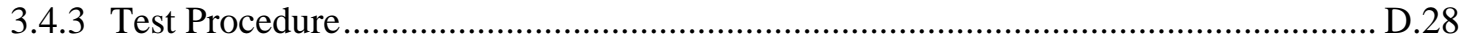

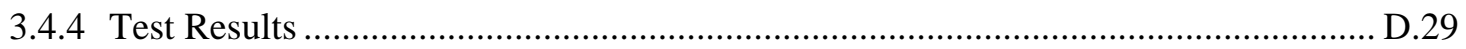

3.5 Molten Glass Crucible Corrosion Test ….......................................................................... D. D.

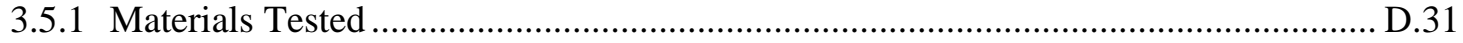

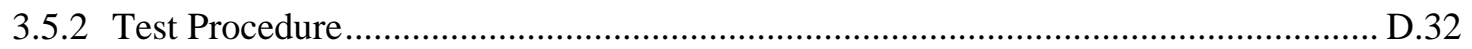

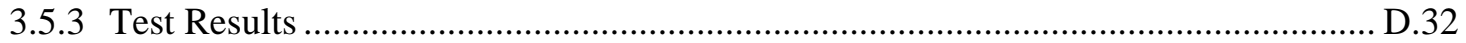

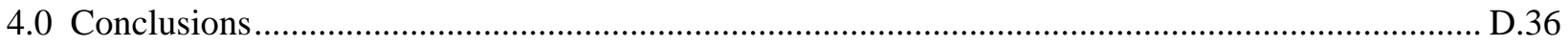

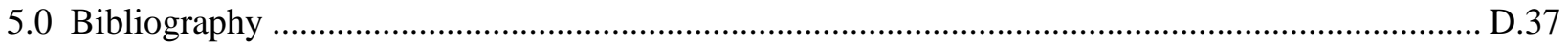




\section{Figures}

D.1. MIS Composition ..................................................................................................... D.

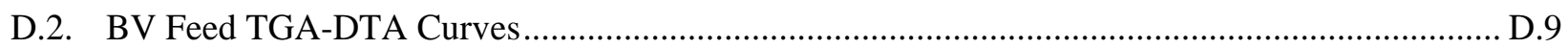

D.3. BV Feed Volume Expansion in Quartz-Glass Crucible ........................................................ D.10

D.4. Evolved Gases from and Relative Volume of BV Feed .......................................................... D.11

D.5. AMEC Soil, Optical Micrograph............................................................................................... D.14

D.6. AMEC Soil X-Ray Diffraction Pattern .................................................................................. D.15

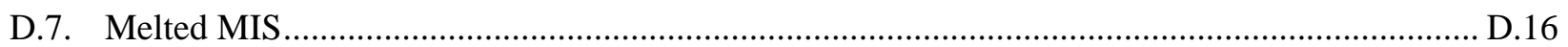

D.8. Refractory-Melt Interaction Test Assembly ....................................................................... D.17

D.9. Alfrax (above) and Vibrocast 60PC (below) Refractory Coupons after Exposure to MIS .......... D.18

D.10. Coupons of Vibrocast 60PC Exposed to MIS at $800^{\circ} \mathrm{C}$ for 24 Hours........................................ D.18

D.11. Fracture Surface of Refractory Coupons Exposed to MIS ....................................................... D.19

D.12. EDS Dot Maps of Fracture Surfaces of Refractory Coupons Exposed to MIS ......................... D.20

D.13. Coupons of Vibrocast 60PC (left) and Alfrax (right) Exposed to Molten Glass at $1300^{\circ} \mathrm{C}$

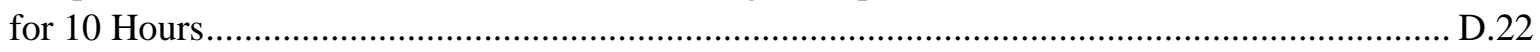

D.14. Vibrocast 60PC (Mullite) Refractory Submerged in Molten Glass at $1300^{\circ} \mathrm{C}$ for 10 Hours ....... D.22

D.15. Alfrax (Alumina) Refractory Submerged in Molten Glass at $1300^{\circ} \mathrm{C}$ for 10 Hours ................... D.23

D.16. Sections of Coated Coupons of Refractory Materials After Their 9-h Exposure to Molten

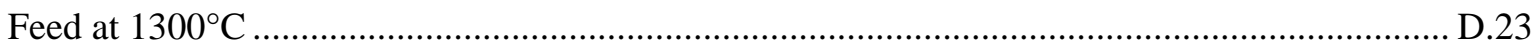

D.17. Sections of Coated Coupons of Fire Brick Yukon After 10-h Exposure to Molten Feed at $1300^{\circ} \mathrm{C}$

D.18. Sections of Coated Coupons of Fire Clay with 50 Mass\% Silica After 10-h Exposure to

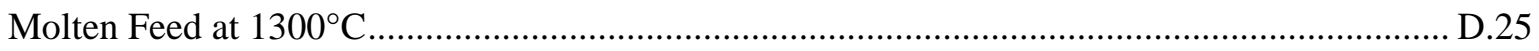

D.19. Section through Fireclay Material (with 50 mass\% silica flour) ............................................. D.25

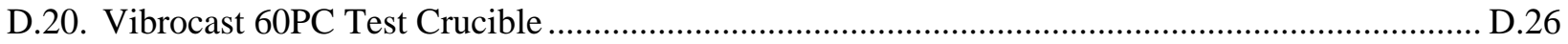

D.21. Cracks in Vibrocast 60PC Test Crucible Heated with BV Feed to $1150^{\circ} \mathrm{C}$............................... D.26

D.22. Side View of Vibrocast 60PC Test Crucible as in Figure D.21 …............................................. D.27

D.23. View of Inner Coating on Vibrocast 60PC Crucible .............................................................. D.28

D.24. Fireclay Crucible Before and After Coating........................................................................ D.28

D.25. Vibrocast 60PC Crucible Corroded with BV Feed at $1400^{\circ} \mathrm{C}$ for 24 Hours ............................. D.29

D.26. Detail of Vibrocast 60PC Crucible in Figure D.25 .................................................................. D.29

D.27. Detail of Corrosion Damage of Coated Vibrocast 60PC Crucible ............................................. D.30

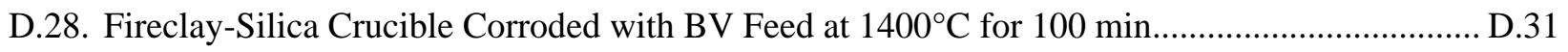




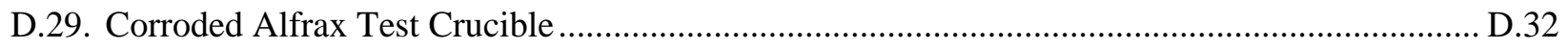

D.30. View of Corroded and Sectioned Alfrax Test Crucible............................................................ D.33

D.31. Corroded Vibrocast 60PC Test Crucibles: 3 Hours at $1500^{\circ} \mathrm{C}$ (left) and 24 Hours at $1500^{\circ} \mathrm{C}$

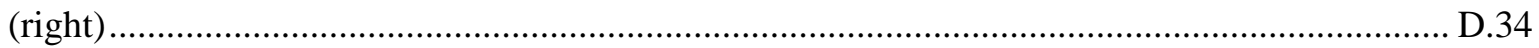

D.32. Corroded Vibrocast 60PC Crucible Cross-Section, 24 Hours at $1500^{\circ} \mathrm{C}$.................................. D.34

D.33. Vibrocast 60PC, 24 Hours at $1500^{\circ} \mathrm{C}$; Melt-Refractory Interface............................................. D.35

\section{Tables}

D.1. Concentrations of Reagents in LAW Solution Simulant and MIS .......................................... D.9

D.2. Room-Temperature Volumes of Gases Evolved from BV Feed in mL/g ................................. D.10

D.3. Compositions of Tested Refractory Materials (in mass fractions) …......................................... D.14

D.4. MIS Preparation Melting Schedule ................................................................................ D.16

D.5. Crucible Losses to Corrosion in $\mathrm{mm}$................................................................................... D.3

D.6. Crucible Losses to Corrosion in $\mathrm{mm}$........................................................................................... D.33 


\subsection{Introduction}

This appendix was adopted from a test report that documents laboratory studies at Pacific Northwest National Laboratory (PNNL) in support of the bulk vitrification (BV) process enhancements. The work was done in 2003, but was never issued in a published report. The purpose for testing was to supply the design basis for selecting the castable refractory lining for the BV waste container. It became clear, after the initial engineering-scale and large-scale tests, that melting reactions and the refractory-meltinteraction are important aspects of the BV process. The 2003 results are appended to this report to provide important background for the study of Tc/Re transport into the castable refractory block (CRB) through penetration of liquid phases at early stages of melting.

The first step of the 2003 work was to understand the basic melting reactions that occur during the BV process. Scoping tests were performed to characterize the processes associated with waste salt melting, migration, decomposition, and incorporation into a glass.

The next step was to select a suitable material for the CRB that would contain the glass and not substantially change the glass formulation so that the entire waste glass block, including the refractory interface and the top surface, meets glass performance acceptance criteria. Suitable CRB materials had to minimize the permeation of molten salt into the pores of refractory walls during the initial stages of melting to reduce the susceptibility to subsequent attack by molten glass and to reduce the amount of unreacted material remaining inside the pores where they would be susceptible to water leaching after disposal.

Several types of refractory materials considered for the BV process melter lining were subjected to a series of laboratory tests. Tests were designed to assess the penetration of molten low-activity waste (LAW) and molten ionic salt (MIS) $)^{(\mathrm{a})}$ into the refractory liner material, its impact on the refractory, and the rate of subsequent corrosion by molten glass. An attempt was made to use protective coating that would prevent the initial attack by MIS, which is abundant in the melter feed, at temperatures below $750^{\circ} \mathrm{C}$.

(a) Molten LAW and MIS are used interchangeably in this Appendix because molten LAW was used for the experiments conducted. However, in the BV feed, MIS contains also borate that is used, in the form of $\mathrm{B}_{2} \mathrm{O}_{3}$, as an additive. 


\subsection{Melt Reaction Tests}

Scoping tests were performed to gain understanding of the basics of the BV melting process. The MIS melts at temperatures well below the temperature where the soil and glass-forming constituents participate in glass-forming reactions. The MIS wets the soil grains, but excess MIS melts may drain and penetrate into other porous solids like the CRB. The volatilization of MIS components may also occur with vaporized species eventually condensing in bubbles, pores in the refractory walls, and the space above the melt. The undesirable transport of the MIS is reduced by the volume reduction during nitrate decomposition and the increasing viscosity associated with reactions with the mineral constituents of the soil and additives to form glass. The following scoping tests were performed to characterize the processes of molten salt formation, migration, decomposition, and volatilization:

1. Differential thermal analysis (DTA)

2. Thermogravimetric analysis (TGA)

3. Evolved gas analysis (EGA).

\subsection{Description of Tests}

The DTA, TGA, and EGA were conducted simultaneously on a small sample of feed with the SDT 2960 thermoanalytical equipment to provide information on reaction products and mass changes associated with the feed-to-glass conversion process. Approximately 50-mg samples were heated at $4^{\circ} \mathrm{C} / \mathrm{min}$ in $\mathrm{He}$ from room temperature to $1500^{\circ} \mathrm{C}$. The off-gas was analyzed quantitatively by gas chromatography-mass spectrometry (GC-MS) (Hewlett Packard 5890A GC with 5971A MS). The fractions of gases (e.g., $\mathrm{CO}_{2}$, $\mathrm{CO}, \mathrm{NO}_{2}, \mathrm{~N}_{2} \mathrm{O}, \mathrm{H}_{2}$ ) were recorded as a function of temperature. The feed melting reactions are basically decomposition reactions of the MIS and reactions of MIS with soil, boric acid, and zirconia. The composition of the LAW simulant and the corresponding MIS after all the chemical water has been removed are shown in Table D.1 and Figure D.1.

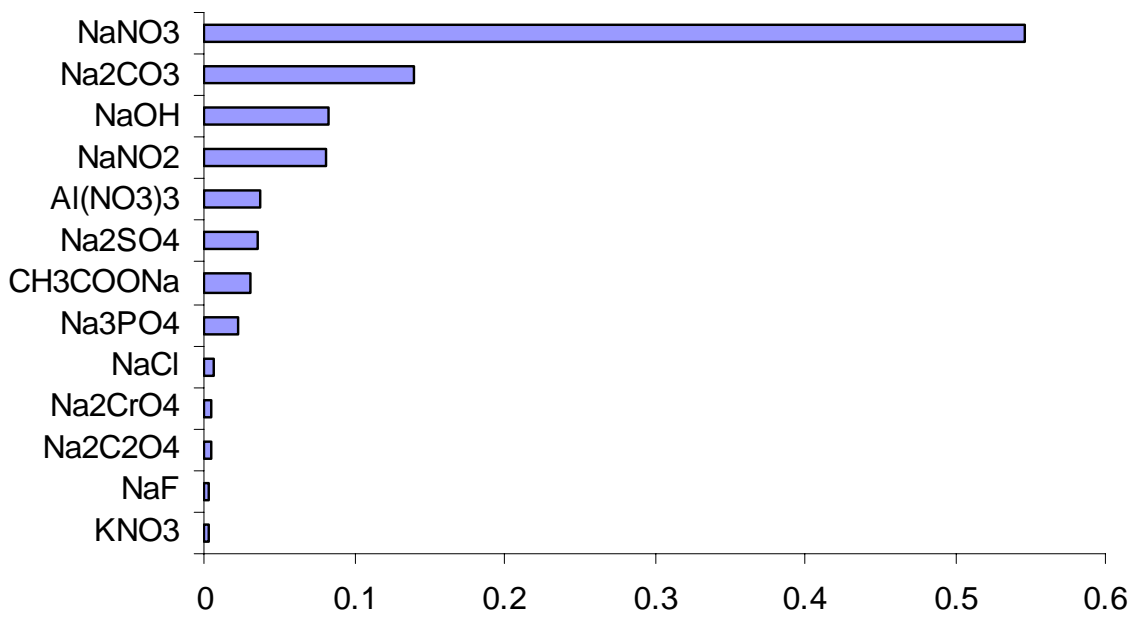

Figure D.1. MIS Composition 
Table D.1. Concentrations of Reagents in LAW Solution Simulant and MIS

\begin{tabular}{|c|c|c|c|}
\hline LAW & g/L & MIS & Mass Fraction \\
\hline $\mathrm{H}_{2} \mathrm{O}$ & 860 & & \\
\hline $\mathrm{Na}_{2} \mathrm{C}_{2} \mathrm{O}_{4}$ & 1.58 & $\mathrm{Na}_{2} \mathrm{C}_{2} \mathrm{O}_{4}$ & 0.0044 \\
\hline $\mathrm{CH}_{3} \mathrm{COONa}$ & 10.79 & $\mathrm{CH}_{3} \mathrm{COONa}$ & 0.0301 \\
\hline $\mathrm{NaNO}_{3}$ & 196.11 & $\mathrm{NaNO}_{3}$ & 0.5464 \\
\hline $\mathrm{KNO}_{3}$ & 1.25 & $\mathrm{KNO}_{3}$ & 0.0035 \\
\hline $\mathrm{NaOH}$ & 29.58 & $\mathrm{NaOH}$ & 0.0824 \\
\hline $\mathrm{Al}\left(\mathrm{NO}_{3}\right)_{3} \cdot 9 \mathrm{H}_{2} \mathrm{O}$ & 23.90 & $\mathrm{Al}\left(\mathrm{NO}_{3}\right)_{3}$ & 0.0378 \\
\hline $\mathrm{Na}_{2} \mathrm{CO}_{3}$ & 50.35 & $\mathrm{Na}_{2} \mathrm{CO}_{3}$ & 0.1403 \\
\hline $\mathrm{Na}_{2} \mathrm{SO}_{4}$ & 12.78 & $\mathrm{Na}_{2} \mathrm{SO}_{4}$ & 0.0356 \\
\hline $\mathrm{Na}_{2} \mathrm{CrO}_{4}$ & 1.68 & $\mathrm{Na}_{2} \mathrm{CrO}_{4}$ & 0.0047 \\
\hline $\mathrm{Na}_{3} \mathrm{PO}_{4} \cdot 12 \mathrm{H}_{2} \mathrm{O}$ & 18.70 & $\mathrm{Na}_{3} \mathrm{PO}_{4}$ & 0.0225 \\
\hline $\mathrm{NaCl}$ & 2.56 & $\mathrm{NaCl}$ & 0.0071 \\
\hline $\mathrm{NaF}$ & 1.33 & $\mathrm{NaF}$ & 0.0037 \\
\hline $\mathrm{NaNO}_{2}$ & 29.26 & $\mathrm{NaNO}_{2}$ & 0.0815 \\
\hline $\mathrm{CsNO}_{3}$ & $1.0 \mathrm{e}-05$ & & \\
\hline
\end{tabular}

\subsection{Test Results}

The TGA-DTA data of the BV feed are shown in Figure D.2. Figure D.3 shows photographs of the quartz-glass crucible with feed at different temperatures during $4^{\circ} \mathrm{C} / \mathrm{min}$ heat treatment. The EGA results in Figure D.4 show the evolution of gases and sample volume as functions of temperature. Table D.2 lists the integrated volumes of gases. The total volume of gasses evolved from $1 \mathrm{~g}$ of feed amounts to $7 \mathrm{~mL}$ at room temperature, or $24.5 \mathrm{~mL}$ at $750^{\circ} \mathrm{C}$. Based on stoichiometric calculation, the corresponding mass is $10 \mathrm{mg}$ gas per $1 \mathrm{~g}$ of feed. Because $1 \mathrm{~g}$ of glass is produced from $1.24 \mathrm{~g}$ of feed, and the glass density is $1.65 \mathrm{~g} / \mathrm{mL}$, then $50 \mathrm{~mL}$ of gas evolves from $1 \mathrm{~mL}$ of glass at $750^{\circ} \mathrm{C}$.
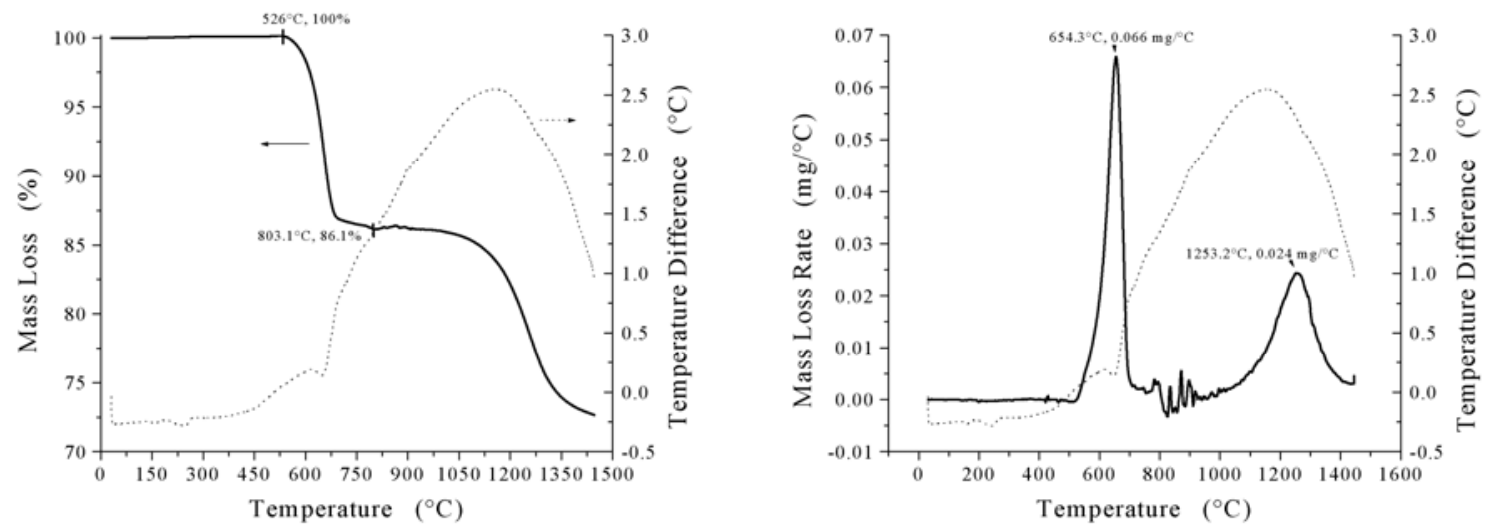

Figure D.2. BV Feed TGA-DTA Curves 

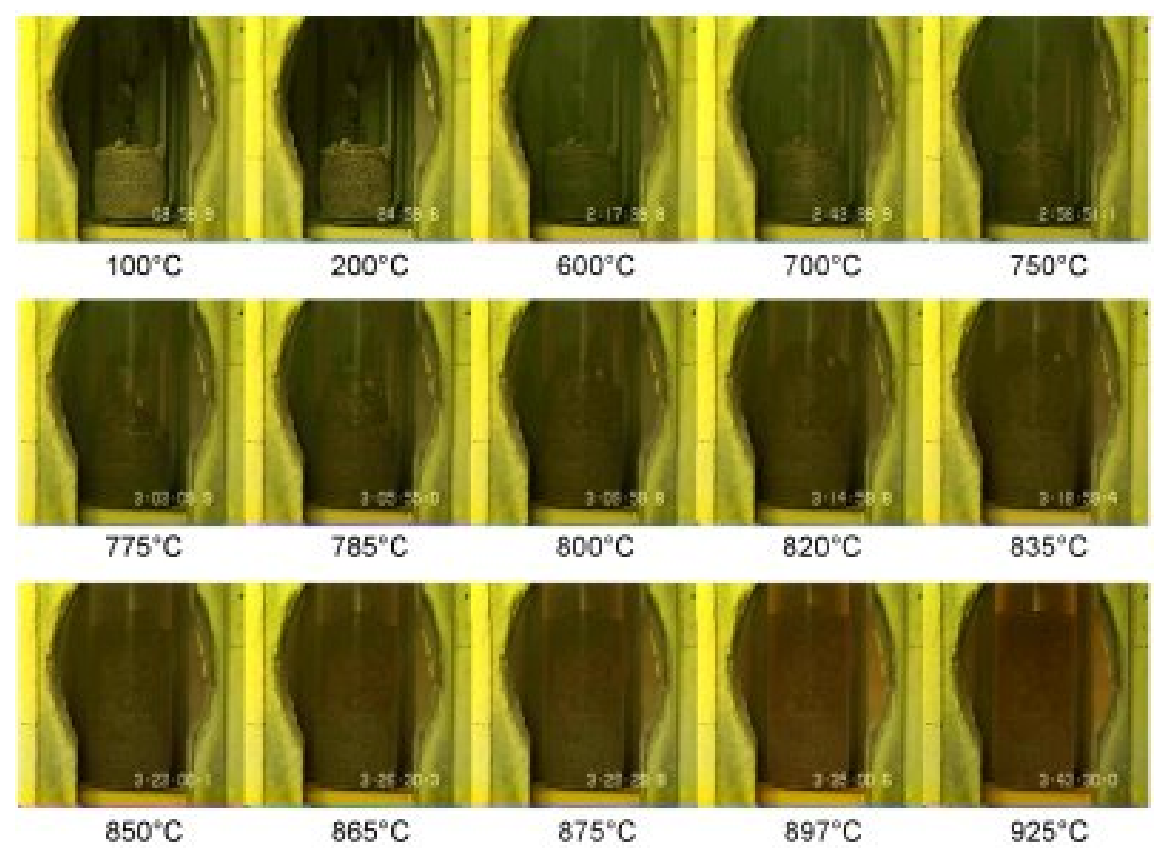

Figure D.3. BV Feed Volume Expansion in Quartz-Glass Crucible

Table D.2. Room-Temperature Volumes of Gases Evolved from BV Feed in mL/g

\begin{tabular}{||l|l||}
\hline $\mathrm{NO}$ & 2.611 \\
\hline $\mathrm{N}_{2} \mathrm{O}$ & 0.041 \\
\hline $\mathrm{CO}_{2}$ & 1.669 \\
\hline $\mathrm{CO}$ & 1.755 \\
\hline $\mathrm{O}_{2}$ & 0.951 \\
\hline Total & 7.027 \\
\hline
\end{tabular}

Feed expansion occurs only when a sufficient fraction of glass melt is formed to trap bubbles. Mild expansion starts at $600^{\circ} \mathrm{C}$. Major expansion occurs between $750^{\circ}$ and $850^{\circ} \mathrm{C}$. The feed approximately doubles its volume before releasing virtually of all the gas phase by $925^{\circ} \mathrm{C}$.

\subsection{Discussion}

The chemical reactions associated with individual peaks cannot be conclusively identified without a more detailed study, but suggestions regarding the possible chemical reactions are presented below.

The evolution of $\mathrm{CO}_{2}, \mathrm{CO}$, and $\mathrm{NO}$ at $150-200^{\circ} \mathrm{C}$ seen in the EGA are probably associated with the decomposition of the oxalate and oxalate reaction with nitrate:

$$
\begin{gathered}
\mathrm{Na}_{2} \mathrm{C}_{2} \mathrm{O}_{4} \rightarrow \mathrm{Na}_{2} \mathrm{O}+\mathrm{CO}_{2}+\mathrm{CO} \\
3 \mathrm{Na}_{2} \mathrm{C}_{2} \mathrm{O}_{4}+2 \mathrm{NaNO}_{3} \rightarrow 4 \mathrm{Na}_{2} \mathrm{O}+6 \mathrm{CO}_{2}+2 \mathrm{NO}
\end{gathered}
$$




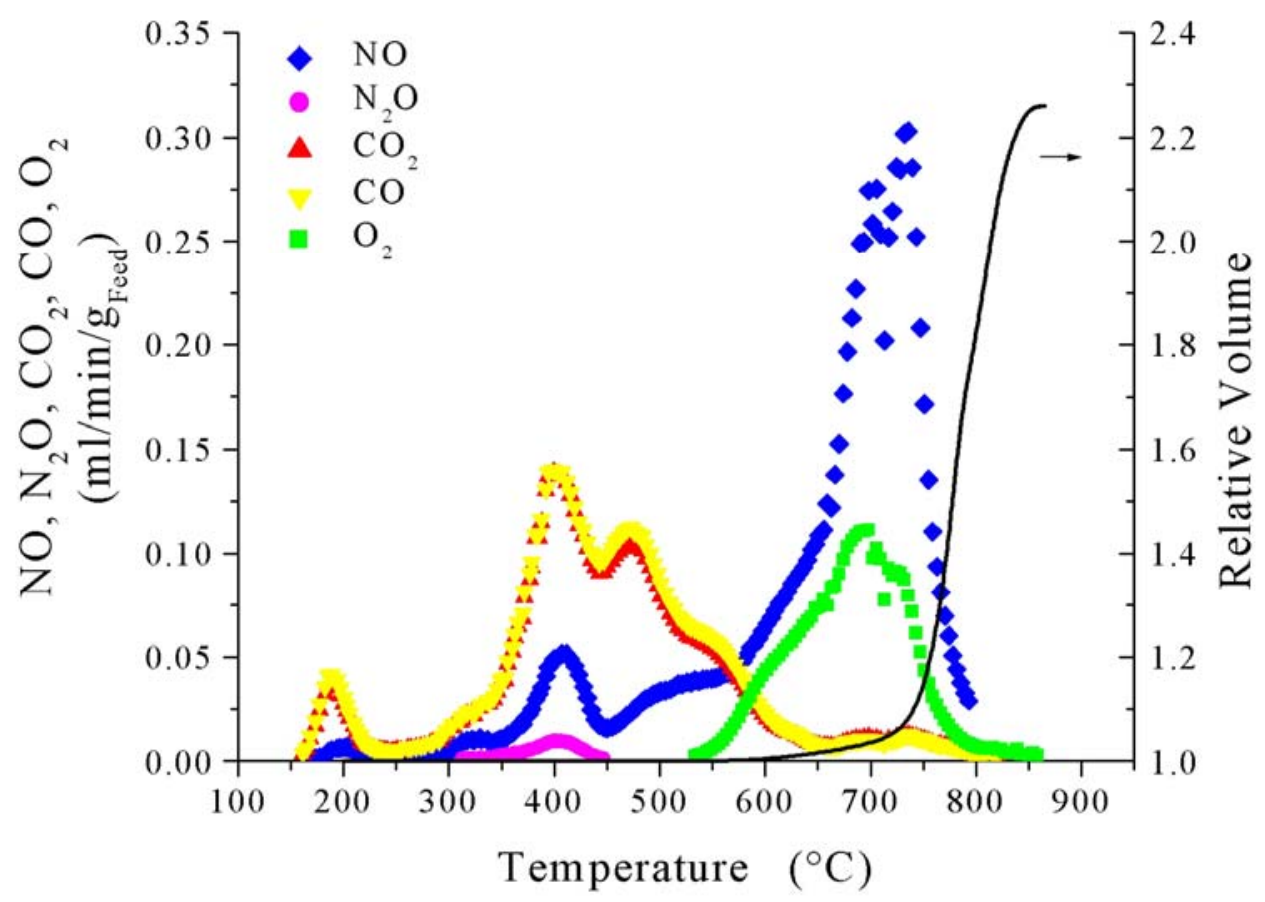

Figure D.4. Evolved Gases from and Relative Volume of BV Feed

The DTA shows that there is a small endothermic peak at approximately $175^{\circ} \mathrm{C}$ followed by a small exothermic peak at $200^{\circ} \mathrm{C}$. The peaks are possibly caused by the initial partial melting of the MIS followed by oxidation of the oxalate. The TGA shows no significant mass loss at these lower temperatures.

The evolution of $\mathrm{CO}_{2}$, $\mathrm{CO}$, NO, and $\mathrm{N}_{2} \mathrm{O}$ seen in the EGA at $300-450^{\circ} \mathrm{C}$ may be associated with the decomposition and reaction acetate of the acetate in the waste and carbon in the soil with carbonate and nitrate or nitrite:

$$
\begin{gathered}
2 \mathrm{CH}_{3} \mathrm{COONa}+2 \mathrm{Na}_{2} \mathrm{CO}_{3} \rightarrow 3 \mathrm{Na}_{2} \mathrm{O}+3 \mathrm{H}_{2} \mathrm{O}+4 \mathrm{CO} \\
\mathrm{CH}_{3} \mathrm{COONa}+2 \mathrm{NaNO}_{2} \rightarrow 3 \mathrm{Na}_{2} \mathrm{O}+2 \mathrm{CO}+\mathrm{N}_{2} \mathrm{O}
\end{gathered}
$$

At temperatures above $300^{\circ} \mathrm{C}$, there is a broad endothermic peak in the TGA that is probably caused by melting and formation of the MIS. The TGA continues to show little mass loss up to a temperature of $525^{\circ} \mathrm{C}$.

The EGA shows that the rate of NO generation increases at $450^{\circ} \mathrm{C}$ and peaks at $750^{\circ} \mathrm{C}$, and the evolution of $\mathrm{O}_{2}$ starts at $525^{\circ} \mathrm{C}$ and peaks at $700^{\circ} \mathrm{C}$. The evolution of these gases is probably related to the decomposition of nitrates:

$$
4 \mathrm{NaNO}_{3} \rightarrow 2 \mathrm{Na}_{2} \mathrm{O}+4 \mathrm{NO}+3 \mathrm{O}_{2}
$$


The TGA shows a significant mass loss (approximately 14\%) between the temperatures of 525 and $650^{\circ} \mathrm{C}$ with a continued endothermic reaction shown on the DTA in this temperature range. These indications are also consistent with the decomposition of the nitrates. The decomposition of residual carbonates occurs parallel with nitrate decomposition and shows up in the EGA as small $\mathrm{CO}_{2}$ and $\mathrm{CO}$ peaks between $650^{\circ}$ and $800^{\circ} \mathrm{C}$.

A large, broad endothermic DTA peak starts at $650^{\circ} \mathrm{C}$ and continues to $1200^{\circ} \mathrm{C}$ where the melt reactions are essentially complete. The TGA shows a reduced rate of mass loss from 650 to $1100^{\circ} \mathrm{C}$, but at temperatures above $1100^{\circ} \mathrm{C}$, evaporation of the more volatile glass constituents leads to an increase in the rate of mass loss. 


\subsection{Refractory-Melt Interaction}

The refractory/melt interaction studies were developed based on the following conceptual model for waste feed melting. MIS penetrates the open pores of the refractory wall. The depth of penetration depends on the temperature gradient within the wall, the availability of MIS in the BV feed, the CRB porosity and pore size distribution, and the time available. The fraction of MIS that wets and bridges the grains of soil and $\mathrm{ZrO}_{2}$ is unavailable to migrate to the CRB. As the temperature reaches $\sim 750^{\circ} \mathrm{C}$, filling the CRB pores with MIS stops because most of the MIS disappears as its main component, nitrate, decomposes. The remaining salt reacts with the refractory and forms a durable glass phase. Since the MIS contains radioactive ${ }^{99} \mathrm{Tc}$, it is important to prevent salt solidification inside the refractory wall where it would be susceptible to leaching into an aqueous environment. Fortunately, refractory material containing molten salt is prone to rapid corrosion that turns any unreacted MIS into more durable bulk glass. However, a fraction of sulfates and chlorides from the MIS may survive in the CRB porosity.

This part of the work focused on the refractory-melt interaction from the viewpoint of refractory corrosion. The goal of this work was to determine the extent of melt penetration and refractory dissolution during the BV process. A series of tests were performed:

1. Molten salt permeability test

2. Molten glass permeability test

3. Feed melting crucible corrosion test

4. Molten glass crucible corrosion test.

\subsection{Summary of Tests and Materials}

1. The molten salt permeability test exposes refractory coupons to MIS to assess the degree of the reaction between the salt and the refractory material. Refractory blocks are cut to obtain cubic coupons $2 \times 2 \times 2 \mathrm{~cm}$ in size. The coupons are suspended in MIS in a platinum crucible at different temperatures, typically $400,600,800$, and $1000^{\circ} \mathrm{C}$. Coupons are cross-sectioned, and the salt penetration is evaluated by optical and electron microscopy.

2. The molten glass permeability test is performed in the same manner as the molten salt permeability test except that coupons are initially submerged in the feed that melts as the temperature is increased. The test is conducted at higher temperatures, typically $1250^{\circ} \mathrm{C}$ and $1500^{\circ} \mathrm{C}$.

3. The feed melting crucible corrosion test is performed in a crucible made from the test material. Typically, the crucible with feed is ramp heated at $4^{\circ} \mathrm{C} / \mathrm{min}$ to $1500^{\circ} \mathrm{C}$ and held at $1500^{\circ} \mathrm{C}$. Crucibles are sectioned and examined for corrosion and melt penetration.

4. The molten glass crucible corrosion test uses the same crucibles filled with BV glass. Typically, crucibles are held at $1500^{\circ} \mathrm{C}$. These tests where conducted to assess the reaction between a refractory wall and molten glass without the prior influence of the MIS.

The test crucibles were made of the following refractories: Alfrax 66, Vibrocast 60PC, and a low-cost fire clay. Compositions of these materials are listed in Table D.3. 
- Alfrax is a high-purity alumina-spinel for steelmaking. It withstands $1800^{\circ} \mathrm{C}$.

- Vibrocast 60PC is a mullite-based material for severe high-temperature corrosive and erosive environments. Pure mullite $\left(3 \mathrm{Al}_{2} \mathrm{O}_{3} \cdot 2 \mathrm{SiO}_{2}\right)$ contains 71.8 mass $\% \mathrm{Al}_{2} \mathrm{O}_{3}$ and 28.2 mass $\% \mathrm{SiO}_{2}$. Vibrocast $60 \mathrm{PC}$ has approximately $17 \%$ porosity and withstands $1700^{\circ} \mathrm{C}$.

- Fire clay is a low-cost mined material that is high in alumina and is used to produce refractories that can withstand severe conditions relative to other clay materials. Until the 1960s, the glass industry used heavy-duty fire clay refractory for glass-making furnaces, pots, floaters, and other elements. These refractories, often large single blocks, had low porosity and high corrosion resistance. The cost of fireclay is a fraction of the cost of mullite. A fire clay brick (fire brick Yukon) and a 50-wt\% fire clay/50-wt\% silica flour mix were tested.

The BV feed used for testing was made from AMEC soil (Figure D.5), LAW, and additives. The soil contained quartz and various aluminosilicates (albite, anorthite, sanidine, and muscovite)—Figure D.6. AMEC provided approximately $2.5 \mathrm{~kg}$ dry feed and $1 \mathrm{~kg}$ dry LAW.

Table D.3. Compositions of Tested Refractory Materials (in mass fractions)

\begin{tabular}{|l|c|c|c|c||}
\hline & $\begin{array}{c}\text { Vibrocast } \\
\text { 60PC }\end{array}$ & $\begin{array}{c}\text { Alfrax } \\
\text { No.66 }\end{array}$ & Fire Clay & Fire Clay/Silica Flour \\
\hline $\mathrm{Al}_{2} \mathrm{O}_{3}$ & 0.608 & 0.960 & 0.375 & 0.188 \\
\hline $\mathrm{SiO}_{2}$ & 0.345 & 0.001 & 0.565 & 0.783 \\
\hline $\mathrm{Fe}_{2} \mathrm{O}_{3}$ & 0.0010 & 0.001 & 0.017 & 0.009 \\
\hline $\mathrm{TiO}_{2}$ & 0.018 & & 0.025 & 0.013 \\
\hline $\mathrm{CaO}$ & 0.016 & 0.036 & 0.003 & 0.002 \\
\hline $\mathrm{MgO}$ & & 0.001 & 0.003 & 0.002 \\
\hline $\mathrm{Na}_{2} \mathrm{O}$ & 0.001 & & \\
\hline Other & 0.003 & & & \\
\hline $\begin{array}{l}\text { (a) Approximate composition taken from Tooley (1974). } \\
\text { (b) Estimated Composition. }\end{array}$ \\
\hline
\end{tabular}

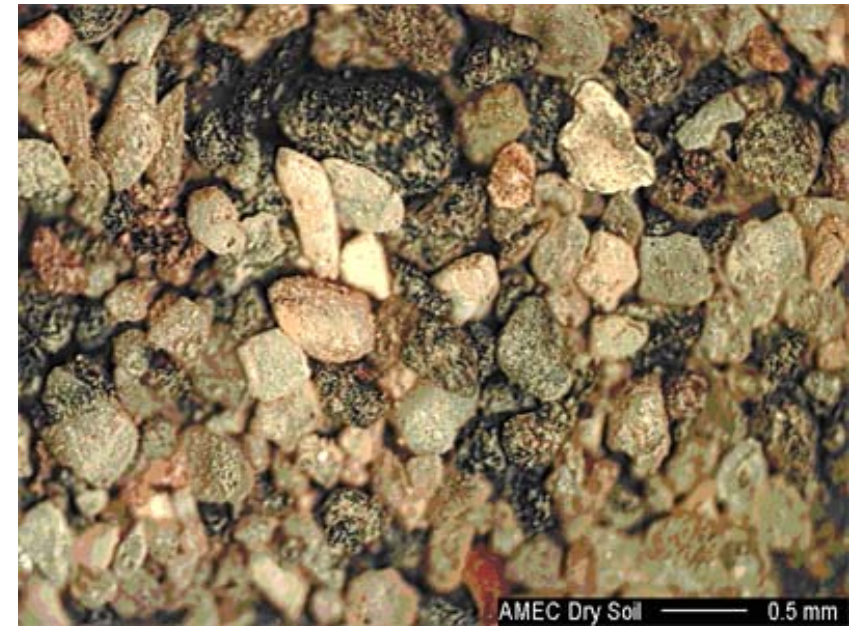

Figure D.5. AMEC Soil, Optical Micrograph 


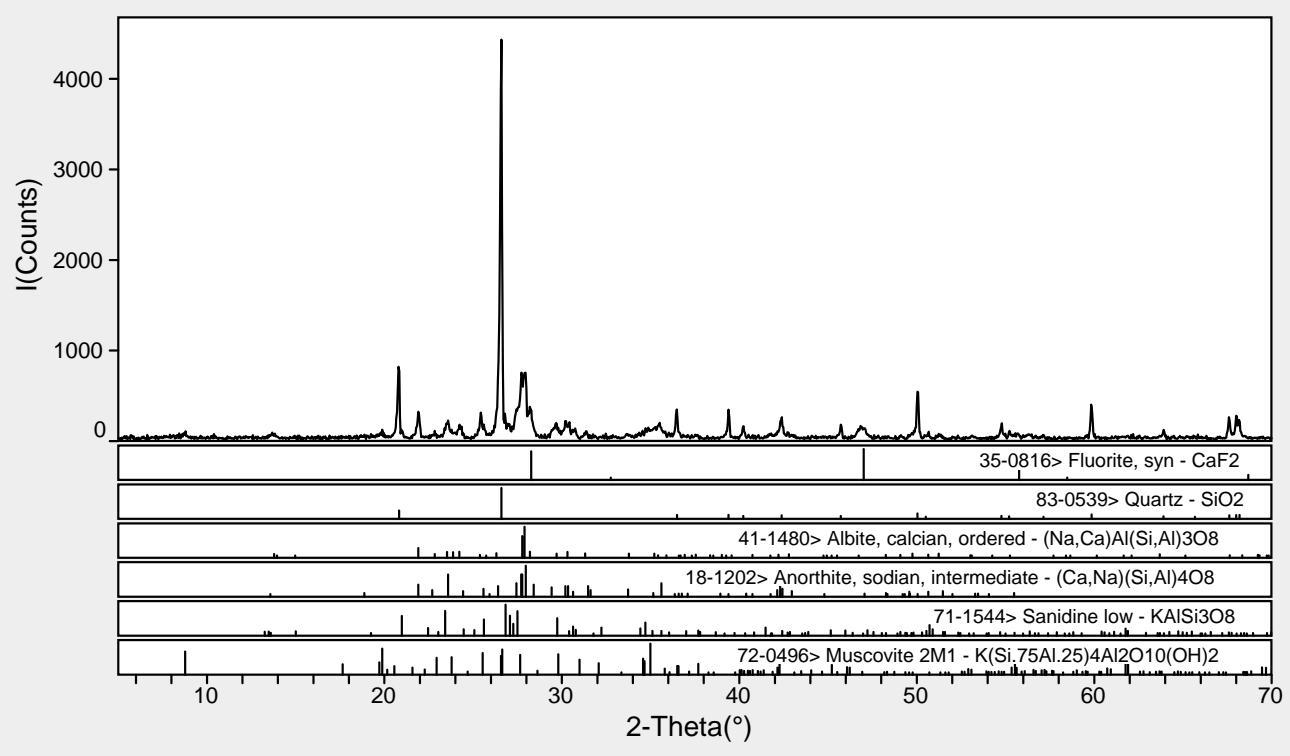

Figure D.6. AMEC Soil X-Ray Diffraction Pattern

\subsection{Molten Ionic Salt (MIS) Permeability Test}

The heat-treatment schedule for the MIS permeability test was developed to reduce undesirable foaming that occurs at temperatures below $400^{\circ} \mathrm{C}$. A series of preliminary tests were performed as described below.

\subsubsection{MIS Preparation}

Preparation experiments were conducted as follows: Approximately $20 \mathrm{~g}$ of dry salts were placed in a small Ni crucible. The objective of these experiments was to produce a stable salt melt that did not foam. These trials and the results are described below.

- In the first trial, the crucible was placed in a furnace preheated at $400^{\circ} \mathrm{C}$. Melting and foaming was extremely rapid.

- In the second trial, the starting temperature was decreased to $300^{\circ} \mathrm{C}$. No reaction was observed. When the temperature was raised to $350^{\circ} \mathrm{C}$ after $5 \mathrm{~min}$, the sample melted and foamed in a controlled fashion, and the foam collapsed after $10 \mathrm{~min}$ at $350^{\circ} \mathrm{C}$. When the temperature was increased to $370^{\circ} \mathrm{C}$, the experiment was terminated because of vigorous foaming.

- In the third trial, the procedure was repeated except that the temperature was increased to $360^{\circ} \mathrm{C}$ after $10 \mathrm{~min}$ at $350^{\circ} \mathrm{C}$. No reaction was observed for $5 \mathrm{~min}$. Then the temperature was raised to $370^{\circ} \mathrm{C}$, and vigorous foaming necessitated the termination of the experiment.

- The trial was repeated with a smaller amount of MIS (approximately $13 \mathrm{~g}$ ) and a more gradual increase of temperature: after $5 \mathrm{~min}$ at $350^{\circ} \mathrm{C}$ and $10 \mathrm{~min}$ at $360^{\circ} \mathrm{C}$, the temperature was increased to $365^{\circ} \mathrm{C}$, and the test was terminated after 5 min because of severe foaming.

- In the final trial, a large Pt crucible with about $20 \mathrm{~g}$ MIS was loaded into a furnace preheated at $360^{\circ} \mathrm{C}$. A mild foaming of the molten sample stopped in $5 \mathrm{~min}$. When the temperature was 
raised to $365^{\circ} \mathrm{C}$, the MIS foamed, and the foam collapsed in 8 min. Further increases in temperature $\left(380^{\circ} \mathrm{C}\right.$ for $7 \mathrm{~min}, 400^{\circ} \mathrm{C}$ for $5 \mathrm{~min}, 420^{\circ} \mathrm{C}$ for $5 \mathrm{~min}$, and then by $20^{\circ} \mathrm{C}$ increments for 5 min up to $640^{\circ} \mathrm{C}$ ) did not result in any visible reaction. Then the temperature was increased to $750^{\circ} \mathrm{C}$, resulting in gas-releasing decomposition that continued for approximately $20 \mathrm{~min}$.

Based on these trials, the following melting procedure is recommended for MIS preparation:

- Fill the Pt crucible with the dry salt mixture to less than $1 / 3$ of its volume and load the crucible into a furnace preheated at $350^{\circ} \mathrm{C}$.

- Increase the temperature according to the schedule shown in Table D.4.

- $\quad$ Pour the melt after 5 or more min at $400^{\circ} \mathrm{C}$.

Table D.4. MIS Preparation Melting Schedule

\begin{tabular}{||c|c||}
\hline \hline Time, min & Temperature, ${ }^{\circ} \mathbf{C}$ \\
\hline 0 & 350 \\
\hline 5 & 360 \\
\hline 10 & 370 \\
\hline 15 & 380 \\
\hline 20 & 390 \\
\hline 25 & 400 \\
\hline
\end{tabular}

The melted MIS is yellow-green in color (Figure D.7).
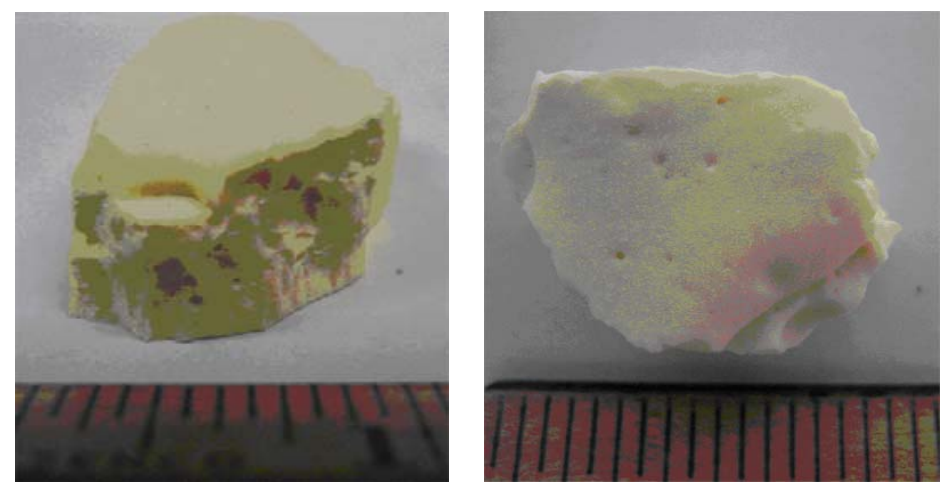

Figure D.7. Melted MIS

\subsubsection{Test Materials, Assembly, and Procedure}

The molten salt penetration tests were conducted on the Alfrax and Vibrocast PC60 materials. The test assembly for refractory coupons is shown in Figure D.8. Two $2 \times 2 \times 2-\mathrm{cm}$ cubic coupons cut from the refractory material are attached to the Pt lid with a Pt wire to be submerged into the MIS in a tall Pt crucible. 


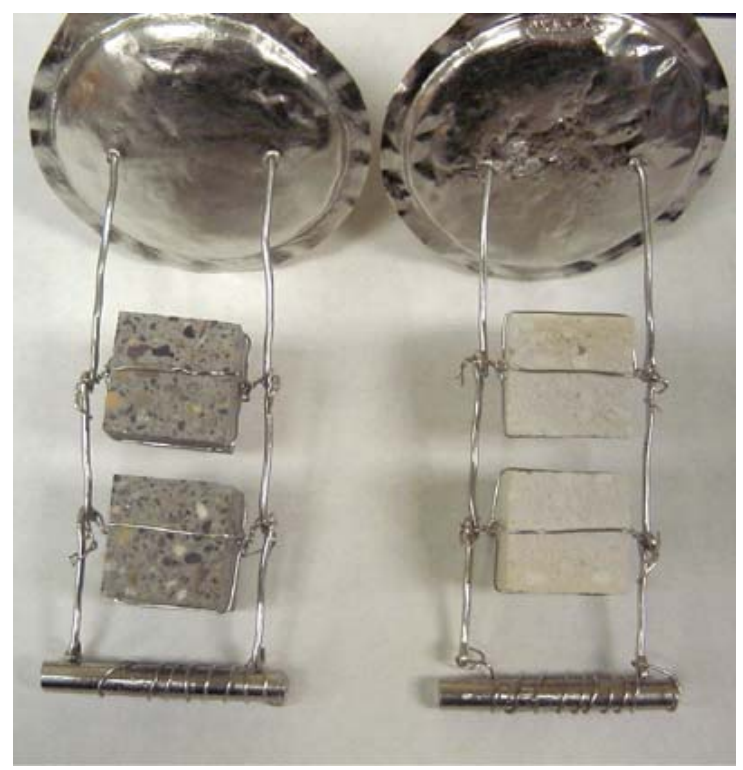

Figure D.8. Refractory-Melt Interaction Test Assembly

Coupons of Vibrocast 60PC and Alfrax were exposed to MIS at $400^{\circ} \mathrm{C}$ for 6 hours, $600^{\circ} \mathrm{C}$ for 24 hours, $700^{\circ} \mathrm{C}$ for $6 \mathrm{~h}$ (Figure D.9), and at $800^{\circ} \mathrm{C}$ for 6 hours where the coupons swelled and partly disintegrated (Figure D.10).

\subsubsection{Test Results}

Coupons were fractured for evaluation (Figure D.11). All coupons were soaked with molten salt.

- The Vibrocast 60PC coupons were originally grey, consisting of dark grey, light grey, and whitish grains embedded in a light grey matrix of fine grains. The coupons turned slightly purple after the exposure to MIS, probably because the $\mathrm{FeO}$ oxidized to $\mathrm{Fe}_{2} \mathrm{O}_{3}$. Energy dispersive spectroscopy (EDS) dot maps (Figure D.12) show that sodium-rich salt permeated the coupon at a temperature as low as $400^{\circ} \mathrm{C}$.

- The originally white color of Alfrax coupons turned into bright yellow, indicating that the coupons were soaked with MIS even at $400^{\circ} \mathrm{C}$. EDS dot maps (Figure D.12) show that sodiumrich salt fully saturated the Alfrax coupons at $600^{\circ} \mathrm{C}$.

- Both Alfrax and Vibrocast 60PC coupons disintegrated after 24 hours at $800^{\circ} \mathrm{C}$ when the nitrates decomposed and produced a large volume of gas. 


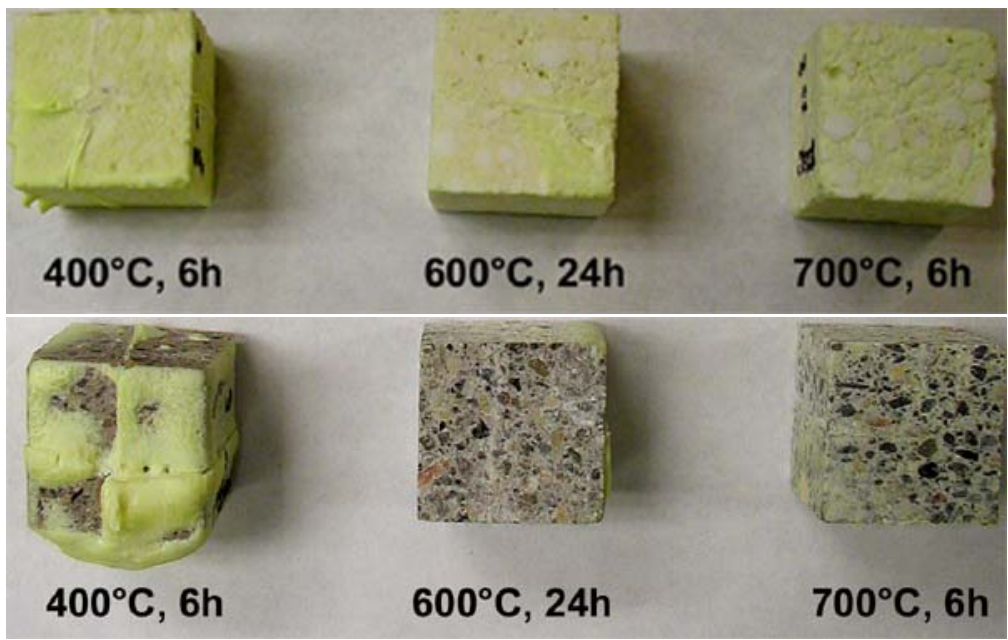

Figure D.9. Alfrax (above) and Vibrocast 60PC (below) Refractory Coupons after Exposure to MIS

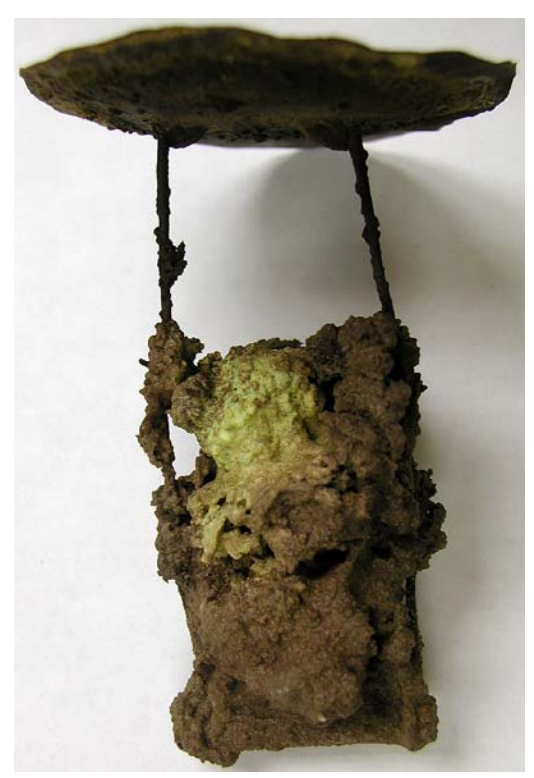

Figure D.10. Coupons of Vibrocast 60PC Exposed to MIS at $800^{\circ} \mathrm{C}$ for 24 Hours 


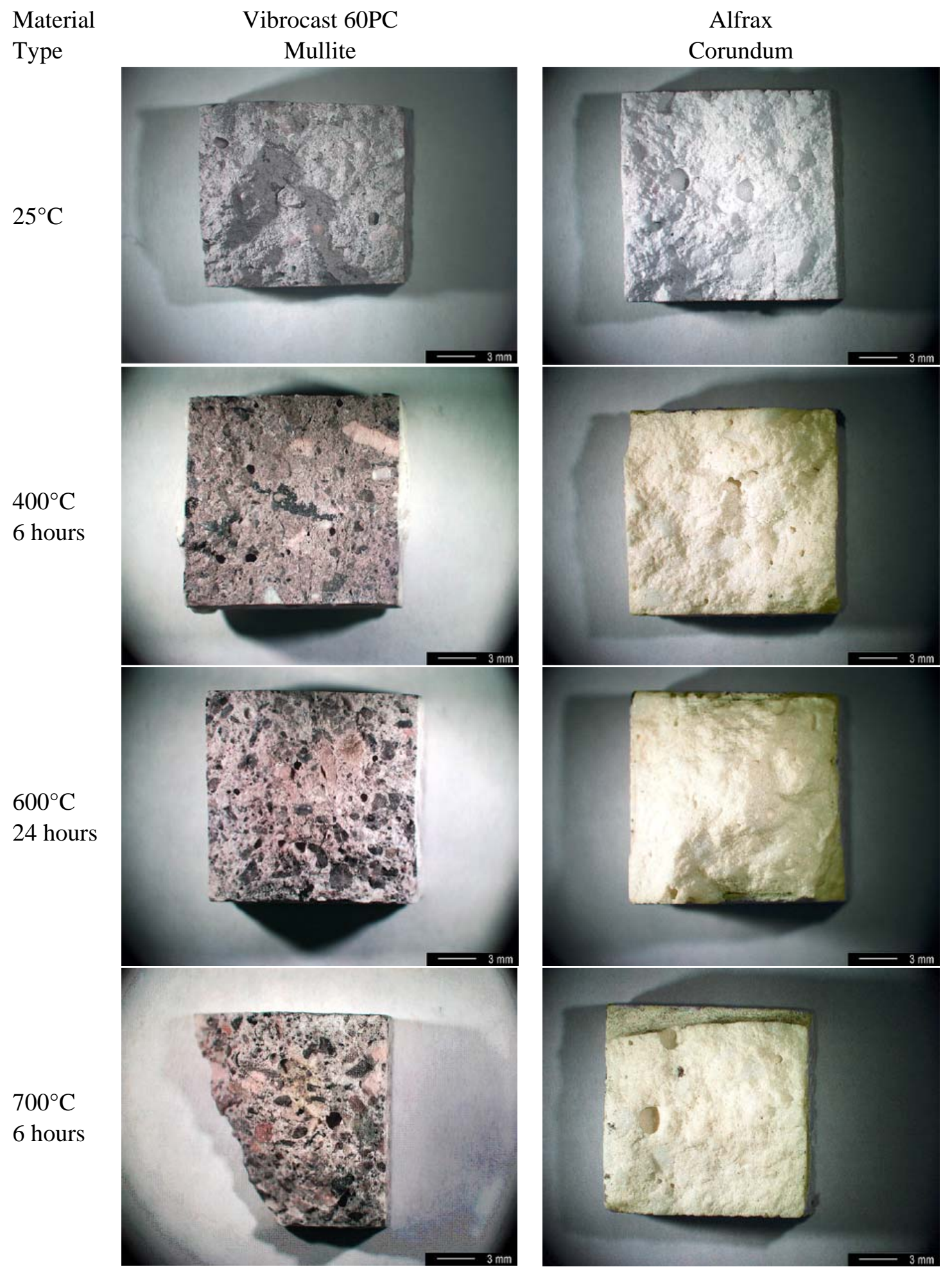

Figure D.11. Fracture Surface of Refractory Coupons Exposed to MIS 




Figure D.12. EDS Dot Maps of Fracture Surfaces of Refractory Coupons Exposed to MIS 


\subsection{Molten Glass Permeability Test}

\subsubsection{Materials Tested}

Four coupon materials were tested in the molten glass permeability tests:

- Vibrocast 60 PC

- Alfrax

- A fire clay brick (fire brick Yukon)

- A commercial fireclay (50 mass\%) with silica flour (50 mass\%).

All materials were tested alone and with borax and sodium metasilicate glazes. The intent of the glazes was to protect the base material from molten-salt attack. Sodium metasilicate, also known as water glass, is water soluble. A paste was prepared from crushed sodium metasilicate that contained a mixture of a solid with saturated solution. Similarly, sodium metaborate paste was prepared by mixing metaborate powder with water. The pastes were spread on the coupon surfaces with a brush. Glazed coupons were then baked at $\sim 1100^{\circ} \mathrm{C}$ for sodium silicate glaze and $\sim 1350^{\circ} \mathrm{C}$ for metaborate glaze.

\subsubsection{Test Procedure}

The coupons were assembled as shown in Figure D.8, placed in a tall Pt crucible, and filled with the BV feed. To avoid excessive foaming, the BV feed was added in two layers. The bottom layer was asreceived feed, and the top layer was crushed feed that had been calcined at $650^{\circ} \mathrm{C}$ for 2 hours (most of the MIS is still preserved at this temperature). Crucibles with unglazed coupons were loaded in the furnace at $400^{\circ} \mathrm{C}$ and heated at $4^{\circ} \mathrm{C} / \mathrm{min}$ to $1300^{\circ} \mathrm{C}$. Calcined feed was periodically added to keep the coupons submerged. Unglazed Vibrocast 60PC coupons exposed to molten glass at $1300^{\circ} \mathrm{C}$ for 24 hours fully dissolved. Subsequently, the exposure time was decreased to 10 hours (Figure D.13). The coated coupons were heated at $4^{\circ} \mathrm{C} / \mathrm{min}$ from $400^{\circ} \mathrm{C}$ to $1300^{\circ} \mathrm{C}$ with a 9-h hold.

\subsubsection{Test Results}

Cross sections of the unglazed Viborcast 60PC and Alfrax coupons are shown in Figure D.14 and Figure D.15. Molten glass attacks the mullite refractory by dissolving the bonding material and disengaging the grains. Although the core of the coupon does not appear deteriorated, the melt-refractory interface is irregular because melt locally penetrates into the coupon, possibly following a penetration path of the MIS. The large pores and bubbles seen in the samples (Figure D.14) were caused by gases from MIS decomposition. Alfrax coupons were attacked more severely than Vibrocast 60PC. Molten glass penetrated throughout the whole volume of the Alfrax coupons, causing substantial swelling (Figure D.15).

The corrosion results for the glazed materials are shown in Figure D.16. Sodium metasilicate appeared slightly more protective than borax for both materials. The glazes appeared to improve the performance of the Vibrocast 60PC but failed to prevent the penetration of molten glass deep into the Alfrax coupon. 

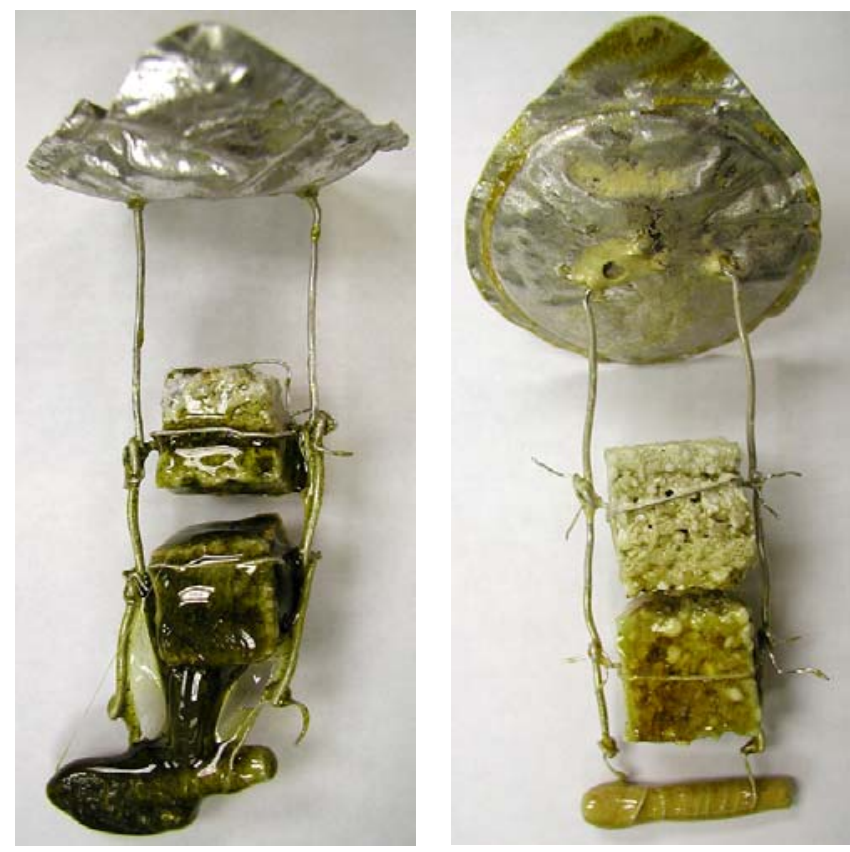

Figure D.13. Coupons of Vibrocast 60PC (left) and Alfrax (right) Exposed to Molten Glass at $1300^{\circ} \mathrm{C}$ for 10 Hours
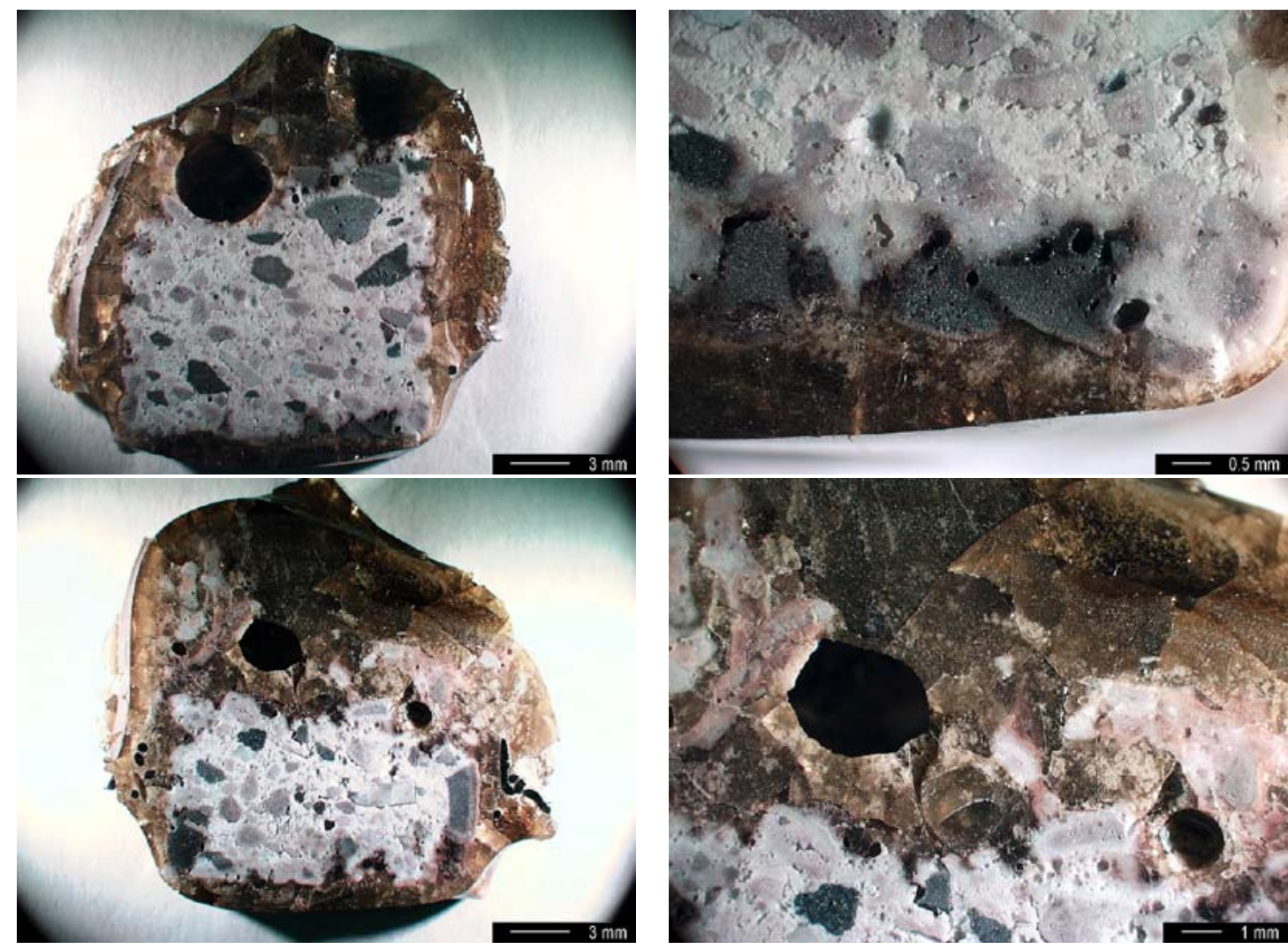

Figure D.14. Vibrocast 60PC (Mullite) Refractory Submerged in Molten Glass at $1300^{\circ} \mathrm{C}$ for 10 Hours 

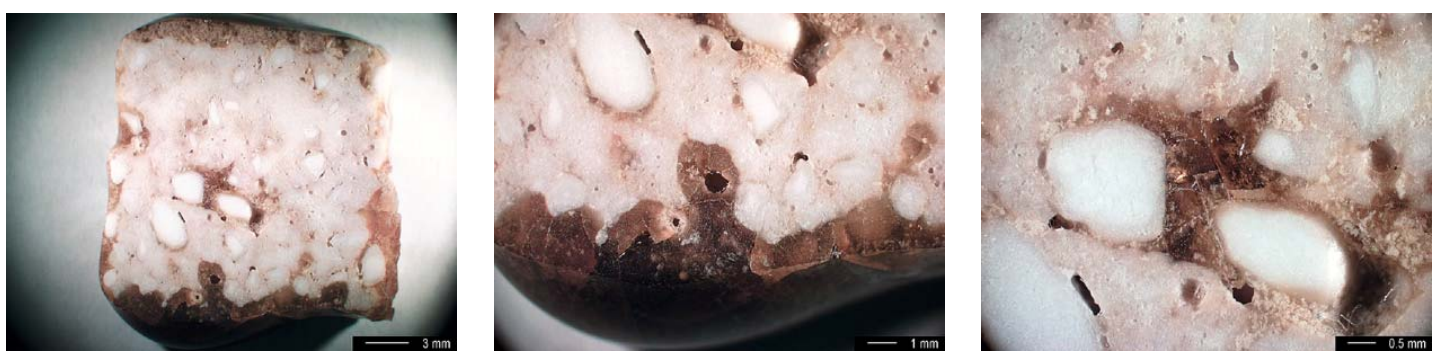

Figure D.15. Alfrax (Alumina) Refractory Submerged in Molten Glass at $1300^{\circ} \mathrm{C}$ for 10 Hours

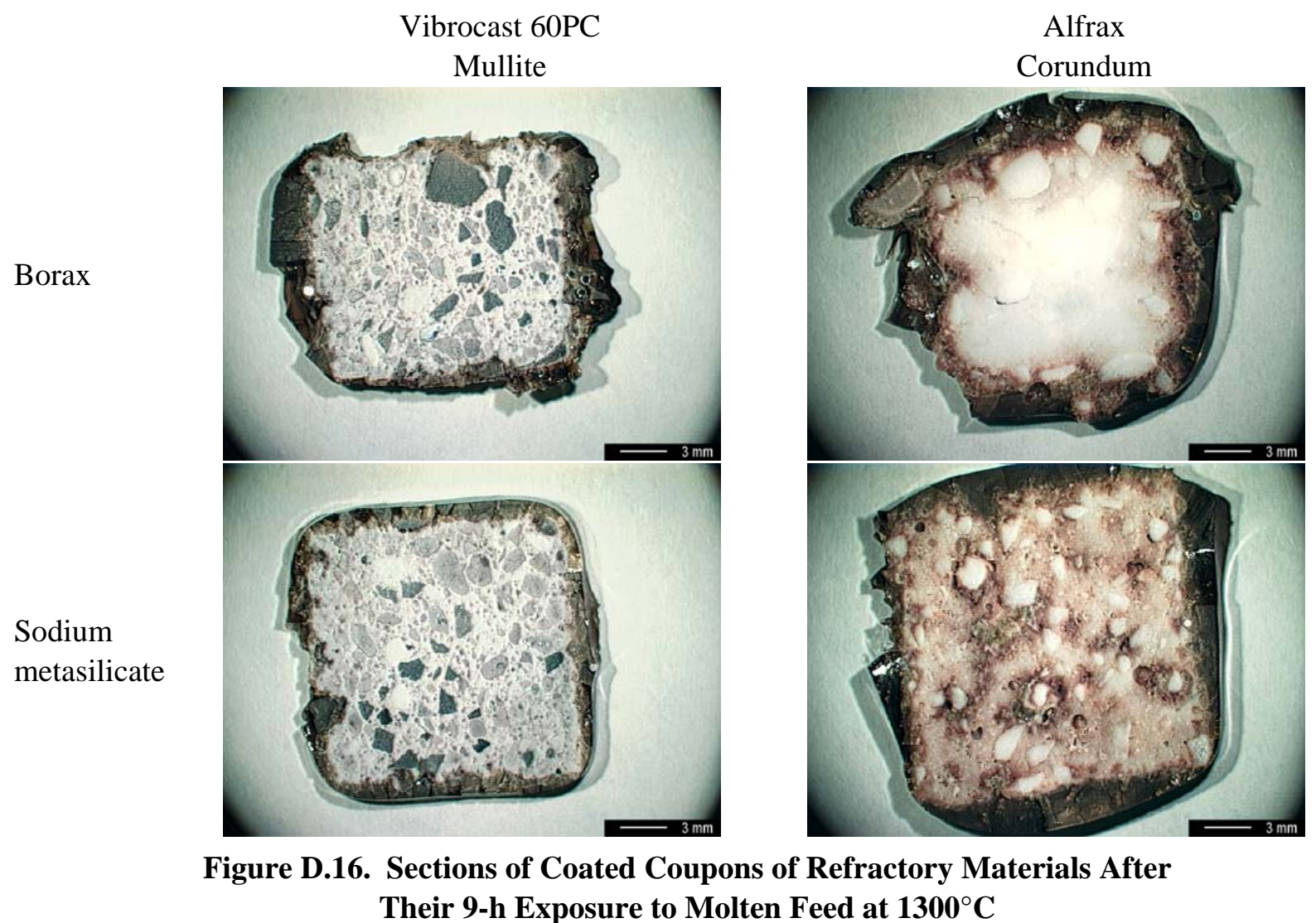

Fire clay aluminosilicate materials were also tested, coated and uncoated. Fire-brick Yukon (Figure D.17) withstood heating from $400^{\circ} \mathrm{C}$ to $1300^{\circ} \mathrm{C}$ at $4^{\circ} \mathrm{C} / \mathrm{min}$ with 10 -h hold at $1300^{\circ} \mathrm{C}$ without visible signs of MIS penetration. The borax glaze attacked the material and made it susceptible to corrosion damage. There was no obvious improvement associated with the sodium silicate coating.

Commercial fire clay mixed with 50 mass\% silica flour (Figure D.18) cracked and was severely attacked, though without visible signs of MIS penetration. Glazes did not improve performance. Both sodium borate and sodium silicate accelerated corrosion; the coupon glazed with sodium silicate dissolved during the test. The poor performance is probably related to the preparation technique. While other materials were densified using a vibratory hammer, commercial fireclay coupons were shaped from plastic bodies, leaving the fireclay-silica composite material with a high porosity (Figure D.19). 


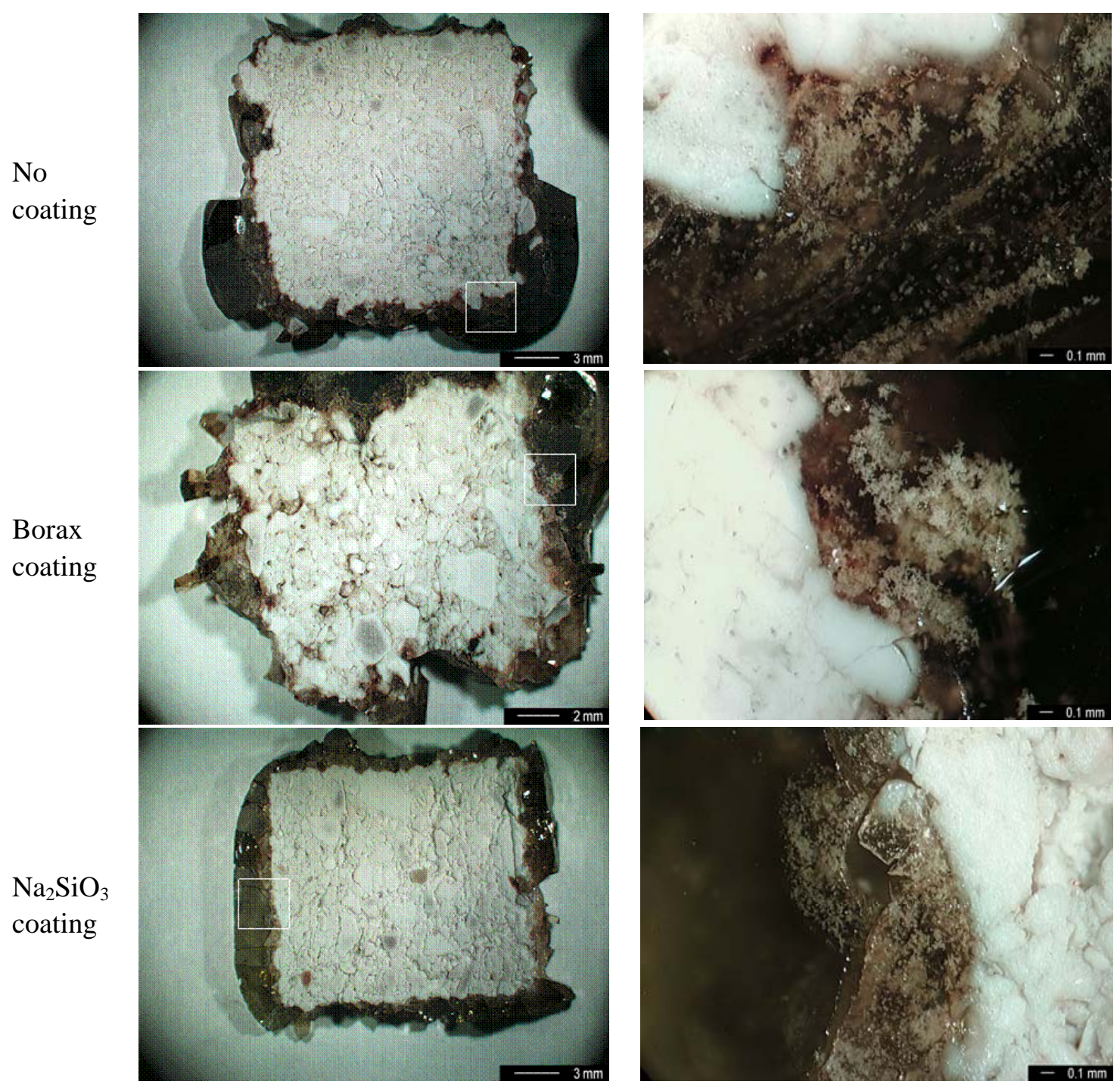

Figure D.17. Sections of Coated Coupons of Fire Brick Yukon After 10-h Exposure to Molten Feed at $1300^{\circ} \mathrm{C}$ 

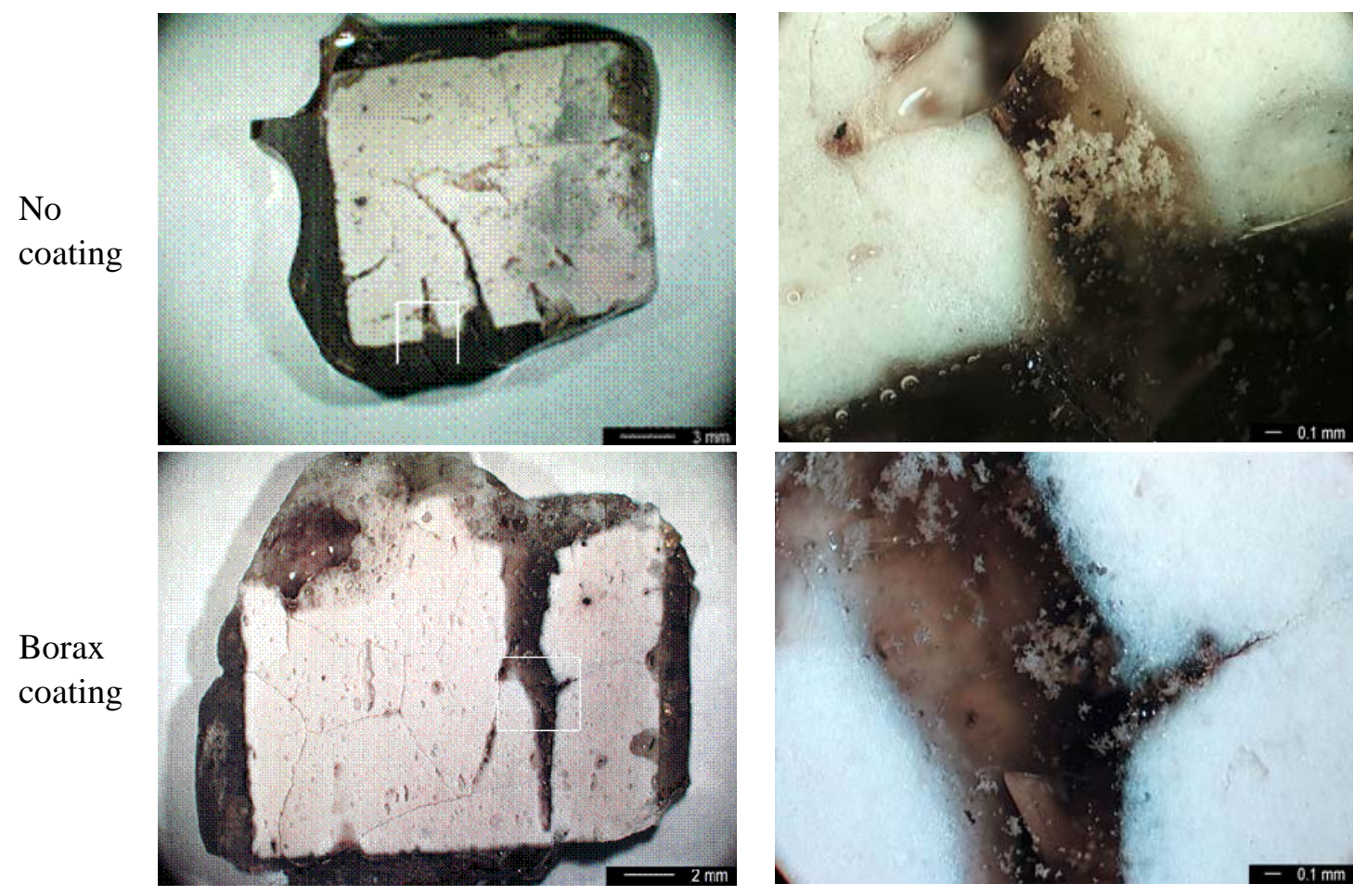

Figure D.18. Sections of Coated Coupons of Fire Clay with 50 Mass\% Silica After 10-h Exposure to Molten Feed at $1300^{\circ} \mathrm{C}$

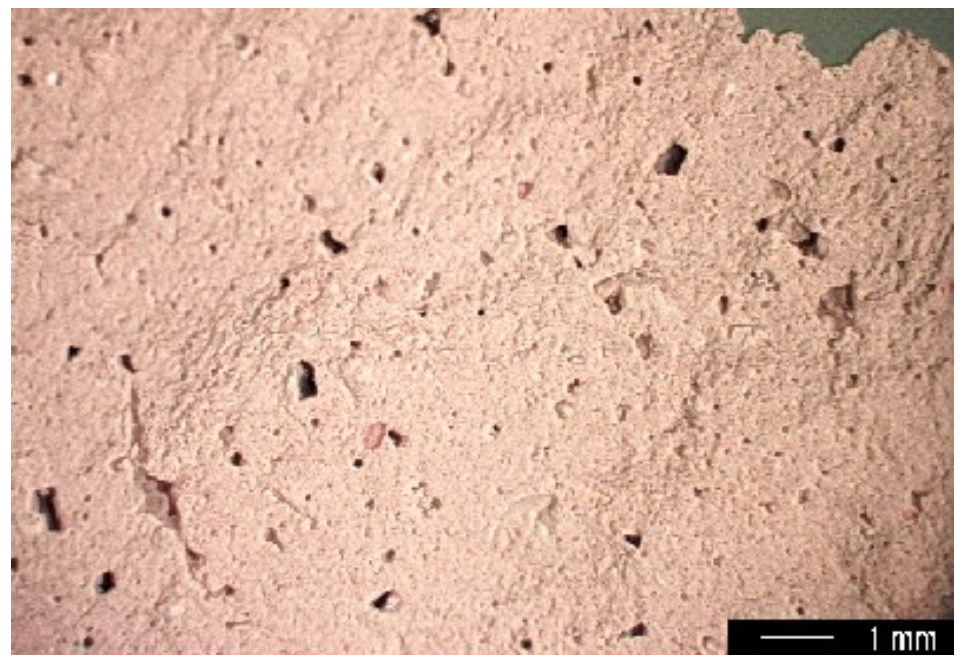

Figure D.19. Section through Fireclay Material (with 50 mass\% silica flour) 


\subsection{Feed Melting Crucible Corrosion Test}

\subsubsection{Preliminary Testing}

A Vibrocast 60PC crucible (Figure D.20) was used in the following preliminary test to help establish the test procedure. The crucible was preheated at a rate of $1{ }^{\circ} \mathrm{C} / \mathrm{min}$ to $975^{\circ} \mathrm{C}$ and held overnight at this temperature. The preheated crucible was filled to three quarters of capacity with feed, placed in a furnace at $825^{\circ} \mathrm{C}$, and ramp heated at $4^{\circ} \mathrm{C} / \mathrm{min}$. This treatment appeared too extreme. The feed boiled vigorously, and the crucible cracked at about $1150^{\circ} \mathrm{C}$ (Figure D.21). The melt spilled through the crack and over the crucible rim (Figure D.22). The cracks were probably caused by the propagation of preexisting small cracks, perhaps enhanced by the thermal shock during transferring the crucible from the preheating furnace. Heat-treatments with slower heating rates were performed in subsequent tests.
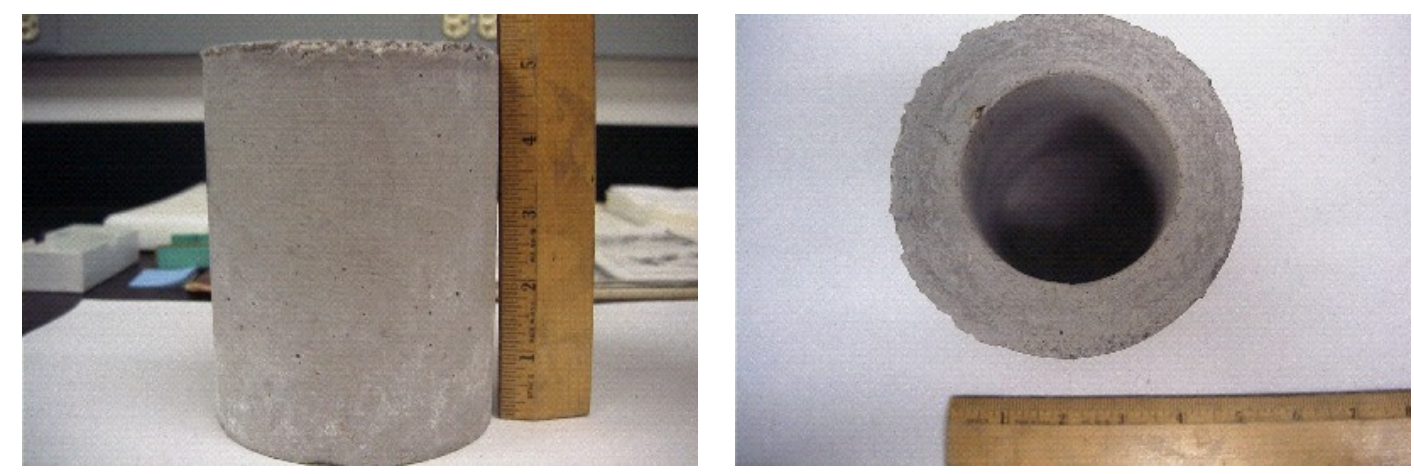

Figure D.20. Vibrocast 60PC Test Crucible
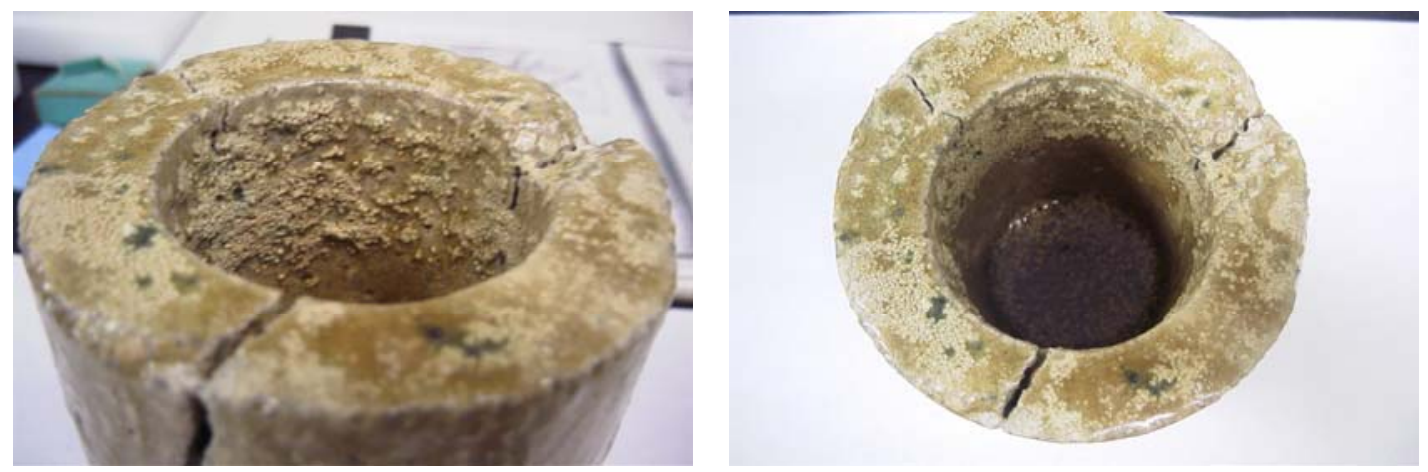

Figure D.21. Cracks in Vibrocast 60PC Test Crucible Heated with BV Feed to $1150^{\circ} \mathrm{C}$ 


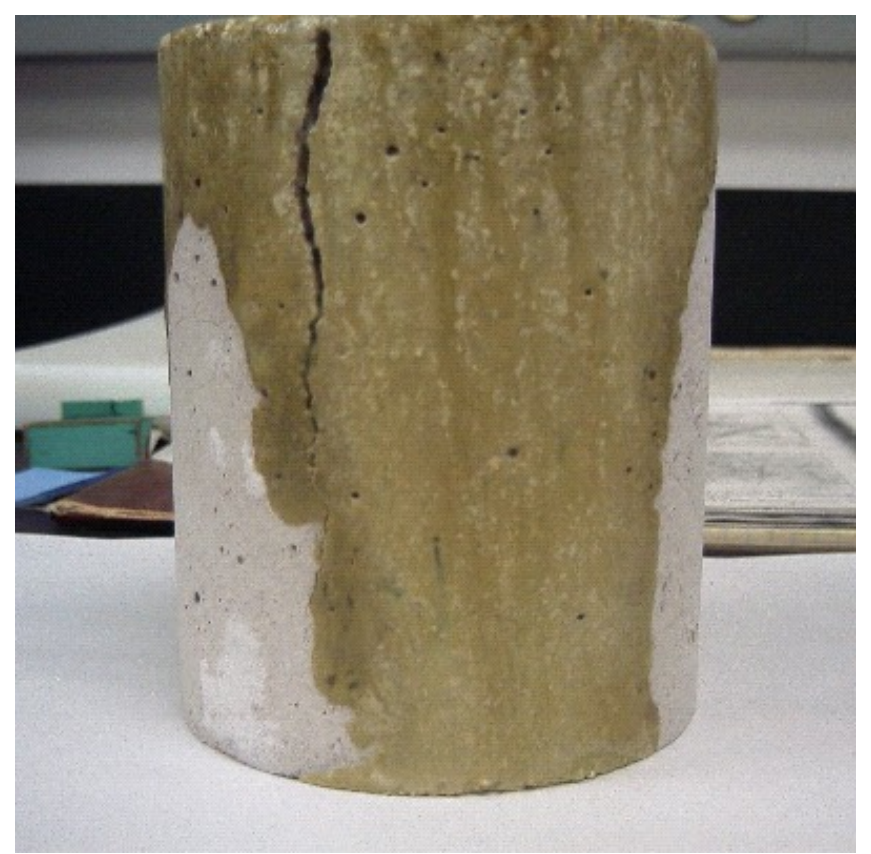

Figure D.22. Side View of Vibrocast 60PC Test Crucible as in Figure D.21

\subsubsection{Materials Tested}

Three materials were tested in the crucible feed tests:

- $\quad$ an unglazed Vibrocast 60 PC crucible (Figure D.20)

- a Vibrocast 60 PC crucible glazed with sodium metasilicate (Figure D.23)

- a fireclay crucible prepared from commercial fireclay (50 mass\%) and silica flour (50 mass\%) glazed with sodium metasilicate (Figure D.24).

The Vibrocast $60 \mathrm{PC}$ crucible was glazed with the following procedure. It was heated at $1^{\circ} \mathrm{C} / \mathrm{min}$ to $800^{\circ} \mathrm{C}$ and cooled down at $4^{\circ} \mathrm{C} / \mathrm{min}$ to room temperature. The cold crucible was coated with sodium metasilicate paste and heated at $2^{\circ} \mathrm{C} / \mathrm{min}$ to $1000^{\circ} \mathrm{C}$, held for $30 \mathrm{~min}$, and then cooled down at $3^{\circ} \mathrm{C} / \mathrm{min}$ to $200^{\circ} \mathrm{C}$. The glaze formed a nearly uniform glassy layer of sodium silicate on the inside surface of the crucible (Figure D.23). Tiny cracks in the coated layer were caused by the thermal expansion mismatch (cracks are not visible in figure).

The fireclay crucible was prepared from commercial fireclay (50 mass\%) and silica flour (50 mass\%) on a pottery wheel (courtesy of Richland High School Art Department). The wet crucible was allowed to dry at room temperature for 4 days. The air-dried crucible was heated to $100^{\circ} \mathrm{C}$ at $1{ }^{\circ} \mathrm{C} / \mathrm{min}$ and held at that temperature for 4 hours to dry. Then the temperature was increased at $1{ }^{\circ} \mathrm{C} / \mathrm{min}$ to $200^{\circ} \mathrm{C}$ and held at that temperature for 13.5 hours to complete drying. Finally, the crucible was transferred to another furnace, held at $485^{\circ} \mathrm{C}$ for 2 hours, and cooled down to $25^{\circ} \mathrm{C}$ at $3^{\circ} \mathrm{C} / \mathrm{min}$. The inside of the crucible was then coated with sodium metasilicate glass powder paste, heated from room temperature at $1.5^{\circ} \mathrm{C} / \mathrm{min}$ to $1000^{\circ} \mathrm{C}$, held for 1 hour, cooled down to $200^{\circ} \mathrm{C}$ at $3^{\circ} \mathrm{C} / \mathrm{min}$, and allowed to cool to room temperature at the furnace rate. The coated crucible is shown in Figure D.24. Tiny cracks appeared in the glaze layer because of the thermal expansion mismatch. 


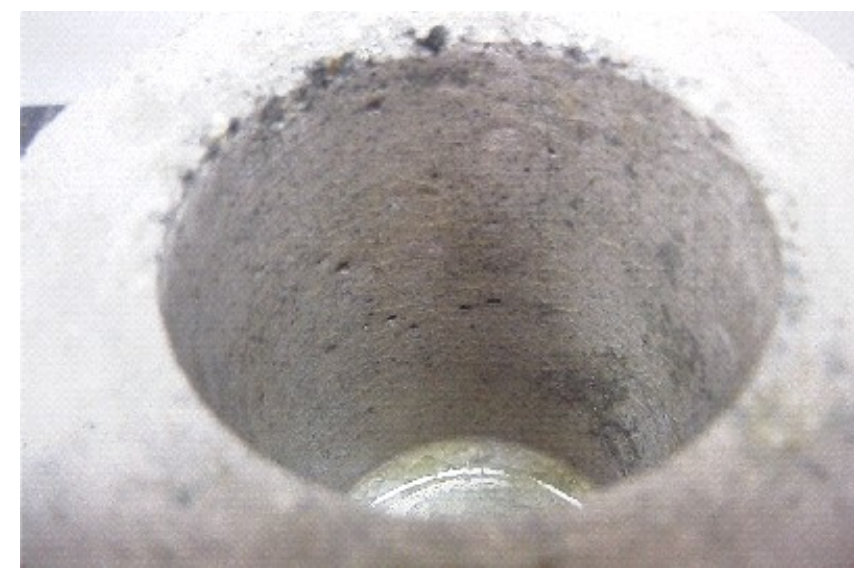

Figure D.23. View of Inner Coating on Vibrocast 60PC Crucible
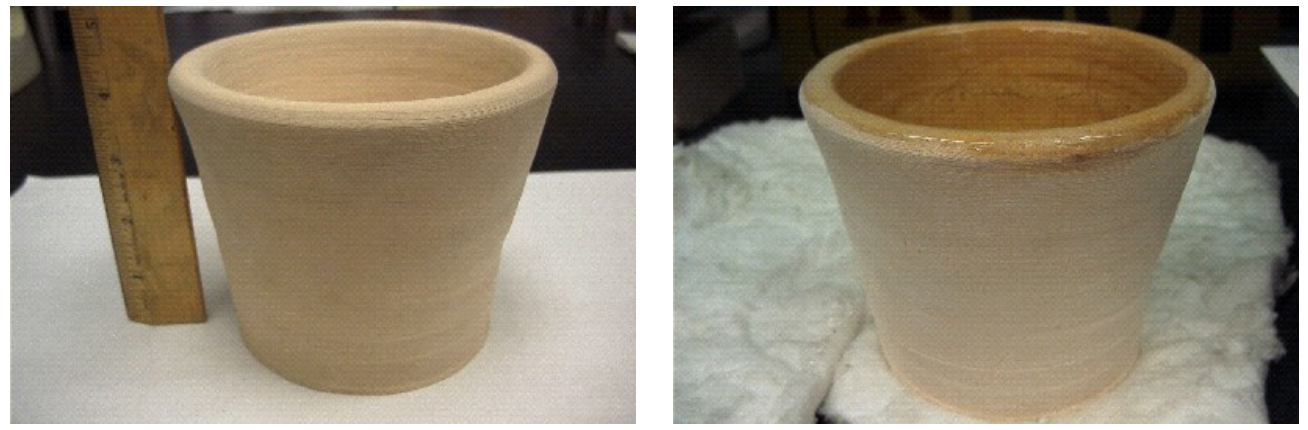

Figure D.24. Fireclay Crucible Before and After Coating

\subsubsection{Test Procedure}

An unglazed Vibrocast 60PC crucible was preheated to $975^{\circ} \mathrm{C}$ at $1^{\circ} \mathrm{C} / \mathrm{min}$ and held overnight. After cooling, one third of the crucible volume was filled with feed, placed in a furnace at $200^{\circ} \mathrm{C}$, ramp heated to $600^{\circ} \mathrm{C}$ at a rate of $1^{\circ} \mathrm{C} / \mathrm{min}$, and held overnight. To minimize cracking and foaming, heating continued at small steps and a slow rate. From $600^{\circ} \mathrm{C}$, the crucible with feed was heated at $1^{\circ} \mathrm{C} / \mathrm{min}$ to $930^{\circ} \mathrm{C}$ while feed was periodically added. After an overnight hold at $930^{\circ} \mathrm{C}$, heating resumed at $1^{\circ} \mathrm{C} / \mathrm{min}$, and then at $2^{\circ} \mathrm{C} / \mathrm{min}$ from $1090^{\circ} \mathrm{C}$ to $1150^{\circ} \mathrm{C}$ and at $3^{\circ} \mathrm{C} / \mathrm{min}$ to $1200^{\circ} \mathrm{C}$. After a 3-h hold, heating continued at $3^{\circ} \mathrm{C} / \mathrm{min}$ to $1300^{\circ} \mathrm{C}$ and at $4^{\circ} \mathrm{C} / \mathrm{min}$ to $1400^{\circ} \mathrm{C}$, at which the crucible was held for 24 hours. The crucible was removed from the furnace to cool in air, cut in half, and evaluated.

The glazed Vibrocast 60PC was filled to one third with BV feed, placed in a furnace at $200^{\circ} \mathrm{C}$, and ramp heated at $2^{\circ} \mathrm{C} / \mathrm{min}$ to $1100^{\circ} \mathrm{C}$. A half tablespoon of feed was added at $900^{\circ} \mathrm{C}$ to see the effect of adding feed to a crucible exposed to molten glass (after the glaze was destroyed by molten glass in the melt line area). Then the temperature was increased at $3^{\circ} \mathrm{C} / \mathrm{min}$ to $1120^{\circ} \mathrm{C}$ and at $4^{\circ} \mathrm{C} / \mathrm{min}$ to $1400^{\circ} \mathrm{C}$ with a hold for 24 hours. A small crack propagated through the upper two thirds of the crucible height without causing a leakage. The crucible was removed from the furnace at $1000^{\circ} \mathrm{C}$ to cool in air and then cut in half and evaluated. 
The glazed fireclay crucible was filled to one third with the BV feed, placed in a melting furnace preheated at $200^{\circ} \mathrm{C}$, heated at $1.5^{\circ} \mathrm{C} / \mathrm{min}$ to $970^{\circ} \mathrm{C}$, and held overnight. Heating continued at $2^{\circ} \mathrm{C} / \mathrm{min}$ to $1200^{\circ} \mathrm{C}$, at $3^{\circ} \mathrm{C} / \mathrm{min}$ to $1300^{\circ} \mathrm{C}$, and at $4^{\circ} \mathrm{C} / \mathrm{min}$ to $1400^{\circ} \mathrm{C}$. Two tablespoons of feed were added at $1000^{\circ} \mathrm{C}$. At $1350^{\circ} \mathrm{C}$, foaming occurred, reaching the top of crucible. The crucible was removed from the furnace at $1000^{\circ} \mathrm{C}$ to cool in air and then cut in half and evaluated.

\subsubsection{Test Results}

The cross section of the unglazed Vibrocast 60PC crucible is shown in Figures D.25 and D.26. The corrosion of the refractory over most of the area was acceptable (see Table D.5). The refractory-melt interface was pitted, and the meniscus area showed a bulging. The bugling is explained as follows. The low-viscosity MIS penetrated into the open porosity of the refractory material by capillary suction and reacted with the aluminosilicate material, creating a high-viscosity sodium-alumino-silicate melt. The unreacted residue of the MIS melt evolved gas that was unable to escape through the open porosity of the refractory and bloated the high-viscosity melt, expanding both into the interior and the exterior of the crucible wall.
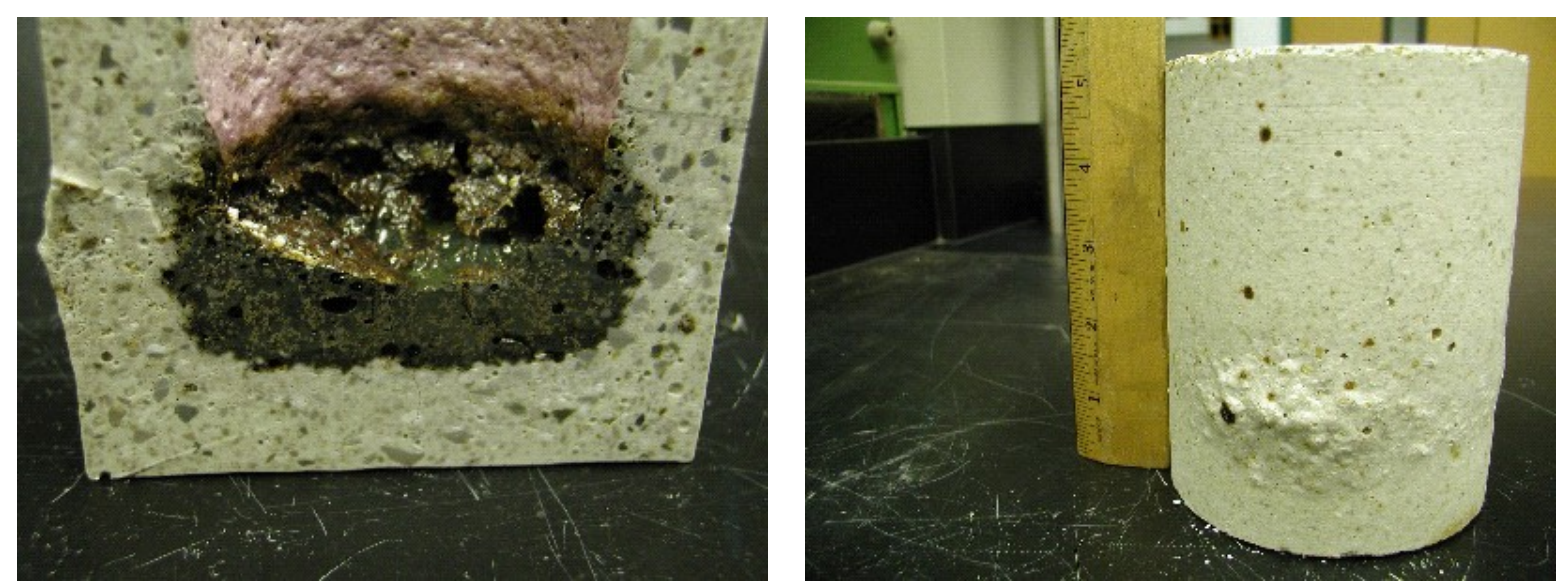

Figure D.25. Vibrocast 60PC Crucible Corroded with BV Feed at $1400^{\circ} \mathrm{C}$ for 24 Hours

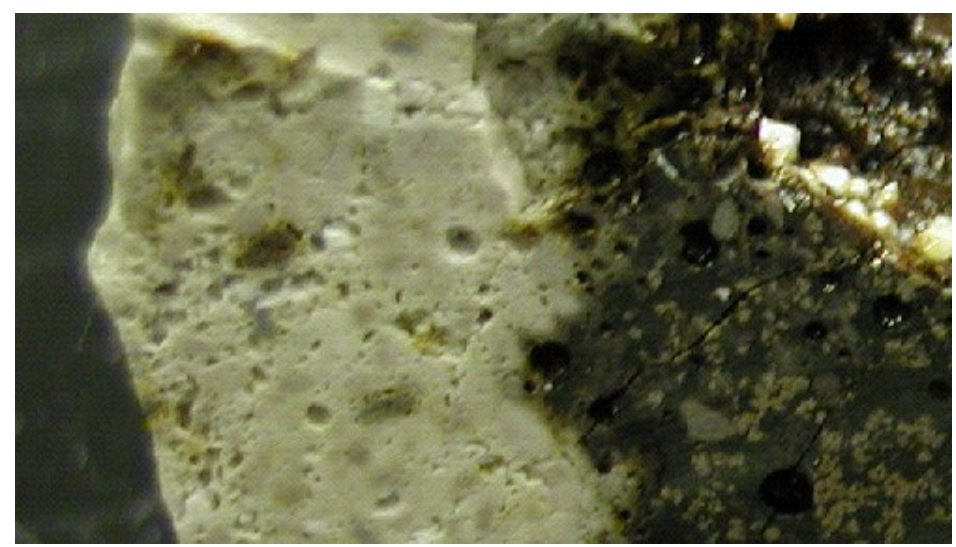

Figure D.26. Detail of Vibrocast 60PC Crucible in Figure D.25 
The cross-section of the glazed Vibrocast 60PC crucible is shown in Figure D.27. The corrosion pattern seen in the crucible is similar to the unglazed crucible, but the coating reduced both the corrosion extent (see Table D.5) and the damage seen in the unglazed crucible in Figure D.25. The glaze was dissolved in the meniscus area where MIS penetrated into the refractory, causing a slight bulging.

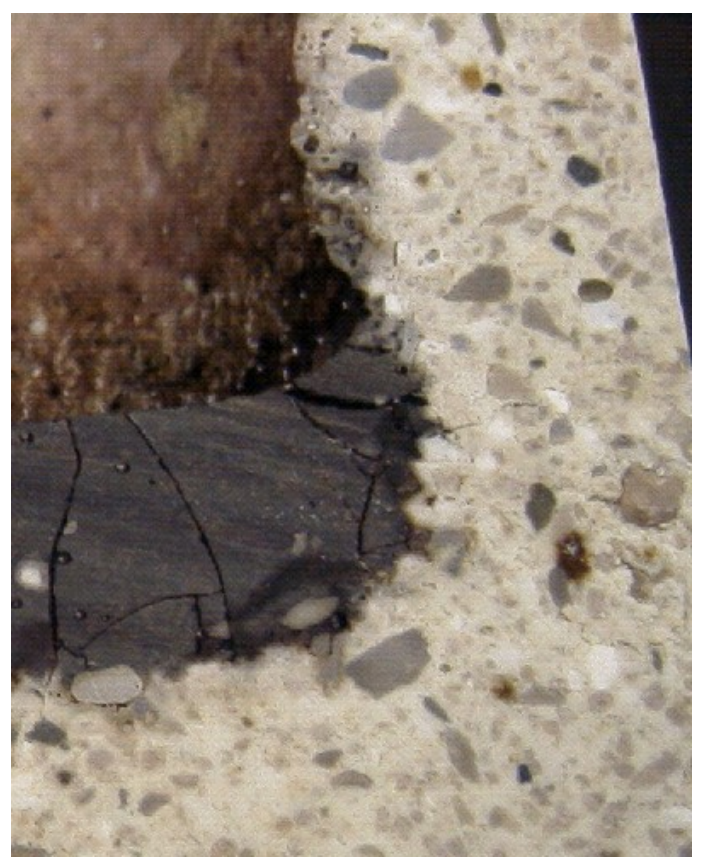

Figure D.27. Detail of Corrosion Damage of Coated Vibrocast 60PC Crucible

The cross-section of the fire clay-silica crucible is shown in Figure D.28. The crucible was severely damaged by the feed. MIS penetrated into the body of the crucible in the melt line area where convection driven by surface forces ${ }^{(a)}$ helped dissolve the protective coating and reacted with the aluminosilicate material, producing a high-viscosity melt. The MIS residue generated gases that were trapped in the viscous melt, causing large swelling in the inner side of the crucible, creating a ring along the melt line and a penetration of the exterior wall. This reaction prevented a quantitative measurement of a side wall loss caused by corrosion but the amount of corrosion was clearly extensive. Table D.5 lists the extent of corrosion on the bottom wall.

(a) See footnote (a) in Section 3.2 of the main text. 


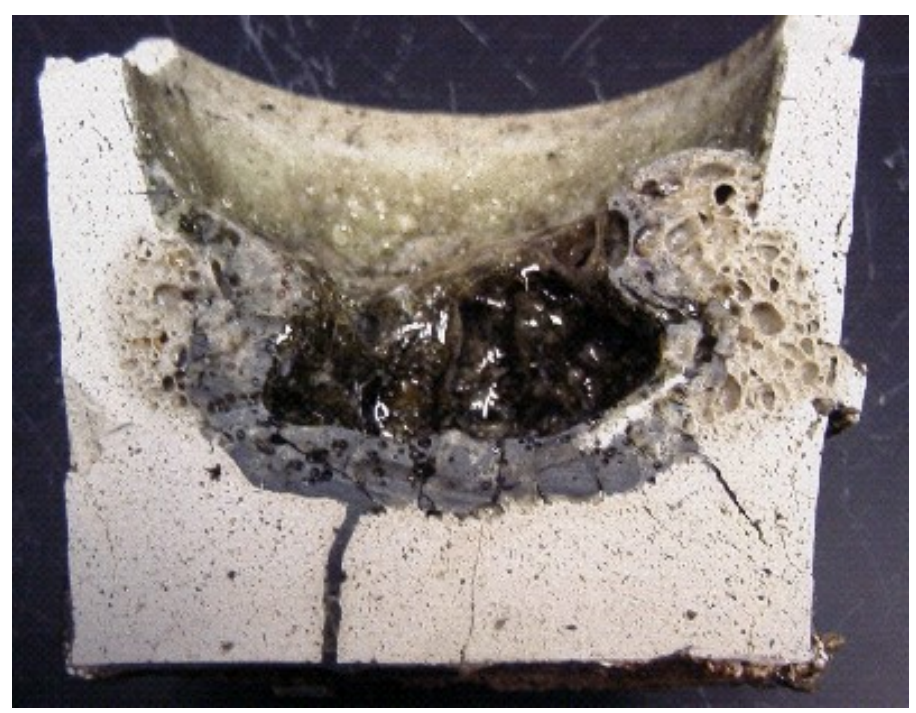

Figure D.28. Fireclay-Silica Crucible Corroded with BV Feed at $1400^{\circ} \mathrm{C}$ for $100 \mathrm{~min}$

Table D.5 summarizes the losses to corrosion for all three crucibles tested. Corrosion in the unglazed Viborcast 60PC crucible ranged from 4-10 mm while the glazed crucible showed less overall corrosion with crucible wall thickness losses that ranged from 3-5 mm. The side walls of the fire clay/silica crucible were severely corroded while the bottom of the crucible showed 7-10 mm of wall thickness loss. The enhanced corrosion in the melt line removed protective coating and exposed the porous body to molten salt penetration when additional feed was added to the crucible. The damage by MIS was extensive in test crucibles because the refractory material was exposed to a uniform temperature. The extent of attack may be limited in a large refractory block because of temperature gradients.

Table D.5. Crucible Losses to Corrosion in mm

\begin{tabular}{||l|c|c|c||}
\hline \multicolumn{1}{|c|}{ Test } & $\begin{array}{c}\text { Unglazed } \\
\text { Vibrocast 60PC }\end{array}$ & $\begin{array}{c}\text { Glazed } \\
\text { Vibrocast 60PC }\end{array}$ & Glazed Fireclay \\
\hline Wall at melt mid height & $4-6$ & $3-5$ & Severe corrosion \\
\hline Wall at melt line & $5-8$ & $3-4$ & Severe corrosion \\
\hline Bottom & $8-10$ & $3-5$ & $7-10$ \\
\hline
\end{tabular}

\subsection{Molten Glass Crucible Corrosion Test}

To assess the reaction between a refractory wall and molten glass without the prior influence of the MIS, several tests were performed with engineering scale (ES)-3 test glass heated in the crucibles at temperatures of $1500^{\circ} \mathrm{C}$.

\subsubsection{Materials Tested}

Two materials were tested in the molten glass crucible tests:

- an unglazed alfrax crucible

- $\quad$ an unglazed Vibrocast 60 PC crucible (Figure D.20). 


\subsubsection{Test Procedure}

The Alfrax test crucible was filled to approximately one half with BV glass powder, placed in a furnace at $200^{\circ} \mathrm{C}$, ramp heated at $1^{\circ} \mathrm{C} / \mathrm{min}$ to $950^{\circ} \mathrm{C}$, and held overnight. Heating resumed at $1^{\circ} \mathrm{C} / \mathrm{min}$ to $1150^{\circ} \mathrm{C}$ and at $3^{\circ} \mathrm{C} / \mathrm{min}$ to $1500^{\circ} \mathrm{C}$ with 1-h hold. Additional glass powder was loaded at $1150^{\circ} \mathrm{C}$. Reboil, probably caused by the reduction of Fe(III) to $\mathrm{Fe}(\mathrm{II})$, occurred at about $1400^{\circ} \mathrm{C}$, resulting in a glass foam spill out of the crucible (Figure D.29). The crucible was annealed at $525^{\circ} \mathrm{C}$ for 2.5 hours, and then cut in half and evaluated.

Two tests were conducted with the unglazed Vibrocast 60PC crucibles. BV glass powder was loaded into each crucible to fill approximately one half of the volume. The crucibles were ramp-heated at $1{ }^{\circ} \mathrm{C} / \mathrm{min}$, starting at $200^{\circ} \mathrm{C}$, and held at $950^{\circ} \mathrm{C}$ overnight. Heating continued at $1^{\circ} \mathrm{C} / \mathrm{min}$ to $1150^{\circ} \mathrm{C}$, at $3^{\circ} \mathrm{C} / \mathrm{min}$ to $1300^{\circ} \mathrm{C}$, and at $4^{\circ} \mathrm{C} / \mathrm{min}$ to $1500^{\circ} \mathrm{C}$ with a 3-h hold (the first crucible) and a 24 -h hold (the second crucible). Glass was added to the melt at $1150^{\circ} \mathrm{C}$. The crucibles were air-cooled to about $600^{\circ} \mathrm{C}$ and annealed for 3 hours at $525^{\circ} \mathrm{C}$. The melt reboiled in the first crucible at $\sim 1450^{\circ} \mathrm{C}$, causing a small spill. A small crack was visible in the rim of each crucible before the test. The cracks propagated to approximately half of the crucible length, but no melt was lost through the cracks. After cooling, both crucibles were cut in half and evaluated.

\subsubsection{Test Results}

The Alfrax crucible surfaces contacted by melt showed severe corrosion (Figure D.29). The molten glass penetrated into the walls and loosened alumina grains that subsequently mixed with the melt. Figure D.30 shows corrosion on both the interior of the crucible and the exterior wall where the glass had foamed out of the crucible. The test showed that even without molten salt present, Alfrax pure alumina refractory is not suitable for BV processing because of severe corrosion and the potential for adding unacceptable levels of alumina to the glass melt.
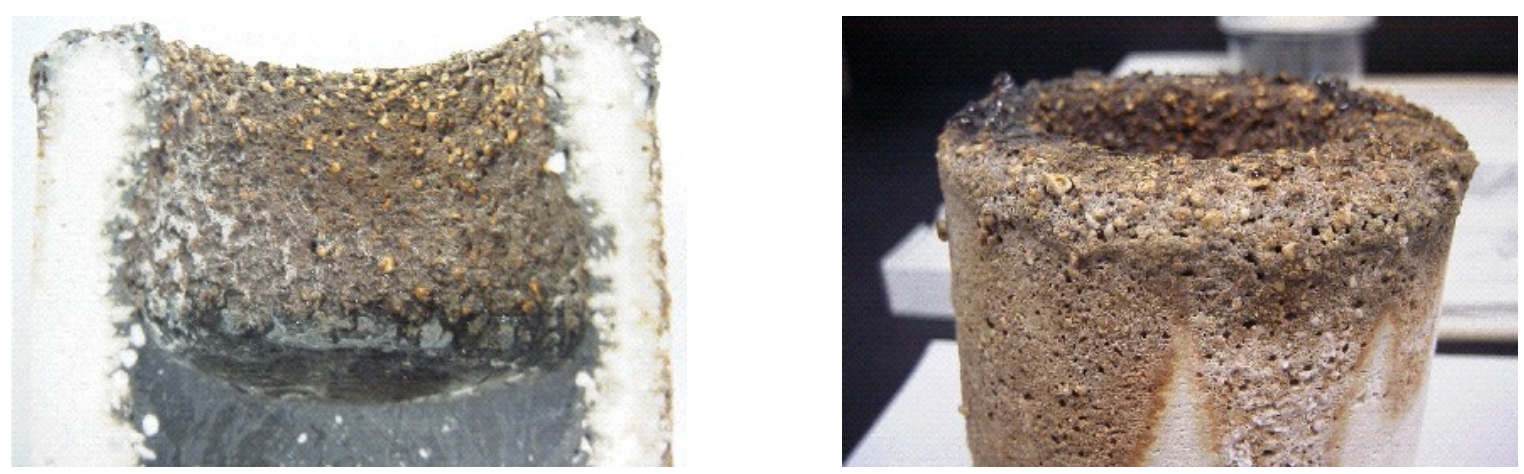

Figure D.29. Corroded Alfrax Test Crucible 

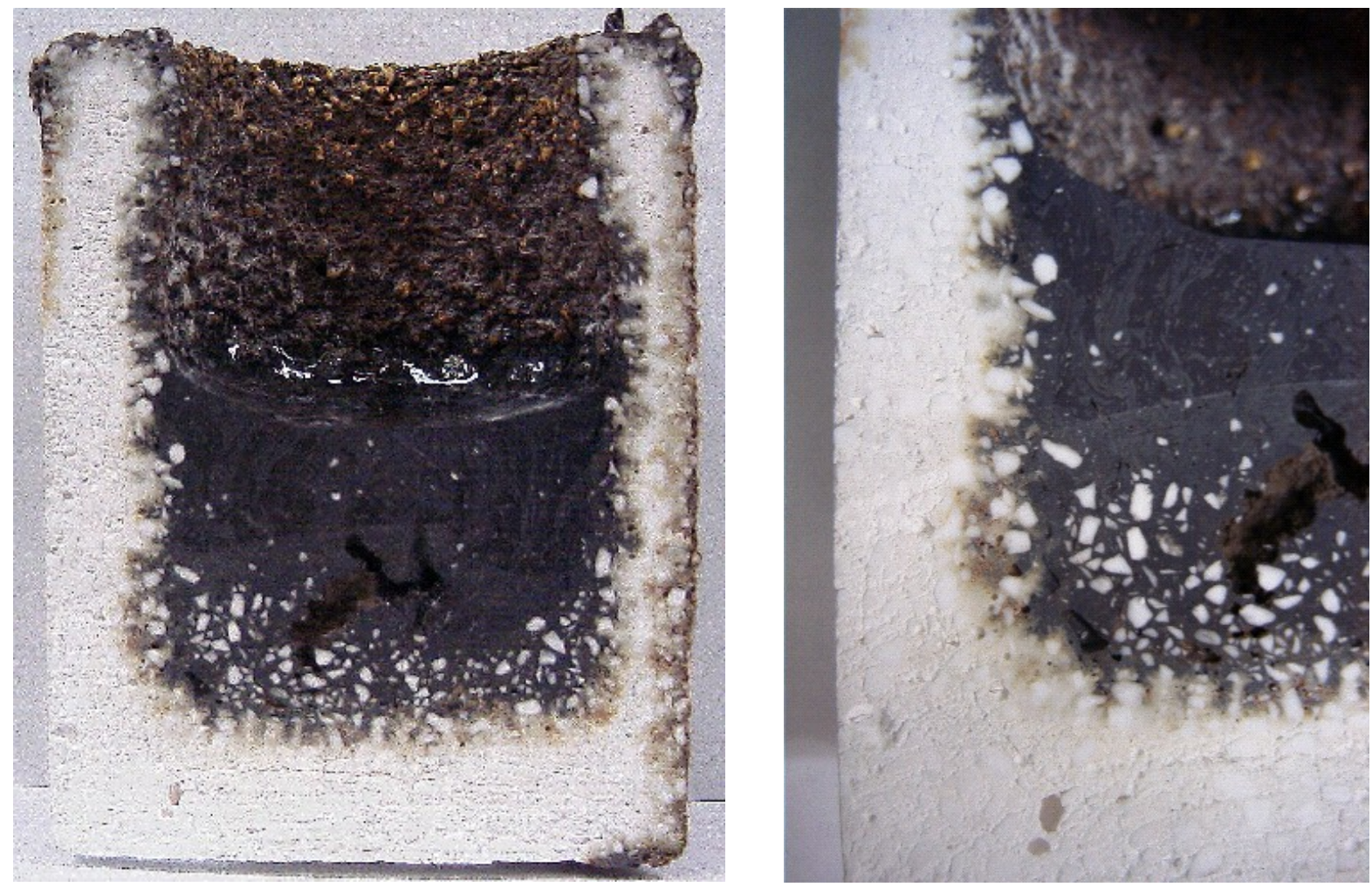

Figure D.30. View of Corroded and Sectioned Alfrax Test Crucible

Figure D.31 and Figure D.32 show sections of the two unglazed Vibrocast PC60 crucibles. The unglazed crucibles do not show any of the localized damage seen in Figure D.25 that resulted from the MIS. The 3-h exposure shows very little refractory corrosion because of the glass. After 24 hours, the corrosion was more extensive. A detail of the glass-refractory interface at the crucible bottom seen in Figure D.33 shows large loose grains of mullite suspended in the melt.

Table D.6 summarizes the losses to corrosion for the crucibles tested. Alfrax material was lost partly by dissolution, but mainly by the release of refractory grains into the melt after only 1 hour at $1500^{\circ} \mathrm{C}$.

Although it was difficult to determine precise corrosion levels because of the uneven corrosion profiles, the two different periods of corrosion time for the unglazed Vibrocast 60PC crucibles indicate that the dissolution rate is relatively constant with time.

Table D.6. Crucible Losses to Corrosion in mm

\begin{tabular}{||l|c|c|c||}
\hline Test & Alfrax & $\begin{array}{c}\text { Vibrocast 60PC } \\
\text { 3 hour }\end{array}$ & $\begin{array}{c}\text { Vibrocast 60PC } \\
\text { 24 hour }\end{array}$ \\
\hline Wall at melt mid height & $2-7$ & $1-2$ & $7-8$ \\
\hline Wall at melt line & $2-7$ & $1-2$ & $6-7$ \\
\hline Bottom & $2-7$ & $\sim 0$ & $\sim 8$ \\
\hline
\end{tabular}




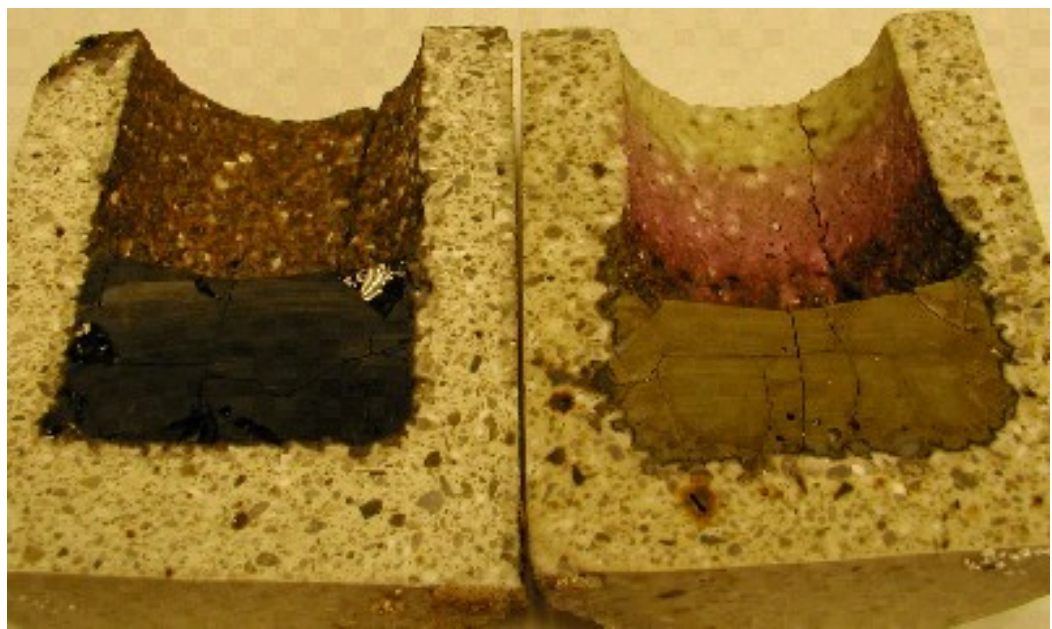

Figure D.31. Corroded Vibrocast 60PC Test Crucibles: 3 Hours at $1500^{\circ} \mathrm{C}$ (left) and 24 Hours at $1500^{\circ} \mathrm{C}$ (right)
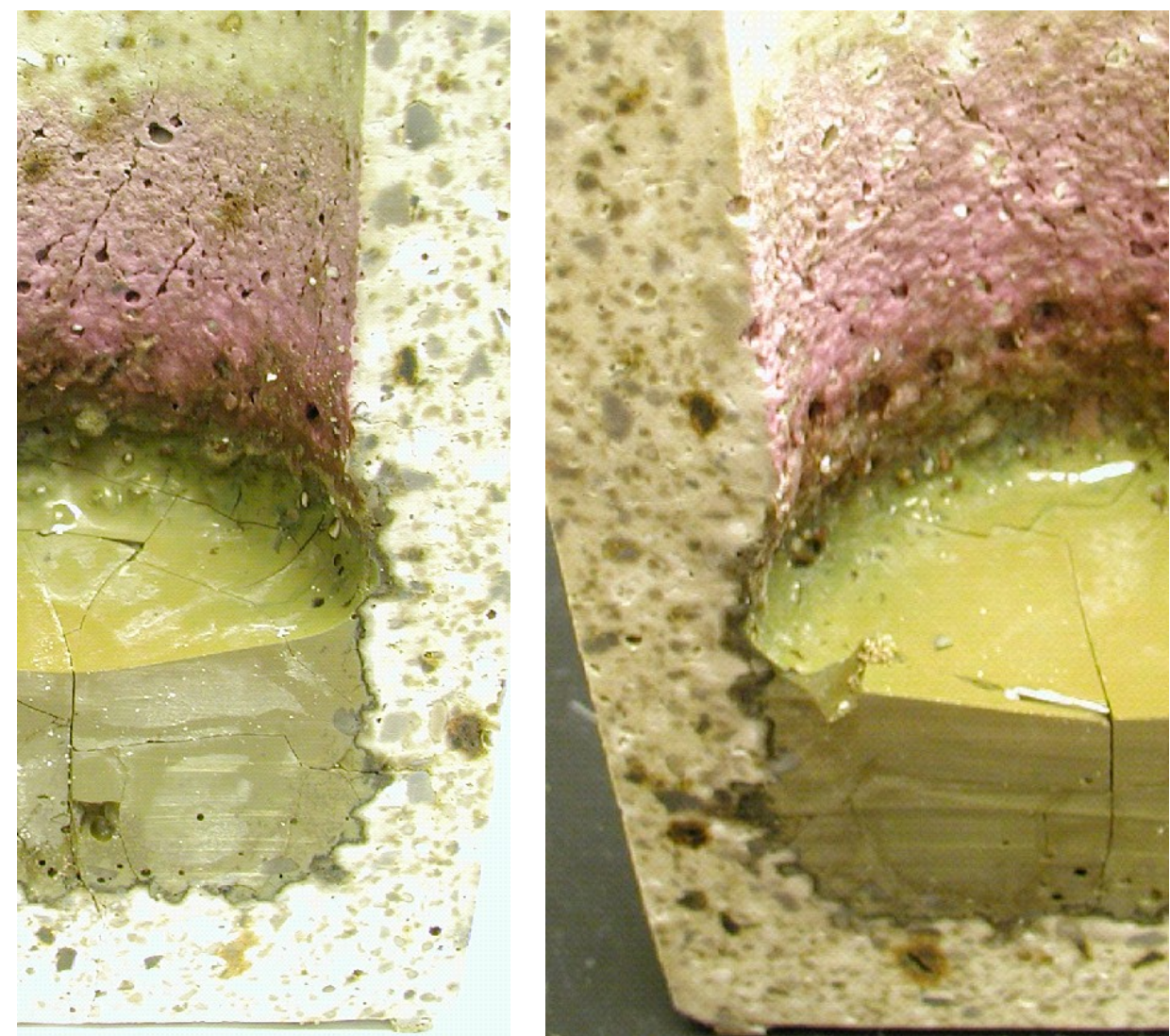

Figure D.32. Corroded Vibrocast 60PC Crucible Cross-Section, 24 Hours at $1500^{\circ} \mathrm{C}$ 


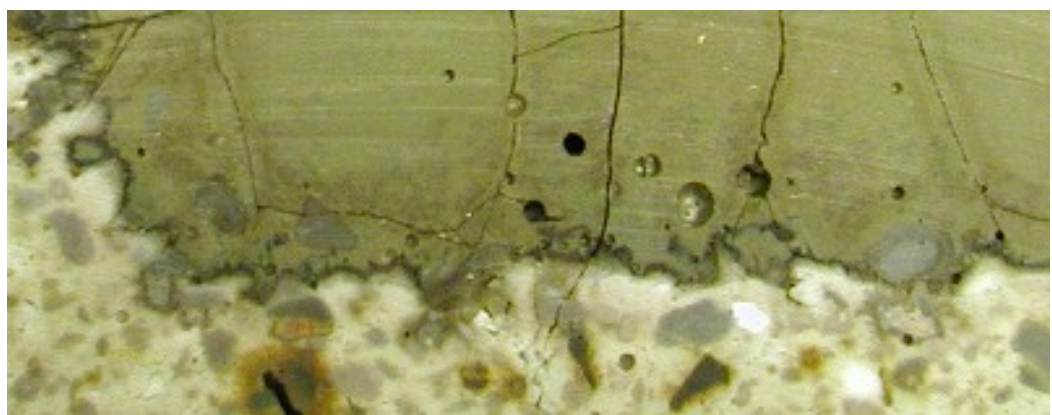

Figure D.33. Vibrocast 60PC, 24 Hours at $1500^{\circ} \mathrm{C}$; Melt-Refractory Interface 


\subsection{Conclusions}

The evolution of $\mathrm{CO}_{2}$, $\mathrm{CO}$, and $\mathrm{NO}$ from the feed begins at $150^{\circ} \mathrm{C}$, probably from decomposing oxalate and its reaction with nitrate. The evolution of $\mathrm{CO}_{2}, \mathrm{CO}, \mathrm{NO}$, and $\mathrm{N}_{2} \mathrm{O}$ at $300^{\circ} \mathrm{C}$ to $650^{\circ} \mathrm{C}$ probably results from the decomposition and reactions of acetates, carbonates, nitrates, and nitrites. The evolution of NO and $\mathrm{O}_{2}$ at $550^{\circ} \mathrm{C}$ to $800^{\circ} \mathrm{C}$ can be attributed to the decomposition of nitrates. Residual carbonates decompose in parallel with nitrate decomposition. Carbon from the soil is an additional source of $\mathrm{CO}_{2}$. The melting of the feed is an endothermic process with significant mass loss between 525 and $650^{\circ} \mathrm{C}$ associated with nitrate decomposition.

Vibrocast 60PC appears to have better resistance to corrosion by molten glass than the other material tested. However, its $17 \%$ open porosity allows for penetration of MIS from the feed at temperatures below $800^{\circ} \mathrm{C}$. The salt reacts with the refractory block and produces swelling. The swollen portion of the CRB appeared to be more susceptible to molten glass attack.

Coating refractory coupons with a sodium silicate glaze provided a limited protection against the penetration of submerged coupons by the MIS. The protection failed at the melt line area in refractory crucibles when additional feed was added to molten glass. 


\subsection{Bibliography}

Cuta JM. 2003. Letter Report - ILAW Trench Thermal Analysis with COBRA-SFS. TWS03.029, Pacific Northwest National Laboratory, Richland, WA.

Hrma PR, D Kim, JD Vienna, J Matyáš, DE Smith, MJ Schweiger, JD Yeager. 2003. Testing of LargeScale BV Glasses with Hanford LAW Simulant. PNNL-1517.

Kim D, JD Vienna, P Hrma, MJ Schweiger, J Matyas, JV Crum, DE Smith, WC Buchmiller, JS Tixier, Jr., JD Yeager, and KB Belew. 2003. Development and Testing of BV Glasses for Hanford LAW. PNNL-14351, Pacific Northwest National Laboratory, Richland, WA.

Mahoney LA, and SD Rassat. 2003. Letter Report - Tank 241-S-109 Cold MIS Simulant Formulation, ST04.002, Pacific Northwest National Laboratory, Richland, WA.

SciGlass Version 4.0, Database software; sources: SN Salama, SM Salman, and S Gharib. 1987. J. NonCryst. Solids. 93(1):203; SM Salman. 1984. Thermochim. Acta. 81(125); SM Salman, NA Ghoneim, and S Gharib. 1984. Thermochim. Acta. 72(3):269; NA Ghoneim, and MM Halawa. 1985. Thermochim. Acta. 83(2):341.

Tooley FV. 1974. The Handbook of Glass Manufacture. Books for Industry, New York.

\section{PNNL Technical Procedures}

APEL-PAD-V, Rev. 2, Operation of Scintag Pad-V X-Ray Diffractometer, Safe Operating Procedure, 2002.

GDL-GBM, Rev. 3, Glass Batching and Melting, Pacific Northwest National Laboratory, Technical Procedure, 2002.

GDL-VHT, Vapor Hydration Test Procedure, Pacific Northwest National Laboratory, Technical Procedure, 2000.

GDL-XRD, Quantitative and Semi-quantitative analysis using X-Ray Diffraction, Pacific Northwest National Laboratory, Technical Procedure, 2002.

RPL-PIP-1, Rev.2, Preparation, Processing, and Testing of Radioactive Glass and Ceramics, PNNL Technical Procedure, 2001.

RPL-PIP-4, Rev. 2, Mounting Radioactive Samples in PIP XRD Sample Holder Base, Technical Procedure, 2002. 


\section{Distribution}

No. of

Copies

OFFSITE

2 AMEC

L. Thompson B2-67

$\begin{array}{ll}\text { J. Wise } & \text { B2-67 }\end{array}$

2 DMJM Technology

J. Reddick

K. Wiemers

H0-50

$\mathrm{H} 0-50$

ONSITE

6 CH2M HILL Hanford Group, Inc.

P. K. Brockman

R2-50

D. W. Hamilton (3)

T4-67

R. E. Raymond

S7-83

CH2M HILL Document Control H6-08

1 U.S. Department of Energy/Office of River

Protection

B. M. Mauss

H6-60
No. of

Copies

\section{ONSITE}

23 Pacific Northwest National Laboratory

L. M. Bagaasen K6-28

A. E. Beck K6-24

T. M Brouns K9-69

D. D. Caldwell K6-28

J. V. Crum K6-24

M. L. Elliott K6-28

G. W. Hollenberg K9-85

P. R. Hrma (5) K6-24

D.S. Kim K6-24

J. Matyáš K6-24

B. P. McGrail K6-81

K. B. C. Minister K6-24

E. M. Pierce K6-81

M. J. Schweiger K6-24

D. M. Strachan K6-24

B. P. Tinsley K6-24

D. N. Tran K6-24

J. D. Vienna K6-24

N. H. Wong

Dist. 1 